DOE/EIA-M067(97)

\title{
Model Documentation Report: Residential Sector Demand Module of the National Energy Modeling System.
}

January 1997

RECEIVED

MAR 061997

OSTI

Office of Integrated Analysis and Forecasting

Energy Information Administration

U.S. Department of Energy

Washington, DC

DISTRIBUTON OF THIS DOCUMENT is VivinatiLU

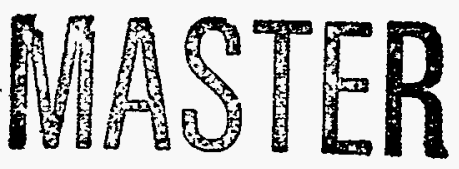




\section{Model Documentation Report: Residential Sector Demand Module of the National Energy Modeling System}

. January 1997

Office of Integrated Analysis and Forecasting

Energy Information Administration

U.S. Department of Energy

Washington, DC

This report was prepared by the Energy Information Administration, the independent statistical agency within the Department of Energy. The information contained herein should not be construed as advocating or reflecting any policy position of the Department of Energy or any other organization. 


\section{DISCLAIMER}

Portions of this document may be illegible in electronic image products. Images are produced from the best available original document. 


\section{Update Information}

This is the third edition of the Model Documentation Report: Residential Sector Demand Module of the National Energy Modeling System. It reflects changes made to the module over the past year for the Annual Energy Outiook 1997. Since last year, a subroutine. was. added to the model which allows technology and fuel switching when space heaters, heat pump air conditioners, water heaters, stoves, and clothes dryers are retired in both pre-1994 and post-1993 single-family homes. Also, a time-dependant function for computing the installed capital cost of equipment in new construction and the retail cost of replacement equipment in existing housing was added.

New columns were added to the technology databases. These columns include technology choice parameters for replacement and logistic shape parameters for the equipment cost function. A new matrix was added to the miscellaneous database to describe the cost of switching from an existing technology to a new technology. 


\section{Table of Contents}

Table of Contents $\ldots \ldots \ldots \ldots \ldots \ldots \ldots \ldots \ldots \ldots \ldots$

Tables

Figures $\ldots \ldots \ldots \ldots \ldots \ldots \ldots \ldots \ldots \ldots \ldots \ldots \ldots \ldots \ldots \ldots$

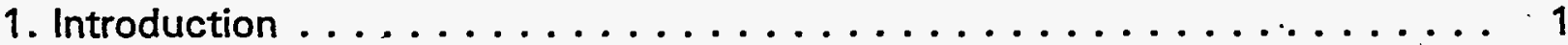

Purpose of this Report $\ldots \ldots \ldots \ldots \ldots \ldots \ldots \ldots \ldots \ldots$

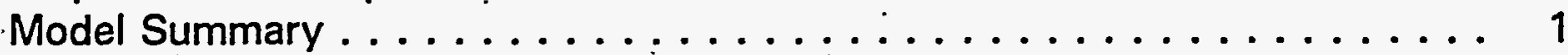

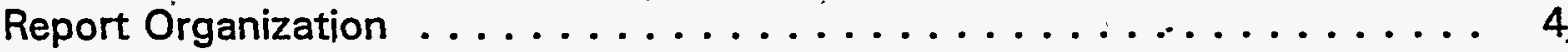

2. Model Purpose .............................. 6

Module Objectives ......................... 6

Module Input and Output .................... 7

Relationship to Other Models ....................... 9

3. Model Rationale $\ldots \ldots \ldots \ldots \ldots \ldots \ldots$

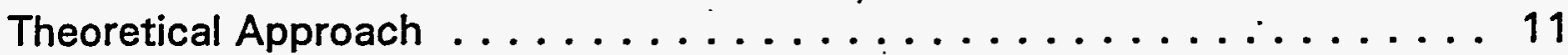

Fundamental Assumptions . . . . . . . . . . . . . . . . . . 12

Further Assumptions $\ldots \ldots \ldots \ldots \ldots \ldots \ldots \ldots$

Alternative Approaches . . . . . . . . . . . . . . . . . . 16

4. Model Structure ........................... 21

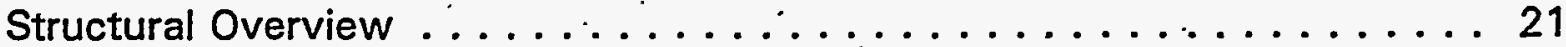

Flow Diagrams . . . . . . . . . . . . . . . . . . . . . . . 24

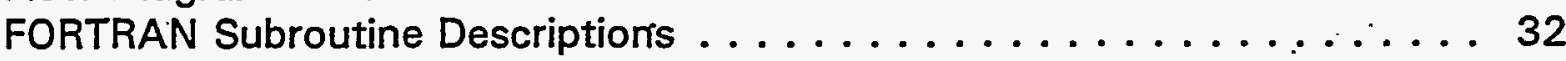

Key Computations and Equations . . . . . . . . . . . . . . 37

Appendix A: Data. Sources and Input Parameters . . . . . . . . . . . . . A-1

Appendix B: Detailed Mathematical Description . . . . . . . . . . . . . B-1

Appendix C: Bibliography ......................... C-1

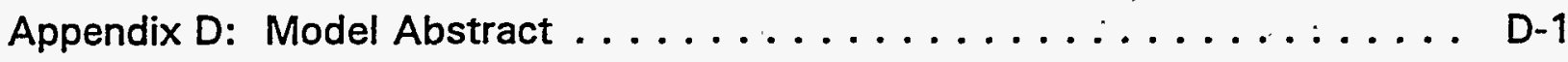

Appendix E: Data Quality .......................... E-1 


\section{Tables}

Table 1. Comparison of Previous EIA Model (REEM) With NEMS Residential Sector

Demand Module . . . . . . . . . . . . . . . . . . . . . . 19

Table 2. Services and Equipment in the NEMS Residential Sector Demand Module . . . . . . . . . . . . . . . . . . . . . . . . 22

- Table 3. Primary NEMS Residential Sector Demand Module Subroutines . . . . 33

Table 4. Definitions of Subscripts . . . . . . . . . . . . . . . . 38

Table 5. Heating Equipment, UEC and Housing Shell Accounting Scheme . . . 48

\section{Figures}

Figure 1. NEMS Residential Sector Demand Module Basic Structure . . . . . 24 Figure 2. Housing Stock Component Flow . . . . . . . . . . . . 27

Figure 3. Technology Choice Component Flow . . . . . . . . . . . 28

Figure 4. Appliance Stock Component Flow . . . . . . . . . . . . . . 29

Figure 5. Building Shell Integrity Component Flow . . . . . . . . 30

Figure 6. Consumption and UEC Component Flow . . . . . . . . . 31 


\section{Introduction}

\section{Purpose of this Report}

This report documents the objectives, analytical approach, and development of the National Energy Modeling System (NEMS) Residential Sector Demand Module. The report catalogues and describes the model assumptions, computational methodology, parameter estimation techniques, and FORTRAN source code.

This document serves three purposes. First, it is a reference document that provides a detailed description for energy analysts, other users, and the public. Second, this report meets the legal requirement of the Energy Information Administration (EIA) to provide adequate documentation in support of its statistical and forecast reports according to Public Law 93-275, section 57(b)(1). Third, it facilitates continuity in model development by providing documentation from which energy analysts can undertake model enhancements, data updates, and parameter refinements.

\section{Model Summäry}

The NEMS Residential Sector Demand Module is currently used for mid-term forecasting purposes and energy policy analysis over the forecast horizon of 1993 through 2015. The model generates forecasts of energy demand, which is used interchangeably with the concept of energy consumption in this document, for the residential sector by service, fuel, and Census Division. The policy impacts that result from the introduction of new technologies, market incentives, and regulatory changes can be estimated using the module, by the user who defines alternative input and parameter assumptions. 
The Residential Sector Demand Module uses inputs from the NEMS system to generate outputs needed in the NEMS integration process. The inputs required by the Residential Sector Demand Module from the NEMS system include energy prices and macroeconomic indicators: These inputs are used by the module to generate energy. consumption by fuel type and Census Division in the residential sector. The NEMS system uses these forecasts to compute equilibrium energy prices and quantities.

The Residential Sector Demand Module is an analysis tool to address current and proposed legislation, private sector initiatives, and technological developments that affect the residential sector. Examples of policy analyses include assessing the potential impacts of the following:

- New end-use technologies (such as natural gas heat pumps)

- New energy supply technologies (such as renewable energy)

- Changes in fuel prices due to tax policies

- Changes in equipment energy efficiency standards

- Financial incentives for energy efficiency investments

- Financial incentives for renewable energy investments

\section{Archival Media}

The Residential Sector Demand Module has been archived as part of the NEMS production runs that generate the Annual Energy Outlook 1997 (AEO97) on the EIA IBM RS-6000 workstation. The archive tape is a Verbatim 8mm-DL $112 \mathrm{M}$ data. cartridge, serial number 1046G112, under the name file1.

\section{Model Contact}

John H. Cymbalsky

Office of Integrated Analysis and Forecasting

Energy Demand Analysis Branch

Phone: (202) 586- 4815 


\section{NEMS Residential Sector Demand Module Structure}

The residential sector encompasses residential housing units classified as singlefamily, multifamily, and mobile homes. Energy consumed in residential buildings is the sum of energy required to provide specific energy services that use selected technologies according to energy efficiency levels of building structures. The Residential Sector Demand Module projects enérgy demand following a sequence of five.steps. The first step is to forecast housing stock. The second step is to select specific technologies to meet the demand for each energy service. The third step is to forecast appliance stocks. The fourth step is to forecast changes in building shell integrity. The fifth step is to calculate the energy consumed by the equipment chosen to meet the demand for energy services.

\section{Housing Stock Component}

The Housing Stock Component forecasts numbers of occupied households by housing type and Census Division. Forecasted housing starts are input from the NEMS Macroeconomic Activity Module (MAM). The housing stock is assumed to retire based on set proportions consistent with available housing demolition data. The housing stock retirement assumptions are presented in the Fundamental Assumptions section of this report.

\section{Technology Choiçe Component}

The Technology Choice Component simulates the behavior of residential consumers based on the relative importance of life-cycle costs, capital costs, and operating costs of competing technologies within a service. New and replacement equipment decisions reflect additional factors beyond the traditional life-cycle cost methodology, including main space heating fuel choice and previous equipment choices. The Technology Choice Component allocates end-use services based upon a defined equipment menu of the various technologies and fuels that compete in the market. The Technology Choice Component also establishes the criteria upon which consumers base equipment choices. 


\section{Appliance Stock Component}

The Appliance Ștock Component forecasts the number of appliances required by each end-use service. A piecewise linear decay function retires equipment based on minimum and maximum life expectancies. The Appliance Stock Component tracks each type of equipment purchased for new households and replacement units.

\section{Shell Integrity Component}

The Residential Sector Demand Module monitors the changes in building shell integrity for the space conditioning services. The Shell Integrity Component computes an index that incorporates increases in existing building shell efficiency based upon responses to fuel price changes from the base year. Building shell efficiency in new and existing housing is assumed to improve over the forecast period because of stricter building codes and other efficiency programs.

\section{Consumption and Unit Energy Consumption Component}

The Consumption and Unit Energy Consumption Component tracks the composition of residential energy use over time as technological advances in residential equipment are introduced to the market. The component includes price elasticities that allow the user to specify consumer responses to changes in real fuel prices. Unit Energy Consumption (UEC) values are adjusted according to heating and cooling degree-day factors and household size.

A new concept called the "rebound effect" accounts for the fact that increasing equipment efficiency for a particular equipment class causes a corresponding change (normally, a decrease) in the price elasticity for the class.

\section{Report Organization}

Chapter 2 of this report discusses the purpose of the Residential Sector Demand Module, with specific details on the objectives, primary inputs and outputs, and relationship of the module to other modules of the NEMS system. Chapter 3 describes 
the rationale behind the design, fundamental assumptions regarding consumer behavior, module structure, and alternative modeling approaches. Chapter 4 reviews the key computations and data flows.

Appendices to this report document the variables and equations contained in the FORTRAN source code. Appendix A catalogues the input data used to generate estimates and forecasts in list and cross-tabular formats. Appendix $B$ provides support to the mathematical representation of the source code equations provided in Chapter 4 of the main text. Appendix $C$ is a bibliography of reference materials used in the development process. Appendix $\mathrm{D}$ consists of a model abstract. Appendix E discusses the data quality issues. The mathematical properties of the solution algorithms will be presented in a separate volume to this report.

Energy Information Administration

NEMS Residential Demand Module Documentation Report

5 


\section{Model Purpose}

\section{Module Objectives}

The NEMS Residential Sector Demand Module holds three fundamental objectives. First, the module generates disaggregated forecasts of energy demand in the residential sector for the period of 1993 through 2015 by housing and fuel type, Census Division, and end-use service. Second, it is a policy analysis tool that can assess the impacts of changes in energy markets, building and equipment technologies, and regulatory initiatives that affect the residential sector. Third, as an integral component of the NEMS system, it provides inputs to the Electricity Market Module, Natural. Gas Supply Module, and Petroleum Market Module of NEMS, contributing to the calculation of the overall energy supply and demand balance.

The Residential Sector Demand Module projects residential sector energy demands in five sequential steps. These steps produce information on housing stocks, technology choices, appliance stocks, building shell integrity, and energy consumption. The module uses a stock-vintaging approach that allows the user to monitor equipment stock and equipment efficiency over time.

The module design allows the user to conduct a variety of policy analyses. Technological advancement in equipment design and efficiency, as well as first-cost incentive programs, are representable at the equipment level. Housing stock attrition and equipment retirement assumptions can be modified to model the accelerated decay of less-efficient energy-using equipment. Building shell characteristics can be modified to model policy options including updates to building codes and market penetration of energy-efficient mortgages.

Forecasted residential fuel demands generated by the Residential Sector Demand Module are used by the NEMS system in the calculation of the demand and supply 
equilibrium state. In addition, the NEMS supply modules referenced previously use the residential sector outputs to determine the patterns of consumption and the resulting amounts of energy delivered to the residential sector.

\section{Module Input. and Output}

\section{Inputs}

The primary module inputs include fuel prices, housing stock characteristics, housing starts, population, and technology characteristics. The technology characteristics used in the module include installed capital costs, equipment efficiency, and expected equipment lifetimes. The major inputs by module component are as follows:

Housing Stock Component

Housing starts

Existing housing stock for 1993

Housing stock attrition rates

Housing floor area trends (new and existing)

Technology Choice Component

Equipment capital cost

Equipment energy efficiency

Market share of new appliances

Efficiency of retiring equipment

Appliance penetration factors

Appliance Stock Component

Expected equipment minimum and maximum lifetimes

Base year appliance market shares

Equipment saturation level 
Building Shell Component

Maximum level of shell integrity

Price elasticity of shell integrity

Rate of improvement in new and existing housing shell integrity

\section{Energy Consumption Component}

Unit energy consumption (UEC)

Heating and cooling degree day.s

Expected fuel savings based upon the 1992 Energy Policy Act (EPACT)

Population

\section{Outputs}

Forecasted residential sector energy consumption by fuel type, service, and Census Division is the primary module output. The module also forecasts housing stock, and energy consumption per household. In addition, the module can produce a disaggregated forecast of appliance stock and efficiency. The types of appliances included in this forecast are:

Heat pumps (electric air-source, natural gas, and ground-source)

Furnaces (electric, natural gás, LPG, and distillate)

Hydronic heating systems (natural gas, distillate, and kerosene)

Wood stoves

Central air conditioners

Room air conditioners

Water heaters (electric, natural gas, distillate, LPG, and solar)

Ranges/Ovens (electric, natural gas, and LPG)

Clothes dryers (electric and natural gas)

Refrigerators

Freezers 


\section{Variable Classification}

The NEMS modules are required to provide and use system data at the nine Census Division level of detail. The input data available from the Residential Energy Consumption Survey (RECS) performed by EIA (which forms the basis for the Residential Sector Demand Module) and other sources are designed to be statistically . significant at various levels, some of which are above the nine Census Division level. Another factor that drives the level of aggregation of the module variables is the technical constraints of the computing system required in order to run the NEMS model within a reasonable turnaround time. The key variables in the NEMS Residential Sector Demand Module are dimensioned as follows:

\section{Census Divisions}

1 New England

2 Middle Atlantic

3 East North Central

4 West North Central

5 South Atlantic

6 East South Centra!

7 West South Central

8 Mountain

9 Pacific
End-Use Services

1 Space Heating

2 Space Cooling

3 Water Heating

4 Cooking

5 Clothes Drying

6 Refrigeration

7 Freezing

8 Lighting

9. Other Appliances

10 Secondary Space Heating
Fuels

- 1 Distillate

2 LPG

3 Natural Gas

4 Electricity

5 Kerosene

6 Wood

7 Geothermal

8 Coal

9 Solar Thermal

\section{Housing Types}

1. Single-Family

2 Multifamily

3 Mobile Home

\section{Relationship to Other Models}

The Residential Sector Demand Module uses data from the Macroeconomic Activity Module (MAM) of the NEMS system. MAM provides forecasted population and 
housing starts by Census Division and housing type. The Residential Sector Demand Module uses fuel price forecasts generated by the NEMS supply modules previously listed as key drivers to calculate operating costs for technology selections, building shell integrity improvements, and short-term behavioral responses. The NEMS supply modules use the residential sector outputs to determine the fuel mix and the resulting amount of energy delivered to the residential sector. 


\section{Model Rationale}

\section{Theoretical Approach}

The NEMS Residential Sector Demand Module is an integrated dynamic modeling system that generates forecasts of residential sector energy demand, appliance stocks, and market shares. The modeling approach is based on accounting principles and addresses residential consumer behavior issues.

The Residential Sector Demand Module is a housing and equipment stock model. The stock of households and the corresponding energy consuming equipment are tracked for each year of the forecast... The housing stock changes each forecast year as houses are retired from the stock and new construction is added. The equipment stock changes each forecast year as appliances fail and are.replaced, and new . technologies enter the market. A log-linear function is used to estimate the market shares of competing technologies within each service category. Market shares are determined for new construction equipment decisions as well as for replacement decisions. The Technology Choice Component of the module weights the relative installed capital and operating costs of each equipment type to allocate the relative market share of the technology within the service, region, and housing type. This approach is implemented in new housing for the services of space heating, space cooling, water heating, cooking, clothes drying, food refrigeration, and food freezing. It is also implemented for replacement equipment in single family housing for space heating, heat pump air conditioning, water heating, cooking, and clothes drying. Lighting and miscellaneous equipment chọices are modeled based upon alternative technology assumptions discussed below.

Base year information developed from the 1993 RECS data base forms the foundation of modeling changes to the equipment and housing stock over the forecast period. Market share information from RECS is used to estimate the number and type of 
replacements and additions to the equipment stock. The choice between the capital cost and the first year's operating cost determines the market share within a given service. Market shares are also modeled as functions of the corresponding fuel prices, expected level of equipment usage, and equipment efficiency characteristics.

Building shell integrity is also considered in the forecast of end-use consumption. Building shell integrity in existing homes is sensitive to real price increases over base year price levels for space conditioning fuels. Final residential sector energy consumption is determined as a function of the equipment and housing stock, average unit energy consumption, weighted equipment characteristics, and building shell integrity improvements.

\section{Fundamental Assumptions}

The Residential Sector Demand Module assumes that the residential energy marketplace has the following characteristics:

- Equipment lifetime is limited by a minimum and maximum number of years. All equipment is assumed to survive a.minimum number of years, and no equipment is assumed to survive beyond the maximum number of years. The equipment retirement rate is defined by a linear decay function.

- The equipment contained in a retiring housing structure is assumed to retire when the structure is removed from the housing stock. Zero salvage value for equipment is assumed.

- Space heaters, heat pump air conditioners, water heaters, stoves, and clothes dryers may be replaced (up to an input percentage) with competing technologies in single-family homes. Switching is based on a technology choice component, retail cost of new equipment, switching cost, and lifecycle cost. 
- New housing stock building shell efficiency is assumed to improve throughout the . forecast period at a specific rate defined by housing type.

- Life-cycle costs used in the technology cost calculations are computed over a 7year time horizon and a discount rate of $20 \%$.

- Two housing vintages are assumed: pre-1994 (old housing) and post-1993 (new . housing).

- The type of fuel used for cooking and water heating in new housing units is assumed to be a function of the main space heating fuel in most cases. Exceptions to this assumption are included for specific cooking fuel decisions. It is assumed that $63 \%$ of new housing units are equipped with natural gas cooking units, while natural gas is the main space heating fuel.

- The type of fuel used for cooking and water heating when replacing retiring equipment in single-family homes is based on an input percentage of those who may switch and a technology choice switching algorithm. Replacements are with the same technology in multifamily and mobile. homes.

- Housing units are removed from the housing stock at a constant rate over time. The survival rates for housing stock types are assumed to be $99.7 \%$ for singlefamily homes, $99.6 \%$ for multifamily homes, and $96.6 \%$ for mobile homes.

- Projected new home heating fuel shares are based on the Census Bureau's new construction data and vary over time due to changes in life-cycle cost for each of the 11 heating system types. 


\section{Further Assumptions}

\section{Technology Choice}

The efficiency choices made for residential equipment are based on a log-linear 'function. The functional form is flexible, to allow the user to specify parameters as either life-cycle costs, or as weighted of bias, capital and discounted operating costs. Currently, the module calculates choices based on the latter approach. A time dependant function calculates the installed capital cost of equipment in new construction based on logistic shape parameters.

\section{Climate Adjustment}

Space conditioning usage is adjusted across Census Divisions by heating and cooling degree day factors to account for potential deviations from "normal" temperatures during the RECS 1993 survey performance period.

\section{Technology Switching}

Space heaters, heat pump air conditioners; water heaters, stoves, and clothes dryers may be replaced with competing technologies in single-family homes. The amount of equipment which may switch is based on a model input. The technology choice is based on a log-linear function. The functional form is flexible to allow the user to specify parameters, such as weighted bias, retail equipment cost, and technology switching cost. Replacements are with the same technology in multifamily and mobile homes. A time dependant function calculates the retail cost of replacement equipment based on logistic shape parameters.

\section{Space Cooling: Room and Central Air Conditioning Units}

Room and central air conditioning units are disaggregated based on existing housing data. The market penetration of room and central air systems by Census Division and housing type, along with new housing construction data, are used to determine the number of new units of each type. The penetration rate for central air-conditioning is estimated by means of time series analysis of RECS survey data. 


\section{Water Heating: Solar Water.Heaters}

Market shares for solar water heaters are tabulated from the 1993 RECS data base. The module currently assumes that solar energy provides $55 \%$ of the energy needed to satisfy hot water demand, and the remaining $45 \%$ is satisfied by an electric backup unit.

\section{Through-the-Door Refrigeration Units}

A recent innovation in residential food refrigerators has been the advancement of through-the-door access panels for ice and water. This added convenience results in a greater energy use than conventional refrigerator models. The Residential Sector Demand Module assumes that $27 \%$ of all post- 1993 refrigerators incorporate the through-the-door access feature, based upon recent appliance shipment data.'

\section{Clothes Dryer Saturation}

The module currently assumes that clothes dryer market penetration occurs over the forecast period, with a terminal saturation level that is consistent with the market penetration of clothes washers. This assumption is based upon analysis of the RECS data base.

\section{Lighting}

Three types of lighting technology characterizations based on efficiency are included in the module. Market shares are assumed for each type of lighting for 1993 (the base year), 2000, and 2015.

\section{Other Appliances}

The consumption of other appliances by Census Division is calculated by multiplying the sum of new and existing housing units by Unit Energy Consumption (UEC), housing type, and Census Division.

\footnotetext{
${ }^{2}$ Association of Home Appliances Manufacturers, "Refrigerators: Energy Efficiency and Consumption Trends," Chicago, $I$, December, 1994.
} 


\section{Secondary Heating}

The consumption of secondary heating fuels is determined by the share of total housing that uses a secondary heating fuel multiplied by the UEC adjusted for the shell integrity.

\section{Alternative Approaches}

Residential models reviewed during the model development process are discussed in this section. ${ }^{2}$ The discussion is presented in the order of the components of the NEMS Residential Sector Demand Module.

\section{Housing Stock}

The Residential End-use Energy Planning System (REEPS) model ${ }^{3}$ developed by the Electric Power Research. Institute (EPRI) and DRI/McGraw-Hill's (DRI) Macroeconomic model ${ }^{4}$ also forecast domestic housing stock. The Bureau of the Census also predicts household formation based on a complex regression with numerous demographic variables.

\section{Appliance Stock}

It is necessary to track the appliance stocks in order to evaluate specific policies likely to affect residential sector energy use. For this reason, models developed recently ${ }^{5}$ have focused on keeping track of the capital stock of major household appliances such as heating and cooling equipment, refrigerators, and clothes dryers.

\footnotetext{
${ }^{2}$ For a more complete description of these residential sector modeling systems see the "Residential Sector Component Design Report," Energy Information Administration, January 19, 1993.

${ }^{3}$ Electric Power Research Institute, "Residential End-Use Energy Planning System (REEPS) Draft Model Documentation," Palo Alto, CA, 1990.

"DRI/McGraw-Hill (DRI), "Quarterly Model' of the U.S. Economy: Version US89A Equation Listing," DRI/McGraw-Hill, Lexingtor, MA, 1990.

${ }^{5}$ REEPS version 2.0, for example, was officially released in 1991. 
REEPS tracks the capital stock of energy-using technologies using a method similar to the method proposed here. The GRI energy model ${ }^{6}$ also tracks the capital stock of major residential appliances in order to forecast residential energy consumption.

\section{Technology Choice}

The Technology Choice component of the NEMS Residential Sector Demand Module requires extensive data that describe end-use technologies. Equipment costs, efficiency levels, and other characteristics must be specified for all technologies modeled. These data are available from Department of Energy sources', Lawrence Berkeley Laboratory (LBL) ${ }^{8}$ studies, engineering analyses performed by Arthur D. Little $(A D L)^{9}$, Gas Research Institute $(G R I)^{10}$ research, Electric Power Reséarch Institute (EPRI) ${ }^{11}$, Gas Appliance Manufacturing Association (GAMA) ${ }^{12}$, Association of Home Appliance Manufacturers (AHAM), the Air Conditioning and Refrigeration Institute $(A R I)^{13}$, and numerous trade publications.

' Gas Research Institute, "1991 Edition for the GRI Baseline Projection Methodology and Assumptions Topical Report," Lexington, MA, December, 1990.

${ }^{7}$ U.S. Department of Energy, Technical Support Document: Energy Conservation Standards for Consumer Products: Dishwashers, Clothes Washers, and Clothes Drvers, DOE/CE-0267, Washington, D.C., July 1989. Also U.S. Department of Energy, Technical Support Document: Energy Conservation Standards for Consumer Products: Refrigerators and Furmaces, DOE/CE-0277, Washington D.C:, , November, 1989.

${ }^{8}$ Koomey, J.G., et al., "The Potential for Electricity Efficiency Improvements in the U.S. Residential Sector," Lawrence Berkeley Laboratory, Berkeley, CA, July, 1991. Turiel, I., et. al., "U.S. Residential Appliance Energy Efficiency: Present Status and Future Directions," Lawrence Berkeley Laboratory, Berkeley, CA, April, 1991. Lawrence Berkeley Laboratory, "Baseline Data for the Residential Sector and Development of a Residential Forecasting Database," Berkeley, CA, May, 1994.

'Arthur D. Little, "Technical Memorandum for Technology Advances and Forecasts-' Residential/Commercial End-Use Equipment," Cambridge, MA, $199 \mathrm{.}$

10 Gas Research Institute, "Baseline Projection Dáta Book," Washington, DC, 1990.

"'Electric Power Research Institute, "Draft Model Documentation for REEPS," 1990.

12 Gas Appliance Manufacturers Association, "Consumers' Directory for Certified Efficiency Ratings," Arlington, VA, 1994.

${ }^{23}$ Air Conditioning and Refrigeration Institute, "Directory of Certified Cooling Equipment," Arlington, VA, 1994. 
REEPS simulates consumer choice based on the consumer's evaluation of certain equipment attributes (such as capital cost and energy efficiency), with the choice of a particular unit expressed as a probability of the consumer choosing that unit. This probability is based on empirical estimation that reflects observed trends in the home appliance market described in home appliance trade publications.

\section{Shell Integrity.}

The EPRI, LBL, and GRI models account for energy conservation through shell retrofit. EPRI's REEPS and LBL's REM models both use a sophisticated approach tó account for shell retrofits. The REEPS model groups different retrofits into several levels, with each level assigned a different cost and energy savings. Over time, housing structures choose better combinations of shell attributes, which causes a savings in energy consumption. The decision process is simulated by a log-linear function that weighs parameters such as first cost, energy savings, and discount rate. The LBL model uses conservation supply curves to describe the trade-off between investment in different shell measures and the energy savings associated with them. The choice to retrofit depends on the cost of conserved energy. If the retrofit option saves more money than it costs, the option is selected. The GRI model assumes an exogenous rate of annual improvement.

\section{Reasons for Selecting the NEMS Residential Sector.Demand Module Approach}

Execution time and memory requirements established in the design stage of the NEMS model development effort contribute to the ultimate design of the Residential Sector Demand Module. The component approaches for modeling housing stock, appliance stock, technology choice, and shell integrity are designed in a modular fashion to facilitate enhancements to each component design. The module design draws upon aspects of the REEPS, DRI, and GRI models discussed above, in an attempt to enhance previous modeling methodologies while retaining as much simplicity as possible in the modeling approach. The current module design is flexible enough to lend itself to further enhancement in all components. 
Table 1 compares the previous EIA residential sector demand model with the NEMS approach. The Residential Energy End-Use Demand Model (REEM), developed in 1989, consisted of four modules - housing stock, service demand, service capacity, and new technology choice. REEM was used to produce long-term projections of residential energy consumption. Limitations of REEM as compared to the NEMS Residential Demand Module include:

1) Inability to track appliances through time,

2) Projections were generated for only four Census regions (Northeast, South, Midwest, and West),

3) Only six fuel types and six services were considered,

4) Did not incorporate consumer choice parameters in the technology choice module,

5) Technology choice methodology was limited to a life-cycle cost approach,

Table 1. Comparison of Previous EIA Model (REEM) With NEMS Residential Sector Demand Module

\begin{tabular}{|c|c|c|}
\hline Conceptual Task & REEM Methodology & NEMS Methodology \\
\hline $\begin{array}{l}\text { Forecast housing stock } \\
\text { additions }\end{array}$ & $\begin{array}{l}\text { Increase additions (for } \\
\text { each housing type) by } \\
\text { proportion of national } \\
\text { housing starts. Regional } \\
\text { shares of each housing } \\
\text { type are constant over. } \\
\text { time }\end{array}$ & $\begin{array}{l}\text { Forecast by housing type and } \\
\text { region, based on demographic } \\
\text { variables exogenous to the } \\
\text { Residential Module. Housing } \\
\text { starts by type and region } \\
\text { provided by the NEMS } \\
\text { Macroeconomic Module }\end{array}$ \\
\hline $\begin{array}{l}\text { Compute and forecast } \\
\text { appliance stock and } \\
\text { appliance penetration for } \\
\text { new and existing housing }\end{array}$ & $\begin{array}{l}\text { No stock method } \\
\text { employed; use service } \\
\text { demand and capacity as } \\
\text { proxies }\end{array}$ & $\begin{array}{l}\text { Count appliance stock in base } \\
\text { year; vintage and add } \\
\text { equipment over time; forecast } \\
\text { penetration based on } \\
\text { assumptions }\end{array}$ \\
\hline $\begin{array}{l}\text { Choose equipment to meet } \\
\text { appliance stock demand }\end{array}$ & $\begin{array}{l}\text { Use logit function based on } \\
\text { minimum life-cycle cost; } \\
\text { assume initial equipment } \\
\text { shares, fixed discount rate, } \\
\text { and inertia factor (lagged } \\
\text { penetration) }\end{array}$ & $\begin{array}{l}\text { Segment market based on type } \\
\text { of acquisition, house type, etc.; } \\
\text { vary consumer preference } \\
\text { parameters by service type. }\end{array}$ \\
\hline $\begin{array}{l}\text { Calculate energy } \\
\text { consumption }\end{array}$ & $\begin{array}{l}\text { Weight share of equipment } \\
\text { chosen by average } \\
\text { efficiency for each fuel and } \\
\text { apply to service demand }\end{array}$ & $\begin{array}{l}\text { Weight share of equipment } \\
\text { chosen by average efficiency } \\
\text { for each technology and ápply } \\
\text { to appliance (unit) demand }\end{array}$ \\
\hline
\end{tabular}


6) Did not produce energy consumption forecasts for each service by fuel type,

7) Did not explicitly include dispersed renewable technologies, and

8) Did not account for weather effects. 


\section{Model Structure}

Structural Overview:

The NEMS Residențial Sector Demand Module characterizes energy consumption using an algorithm that accounts for the stocks of housing and appliances, equipment market shares, and energy intensity. The module assesses the shifts of market shares between competing technologies based on assumptions about the behavior of residential consumers.

The NEMS Residential Sector Demand Module is a sequential structured system of algorithms, with succeeding computations using the results from previously-executed. components as inputs. The module is composed of five logical components: housing stock forecast, technology choice, appliance stock forecast, building shell integrity, and energy consumption.

\section{Housing Stock Forecast}

The location and type of housing stock are the primary model drivers. The first component uses data from the NEMS Macroeconomic Activity Module to project new and existing housing for three dwelling types at the nine Census Division level. The three housing types are as follows:

- Single-Family Homes

- Multifamily Homes

- Mobile Homes

\section{Technology (Equipment) Choice}

The Technology Choice Component simulates the behavior of consumers by forecasting market shares for each available equipment type. New and replacement 
equipment decisions are modeled for each technology type. For new construction, home heating fuel is determined by relative life-cycle costs of all competing heating systems.

Table 2. Services and Equipment in the NEMS Residential Sector Demand Module

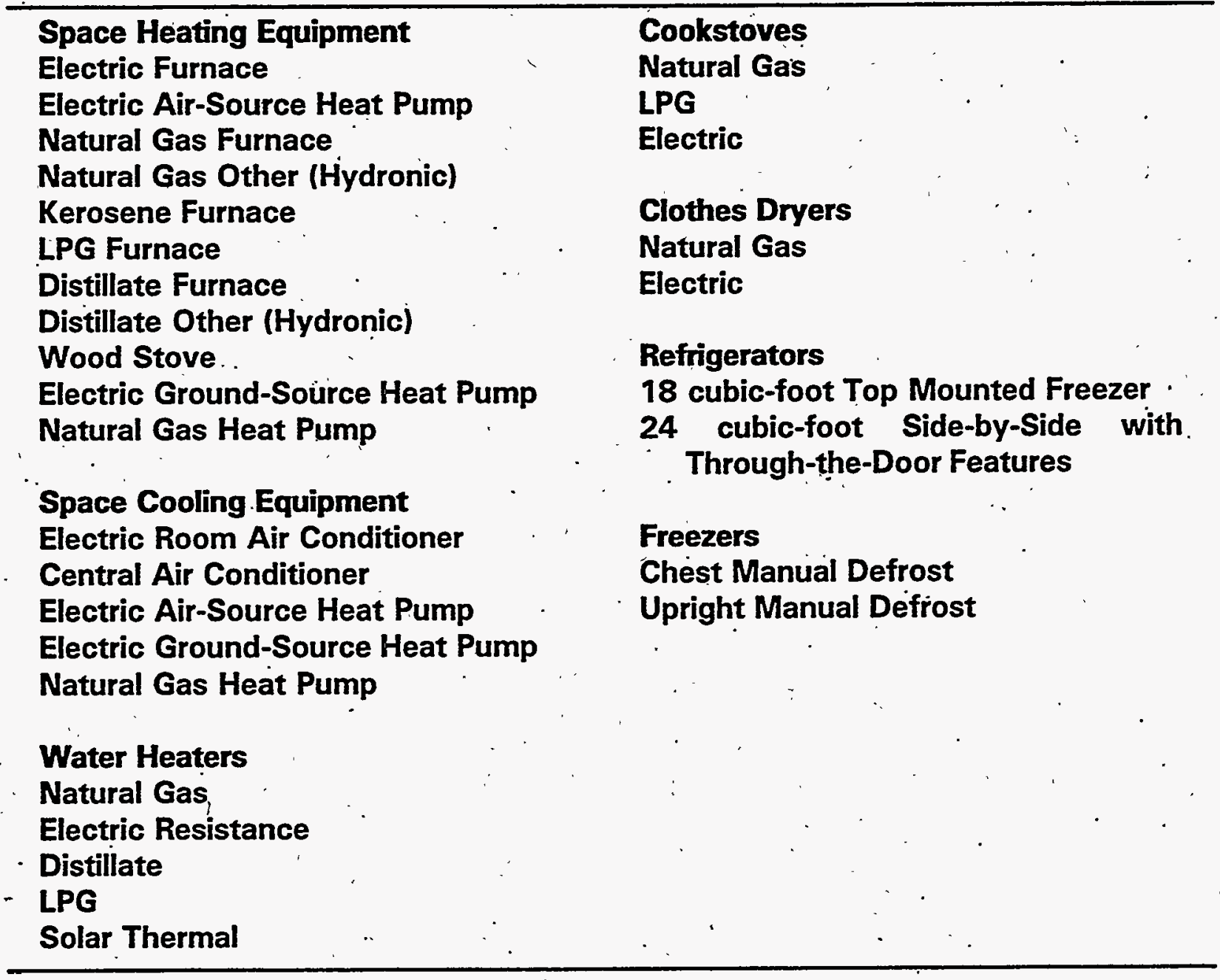

Relative weights are determined for each equipment type based on the existing market share, the installed capital cost, and the operating cost. These relative weights are then used to compute the market shares and composite average efficiencies for each service. The technologies are distinguished by the service demand that they satisfy, by the fuel that they consume, and by their efficiency. 


\section{Appliance Stock Forecast}

The Appliance Stock Component forecasts the number of end-use appliances within all occupied households. This component tracks equipment additions and replacements. Equipment is required to meet the following services:

- Space Heating

- Water Heating

- Clothes Drying

- Food Freezing
- Space Cooling

- Cooking

- Food Refrigerating

\section{Buniling Shell Integrity}

Building shell integrity is modeled for existing and new housing. The existing housing stock responds to rising prices of space conditioning fuels by improving shell integrity. Shell integrity improvements might range from relatively inexpensive measures (such as caulking and weatherstripping) to projects with substantial costs (such as window replacement).

New housing stock also incorporates shell integrity improvements. The shell integrity of new and existing housing is assumed to improve throughoụt the forecast horizon, as building codes and other efficiency programs become more widespread.

\section{Energy Consumption}

The Energy Consumption Component calculates end-use consumption for each service . and fuel type. The consumption forecasts are constructed as the product of the number of units in the equipment stock and the average technology UEC. The average UEC changes over time as the composition of the equipment stock changes over time. .

In each year of the forecast, the following steps are performed to develop the energy consumption forecast: 
1. A forecast of housing stock is generated based on the retirement of existing housing stock and the addition of new construction as determined in the MAM.

2. Prè-1994 vintage equipment stock is estimated, accounting for housing demolitions and additions.

Figure 1. NEMS Residential Sector Demand Module Basic Structure

3. Market shares are determined for equipment types by service.

4. The previous year's equipment additions and replacements for both pre-1994 and post-1993 vintage are determined based on the current year market share.

5. Efficiencies weighted by market share are calculated.

6. Fuel consumption is calculated using UEC and the weighted efficiencies (shell integrities and household size, if applicable).

\section{Flow Diagrams}

This section includes flow diagrams that represent the structure of the NEMS Residential Sector Demand Module. Figure 1 presents the overall sequential structure. Figure 2 illustrates the Housing Stock Component flow. The Technology Choice Component flow is represented in Figure 3. Figure 4 provides the flow of the Appliance Stock Additions and Replacements Component, the calculation of building shell efficiencies is found in Figure 5, and the Consumption and UEC Component .

FORECAST HOUSING STOCK
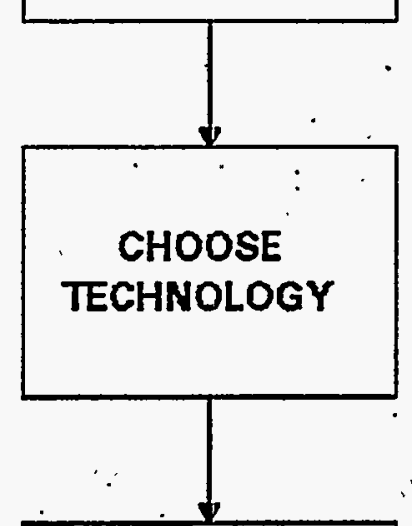

FORECAST

APPLIANCE.

STOCK

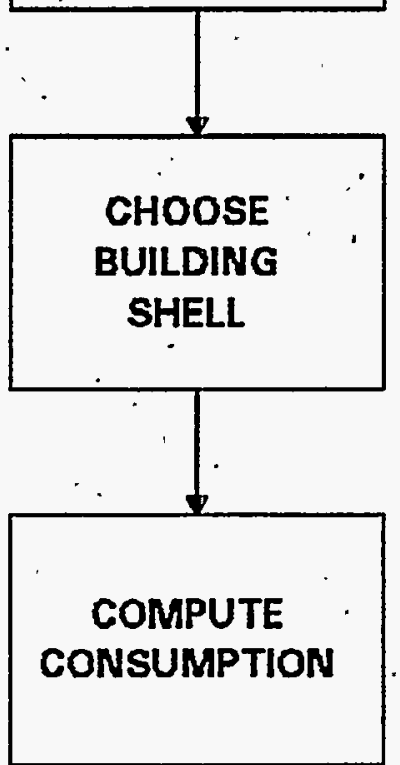
flow is provided in. Figure 6. 
The overall sequential structure as illustrated in Figure 1 details the five primary steps that calculate the final residential sector energy consumption. These five steps are discussed in the first chapter of this report.

Figure 2 illustrates the Housing Stock Component of the module. This component draws upon existing housing characteristics from the RECS data base and new housing characteristics from the MAM forecast. The Housing Stock calculates housing stock additions, survival, and retirements in order to produce the total housing stock by vintage, type, and Census Division.

Figure 3 illustrates the Appliance Stock Component of the module. The base year existing stock of major household appliances is derived from analysis of the RECS 1993 data. Appliance retirements are determined based upon the minimum and maximum equipment lifetime assumptions discussed in the Fundamental Assumptions section of this report. Additions to the appliance stock are calculated in this component, as is the surviving stock of equipment.

Figure 4 illustrates the Technology Choice Component of the module. The existing, replacement, and new appliance stock characteristics are used by this component to determine the stock requirements. Technology characterization information input to this component determines the set of equipment from which the required choices are made. The consumer choice functions by decision type determine the type, number, and equipment efficiency by end-use service.

Figure 5 illustrates the Building Shell Integrity Component, which calculates indices that reflect increasing building shell efficiencies over time, in response to increasing energy prices, EPACT window labeling standards, and technology improvement.

Figure 6 illustrates the Consumption and UEC. Component of the module. This component uses the base year UEC information developed from the RECS data, the technology selection information developed previously, building shell integrity, 
household size, and heating- and cooling-degree day effects to determine end-use consumption. 


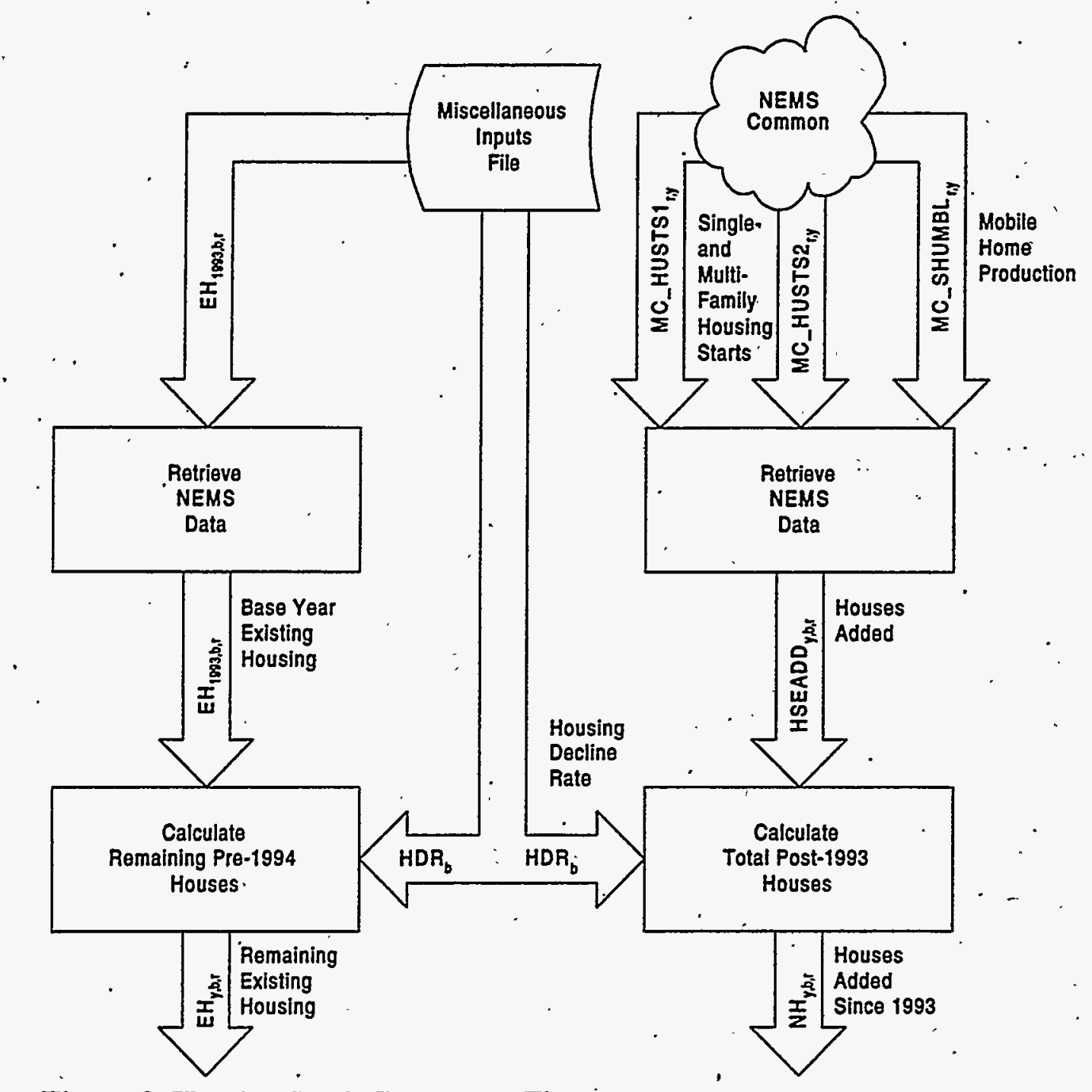

Figure 2. Housing Stock Component Flow: 


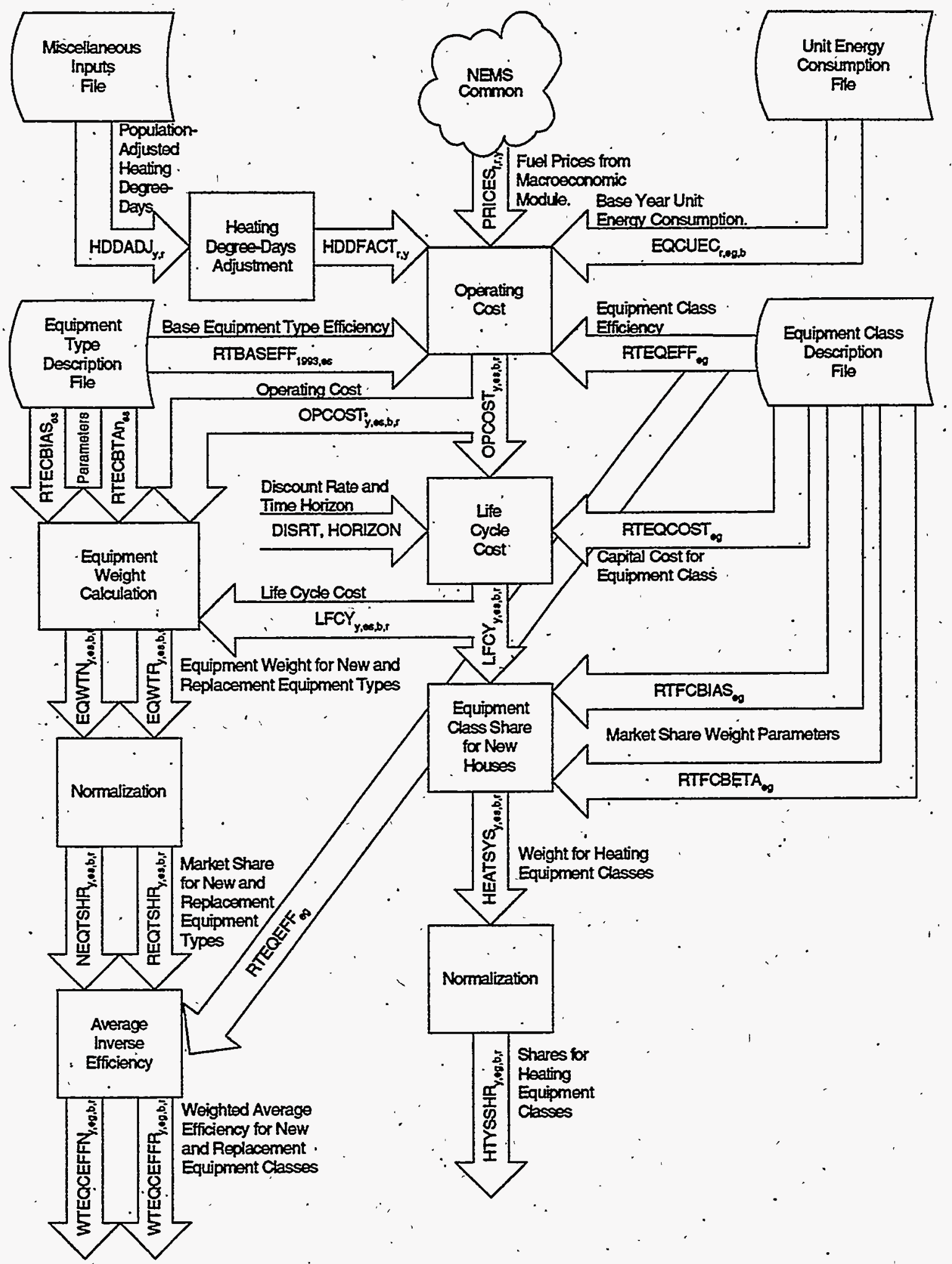

Figure 3. Technology Choice Component Flow. 


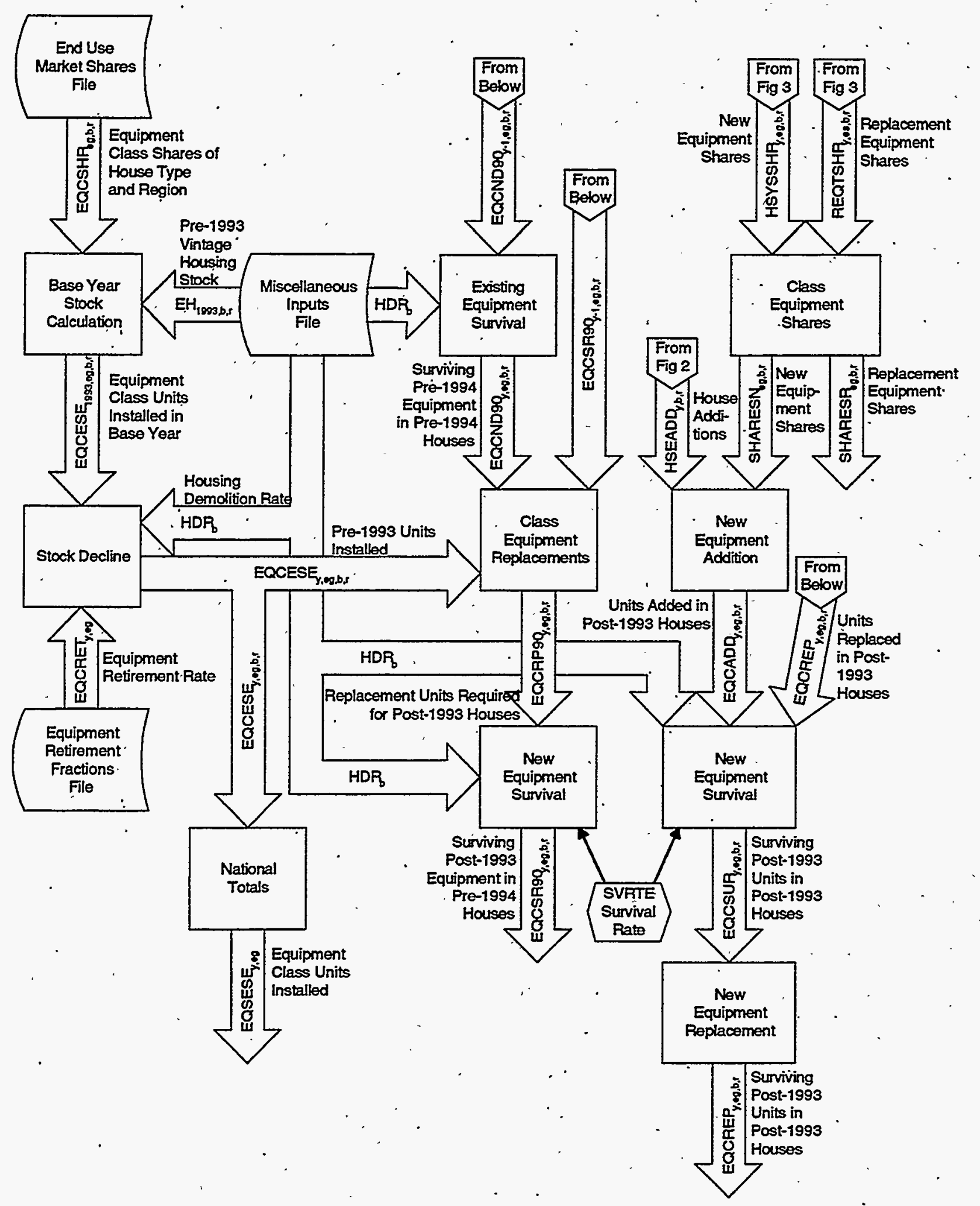

Figure 4. Appliance Stock Component Flow. 

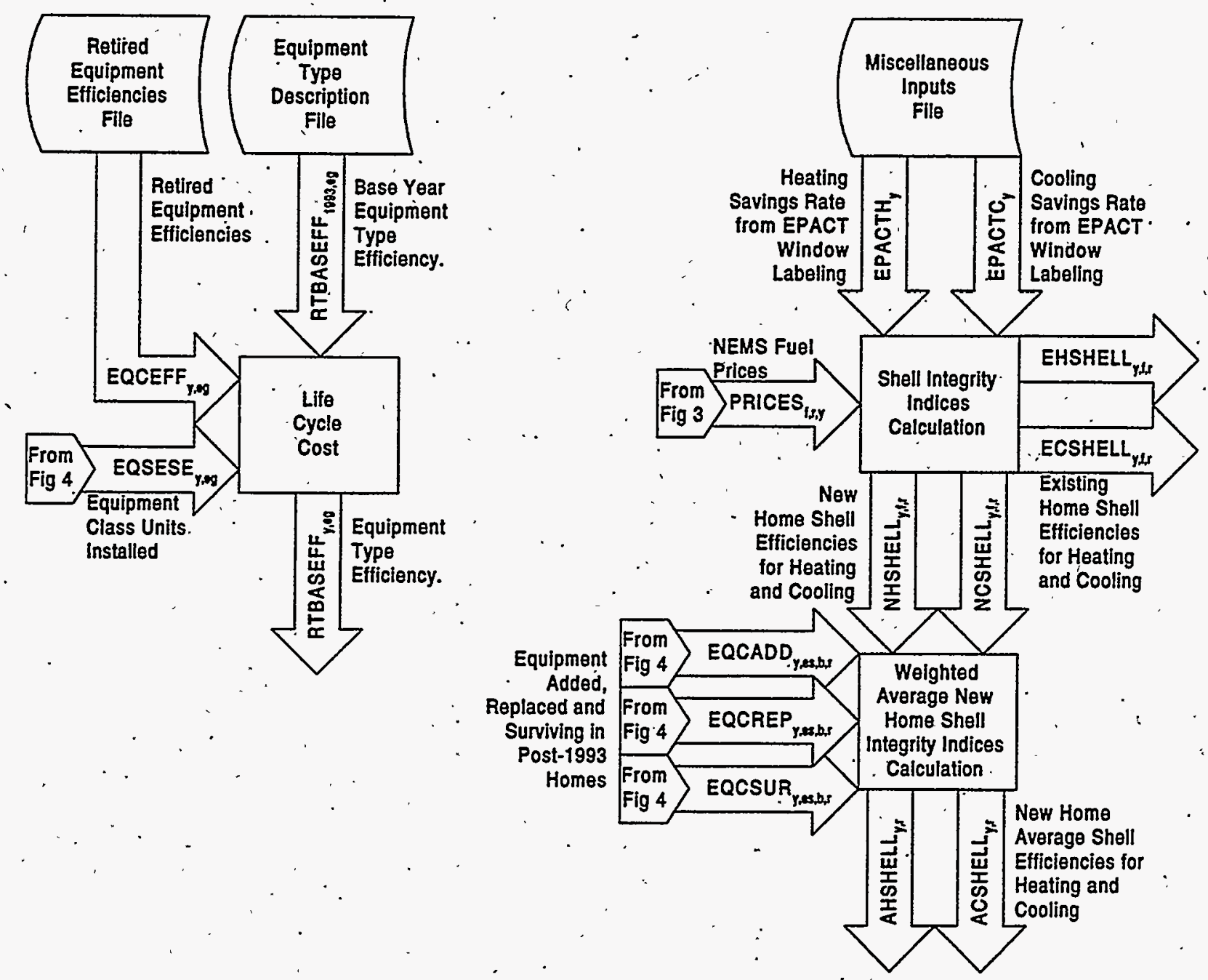

Figure 5. Building Shell Integrity Component Flow. 


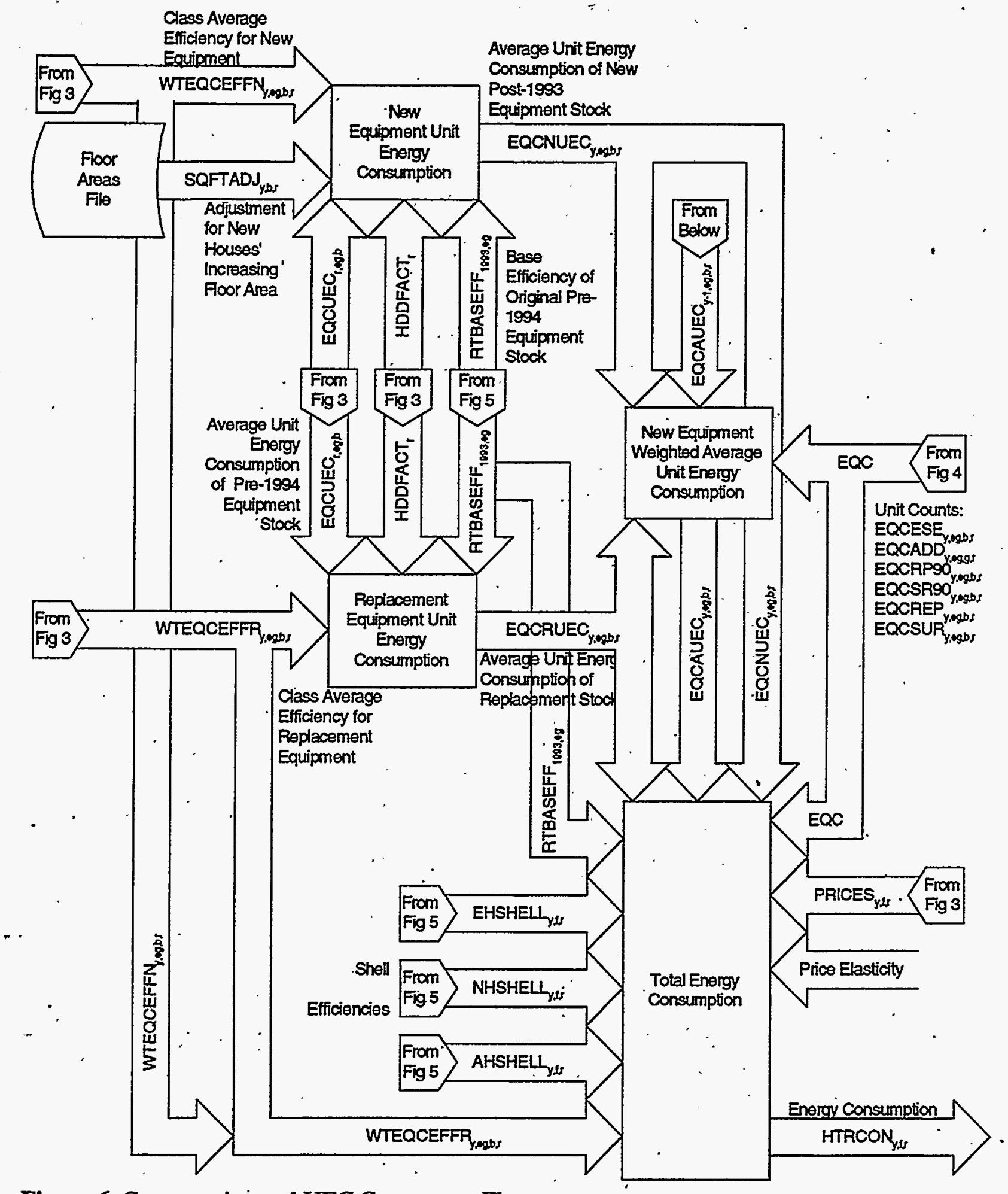

Figure 6. Consumption and UEC Component Flow. 


\section{FORTRAN Subroutine Descriptions}

The NEMS Residential Sector Demand Module FORTRAN source code consists of more than 50 subroutines sequentially called during the execution of the module. Table 3 . lists the major subroutines and their corresponding descriptions. The subroutines can be grouped into the following categories according to their functions:

\section{Fuel Price Subroutine}

The code includes the following subroutine that reads fuel prices:

RDPR reads in fuel prices from the NEMS system.

\section{Initialization Subroirtines}

The code includes the following subroutine for initialization purposes:

INTEOT initializes heating equipment market shares and applies the decay rate to the existing equipment.

\section{Housing Subroutines}

The code includes the following subroutine to assess housing stocks:

NEWHSE Reads housing starts from NEMS Macroeconomic Activity Module and computes new housing stock

\section{Existing Equipment - RDHTRTEC Subroutine}

This subroutine projects pre-1994 (existing) vintage equipment by service. In this subroutine, the following operations are performed:

1. The equipment market share is read from an exogenous data file by equipment type, housing type, and Census Division. 
Table 3. Primary NEMS Residential Sector Demand Module Subroutines

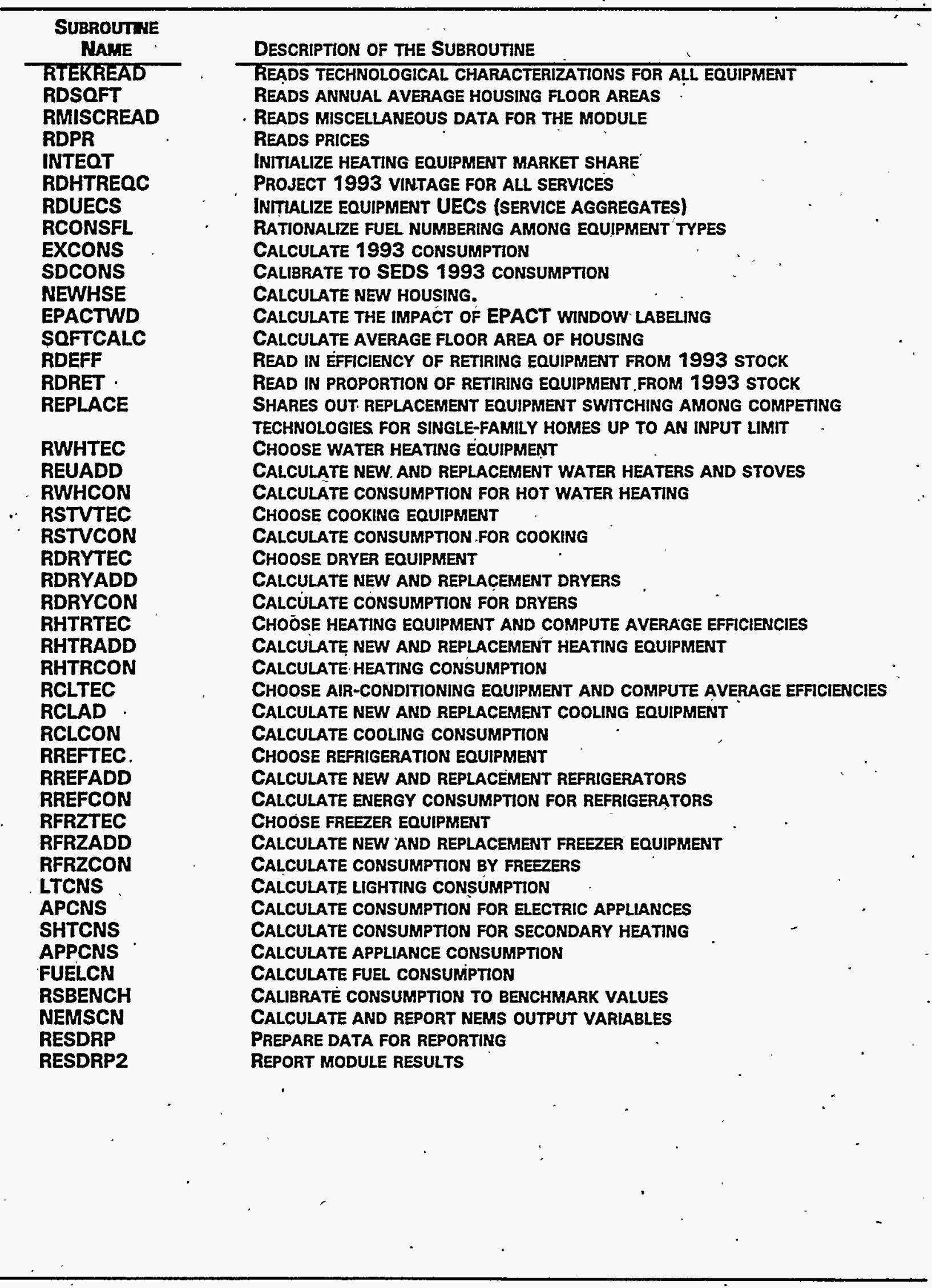


2. The base year equipment stock or the pre-1994 vintage stock is the product of the share and the amount of existing housing.

3. Surviving equipment of the pre-1994 vintage is forecasted using the equipment survival rate and the housing decay rate for every year in the forrecast.

These subroutines are as follows:

RDHTEQC

RDCLEQC

RDWHEQC
RDSTVEQC

RDDRYEQC

RDREFEQC

RDFRZEQC

\section{Other Input Subroutines}

These subroutines read other information from files:
RDEFF
reads efficiencies of retiring equipment
RDRET
reads equipment retirement rates
RTEKREAD
reads the detailed technology data
RMISCREAD
reads miscellaneous variables
RDSOFT
reads home floor areas
RDUECS
reads unit energy consumption data

\section{Calculation Subroutines (2)}

- The model includes a subroutine identified as EPACTWD to estimate the EPACT window labeling impact, and another, SOFTCALC, to calculate average home floor areas.

\section{Technology Choice - TEC Subroutines (7)}

The code includes seven technology choice subroutines that follow these general steps:

1. Initialize capital costs and equipment efficiencies.

2. Set discount rate, adjusstment factors and present value horizon. 
3. Compute operating costs of each equipment type.

4. Compute life cycle costs of each equipment type.

5. Compute technology share for new housing.

6. Calculate new and replacement equipment weights based on the bias, capital cost, and operating costs using a log-linear function.

7. Compute new market shares, ratio between equipment weights and total equipment weight.

8. Efficiencies for equipment types are calculated for new and replacement equipment. weighted by their respective market shares.

These subroutines are as follows:

RHTRTEC

RCLTEC

RWHTEC
RSTVTEC RDRYTEC RREFTEC
RFRZTEC

\section{RFRZTEC}

In addition to the TEC subroutines, the LTCNS subroutine assigns market shares to the different lighting technologies.

\section{Replacements and Additions - ADD Subroutines (6)}

The code contains six equipment replacement and additions subroutines. (Water heaters and stoves use the same "ADD" subroutine.) "TEC" subroutines for each service are followed by "ADD" subroutines that calculate new and replacement equipment for the previous year based on the current year's market share. The : following steps are implemented in these subroutines:

1. The post- 1993 vintage equipment additions are determined by the share of new. (post-1993) houses from the MAM that demand that service.

2. Compute the surviving post-1993 vintage equipment in pre-1994 vintage houses.

3. Compute total equipment required for pre-1994 vintage houses. 
4. Compute the equipment replacements in pre-1994 vintage houses by subtracting the sum of surviving pre-1994 vintage equipment and surviving post-1993 vintage equipment in pre-1994 vintage houses from the total equipment demanded for pre1994 vintage houses. Technology switching is allowed at replacement for space heaters, heat pump air conditioners, water heaters, stoves, and clothes dryers in single-family homes.

5. Compute the surviving post-1993 vintage equipment that was purchased as either additions or replacements for post-1993 houses.

6. Calculate the current year's replacements of post-1993 vintage equipment in post1993 houses as by subtracting the surviving replacements and equipment additions in post-1993 houses from the stock of surviving post-1993 houses. Technology switching is allowed at replacement for space heaters, heat pump air conditioners, water heaters, stoves, and clothes dryers in single-family homes. These subroutines are as follows:

RHTADD

RCLADD
REUADD

RDRYADD
RREFADD RFRZADD

\section{End-use Consumption - CON/CNS Subroutines (11)}

The code contains 11 end-use consumption subroutines defined by service. The ADD subroutines are followed by consumption subroutines. Within each of these subroutines the new, replacement and average unit energy consumption. values are calculated. These UECs are then multiplied by the equipment stock (and climate adjustment factor and shell integrity for space conditioning) to yield final fuel consumption. These subroutines, which follow, also include a price sensitivity expression that adjusts short-term demand for fuels:

\begin{tabular}{|c|c|c|}
\hline RHTRCON & RDRYCON & APCNS \\
\hline RCLCON & RREFCON & SHTCNS \\
\hline RWHCON & RFRZCON & APPCNS \\
\hline RSTVCON & LTCNS & \\
\hline
\end{tabular}


Overall, Consumption - CN Subroutines (2)

The model includes the following two subroutines that calculate overall fuel consumption and list output NEMS consumption:

FUELCN calculates fuel consumption

NEMSCN Output NEMS consumption

\section{Historical Consumption/Calibration Subroutines (3).}

The code includes the following three subroutines to determine historical energy consumption and to calibrate to the historical SEDS values:

EXCONS calculate 1993 consumption

SDCONS calibrate UEC's to SEDS 1993 consumption

RSBENCH calibrate consumption to 1991-1994 SEDS consumption

\section{Report Subroutines (2)}

The following subroutines produce the output reports:

\section{RESDRP}

\section{RESDRP2}

\section{Key.Computations and Equations}

This section presents the detailed calculations used in each of the module components, couched in terms of the space heating end use, because it provides the best examples for generalization. Calculations for other end uses follow the space heating pattern, with different variable names. For more detail refer to Appendix $B$, where calculations are provided at the subroutine level. Table 4 shows the correspondence between the subscripts in the documentation and the subscripts in the FORTRAN source code.

Please note the following conventions: 
Table 4. Definitions of Subscripts

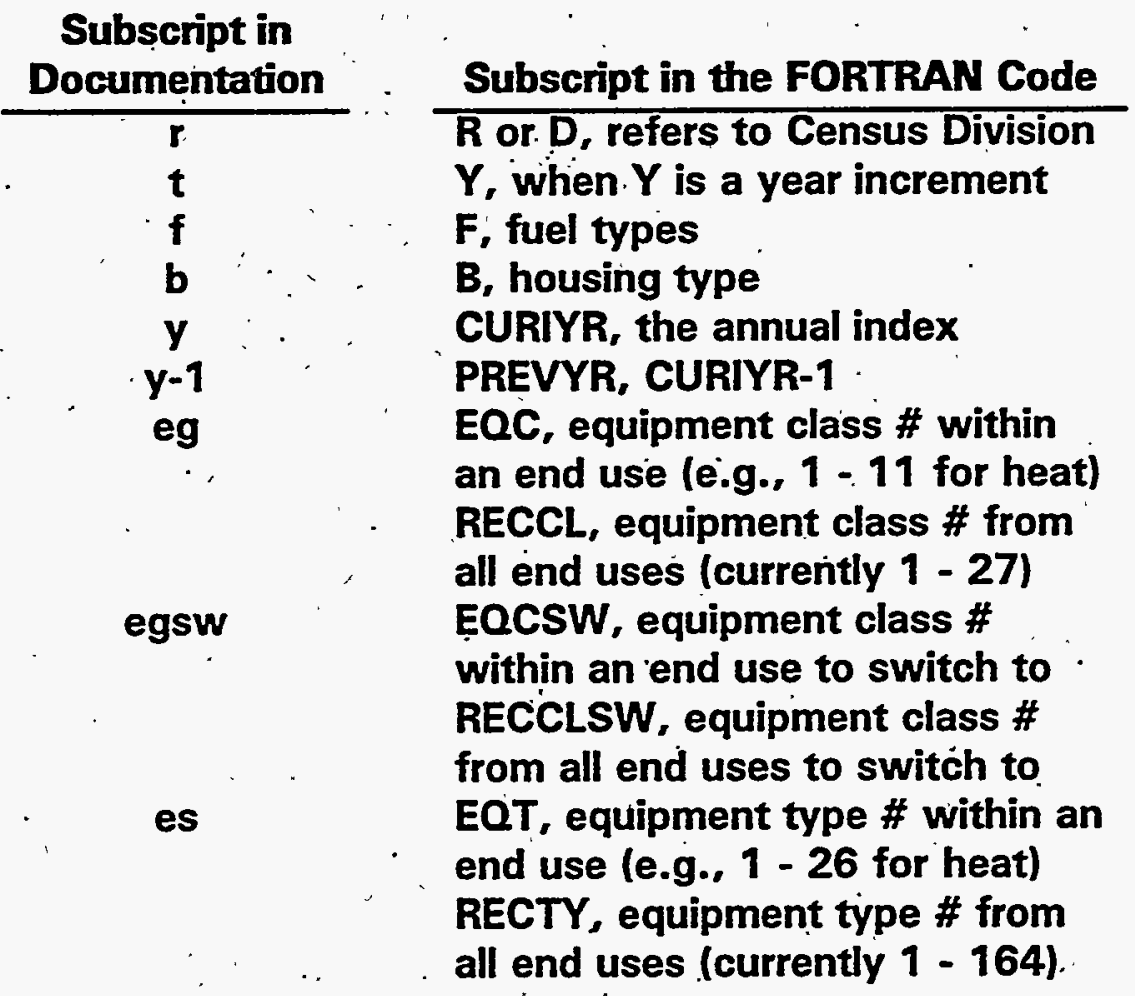

- The table of subscripts includes all of the major usages. In some minor instances, additional subscripts are defined as needed.

- The equations follow the logic of the FORTRAN code very closely to facilitate an understanding of the code and its structure. In several instances, a variable appears on both sides of an equation. This is a FORTRAN programming device that allows a previous calculation to be updated (for example, multiplied by a factor) and re-stored under the same variable name (i.e., in the same memory location).

- The subscript, $y$, in the documentation refers to the year represented as 1990 through 2015.' In the FORTRAN code, the subscripts for CURIYR represent array dimensions starting with an index of 1 to represent 1990 (in some cases, the array index of 1 represents 1991 as explained below). Not all arrays begin with an array position for 1990 . Specifically, the arrays that represent or relate to equipment 
added after the 1990 base year begin with the first array position representing 1991 (PREVYR), to economize on memory storage.

- Some variables are documented as having a " $y$ " dimension when in fact they do - not. The most common instances are for the variables, LFCY, OPCOST, SA, SHARESN, and SHARESR. These variables are calculated on an annual basis, but are retained only for the current year. The " $y$ " dimension is used in the documentation to highlight 1) that the calculations do vary by year, and 2) to indicate the current year in formulas to avoid confusion.

- Summations over all relevant variables are usually written without upper and lower range limits on the summation signs.

- Unless otherwise stated, the range of $y$ for an equation is 1991 through 2015.

\section{Housing Stock Component}

To calculate the number of existing dwellings, the Housing Stock Component adds newly-built homes to the inventory and subtracts demolitions. Housing construction starts are obtained from regional outputs of the MAM. Existing base year housing stock is designated as the "pre-1994" vintage, and new additions to the housing stock are referred to as the "post-1993" vintage. Additions and replacements for both housing vintages are tracked through the forecast period.

Houses are removed from the stock at a constant rate over time. The survival rates for the household types $\left(H D R_{b}\right)$ are as follows:

Single-Family Homes: $H D R_{1}=0.997$

Multifamily Homes: $H D R_{2}=0.996$

Mobile Homes: $\quad H D R_{3}=0.966$ 
The surviving 1993 housing stock is defined by

$$
\begin{aligned}
& E H_{y, b, r}=R E C S \text { datar, if } y=1993 \\
& E H_{y, b, r}=E H_{y-1, b, r} \times E D R_{b}, \text { if } y>1993
\end{aligned}
$$

where,

$E H_{y, b, r}$ is 1993 housing stock surviving by year, housing type and Census Division.

\section{Technology Choice Component}

The Technology Choice Component uses a log-linear function to estimate technology market shares. The module is able to calculate market shares based on consumer behavior as, a function of bias, capital costs, and operating costs or as a function of life-cycle costs.

The seven major services modeled are:

$$
\begin{aligned}
& \text { Space Heating } \\
& \text { Space Cooling } \\
& \text { Water Heating } \\
& \text { Cooking } \\
& \text { Clothes Drying } \\
& \text { Food Refrigeration } \\
& \text { Food Freezing }
\end{aligned}
$$

Lighting and other appliance decisions are modeled differently from the major services listed above.

Equipment operating costs are computed by the expression,

$$
O P C O S T_{y, e s, b, r}=P R I C E S_{f, r y} \times E Q C U E C_{r, e s, b} \times H D D F A C T_{r, y} \times \frac{R T B A S E F F_{1993, c 8}}{R T E Q E F F_{a}}
$$

where,

OPCOST $_{y, e s, b, r}$ is the operating cost for the specific equipment type by year, housing type, and Census Division, 
PRICES f,ry $_{\text {. }}$ is the fuel prices for the equipment by fuel, by region and forecast year,

$E Q C U E C_{r, e g, b .} \quad$ is the unit energy consumption by Census Division, equipment class and housing type,

$H_{D D F A C T_{r, y}}$ is a factor, the ratio between heating degree days in the current year and in the base year, for adjusting for abnormally warm weather in either the base year or in the current year,

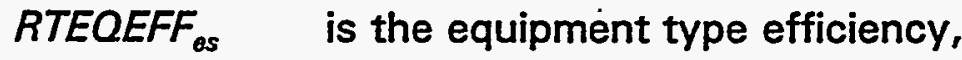

RTBASEFF $_{1993, \mathrm{eg}}$ is the 1993 stock-average efficiency.

The consumer is allowed to choose among the various levels of cost and efficiency for a given class of equipment. Electric heat pumps are an example of an equipment class (denoted by eg). Equipment type (denoted by. es) refers to the same class of equipment with different efficiency ratings (e.g., high vs low efficiency electric heat pumps).

EOCOST is a time-dependant function for computing the installed capital cost of equipment in new construction and the retail replacement cost of equipment in existing housing. It is called if the cost trend switch COSTTRSW $=1$ in COMMON RTEK (which is the default). Its mathematical description is as follows:

$$
\begin{aligned}
& E Q C O S T_{c y, C A P}=R T E Q C O S T_{\alpha s} \text {, if RTMATURE } E_{e s}=M A T U R E \\
& \text {. } E Q C O S T_{\text {CSy, RET }}=R T R E C O S T_{\text {is }} \text {, if } R T M A T U R E_{e s}=\text { MATURE } \\
& E Q \operatorname{COST} T_{c y, C A P}=\frac{\text { RTEQCOST }_{c s} \times 2 \times d}{\left(y-y_{1}\right)^{\gamma}}+(1-d) \times \text { RTEQCOST }_{e s} \text {, if RTMATURE } E_{c s}=A D O L E S C E N T \\
& 1+\left(\frac{y-y_{1}}{y_{0}-y_{1}}\right)^{\gamma}
\end{aligned}
$$

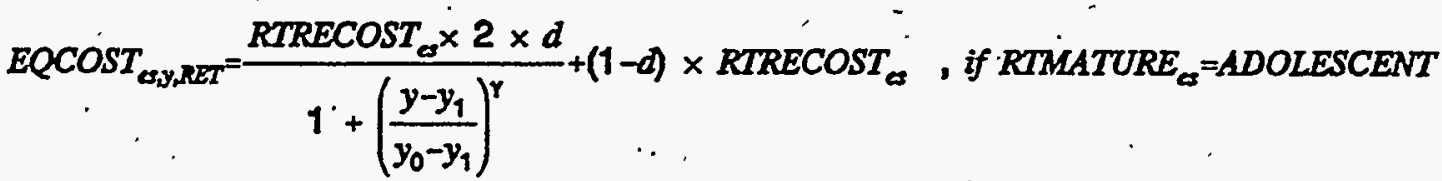




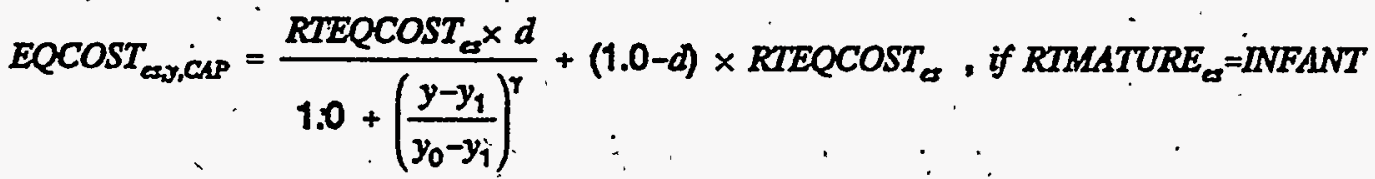

$$
\begin{aligned}
& E Q C O S T_{c=y, d E T}=\frac{R T R E C O S T_{e s} \times d}{1.0+\left(\frac{y-y_{1}}{y_{0}-y_{1}}\right)^{\gamma}}+(1.0-d) \times R T R E C O S T_{c s} \text {, if RTMATURE }{ }_{e s}=I N F A N T
\end{aligned}
$$

where,

$E_{\text {OCOST }}$ es,y,ctype. is time-dependant installed capital cost of equipment in new construction or the retail replacement cost of equipment in existing housing,

ctype . tells function type of equipment cost to return,

CAP = Return installed capital cost in new construction,

RET $=$ Return retail replacement cost in existing housing,

RTMATURE

MATURE = No further equipment cost reductions expected,

ADOLESCENT = Major cost reductions occurred before base

year,

INFANT = All cost reductions expected after first year available,

- RTEQCOST remains constant for MATURE technologies only lused when ctype $={ }^{\circ} C A P$,

RTRECOST es Retail capital cost in $\$ 1990$ per unit for replacements, remains constant for MATURE technologies only (used when ctype = RET,

Yo is the year of inflection of cost trend,

RTINITYR $R_{\text {es }}$ if ADOLESCENT,

RTCOSTP1 if INFANT,

$y_{1}$ is the year cost decline began,

RTCOSTP1 ${ }_{\text {os }}$ if ADOLESCENT,

$R T I N I T Y R_{\text {es }}$ if INFANT, 
is the total possible proportional decline in equipment cost, RTCOSTP3 ${ }_{\text {es, }}$

from $y_{0}$ onward if ADOLESCENT,

from $y_{1}$ onward if INFANT,

$r$ is the logistic curve shape parameter, RTCOSTP ${ }_{i s}$.

The module includes the option to use life-cycle costing to calculate market share weights. The life cycle cost calculation is,

$$
L F C Y_{y, a s, b r}=C A P T A L_{e s}+O P C O S T_{y, s, b, r} \times\left[\frac{1-(1+D I S R T)^{-B O R E O N T}}{D I S R T}\right]
$$

where,

$L_{\text {LCY }} Y_{y, e s, b, r}$ is the life cycle cost of an equipment type by forecast year, housing type, and Census Division,

CAPITAL $L_{\text {es }}$ is the installed capital cost of an equipment type based on calling EQCOST with RTEQCOST

HORIZON . is the number of years into the future that is used to compute the present value of future operating cost expenditures presently set to seven years, and.

DISRT is the discount rate applied to compute the present value of future operating costs presently at 20 percent.

A weight for each equipment class is calculated to estimate the market share for each of the 11 heating systems for new construction based on the cost factors computed above: The functional form is expressed as,

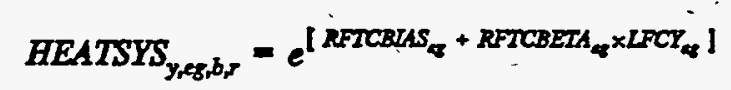

where,

HEATSYS ${ }_{y, g, b, r}$ is the equipment weight for a heating equipment class for new housing by year, housing type, and Census Division, 
RTFCBIAS $_{\text {eg }}$ is a consumer preference parameter that fits the current market share to historical shipment data,

LFCY $_{y, e g, b, r} \quad$ is the life cycle cost for the equipment class by year, housing type, and Census Division, and

RTFCBETA $A_{e g}$ is a parameter value of the log-linear function:

The sum over the heating equipment classes gives the total weight for all of the heating equipment:

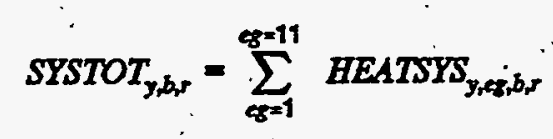

where,

SYSTOT $_{y, b, r}$ is the sum of equipment class weights for the all equipment classes.

The equipment class fuel share is computed by

$$
\begin{aligned}
& \text { HTYSSHR }_{y_{, 6 z, b, r}}=\frac{\text { HEATSYS }_{y, 6 g, b, r}}{S Y S T O T_{y, b, r}} \text {, if SYSTOT } T_{y, b, r}>0 \text {. } \\
& H_{T Y S S H R} R_{y, e s, b, 5}=0 \text {, otherwise }
\end{aligned}
$$

where,

HTYSSHR ${ }_{y, e g, b, r}$ is the equipment class fuel share by year, building type, and Census Division.

For each equipment type within each class, a weight is calculated based on the cost factors computed above. The functional form is expressed as,

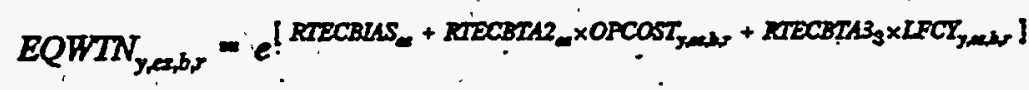

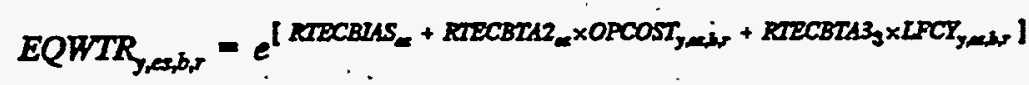

where,

$E Q W T N_{y, e s, b, r}$ is the equipment weight for new equipment type by year, housing type, and Census Division, 
$E Q W T R_{y, e s, b, r}$ is the equipment weight for replacement equipment type by year, $\therefore$ housing type, and Census Division,

$O P C O S T_{y, e s, b, r}$ is the operating cost for the equipment type by year, housing type, and Census Division,

$L F C Y_{\text {v,es,b,r }}$ is the life cycle cost for the equipment type by year, housing type, , and Census Division, and

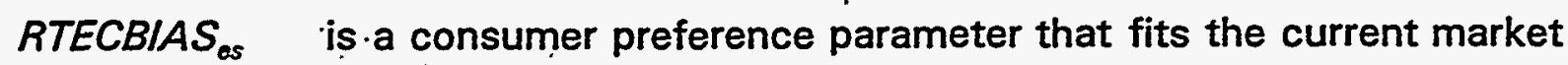
share to shipment data,

$R T E C B T A 2_{\text {es' }}$, are parameter values of the same fit.

RTECBTA3 ${ }_{\text {es }}$

Sums over the equipment types within each class give total weights for the equipment classes:

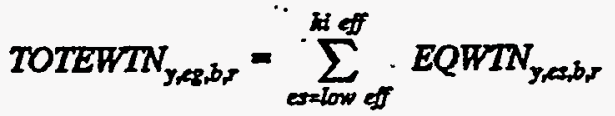

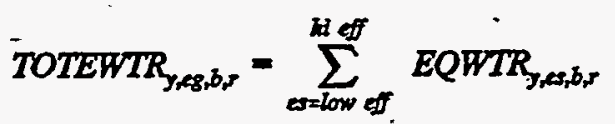

where,

TOTEWTN $N_{y, e g, b, r}$ is the sum of weights for the new equipment types within equipment classes,

TOTEWTR $_{y, e g, b, r}$ is the sum of weights for the replacement equipment types within equipment classes.

The equipment type fuel share is computed by 


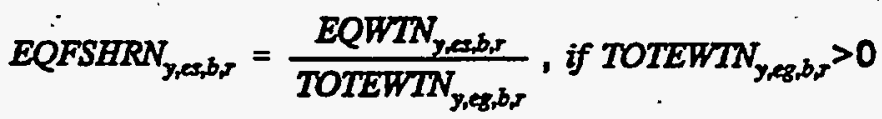

$$
\begin{aligned}
& \text { EQFSHRN }_{\text {y,es,b, }}=0 \quad \text {, otherwise }
\end{aligned}
$$

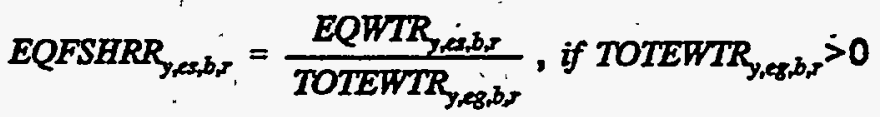

$$
\begin{aligned}
& \text { EQFSHRR }{\text {,es, }, b_{5}=0}=0, \text { otherwise }
\end{aligned}
$$

where,

EQFSHRN $_{y, e s, b, r}$ is the new equipment type fuel share by year, building type, and Census Division:

EQFSHRR $_{\text {y,es,b,r }}$ is the replacement equipment type fuel share by year, building type, and Census Division.

This value is multiplied by the market share of the equipment type to yield the new market share for the equipment type. The relationship is expressed as,

$$
\begin{aligned}
& N E Q T S H R_{\text {yes, }, 5,5}=E Q F S H R N_{y, e s, b, 5} \\
& R E Q T S H R_{y_{10 s, b, r}}=E Q F S H R R_{y_{y} e x, b r}
\end{aligned}
$$

where,

NEQTSHR $R_{y, e s, b, r}$ is the new market share for the new equipment type by year, housing type, and Census Division.

REQTSHR $R_{y, e s, b, r}$ is the new market share for the replacement equipment type by year, housing type, and Census Division.

The weighted average equipment efficiencies for the equipment types within each equipment class are then computed as, 


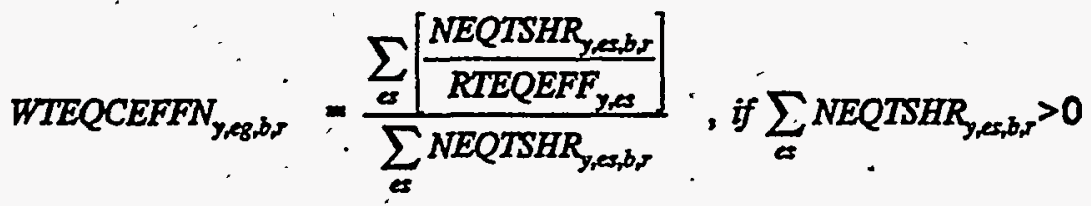

$$
\begin{aligned}
& \text { WTEQCEFFN } \text { Yreg, b, }_{\text {, }}=\frac{1}{\text { RTRASEFF }_{\text {eg }}} \quad \text {, otherwise }
\end{aligned}
$$

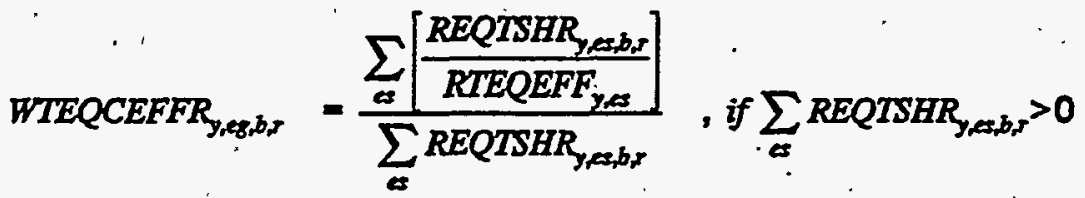

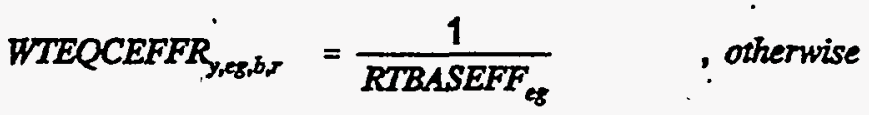

where,

WTEQCEFFN $N_{y, e g, b, r}$ is the weighted average efficiency of new equipment type within each equipment class by year, housing type; and Census Division.

WTEQCEFFR $R_{y, e g, b, r}$ is the weighted average efficiency of replacement equipment types within each equipment class by year, housing type, and Census Division.

\section{Appliance Stock Component}

The appliance stock component tracks the major energy-consuming equipment by housing vintage and equipment vintage for additions, replacements, and surviving equipment.

Table 5 depicts the equipment accounting methodology. For simplicity, this discussion omits the details of the variable subscripts, which is explained later. The equipment accounting system partitions equipment into two major categories, depending on the vintage of the housing unit: equipment installed in housing units built before 1994 lat the beginning of a model run) and equipment added to new housing units (those added during the model run). Equipment is further partitioned into three additional survival/replacement categories: equipment that survives, equipment purchased to 
Table 5. Heating Equipment, UEC and Housing Shell Accounting Scheme

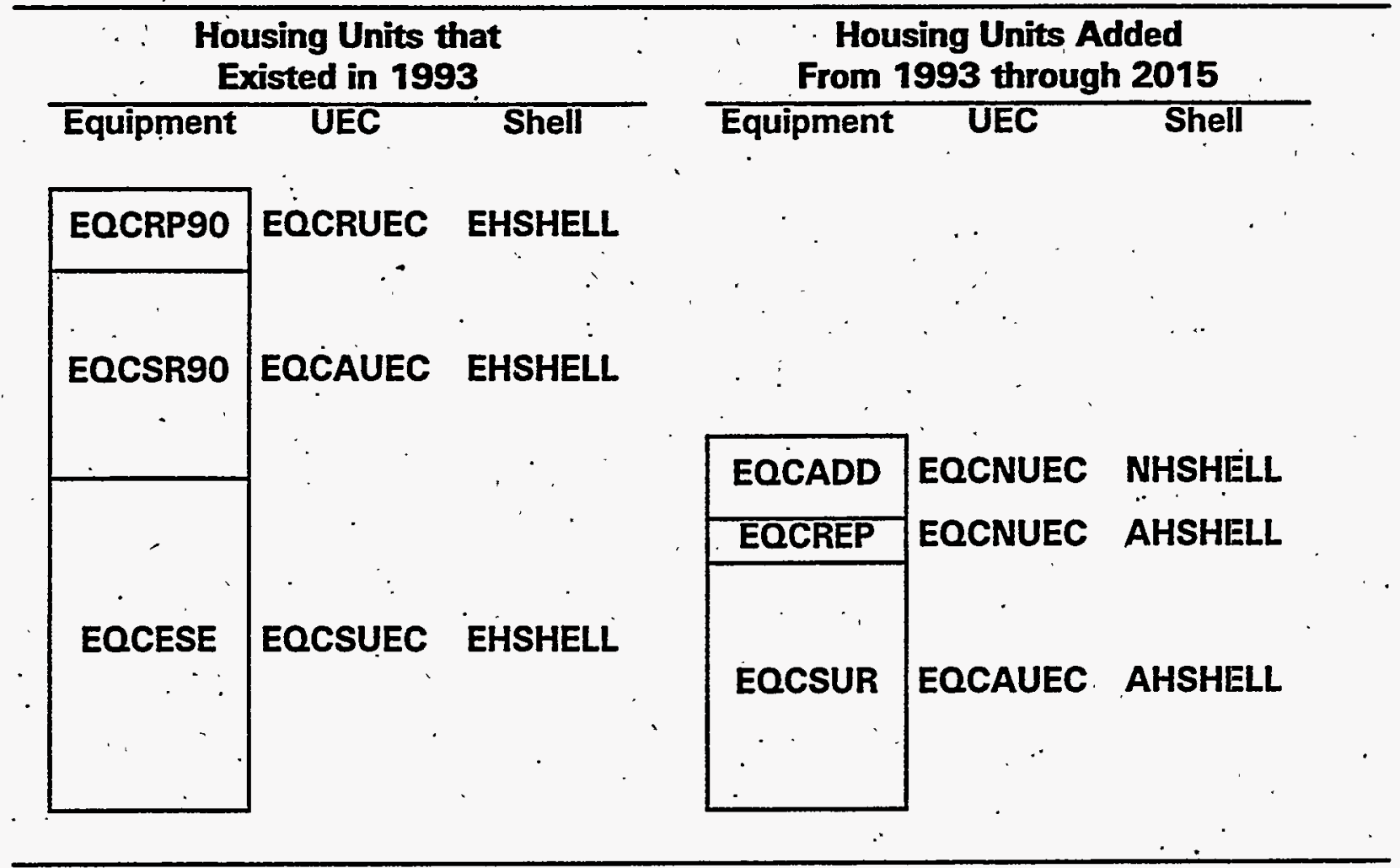

replace other equipment, - and equipment purchased for new construction. The categorization of equipment by housing vintage and surviving/replacement type results in six categories of equipment that are tracked.

The equipment categories for pre-1994 housing units are:

EOCESE denotes the surviving pre-1.994 equipment stock in pre-1994 homes, EOCSR90 represents equipment stock in pre-1994 homes that has been replaced after 1993 and that still survives, ${ }_{i}$ and

EQCRP90 is current-year replacement equipment for pre-1994 housing.

Note: EQCND9O is the sum of EQCESE, EOCSR9O and EQCRP9O.

The equipment categories for post-1993 housing units are:

EOCSUR denotes equipment that has been modeled as added and still survives, EOCREP is equipment that has been modeled as added and is in need of replacement in the current year, and 
ĖCADD is equipment for housing units added in the current year.

Unit energy consumption (UEC) is tracked for equipment added by category of housing. unit:

EOCUEC is the average UEC for the original 1993 equipment in housing units that existed in 1993,

EQCSUEC is the average UEC for surviving equipment in pre-1994 housing units, EQCAUEC is the average UEC for surviving equipment in post-1994 housing units, EQCRUEC is the UEC for all equipment added in the current year to replace pre1994 equipment, and

EOCNUEC is the UEC for all equipment added in the current year for post-1993 homes.

Shell indices are modeled for three categories of housing units:

EHSHELL is the shell index applicable to pre-1994 housing units,

AHSHELL is the shell index applicable to housing units added in all but the current year, and

NHSHELL is the shell index for housing units added in the current year.

For example, in accounting for the heating energy consumption of surviving equipment installed in pre-1994 housing units, the equipment stock, HTESE, would be multiplied by the unit energy consumption; HTUEC, and by the shell index EHSHELL. This explanation was designed to account for heating equipment, but the accounting principle is used throughout the residential module. For the pre-1994 housing example above, the appropriate space cooling variables would be CLESE, CLUEC and ECSHELL. The shell indices apply only to heating and cooling, thus, for example, for refrigeration the accounting requires only RFESE and RFUEC.

The housing decay rate. is used in conjunction with the equipment survival rate to determine the number of equipment units that survive/retire each year in the forecast. 
A linear function is used to model the retirement of equipment after a minimum age is reached up to its maximum age. The linear function is expressed by,

$$
\begin{aligned}
& S Y R T E_{y-h x_{\operatorname{mon}} I_{\max }}=1.0 . \quad \text {, if } y-t \leq I_{\min } \\
& S V R T E_{y-L_{2} L_{\min } I_{\max }}=\frac{L_{\max }-(y-t)}{L_{\max }-L_{\operatorname{man}}} \text {, if } L_{\min }<y-t<L_{\max } \\
& S V R T E_{y-t I_{\min } l_{\max }}=0.0^{\prime} \quad, \quad \text { if } y-t \geq L_{\max }
\end{aligned}
$$

where,

$$
S V R T E_{y-t, L_{\text {matrax }}}
$$

is the equipment survival function,
$y-t$
is the age of the equipment,
$L_{\min }$
is the minimum equipment lifetime in years, and
$L_{\max }$ is the maximum equipment lifetime in years.

Equipment in post-1993 (new) houses is the product of the number of new houses and the market share of each equipment class. This is expressed as,

$$
E Q C A D D_{y, e g, b, r}=H S E A D D_{y, b, r} \times \operatorname{SHARESN}_{y, e g, b, r}
$$

where,

$E Q C A D D_{y, e g, b, r}$ is the number of post-1993 vintage equipment units added to new houses by forecast year, housing type and Census Division,

$H S E A D D_{y, b, r}$ is the number of new housing units constructed in the forecast year by housing type and Census Division,

SHARESN $_{\text {y,eg,b,r }}$ is the current year market share for each equipment class by housing type and Census Division.

The surviving post-1993 vintage equipment in pre-1994 houses is computed as,

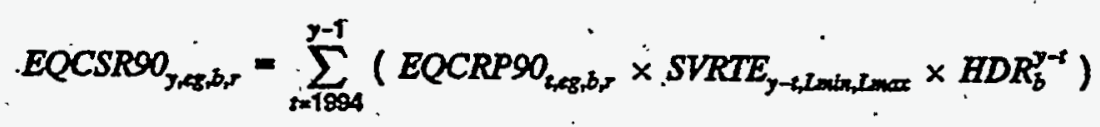

where, 
EQCSR90 ${ }_{y, e g, b, r}$. is the equipment stock in pre-1994 homes that has been replaced after 1993 and still survives by housing type and. Census Division,

EQCRP9O $_{t, e g, b, r}$ is the number of replacement (post-1993 vintage) equipment units demanded each year in pre-1994 houses by housing type and Census Division,

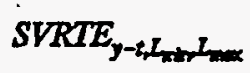

is the equipment survival function, $H D R_{b}$ is the housing survival rate by housing type, and $y-t$ represents the age of the equipment.

The total amount of pre-1994 equipment in pre-1994 houses is computed as:

$$
\begin{aligned}
& E Q C N D 90_{y, c 8, b, r}=E Q C E S E_{1983, e g, b, r} \times H D R_{b} \text {, if } y=1993 \\
& E Q C N D 90_{y, e g, b, r}=E Q C N D 90_{y-1, e \&, b, r} \times H D R_{b} \quad \text { if } y>1993
\end{aligned}
$$

where,

EOCND90 ${ }_{y, e g, b, r}$ is the total amount of equipment in pre-1994 houses by year, equipment class, housing type and Census Division,

EOCESE $_{1993, e g, b, r}$ is the stock of equipment in 1993 by equipment class, housing type and Census Division,

$H D R_{b} \quad$ is the housing survival rate by housing type.

For replacement units (post 1993) equipment required for pre-1994 single-family homes in the current year technology switching is allowed. The number of homes that may switch in each equipment class is calculated as,

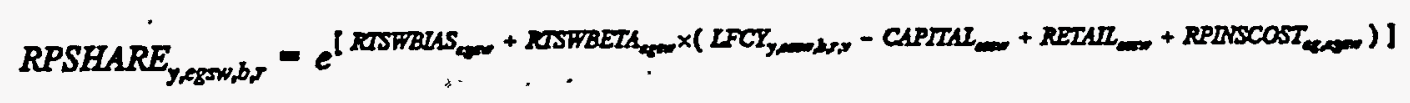

Sum to find the total number of switches. 


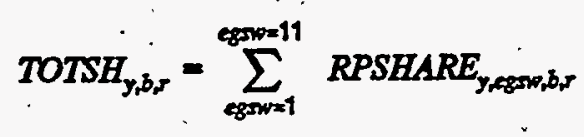

Finally, divide the number of switches in each equipment class by the total number of switches (if $>0$ ) to calculate the share of replacement equipment. which may switch.

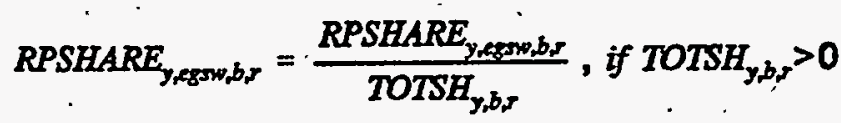

$$
\begin{aligned}
& R P S H A R E_{\text {yegsw, } b, 5}=0 \quad \text {, otherwise }
\end{aligned}
$$

where,

RPSHARE ${ }_{y, \text { ogsw,b,r }}$ in Figure 1 is the number that will switch to equipment class egsw on replacement by year, housing type, and Census Division,

RPSHARE ${ }_{y, e g s w, b, r}$ in Figure 1 is the share that will switch to equipment class egsw on replacement by year, housing type, and Census Division;

RTSWBIA $S_{\text {egsw }}$ is the consumer preference parameter for switching to this equipment class;

RTSWBETA $A_{\text {egsw }}$ is the parameter value for the same fit, $L F C Y_{y, e s s w, b, r, v}$ is the lifecycle cost of the equipment type switching to (essw) by year, building type, region, and vintage,

CAPITAL essw is the original equipment type cost (based on calling EOCOST with RTEQCOST ${ }_{\text {essw }}$ ) which is subtracted from the lifecycle cost for replacements,

RETAIL with RTRECOST ${ }_{\text {essw }}$ ) which is added to the lifecycle cost for replacements, 
RPINSCOST eg,egsw : is the cost of switching from equipment class eg to egsw. on switching, and

TOTSH $_{y, b, r} \quad$ is the total number of homes that will switch space heater technologies.

Replacement units (post-1993) equipment required for pre-1994 homes in the current year for single-family homes where switching is allowed are calculated as,

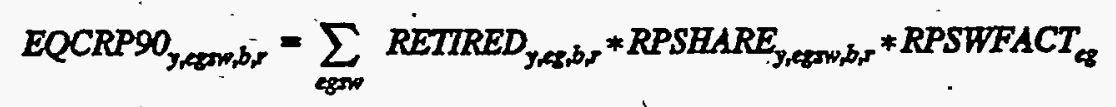

where,

EQCRP90

is the number of replacement units required for singlefamily pre-1994 houses by forecast year, housing type and Census Division,

RETIRED $D_{y, g, b, r}$ is calculated as in Figure 1, EQCRP9O for multifamily and mobile homes by forecast year, housing type and Census Division,

RPSHARE y,egsw,b,r $_{\text {is }}$ is share that will switch equipment class (egsw) on replacement by year, housing type, and Census Division, and

$R T S W F A C T_{e g} . \quad$ is the fraction who may switch from equipment class eg.

Post-1993 replacement units required for single-family pre-1994 homes in the current year where switching is not allowed (due to the switching limit) are calculated as,

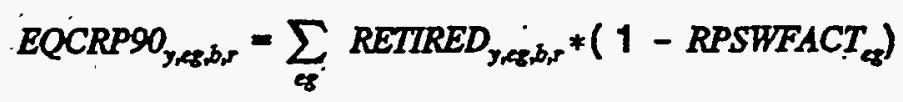

where,

EQCRP9O ${ }_{y, e g, b, r}$ is the number of replacement units required for single-family pre-1994 houses by forecast year, housing type and Census Division, 
RETIRED $D_{y, e g, b, r}$ is calculated as in Figure 1, EQCRP9O for multifamily and mobile homes by forecast year, housing type and Census Division,

1-RTSWFACT $T_{\text {og }}$ - is the fraction who may not switch from equipment class . eg.

Post-1993 replacement units required for pre-1994 multifamily or mobile homes in the current year are calculated as,

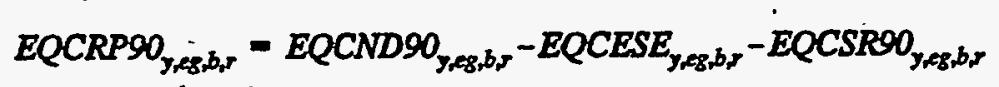

where,

EQCRP9O ${ }_{y, g g, b, r}$ is the number of replacement units required for pre-1994 multifamily or mobile homes by forecast year, housing type. and Census Division,

EOCND90 : forecast year, housing type and Census Division (i.e. the sum of EQCRP9O, EQCSR9O and EQCESE),

EOCESE $E_{y, e g, b, r}$. is the surviving pre-1994 vintage stock of equipment in pre1994 vintage houses by forecast year, housing type and Census Division, and

EOCSR9O $_{\text {y,eg,b,r }}$ is the equipment stock in pre-1994 homes that has been replaced after 1993 and still survives by housing type and Census Division.

Surviving post-1993 equipment, originally purchased as additions or replacements in post-1993 houses, is calculated as,

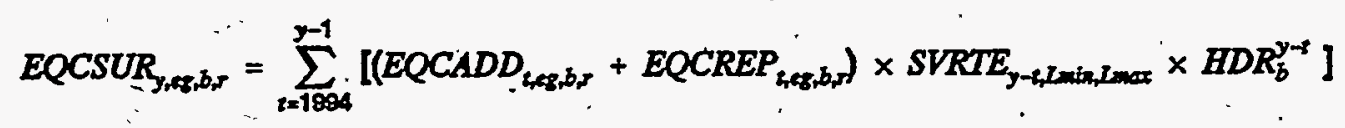

where, 
$E Q C S U R_{y, g g, b, r}$

$E Q C A D D_{t o g, b, r}$

SVRTE $_{y-t, L \min , L \max }$

$H D R_{b}$

EQCREP $P_{\text {tog,b,r }}$

$y-t$

is the surviving post-1993 equipment purchased as additions or replacements in post-1993 houses by housing type and Census Division, is the quantity of post-1993 vintage equipment added to post1993 houses by forecast year, housing type and Census Division, is the equipment survival function, is the housing survival rate by housing type, is the number of equipment replacements of post-1993 equipment in post-1993 houses, and represents the age of the equipment.

For replacement units (post 1993) equipment required for post-1993 single-family homes in the current year technology switching is allowed. The share of replacement equipment which may switch is calculated as in Figure 1 through Figure 1.

Replacement units (post-1993) equipment required for post-1993 homes in the current year for single-family homes where switching is allowed are calculated as,

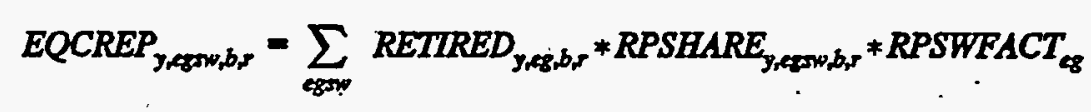

where,

EQCREP $P_{\text {,egsw,b,r }}$, is the number of replacement units required for single-family post-1993 houses by forecast year, housing type and Census Division,

RETIRED $p_{y, g g, b, r}$ is calculated as in Figure 1, EQCREP for multifamily and mobile homes by forecast year, housing type and Census Division, RPSHARE $_{\text {y,ogsw,biri }}$ is the share that will switch equipment class (egsw) on replacement by year, housing type, and Census Division, and RTSWFACT $T_{\text {eg }} \quad$ is the fraction who may switch from equipment class eg. 
Replacement units (post-1993) equipment required for post-1993 homes in the current year for single-family homes where switching is not allowed (due to switching limits) àre calculated as,

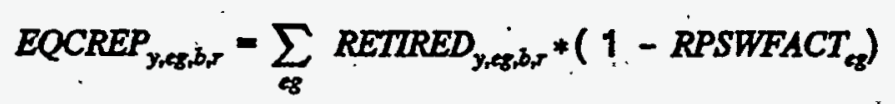

where,

EQCREP. y,gg,b,r $_{\text {. }} \quad$ is the number of replacement units required for single-family post-1993 houses by forecast year, housing type and Census Division,

RETIRED homes by forecast year, housing type and Census Division,

1-RTSWFACT eg is the fraction who may not switch from equipment class eg.

The number of surviving post-1993 equipment units is deducted from total demanded equipment in post-1993 houses to yield the number of replacements of post-1993 equipment in post-1993 multifamily and mobile homes:

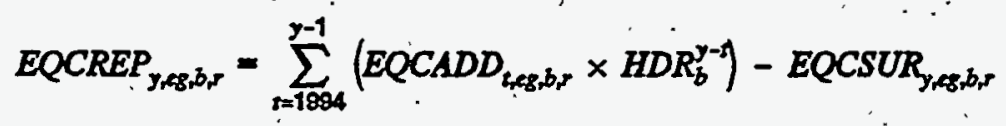

where,

EQCREP $P_{\text {y,eg,b,r }}$ - is the number of equipment replacements of post-1993 equipment in post-1993 multifamily and mobile houses,

$H D R_{b}{ }^{*} \quad$ is the housing survival rate by housing type,

EQCSUR $R_{\text {y,eg,b,r }}$ is the surviving post-1993 equipment purchased as additions or -replacement in post-1993 houses by housing type and Census Division,

$E Q C A D D_{t, e g, b, r}$ is the quantity of post-1993 vintage equipment added to post1993 houses by forecast year, housing type and Census Division, $y-t \quad$ represents the age of the equipment.

\section{Shell Integrity Component}


The shell integrity component uses three indices to capture the increases in the energy efficiency of building shells over time. One index corresponds to the pre-1994 housing stock, and two indices correspond to the post-1993 stock, one for housing constructed in the current year and the other for the average post-1993 stock. The shell indices are adjusted each year to account for fuel price increases (decreases have no effect on shell integrity, i.e., shell efficiency increases as price increases) and technology improvements.

An important part of shell integrity is the quality of windows. In the Energy Policy Act, there are regulations that require that all new windows be labeled with an index that describes their insulation properties. These regulations will be phased in over a period of years, beginning in 1995. The residential module evaluates the impacts of these regulations by means of an annual input variable, EPWINPCT ${ }_{y}$ that gives the proportion of existing houses expected to be subject to window labeling. This quantity, when multiplied by the fraction of heat savings expected to be afforded by labeled windows, currently set at .08, gives the expected savings rate due to window labeling, EPACTH:

The first step in the algorithm calculates the percentage price change for all heating fuels as,

$$
\text { PRIDELTA }_{f r r}=\frac{\text { PRICES }_{f, r y}-\text { PRICES }_{f r, 1993}}{\text { PRICES }_{f r, 1893}} \times \frac{i}{\text { PSTEP }}
$$

where,

PRIDELTA $A_{t, r}$ is the percentage change in price from the base year by fuel and Census Division converted to 5 percentage point increments, PSTEP is a constant that is set to 0.05 to convert the percentage change in fuel price to the number of 5 percentage point increments of price change,

PRICES $f_{f, r y}$ is the fuel price by fuel, Census Division and year, and PRICES $_{f, r, 1993}$ is the 1993 (base year) fuel price by fuel and Census Division. 
The existing housing heating shell index is calculated as,

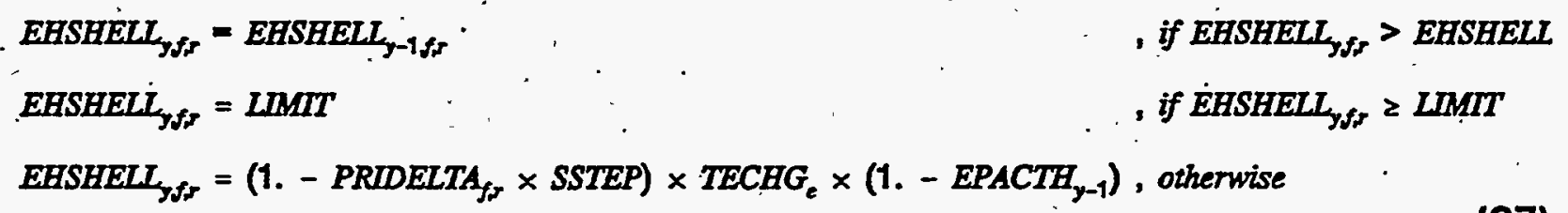

where,

EHSHELL $L_{y, f, r}$ is the shell integrity index for existing housing by year, fuel and Census Division,

LIMIT. limits the maximum shell index efficiency to 0.6 (i.e., maximum shell efficiency is limited to a 40-percent improvement on the base year value), and

SSTEP is set to 0.01 and is a component of the shell elasticity with respect to heating fuel price,

$T E C H G_{e} \quad$ is a parameter that represents the annual increase in existing shell integrity due to technology improvements, and

EPACTH $_{y}$ is the projected national fractional savings in heating energy consumption from the EPACT window labeling program in year $y$, from the RMISC file.

PSTEP converts the percentage change in price to the number of 5 percentage point increments of price change in Equation Figure 1. In equation Figure 1; PRIDELTA is multiplied by SSTEP and converted to the shell efficiency index. Every 5 percentage point increase in fuel price relative to the base year results in a shell efficiency index decrease of 1 percentage point of the base year shell efficiency up to the limit of 0.6.

The new housing heating shell index is calculated as, 


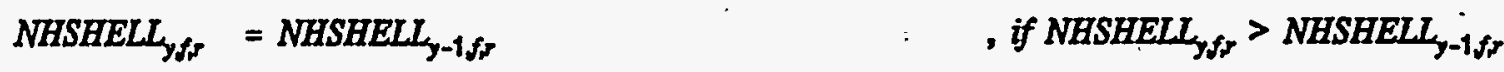

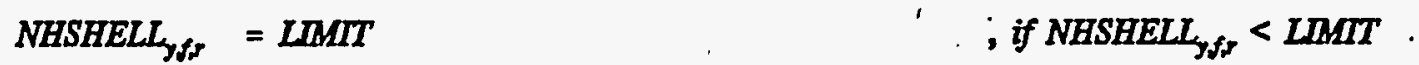

$$
\begin{aligned}
& \text { NHSHELL }_{\text {ffr }}=\text { NHSHELL }_{1993 \text { fr }} \\
& -(y-1) \times T E C H G+P R D E L T A_{f, r} \times S S T E P \text {, otherwise }
\end{aligned}
$$

where,

NHSHELL $L_{y, f, r}$ is the new housing units shell integrity index by year, fuel and Census Division,

$\mathrm{TECHG}_{n}$. . is a parameter that represents the annual increase in new shell .integrity due to technology improvements,

PRIDELTA $A_{f, r}$ is the percent change in price of the fuel by Census Division in 5 percentage point increments,

SSTEP is set to 0.01 and is a component of the shell elasticity with respect to heating fuel price.

The average post-1993 housing heating shell index is calculated as,

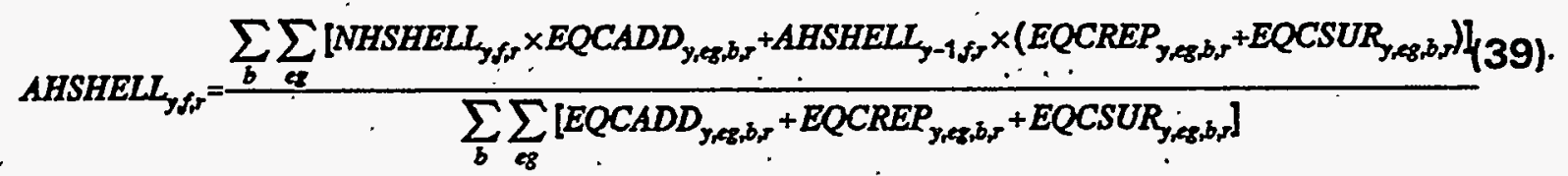

where,

AHSHELL $L_{y, f, r}$ is the average post-1993 heating shell index by year, fuel and Census Division, equal to 1 in 1993,

NHSHELL $L_{y, f, s}$ is the new housing units shell integrity index by year, fuel and Census Division,

$E Q C A D D_{y, e g, b, r}$ is the number of equipment units installed in new construction by forecast year, housing type and Census Division,

$E Q C R E P_{y, e g, b, r}$ is the number of equipment replacements of post-1993 equipment in post-1993 houses, and

EQCSUR $R_{y, o g, b, r}$ is the surviving post-1993 equipment purchased as additions or replacement in post-1993 houses by forecast year, housing type and Census Division. 
In addition to the calculation shown above, the module places two additional restrictions upon $A H S H E L L_{\gamma}$ : it may never increase, and it must not fall below LIMIT. If ever $A H S H E L_{y}$ is calculated to increase, its value is set to the prior year's value; if it falls below LIMIT, it is set equal to LIMIT.

\section{Consumption and UEC Compónent}

Final end-use fuel consumption is determined by the fuels demanded by the equipment to provide households with the demanded services. For each equipment class, the UEC for new equipment, replacement equipment, and the average of all equipment is computed: New equipment UEC values are calculated as:

$$
\begin{aligned}
& E Q C N U E C_{y, e g, b, r}=E Q C U E C_{r, e g, b} \times \text { WTEQCEFFN } N_{y, e g, b, r} \times \text { RTBASEFF }_{1280, e g} .
\end{aligned}
$$

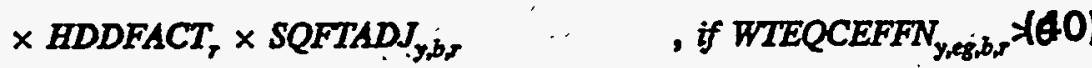

$$
\begin{aligned}
& E Q C N U E C_{y, e g, b, r}=E Q C U E C_{r, e g, b} \times H D D F A C T_{r} \times S Q F T A D J_{y, b r} \quad, \text { otherwise }
\end{aligned}
$$

where,

EOCNUEC $C_{y, e g, b, r} \quad$ is the unit energy consumption for new equipment by forecast year, housing type and Census Division,

WTEOCEFFN $N_{y, e g, b, r}$ is the equipment class efficiency weighted by the market share of the specific equipment as computed in the logistic function in the technology choice component by housing type and Census Division,
RTBASEFF $_{1993, e g}$ is the 1993 stock-average efficiency of the equipment class,
$E_{\text {ECUEC }}, g_{, b}, \quad$ is unit eniergy consumption for original 1993 stock of the. equipment class by Census Division and housing type,
HDDFACT, is the heating degree day adjustment factor by Census Division to correct for the unusually warm weather during the RECS survey year, and.

SQFTADJ $J_{y, b, r}$. . is the adjustment for increasing floor area of new houses.

Replacement equipment UEC values are calculated as: 


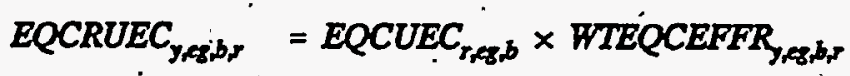

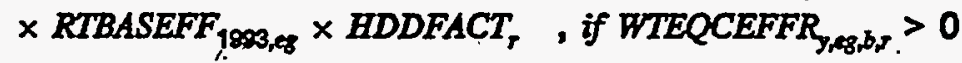

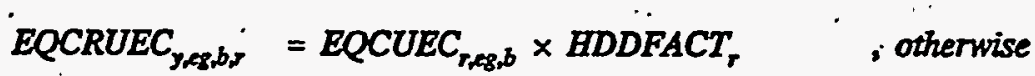

where,

$E Q C R U E C_{y, o g, b, r}$ is the unit energy consumption for replacement equipment by housing type and Census Division,

RTBASEFF 1993, eg is the efficiency of the weighted average of retiring units from the 1993 existing stock, and

WTEQCEFFR $R_{y, e g, b, r}$ is the replacement equipment efficiency weighted by the market share of the specific equipment as computed in the logistic function in the technology choice component by housing type and Census Division.

And the UEC for the surviving stock must be adjusted, according to:

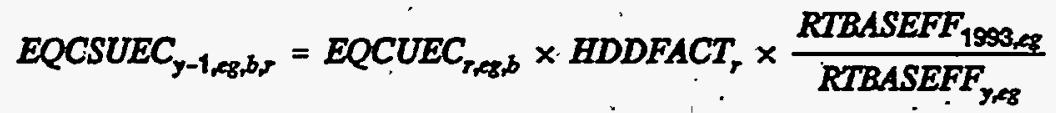

where,

EQCSUEC ${ }_{y, e g, b, r}$ is the average unit energy consumption of the original 1993 equipment stock that remains after the replacements have taken place.

The average UEC for all equipment is calculated as: 


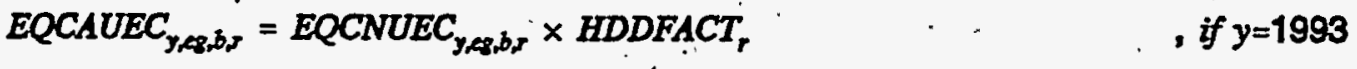

$$
\begin{aligned}
& E Q C A U E C_{\text {y,es,b, }}=E Q C N U E C_{\text {yeg,br }} \\
& \text { EQCRP90 } \\
& \text {, if the equipment stock } \leq 0
\end{aligned}
$$

The final step of this algorithm is to calculate consumption for the service category. This is accomplished in two steps. The first year of the forecast is computed initially as,

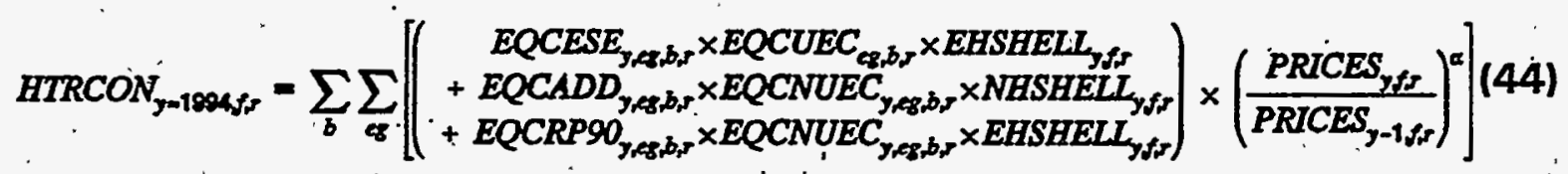

and subsequent consumption as,

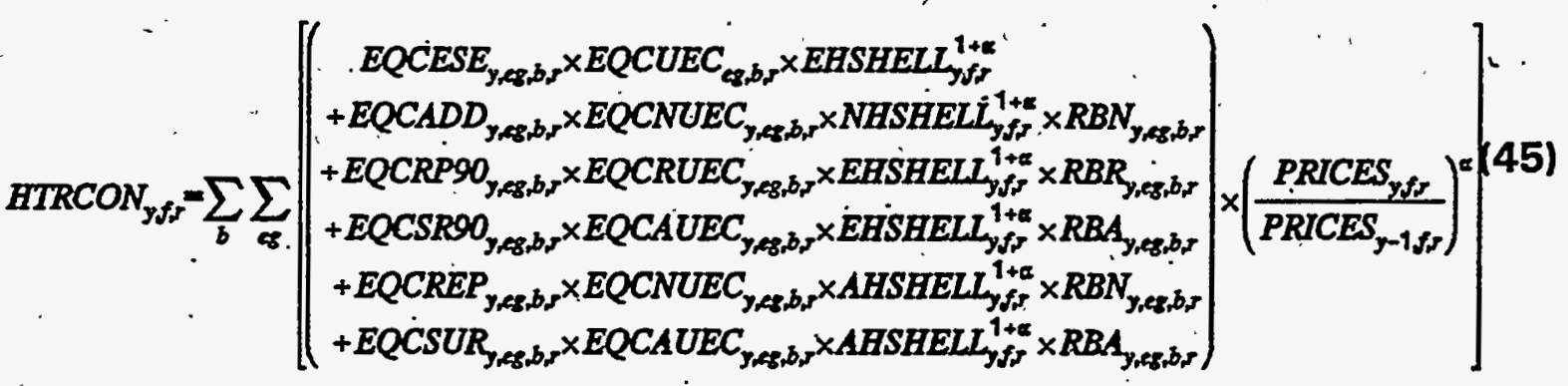

where,

a is the short-term price elasticity, presently valued at .15 .

Here, theire is a new concept called the "rebound effect" that accounts for the fact that increasing equipment efficiency for a particular equipment class causes a corresponding change in the price elasticity for the class. Three variables represent this effect:

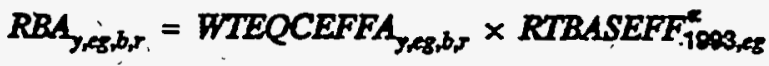

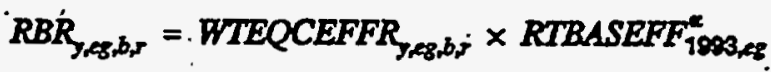

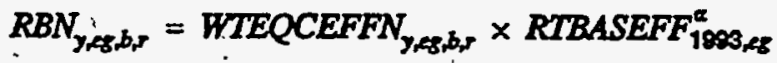

where,

$R B A_{y, g, b, r}$ is the rebound effect factor for surviving equipment, 
$R B R_{y, e g, b, r}$ is the rebound effect factor for replacement equipment, and $R B N_{y, g g, b, r}$ is the rebound effect factor for new equipment. 



\section{Appendix A: Data Sources and Input Parameters}

The Technology Choice Component requires extensive data describing end-use technologies. Equipment costs, efficiency levels, and other characteristics are specified for all the technologies included in the menu of choices. These data are drawn from numerous sources including Lawrence Berkeley Laboratory (LBL) ${ }^{1}$, Arthur D. Little $\left.(A \bar{D})^{2}\right)^{2}$ Gas Research Institute $(G \dot{R})^{3}$, Electric Power Research Institute . $\left(\right.$ (EPRI) ${ }^{4}$, Gas Appliance Manufacturing Association (GAMA) ${ }^{5}$, Association of Home Appliance Manufacturers (AHAM), and the Air Conditioning and Refrigeration Institute (ARI) ${ }^{6}$.

The alphabetical index, found in Appendix I, lists all of the module variables, with page numbers for their definitions and dimensions. The variable names shown in this manual correspond to the variable names used in the FORTRAN source code of the Residential Sector Demand Module.

The remaining text of Appendix A describes the input data sources for the variables presented in Tables A-1 and A-2 where applicable information is available.

\footnotetext{
'Lawrence Berkeley Laboratory, "Baseline Data for the Residential Sector and Development of a Residential Forecasting Database," Berkeley, CA, May, 1994.

2 Arthur D. Little, "Technical Memorandum for Technology Advances and Forecasts-Residential/Commẹrcial End-Use" Equipment," 1990.

${ }^{3}$ Gas Research Institute, "Baseline Projection Data Book," Lexington, MA, 1990.

"Electric Power Research institute, "Draft Model Documentation for Residential End-use Energy Planning System (REEPS), Version 2.0," Palo Alto, CA, 1990.

-Gas Appliance Manufacturers Association, "Consumers' Directory for Certified Efficiency Ratings," Arlington, VA, 1994.

- Air Conditioning and Refrigeration Institute, "Directory of Certified Cooling Equipment," Arlingtori, VA, 1994.
}

Energy Information Administration NEMS Residential Demand Module Documentation Report 


\section{Residential Demand Module Input Data Files}

\section{Residential Equipment Retirement Fractions for 1993 Equipment}

Definition: Retirement fractions for each of the 27 residential Equipment classes in : for all forecast years.

Units: Dimensionless (units retired to date/units extant in 1993).

Source: Results from vintaging models developed based on shipment data. Shipment data from various sources including: AHAM, GAMA, ARI, LBL.

File: $\quad$ RSRET01.

Comments: Values in this table give the fraction of 1993 stocks of equipment expected to be retired as of each year. They are calculated in an external FORTRAN program that vintages efficiencies from the shipment data. Program reads all years:

Sequence of Equipment Classes:

Electric Furnace

Electric Heat Pump

Gas Furnace

Gas Boil/Radiator

Kerosene Furnace

LPG Furnace

Distill Furnace

- Distill Other

Wood Stoves
Geotherm Heat Pump

Nat Gas Heat Pump

Room Air Cond .

Central Air Cond

Electric Heat Pump

Geotherm Heat Pump

Nat Gas Heat Pump

Water Heat Nat Gas

Water Heat Electric
Water Heat Dist

Water Heat LPG

Cooking Nat Gas

Cooking LPG

Cooking Electric

Dryers Nat Gas

Dryers Electric

Refrigerators

Freezers

Variables: EOCRET

\section{Residential Floor Areas by Building Type, Year and Division.}

Definition: Average of floor space in residential buildings in each of 3 house types, .
A-2
Energy Information Administration
NEMS Residential Demand Module Documentation Report 
for each division, from 1990-2015.

Units: $\quad$ Square feet.

Source: RECS and Census C25 data series.

File: RSSORFT.

Comments: Values after the last data year are held constant at that value. Data are used to adjust heating, cooling, and lighting loads.

Variables: SORFOOT $_{y, b, d}$

\section{Residential Existing Equipment}

Definition: . Stock of all equipment types for all end-uses in the base year within each building type in each Census Division.

Units: - Number of units.

Source: ElA, Aggregation from the Residential Energy Consumption Survey 1993, DOE-EIA-0321(93).

File: RSEOP93.

Comments: Each value in the body of the table represents aggregated values from the Residential Energy Consumption Survey 1993. First, the census data were aggregated to determine the number of households in each Census Division of each building type that use the designated equipment class.

Equipment Classes Included:

Electric Furnace
Electric Heat Pump
Gás Furnace
Gas Boil/Radiator
Kerosene Furnace
LPG Furnace
Distill Furnace
Distill Other
Wood Stoves

Geotherm Heat Pump Nat Gas Heat Pump Room Air Conditioner Central Air Conditioner Electric Heat Pump Geotherm Heat Pump Nat Gas Heat Pump Water Heaters Nat Gas Water Heaters Electric
Water Heaters Distill Water Heaters LPG

Cooking Nat Gas

Cooking LPG

Cooking Electric

Dryers Nat Gas

Dryers Electric

Refrigerators

Freezers

Variables: - EQCESE $_{1993, \mathrm{gg}, \mathrm{b}, \mathrm{r}}$ 


\section{Residential Retired Equipment Efficiencies of 1990 stock}

Definition: Efficiencies for each of the 27 residential equipment classes in forecasted y.ears.

Units: - Dimensionless (energy out/energy in) except ref, frz, stoves.

Source: . Results from vintaging models developed based on shipment data. Shipment data from various sources including: AHAM, GAMA, ARI, LBL.

File: . RSEFFO1.

Comments: Values in this table give the average efficiencies of equipment expected to be retired in each year. They are calculated in an external FORTRAN program that vintages efficiencies from the shipment data.

Equipment classes included:

Electric Furnace

Electric Heat Pump

Gas Furnace

Gas Boil/Radiator

Kerosene Furnace

LPG Furnace

Distill Furnace

Distill Other

Wood Stoves
Geotherm Heat Pump

Nat Gas Heat Pump

Room Air Conditioner

Central Air Conditioner.

Electric Heat Pump.

Geotherm Heat Pump

Nat Gas Heat Pump

Water Heaters Nat Gas

Water Heaters Electric
Water Heaters Distill

Water Heaters LPG

Cooking Nat Gas

Cooking LPG

Cooking Electric

Dryers Nat Gas

Dryers Electric

Refrigerators

Freezers

Variables: EQCEFF $_{\text {y,eg }}$

\section{Residential Unit Consumption of Energy.}

Definition: Unit Energy Consumption (UEC) for all Residential equipment classes and building types in each Census Division. Here, the equipment classes include the 27 major classes, plus lighting, 7 secondary heater types, and 4 appliance types.

Units: Classes 1-27: MMBtu/unit/yr; classes 28-39: MMBtu/household/yr.

Source: EIA, Residential Energy Consumption Survey 1993, DOE.EIA-0321. (93).

File: . 1 . RSUEC10.

Comments: Each value in the body of the table represents the annual energy 
consumption of a single unit of the given type in the given building type, in the given Census division, in 1993.

Equipment Classes Included:

Space Heating: Elec Furnace Space Heating: Elec Heat Pump Space Heating: Gas Furnace. Space Heating: Gas Boiler/Rad Space Heating: Kero Furnace Space Heating: LPG Furnace Space Heating: Dist Furnace Space Heating: Dist Other Space Heàting: Wood Stoves Space Heating: Geothermal HP Space Heating: Natural Gas HP Space Cooling: Room Air Cond Space Cooling: Cent Air Cond Space Cooling: Elec Cool Pump Space Coóling:. Geo Cool Pump Space Cooling: Nat G Cool Pump Water Heater: Natural Gas Water Heater: EL Water Heater: Distillate .Water Heater: LPG
Cooking: Natural Gas

Cooking: LPG

Cooking: Electric

Drying: Natural Gas

Drying: Electric

Refrigeration

Freezing .

Lighting

Electric Appliances

Secondary Heater: Natural Gas

Secondary Heater: Electric

Secondary Heater: Distillate

Secondary Heater: LPG

Secondary Heater: Kerosene

Secondary Heater: Coal

- Secondary Heater: Wood

Appliance: Natural Gas

Appliance: LP.G

Appliance: Distillate

Variables: $E Q C U E C_{r, e g, b}$

\section{Residential Heating Equipment Shares for New Equipmenit}

Definition: Market share of general space heating equipment for new homes in the base year. Gives the share of each equipment class by building type and Census Division.

Units: Fraction of purchases.

Source: Bureau of the Census C25 data, as described in Characteristics of New Housing: 1993, C25/93-A.

File:

RSHTSHR.

Comments: Shares of heating equipment classes in new homes. Each value in the body of the table represents a fraction of aggregated values from the 
C25 database. First, the Census data were aggregated to determine the number of new houses in each Census Division of each building type that used the designated equipment class. These values were divided by the number of new houses in each Census Division and building type.

Equipment Classes Included:

Electric Furnace

Electric Heat Pump

Gas Furnace

Gas Boiler/Radiator

Kerosene Furnace

LPG Furnace
Distillate Furnace

Distillate Other

Wood Stoves

Geothermal Heat Pump

Natural Gas Heat Pump

Variables: $H S Y S S H R_{1993, e g, b, r}$

\section{Benchmarking Data from Short-Term Energy Outlook}

Definition: Household energy consumption by fuel and Census Division for the years 1993, 1994, 1995, 1996, and 1997.

Units: . Trillion Btu.

Source: Short-Term Integrated Forecasting System 199604. State Energy Data System, 1994.

File: RSSTEO.

Comments: National total energy consumption by fuel and year comes from STIFS, based on history in 1993, 1994, and 1995 through 1997 forecasts. These forecasts are allocated to Census divisions using SEDS historical .data for 1994 , broken out by fuel and Census division. Calculations are in spreadsheet STE0943F.WB1

Variables: STEOCN $_{\text {y,f,r }}$

\section{Residential Technology Equipment Class Description File}

Definition: Technology choice parameters for classes of equipment.
A-6
NEMS Residential Demańd Module Documentation Report

Energy Information Administration 
Units: See discussion of individual variables below.

Source: RTECH.WB1

File: RTEKCL.

Comments: Each of the 27 lines of this data file gives the important user-modifiable parameters for one equipment class. Used by the RDM for allocating equipment choice among the individual equipment classes.

Variable Descriptions:

RTCLENDU $U_{\text {eg }}$ End use number. Equipment classes having the same end use compete with one another. The RDM allocates equipment among them in the technology choice process.

$$
\begin{aligned}
& 1=\text { Space Heating } \\
& 2=\text { Space Cooling } \\
& 3=\text { Water Heating } \\
& 4=\text { Cooking } \\
& 5=\text { Clothes Drying } \\
& 6=\text { Food Refrigeration } \\
& 7=\text { Food Freezing }
\end{aligned}
$$

Matches RTTYENDU ${ }_{\text {es }}$ in the RTEKTY file.

RTCLEQCL $L_{\text {eg }}$ Equipment class number. Appears on all records. Matches RTTYEOCL $L_{e s}$ in the RTEKTY file for one or more equipment types: there are one or more equipment types in RTEKTY for each class in RTEKCL.

RTCLTYPT eg Required pointer from equipment class to a representative equipment type. This is the only pointer from RTEKCL to RTEKTY. Selects the equipment type used in the log-linear formula for choice of equipment class for newly constructed housing units and replacements in singlefamily houses. Its value is the RTEQTYPE representative equipment.

RTCLPNTR $_{\text {og }} \quad$ Class pointer. Required for end uses 1 through 3 ; zero otherwise. If end use $=1:$ Required pointer from space heater class to 
associated water heater class linking water heater fuel choice to space heater fuel choice for newly constructed housing units.

If end use $=2$ : Required pointer from cooling heat pump class to same class of heating heat pump.

$0=$ Not a heat pump

Integer $=$ Heater heat pump class number

If end use $=3$ : Required pointer from water heater class to matching cooking class linking cooking fuel choice to water heater fuel choice for newly constructed housing units. Also see RTCLREPL $L_{\text {eg }}$ end use 3 below; only natural gas water heaters may point to 2 types of cookstoves.

RTCLREPL $L_{\text {eg }} \quad$ Replacement class. Required for end uses 1 and 3; zero otherwise. If end use $=1$ : Flag for replacing the existing space heater class with a natural gas forced air space heater at retirement (subject to switching limits described under GSL).

If end use $=3$ : Second pointer from natural gas water heater.class to matching cooking class. The model assumes that $65 \%$ of new homes with natural gas water heaters have natural gas ștoves and $35 \%$ have electric stoves.

RTFUEL $_{\text {eg }} \quad$ Fuel used by this equipment.

$1=$ Distillate

$2=L P G$

$3=$ Natural Gas

$4=$ Electricity (wood priced to electricity)

$5=$ Kerosene

RTMAJORF $F_{\text {eg }}$ Major fuel flag. Used only for end use 1; zero otherwise. Space heater shares for systems using major fuels are calculated differently from space heater shares for systems using minor fuels. Set to 1 to indicate a major fuel. Set to 0 to indicate a minor fuel.

Energy Information Administration 
RTBASEFF $_{\text {eg }}$ Base efficiency for this equipment class. Defined differently for different end uses:

End uses 1,2,3,5: base efficiency for this equipment class.

End uses 4,6,7: 1 / base efficiency for this equipment class.

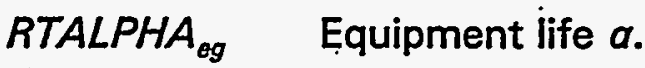

RTMINLIF $_{\text {eg }}$ Minimum life of this equipment class (years).

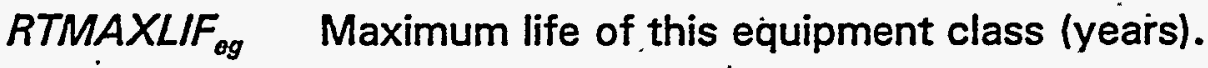

RTFCBETA $_{\text {eg }} \quad$ New home heating technology choice model log-linear parameter $\beta$. Used only for end use 1 ; zero otherwise.

RTFCBIAS $_{e g} \quad$ New home heating technology choice model bias parameter. Used only for end use 1; zero otherwise:

RTSWFACT $T_{\text {eg }}$. Maximum fraction of single-family homes which may switch away from this equipment class on replacement.

RTSWBETA $A_{\text {eg }}$ Replacement technology choice model log-linear parameter $\beta$. Used only for. single-family homes.

RTSWBIAS $S_{\text {eg }}$ Replacement technology choice model bias parameter. Used only for single family homes.

RTCLNAME eg Unique name for each equipment class.

\section{Residential Technology Equipment Type Description File}

Definition: Technology choice parameters for types of equipment.

Units: See discussion of individual variables below.

Source: $\quad$ FTECH.WB1

File: $\cdot$ RTEKTY:

Comments: Each of the 166 lines of this data file gives the important usermodifiable parameters for one equipment type. Used by the RDM for allocating equipment choice among the individual equipment types.

Variable Descriptions:

RTTYENDU es End Use number as in RTEKCL. Matches RTCLENDU in the RTEKCL 
file.

RTTYEOCL Eq Equipment class for this equipment type. MUST match a class number, RTCLEOCL ${ }_{\text {eg }}$ in the RTEKCL file.

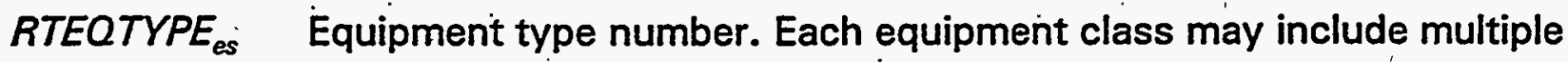
types. Each equipment type may have up to one record for each year of the forecast period. DO NOT overlap years. The user may add equipment types to existing classes. When adding new types, update the type numbers for the rest of that end use; also, adjust the RTTYPNTR pointer for cooling and the RTCLTYPT pointer in the RTEKCL file for heating. If adding heat pump types, add same type to both space heating and space cooling and adjust pointers.

RTINITYR $R_{e s} \quad$ Initial calendar year for this model of this equipment type. The first RTINITYR $R_{\text {es }}$ for a model within a type should be the NEMS base year (1993); subsequent initial years for a model must be previous $R T L A S T Y R_{e s}+1$.

RTLASTYR ${ }_{e s}$ ' Last calendar year for this model of this equipment type. Must greater than or equal to RTINITYR $R_{e s}$ for this model; final $R T L A S T Y R_{e s}$ should be the last year of the forecast period (2015).

RTTYPNTR $R_{e s} \quad$ Required pointer from cooling heat pump type to same type of heating heat pump. Also used as a flag to mark room air conditioners and central air conditioners. Used by end use 2 only; zero otherwise. Modify as follows only if heat pumps added:

$-1=$ Room air conditioner

$0=$ Central air conditioner (not heat pump)

Other Integer = Matching heater heat pump type number

RTEOEFF $_{\text {es }}$ Defined differently for different end uses: If end use $=1,2,3,5$ : Equipment type efficiency (AFUE, COP, etc.). If end use $=4,6,7$ : Energy consumption for prototypical models (e.g., annual Kwh consumption for $15 \mathrm{cu} f t$ refrigerators). 
RTEQCOS.T $T_{\text {es }}$ Installed wholesale capital cost in $\$ 1991$ per unit for new homes. RTRECOST $_{\text {es }}$ Retail capital cost in $\$ 1990$ per unit for replacements. .

RTMATURE $E_{\text {es }}$ 'Technology maturity description.

'MATURE' = No further cost reductions expected; use above constants for installed wholesale and retail capital costs.

'ADOLESCENT' = Main cost reductions occurred before base year (1992); function EQCOST reduces installed wholesale and retail capital cost with 1992 (or first year of availability) as the inflection point.

'INFANT' = All cost reductions expected after first year of availability; function EOCOST reduces installed wholesale and retail capital cost with the inflection point in the future.

RTCOSTP1 $1_{\text {es }}$ If 'MATURE' technology, not used.

If 'ADOLESCENT' technology, representative year cost decline began ( $y_{1}$ in code).

If 'INFANT' technology, year of inflection of cost trend ( $y_{0}$ in code).

RTCOSTP2 $2_{\text {es }}$ If 'MATURE' technology, not used.

If 'ADOLESCENT' or 'INFANT' technology, logistic curve shape parameter (gamma in code).

RTCOSTP $3_{\text {es }}$ If 'MATURE' technology, not used.

If 'ADOLESCENT' technology, total possible proportional decline in equipment cost from $y_{0}$ onward ( $d$ in code).

If 'INFANT' technology, total possible proportional decline in equipment cost from $y_{1}$ onward ( $d$ in code).

RTECBTA $1_{\text {os }}$ If end use $=1,2,3,5,6,7$ : Efficiency choice: model log-linear parameter $\beta_{1}$, weights capital cost.

If end use $=4$ : Share for this stove type. Shares within a class and year must add to 1.00 .

RTECBTA2 $2_{\text {es }}$ If end use $=1,2,3,5,6,7$ : Efficiency choice model log-linear 
parameter $\beta_{2}$, weights fuel cost.

If end use $=4$ : Not used; place holder value required.

RTECBTA3 $_{\text {es }}$ If end use $=1,2,3,5,6,7$ : Efficiency choice model log-linear parameter $\beta_{3}$, weights life cycle cost.

If end use $=4:$ Not used; place holder value required.

RTECBIAS $_{\text {es }}$. If end ușe $=1,2,3,5,6,7$ : 'Efficiency choice model, consumer preference log-linear parameter; fits current market shares to shipment data.

If end use $=4$ : Not used; place holder value required.

$R T T Y N A M E_{\text {es }}$ Unique name for each equipment type. Do not modify existing names. Add unique names for new types.

\section{Miscellaneous Residential Module Inputs}

Definition: This file supplies a number of tables that define parameters for the RDM: Each of the tables is discussed individually below.

Units: - $\quad$ Discussed for each variable.

Source: User Options.

File: RMISC.

Comments: These tables are all read line-by-line in the logic of the RDM. The shape of each is read by the logic that reads the data.

Variables:

$H D R_{b}$ Housing Demolition Rates by Building Type.

$E H_{1993, r, r}$ Existing Houses in 1993 by Building Type and Census Division (With Totals).

RACSAT $T_{b, r}$ Room Air Conditioner Saturation Level by Building Type and Census Divisịon.

CACSAT $_{b, r}$. New Central Air Conditioner Saturation Level by Building Type and Census Division.

CACPR r Central A/C Penetration Rate by Census Division (1. +x). 
FRZSAT $T_{b, r}$ New. Home Freezer Saturation Level by Building Type and Census Division.

ELDRYPR $_{b, r} \quad$ Electric Dryer Penetration Rate by Building. Type and Census Division (1. $+x / 20$.$) .$

GSL $_{\text {og, }} \quad$ Gas Switching Limits for Space Heaters by Equipment Class and Census Division.

$S L S H R_{b, r} \quad$ Solar Water Heating Share by Census Division.

NEWSLSHR, New Solar Water Heating Share by Census Division.

RENSHR, Share of Total Photovoltaic Electricity Consumption Allocated to each Census Division.

$S_{\text {SHSHR }}$. Secondary Heating Share by Fuel and Census Division.

NHSHELL ${ }_{1993, f, r}$ New Heating Shell Indices by Fuel and Census Division (First Year Only).

NCSHELL $1993, \pi$. New Cooling Shell Indices by Census Division (First Year Only). HDDADJ y,r Heating Degree Days by Census Division and Year (1997 is 1997 on). $C D D A D J_{y, r} \quad$ Cooling Degree Days by Census Division and Year (1.997 is 1997 on). - EPWIINPCT Fraction of Existing Houses Affected. by Window Labeling by Year. NEWDRYSAT $T_{\text {eg,b,r }}$ New. Dryer Saturation By Type (Gas, Electric).

RPINSCOST $T_{\text {eg,egsw }}$ Installation cost associated with switching from equipment class eg to equipment class egsw when equipment is replaced. 



\section{Appendix B: Detailed Mathematical Description}

This appendix presents the detailed calculations used in each of the module components. Table $i$ shows the correspondence between each of the subscripts in the documentation and the subscripts in the FORTRAN source code.

Please note the following conventions:

- The table of subscripts includes all of the major usages. In some minor instances, additional subscripts are defined as needed.

- The equations follow the logic of the FORTRAN code very closely to facilitate an

Table 1. Definitions of Subscripts

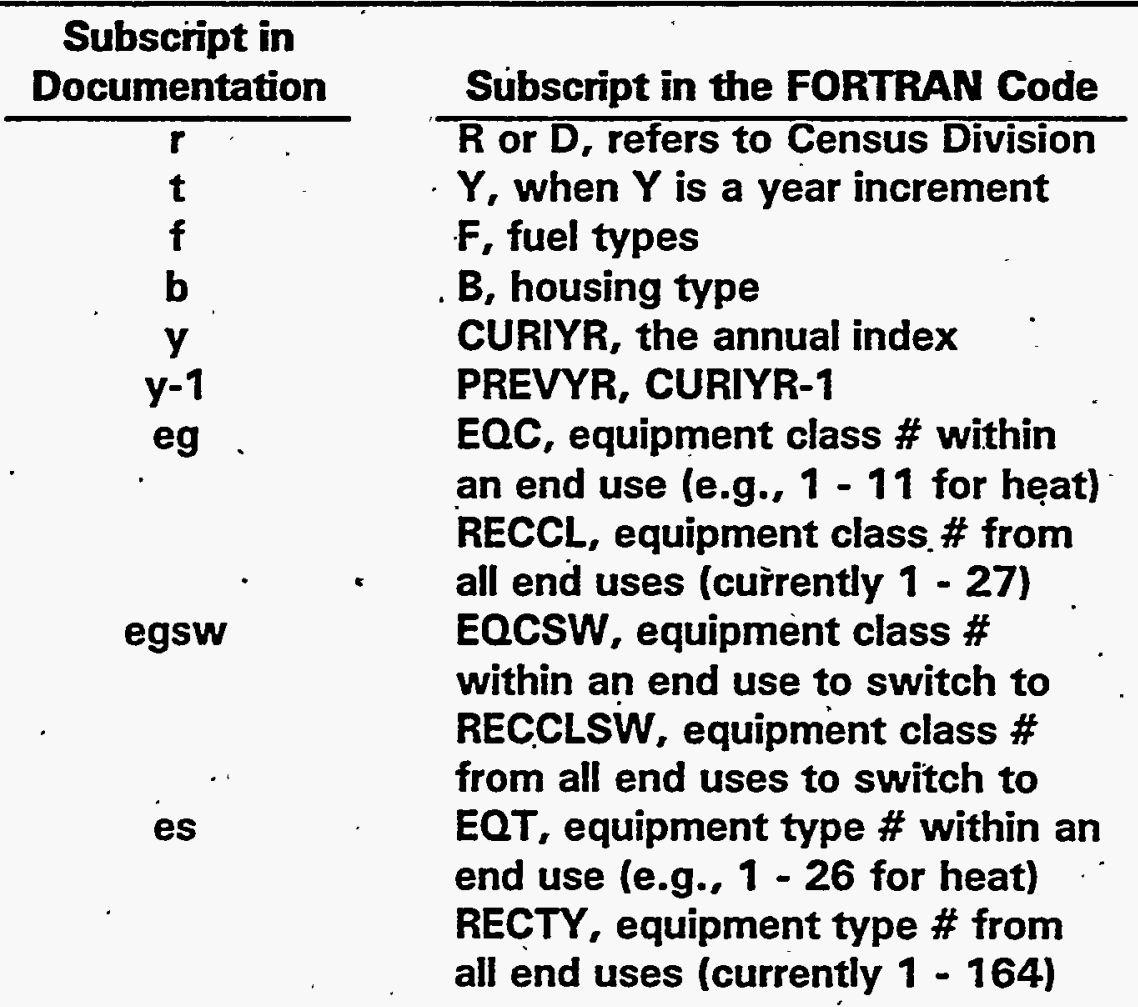


understanding of the code and its structure. In several instances, a variable appears on both sides of an equation. This is a FORTRAN programming device that allows a previous calculation to be updated (for example, multiplied by a factor) and re-stored under the same variable name (i.e., in the same memory location).

- The subscript; $y$, in the documentation refers to the year represented as 1990 through 2015. In the FORTRAN code, the subscript CURIYR represents array dimensions starting with an index of 1 to represent 1990. Not all arrays begin with an array position for 1990. Specifically, the arrays that represent or relate to equipment added after the base year begin with the first array position representing 1991 (PREVYR), to economize on memory storage.

- Some variables are documented having a. " $y$ " dimension when in fact they do not. The most common instances are for the variables, LFCY, OPCOST, SA, SHARESN, and SHARESR. These variables are calculated on an annual basis; but are retained only for the current year. The " $y$ " dimension is used in the documentation to highlight 1) that the calculations do vary by year, and 2) to. indicate the current year in formulas to avoid confusion.

- Summations over all relevant variables are usually written without upper and lower range limits on the summation signs.

- Unless otherwise stated, the range of $y$ for an equation is 1991 through 2015.

- All equation references in this appendix are in parentheses and correspond to equation numbers in this appendix only.

Variable and parameter names in Appendix B match those found in the FORTRAN source code. 


\section{Classification}

The RDM regards the residential sector as a consumer of energy. It has classified this consumption into a series of end uses that represent the various ways in which energy is used by households. The end uses are defined within the logic of the RDM, and determine the organization of the data found the input data files discussed in this document. At present, the following end uses are covered, in the order shown:

1. Space Heating

2. Space Cooling

3. Water Heating

4. Cooking

5. Clothes Drying

6. Food Refrigeration

7. Food Freezing

8. Lighting

9. Other Appliances

10. Secondary Heating

Further, the RDM assumes that a series of broad equipment classes are available to satisfy the demands within the end uses. Using input data files, the user can modify the definitions of equipment classes available for each of the first seven end uses (Lighting and Other Appliances are at present handled by the logic of the RDM, as described later in this appendix). In general, the equipment classes are each used to satisfy a particular end use. However, there are a few cases where one class of equipment (heat pumps, for example) satisfies more than one end use, or where the availability of one class of equipment makes another class more likely la gas furnace is frequently accompanied by a gas water heater and a gas cookstove). The file RTEKCL (Residential Technology Classes), which is outlined below, defines 27 
equipment classes.

Each equipmient class can be satisfied by a variety of specific equipment types that each have their own technological characteristics, such as efficiency, cost, and year when the technology is expected to become available or to become superannuated. Examples of equipment types would be the array of available gas furnaces; the more expensive of which tend to have higher efficiencies. The RDM does not attempt to represent all manufacturers' products, but rather defines broad types that are similar to one another in their technological characteristics. The user has the ability to define and modify the definitions of these equipment types, by modifying the file RTEKTY (Residential Technology Types), which is also outlined below.

Each equipment type can be assigned different characteristics during different ranges of years. Each of these time-related galaxies of characteristics is sometimes referred to as an equipment model of the given equipment type.

These concepts, of equipment classes that can be satisfied by a number of different equipment types that each contain several models, underlie the entire discussion of this manual. In earlier editions of the documentation, these two classifications were referred to as general equipment type (equipment class), and specific equipment type (equipment type). These names survive in the subscripts assigned to the two concepts throughout the document, eg and es, respectively. In order to reinforce the difference, we often add the modifier specific to the term equipment type, but we have avoided the use of the word general in relation to equipment classes.

Other RDM files define the characteristics of the mix of appliances that are in use in the base year, including relative numbers installed, efficiencies, and the rates at which they are expected to be replaced.

B-4 , NEMS Residential Demand Module Documentation Report 


\section{RTEKCL: Technology Classes}

Within the present structure of the Residential Demand Module, there are 27 defined technology classes. These are listed in Table 2. Here, Refrigeration and Freezing each have a single technology class for all installed equipment. The list is not exhaustive, in that there do exist, for example, a few homes that heat their domestic water with wood; the vast majority of equipment used to satisfy the seven major end uses can be fitted into at least one class. Recall that, as mentioned above, Lighting and Other Appliances are handled separately within the logic of the RDM. Seventeen variables, described below, are read from the RTEKCL data file.

RTCLENDU eg: End use number. Equipment classes having the same end use compete with one another. The RDM allocates equipment among them in the technology choice process.

$$
\begin{aligned}
& 1=\text { Space Heating } \\
& 2=\text { Space Cooling } \\
& 3=\text { Water Heating } \\
& 4=\text { Cooking } \\
& 5=\text { Clothes Drying } \\
& 6=\text { Food Refrigeration } \\
& 7=\text { Food Freezing }
\end{aligned}
$$

\begin{tabular}{|c|c|c|}
\hline $\begin{array}{l}\text { Space Heating } \\
\text { Electric Furnaces } \\
\text { Electric Heat Pumps } \\
\text { Natural Gas Forced Air } \\
\text { Natural Gas Radiators } \\
\text { Kerosene Forced Air } \\
\text { LPG Forced Air } \\
\text { Distillate Forced Air } \\
\text { Distillate Radiators } \\
\text { Wood Heaters } \\
\text { Geothermal Heat Pumps } \\
\text { Natural Gas Heat Pumps }\end{array}$ & $\begin{array}{l}\text { Space Cooling } \\
\text { Room Air Conditioners } \\
\text { Central Air Conditioning } \\
\text { Electric Heat Pumps } \\
\text { Geothermal Heat Pumps } \\
\text { Natural Gas Heat Pumps } \\
\\
\text { Water Heating } \\
\text { Natural Gas } \\
\text { Electric } \\
\text { Distillate Oil } \\
\text { LPG }\end{array}$ & $\begin{array}{l}\text { Cooking } \\
\text { Natural Gas } \\
\text { Electric } \\
\text { LPG } \\
\text { Drying } \\
\text { Natural Gas } \\
\text { Electric } \\
\text { Refrigeration } \\
\text { Freezing }\end{array}$ \\
\hline
\end{tabular}

Matches RTTYENDU $U_{e s}$ in the RTEKTY file.

Table 2. RDM Technology Classes. 
RTCLEQCL ${ }_{\text {eg }}$ : Equipment . class number. Appears on all records. Matches RTTYEOCL ${ }_{\text {es }}$ in the RTEKTY file for one or more equipment types: there are one or more equipment types in RTEKTY for each class in RTEKCL.

RTCLTYPT $T_{\text {eg: }}$ Required pointer from equipment class to a representative equipment type. This is the only pointer from RTEKCL to RTEKTY. Selects the equipment type used in the log-linear formula for choice of equipment class for newly constructed housing units and replacements in singlefamily houses. Its value is the RTEQTYPE $E_{e s}$ in RTEKTY of the representative equipment. :

RTCLPNTR $R_{e g}$ : Class pointer. Required for end uses 1 through 3; zero otherwise.

If end use $=1$ : Required pointer from space heater class to associated water heater class linking water heater fuel choice to space heater fuel choice for newly constructed housing units.

If end use $=2$ : Required pointer from cooling heat pump class to same class of heating heat pump.

$0=$ Not a heat pump

Integer $=$ Heater heat pump class number

If end use = 3: Required pointer from water heater class to matching cooking class linking cooking fuel choice to water heater fuel choice for newly constructed housing units. Also see RTCLREPL end use 3 below; only natural gas water heaters may point to 2 types of cookstoves.

RTCLREPL ${ }_{\text {og }}:$. Replacement clasș. Required for end uses 1 and 3; zero otherwise. If end use $=1:$ Flag for replacing the existing space heater class with a natural gas forced air space heater at retirement (́subject to switching limits described under GSL).

If 'end use $=3$ : Second pointer from natural gas water heater class to a cooking class. The model assumes that $65 \%$ of new homes 
with natural gas water heaters have natural gas stoves and $35 \%$ have electric stoves.

RTFUEL $_{\text {eg: }}$ 'Fuel used by this equipment.

$$
\begin{aligned}
& 1=\text { Distillate } \\
& 2=\text { LPG } \\
& 3=\text { Natural Gas } \\
& 4=\text { Electricity (wood priced to electricity) } \\
& 5=\text { Kerosene }
\end{aligned}
$$

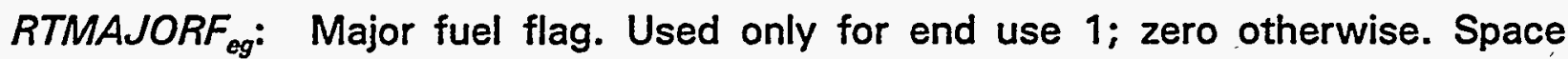
heater shares for systems using major fuels are calculated differently from space heater shares for systems using minor fuels. Set to 1 to indicate a major fuel. Set to 0 to indicate a minor fuel.

RTBASEFF eg: Base efficiency for this equipment class. Defined differently by end uses:

End uses 1,2,3,5: base efficiency for this equipment class.

End uses 4,6,7: 1 / base efficiency for this equipment class.

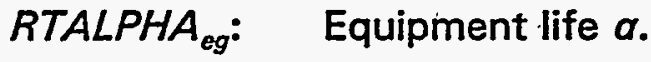

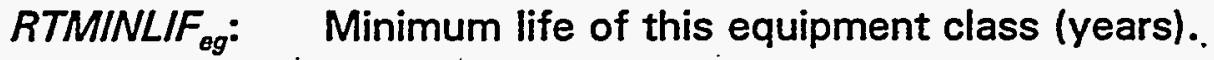

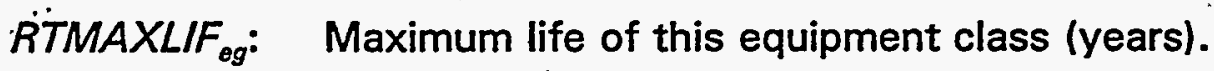

RTFCBETA $A_{\text {eg }}: \quad$ New home heating technology choice model log-linear parämeter $\dot{\beta}$. Used only for end use 1; zero otherwise.

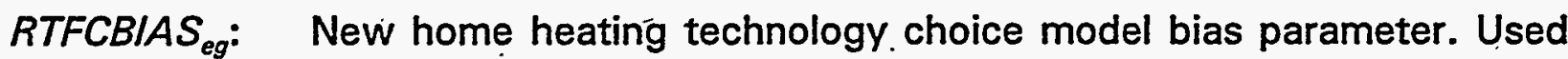
only for end use 1; zero otherwise.

RTSWFACT $T_{\text {eg }}$ : Maximum fraction of single-family homes which may switch away from this equipment class on replacement.

RTSWBETA $A_{e g}$ : Replacement technology choice model log-linear parameter $\beta$. Used only for single-family homes.

RTSWBIAS eg: $^{\prime}$ Replacement technology choice model bias parameter. Used only for single family homes.

RTCLNAME $E_{\text {eg }}$ Unique name for each equipment class.

Energy Information Adminstration NEMS Residential Demand Modulé Documentation Report 


\section{RTEKTY: Technology Types}

Within each of the equipment classes defined in the RTEKCL file, the Residential Demand Module accepts one or more types of equipment. The module chooses among the equipment types according to energy costs, equipment costs, and the relative efficiencies of the available types. The RTEKTY file contains the data used by the model for selecting which of the types are used. In general, the module does not exclusively select one of the alternatives available within a class, but rather changes the proportions of each type according to its evaluation of the equipment characteristics.

The characteristics of each equipment type can change over time, so the RTEKTY file. allows more than one set of characteristics for each equipment type. These are called models, and are tagged with the starting and ending year to which they are applicable. Eighteen variables, described below, are read from the RTEKTY file:

RTTYENDU es: $^{\circ}$ - End Use number as in RTEKCL. Matches RTCLENDU in the RTEKCL file.

RTTYEQCL $L_{\text {es }} \quad$ Equipment class for this equipment type. MUST match a class number, RTCLEQCL ${ }_{\text {egr }}$ in the RTEKCL file.

RTEOTYPE : Equipment type number. Each equipment class may inclúde multiple types. Each equipment type may have up to one record for each year of the forecast period. DO NOT overlap years. The user may add equipment types to existing classes. When adding new types, update the type numbers for the rest of that end use; also, adjust the RTTYPNTR pointer for cooling and the RTCLTYPT pointer in the RTEKCL file for heating. If adding heat pump types, add same type to both space heating and space cooling and adjust pointers.

RTINITYR $R_{e s}$. Initial calendar year for this model of this equipment type. The 
first RTINITY $R_{\text {es }}$ for a model within a type should be the NEMS base year (1993); subsequent initial years for a model must be previous RTLASTYR $R_{e s}+1$.

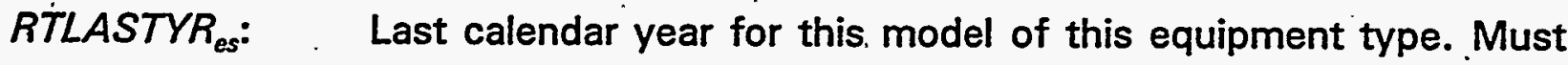
greater than or equal to RTINITYR es for this model; final $R T L A S T Y R_{e s}$ should be the last year of the forecast period (2015).

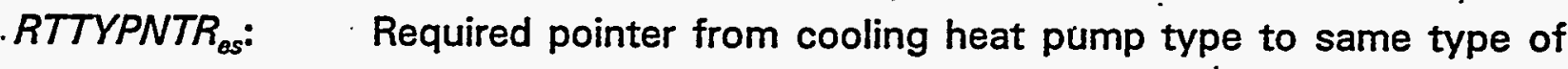
heating heat pump. Also used as a flag to mark room air conditioners and central air conditioners. Used by end use 2 only; zero otherwise. Modify as follows only if heat pump types added:

$-1=$ Room air conditioner

$0=$ Central air conditioner (not heat pump)

Other Integer $=$ Matching heater heat pump type number

RTEQEFF ${ }_{e s}$ : Defined differently for different end uses:

'If end use = 1,2,3,5: Equipment type efficiency (AFUE, COP, etc.). If end use $=4,6,7$ : Energy consumption for prototypical models (e.g., annual Kwh consumption for $15 \mathrm{cu} \mathrm{ft}$ refrigerators).

RTEQCOST $T_{\text {es: }}$.Installed whollesale capital cost in \$1991 per unit for new homes.

RTRECOST $T_{\text {es }}$ : Retail capital cost in $\$ 1990$ per unit for replacements.

RTMATURE $E_{e s}$ : Technology maturity description.

'MATURE' = No further cost reductions expected; use above constants for installed wholesale and retail capital costs.

'ADOLESCENT' = Main cost reductions occurred before base year (1992); function EOCOST reduces installed wholesale and retail capital cost with 1992 (or first year of availability) as the inflection point.

'INFANT' = All cost reductions expected after first year of availability; function EOCOST reduces installed wholesale and retail capital cost with the inflection point in the future.

Energy Information Adminstration

NEMS Residential Demand Module Documentation Report 
RTCOSTP1 ${ }_{e s}:$ If 'MATURE' technology, not used.

If 'ADOLESCENT' technology, representative year cost decline began ( $y_{1}$ in code).

If 'INFANT' technology, year of inflection of cost trend ( $y_{0}$ in code).

RTCOSTP2 ${ }_{\text {es: }}$ If 'MATURE' technology, not used.

If 'ADOLESCENT' or 'INFANT' technology, logistic curve shape parameter (gamma in code).

RTCOSTP3 ${ }_{e s}$ : If 'MATURE' technology, not used.

If 'ADOLESCENT' technology, total possible proportional decline in equipment cost from $y_{0}$ onward ( $d$ in code).

If 'INFANT' technology, total possible proportional decline in equipment cost from $y_{1}$ onward ( $d$ in code).

RTECBTA $1_{e s:}$ If end use $=1,2,3,5,6,7$ : Efficiency choice model log-linear parameter $\beta_{1}$, weights capital cost.

If end use $=4$ : Share for this stove type. Shares within a class and year must add to 1.00 .

RTECBTA2 ${ }_{e s}:$ If end use $=1,2,3,5,6,7$ : Efficiency choice model log-linear parameter $\beta_{2}$, weights fuel cost.

If end use $=4$ : Not used; place holder value required.

RTECBTA3 $_{\text {es: }}$ If end use $=1,2,3,5,6,7$ : Efficiency choice model log-linear parameter $\beta_{3}$, weights life cycle cost.

If end use $=4$ : Not used; place holder value required.

RTECBIAS $_{e s}:$ If end use $=1,2,3,5,6,7$ : Efficiency choice model, consumer preference log-linear parameter; fits current market shares to shipment data.

if end use $=4:$ Not used; place holder value required.

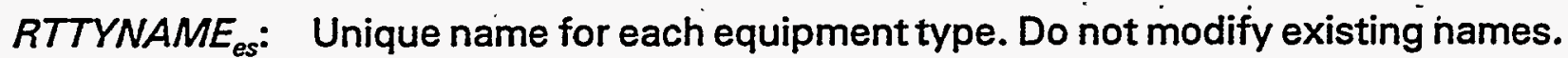
Add unique names for new types. 


\section{Equipment Survival, Housing Survival, and Housing Additions}

\section{SVRTE (Equipment Survival.Function)}

SVRTE is a function in the FORTRAN sense. It is a subprogram that can be called with arguments and returns a single value as its result. The survival rate function is a simple piecewise linear decline, as shown in the picture. Its mathematical description is as follows:

$$
\begin{aligned}
& \therefore S V R T E_{4 L_{\text {man }}, L_{\text {max }}}=1 \quad \text {, if } k L_{\min } \\
& S V R T E_{t, L_{\text {man }}, L_{\text {max }}}=0 . \quad \text {, if } t>L_{\max } \\
& S V R T E_{t, I_{\min } I_{\max }}=1 .-\frac{t-L_{\min }}{I_{\max }-I_{\min }} \text {, otherwise }
\end{aligned}
$$

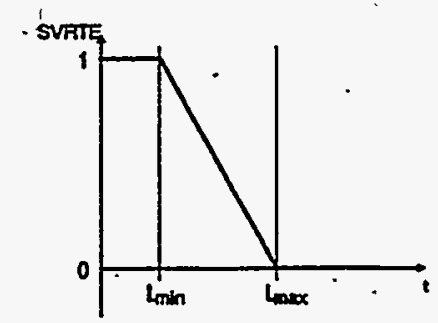

where,

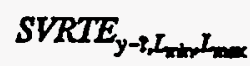

is the proportion of surviving equipment after time $t_{t}$

$\begin{array}{ll}t & \text { is the age of the equipment in years, } \\ L_{\min } & \text { is the minimum equipment lifetime in years, and } \\ L_{\max } & \text { is the maximum equipment lifetime in years. }\end{array}$

Note that function calls to SVRTE in the FORTRAN code include a "place holder" as the first parameter. However, the first parameter is currently not used in the calculations. Since it is not used in the definition of the function in Equation Figure 1, it is not noted explicitly in the remainder of this documentation.

\section{EXHSE (Existing Housing Demolition Rate Component)}

Housing units are removed from the stock at a constant rate over time. The demolition rates for the household types $\left(H D R_{b}\right)$ are as follows:

Single-Family Homes: $H D R_{1}=0.997$ 
$\begin{array}{ll}\text { Multifamily Homes: } & H D R_{2}=0.996 \\ \text { Mobile Homes: } & H D R_{3}=0.966\end{array}$

The surviving pre-1994 housing stock is defined by:

$$
\begin{aligned}
& E H_{j, b, r}=R E C S \text { data } \cdots, \text { if } y=1993 \\
& E H_{y, b r}=E H_{y-1, b, r} \times H D R_{b}, \text { if } y>1993
\end{aligned}
$$

whẹre,

$E H_{y, b, r}$ is the pre-1994 housing stock surviving in year $y$,

$H D R_{b}$ is the housing demolition rate, from the RMISC file.

\section{NEWHSE (Calculate New Housing Component)}

The NEMS Macroeconomic Activity Module provides forecasts of housing starts by Census Division for each forecast year.

$$
\begin{aligned}
& \text { HSEADD } D_{y, \text { single sanityr }}=1,000,000 \times M C_{-} \text {HUSTS1 } 1_{r y}
\end{aligned}
$$

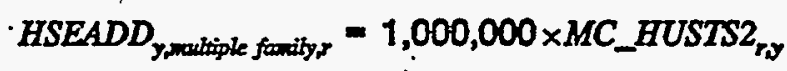

$$
\begin{aligned}
& H S E A D D_{y, \text { mobite hamer }}=1,000,000 \times M C_{-} S H U M B L_{r y} \\
& N H_{y, b,-}=H S E A D D_{y, b, r}+N H_{y-1, b, r} \times H D R_{b}
\end{aligned}
$$

where,

$H S E A D D_{. j, b, r}$ is the number of new housing units constructed in the forecast year by housing type and Census Division,

MC_HUSTS $1_{r, y}$ single family housing starts (millions) by Census Division and year, from the NEMS Macroeconomic Module,

MC_HUSTS2 $2_{r, y}$. multi-family housing starts (millions) by Census Division and year, from the NEMS Macroeconomic Module,

MC_SHUMBL $L_{r, y}$ mobile home shipments (millions) by Census Division and year, from the NEMS Macroeconomic Module,

$N H_{y, b, r} \quad$ is the total post-1993 housing units by housing type, Census 


\section{Division and year, and}

$H D R_{b} \quad$ is the housing demolition rate by housing type.

\section{EPACTWD (Calculate EPACT Window Labeling Impact Component)}

First aggregate the housing stock to the national level,

$$
\begin{aligned}
& \text { OLDHSES, }=\sum_{b, r} E H_{y, b r r} \\
& N E W H S E S_{y}=\sum_{b, r} N H_{y, b, r}
\end{aligned}
$$

where,

OLDHSES $y$ is the national total of remaining pre-1994 housing.

NEWHSES is $_{y}$ the national total of remaining post-1993 housing additions.

Then, calculate the EPACT window labeling impacts for both heating and cooling,

$$
\begin{aligned}
& E P A C T H_{y}=E P W I N P C T_{y} \times E P S A V H T \\
& E P A C T C_{y}=E P W I N P C T_{y} \times E P S A V C L
\end{aligned}
$$

where,

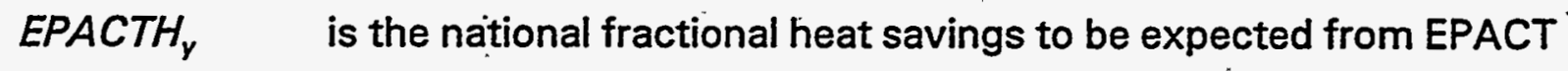
window labeling standards,

- EPACTR $y$ is the national fractional cooling savings to be expected from EPACT window labeling standards,

EPWINPCT $T_{y}$ is the fraction of houses affected by window labeling standards, from the RMISC file,

EPSAVHT is the fraction of heat input to houses expected to be saved by improved window labeling, set in the program to a constant value of .08, and

EPSAVCL is the fraction of cooling input to houses expected to be saved by improved window labeling, set in the program to a constant value 


$$
\text { of .03. }
$$

RDSOFT (Read Floor Areas).

Read the historical and forecast data for average household area, SQRFOOT $T_{y, b, r}$ from the RSSQRFT file, and calculate the ratios, SOFTADJ $y_{y, b}$, between each area and the base year area, SORFOOT $1993, b$, r.

\section{SOFTCALC (Calculate Average Floor Area Component)}

Averages the floor areas of homes,

$$
\begin{aligned}
& \text { SQFTAVG }_{1983}=\frac{\sum_{b, r}\left(S Q R F O O T_{1993, b, r} \times E H_{1993, b r r}\right)}{\text { OLDHSES }}
\end{aligned}
$$

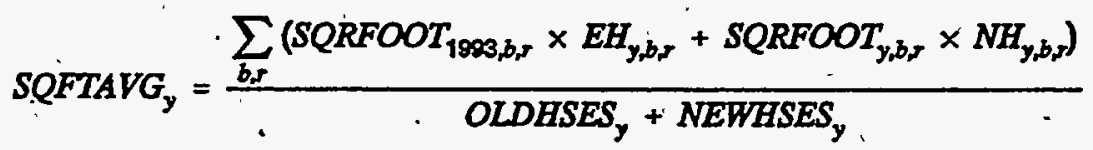

where,

SQFTAVG ${ }_{y}$ is the average floor area of houses of all types, and $S_{\text {SORFOOT }}$,b,r is a table of historical and projected housing floor areas, from the RSSORFT file, by year, housing type and C'ensus Division.

\section{RDHTREQC (Project 1993 Vintage Equipment for all End-Use Services)}

This routine reads in the 1993 equipment stock for all services from external files, then calculates surviving equipment in the pre-1994 housing stock for 1994 through the end of the forecast.

For $y>1993$,

$$
E Q C E S E_{y, e g, b, r}-E Q C E S E_{1983, e g, b, r} \times H D R_{b}^{y-1093} \times\left(1 .-E Q C R E T_{y, e g}\right)
$$

where,

EQCESE $_{y, e g, b, r}$ is the amount of surviving pre-1994 vintage equipment in pre1994 housing by housing type and Census Division, 
$H D R_{b}$ is the housing demolition rate by housing type, and

$E Q C R E \dot{T}_{\text {y.og }}$ are the annual equipment retirement fractions for the equipment classes, from file RSRET01.

Calculate a national total for each equipment type,

$$
E Q S E S E_{y_{1,8}}=\sum_{b, r}\left[E Q C E S E_{y, e z, b r} \times\left(1 .-E Q C R E T_{y, e g}\right)\right]
$$

where,

EQSESE $_{y, e g} \quad$ is the number of installed appliances of each equipment class.

\section{Space Heating}

\section{Heating Equipment, UEC and Housing Shell Accounting Scheme}

Table 3 depicts the equipment accounting methodology. For simplicity, this discussion omits the details of the variable subscripts, which are explained later in this appendix. The equipment accounting system partitions equipment into two major categories, depending on the vintage of the housing unit: equipment installed in pre-1994 housing units (houses that existed at the beginning of a model run) and equipment added to post-1993 housing units (those added during the model run). Equipment is further partitioned into three additional survival/replacement categories: equipment that survives, equipment purchased to replace related equipment, and equipment purchased for new construction. The categorization of equipment by housing vintage and surviving/replacement type results in six categories of equipment that are tracked.

The equipment categories for pre-1994 housing units are:

EOCESE denotes the surviving pre-1994 equipment stock in pre-1994 housing, EOCSR9O represents equipment from pre-1994 housing that has been replaced after 1993 and still survives, and

EQCRP9O is current-year replacement equipment in pre-1994 housing. 
Table 3. Heating Equipment, UEC and Housing Shell Accounting Scheme

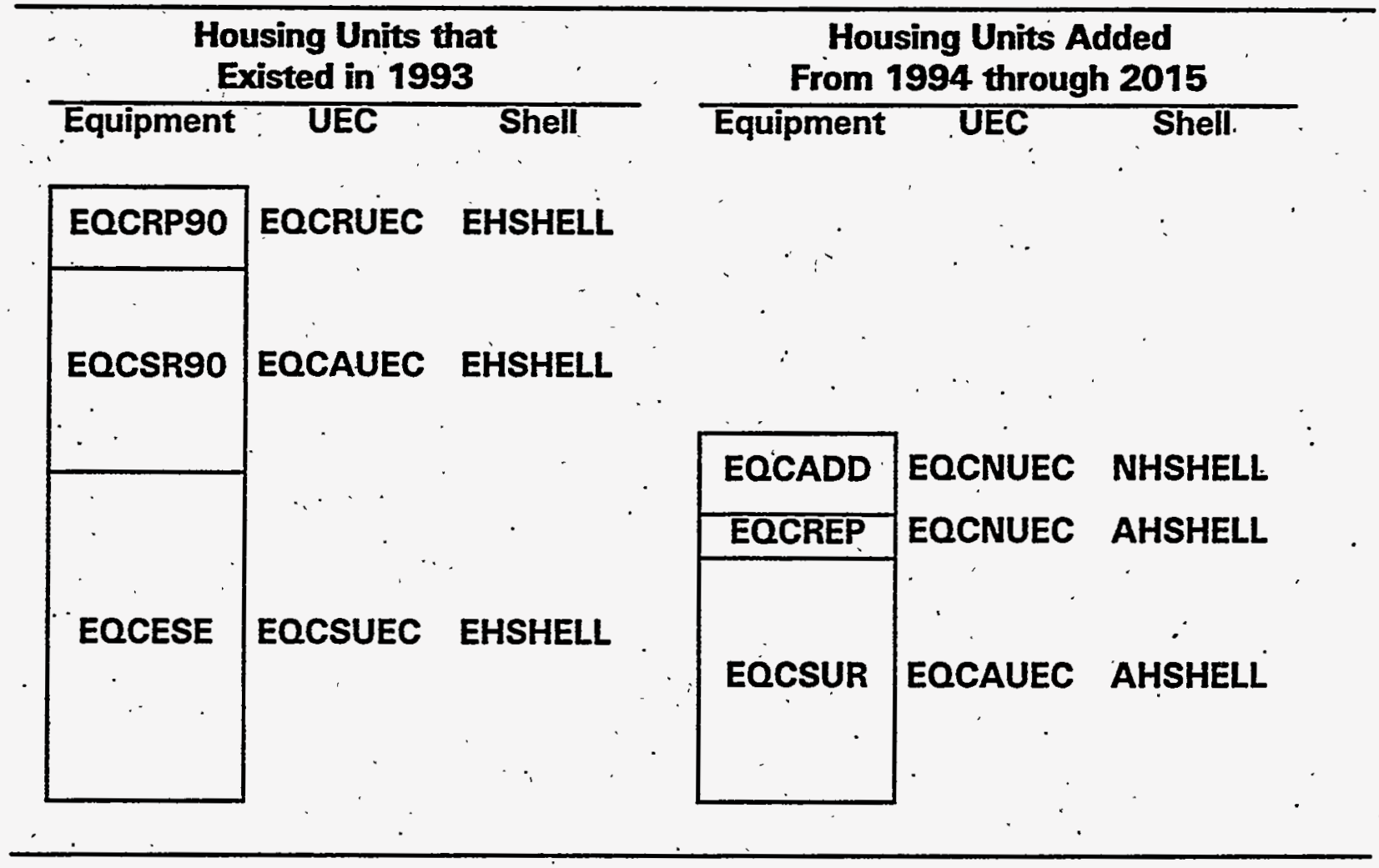

The equipment categories for post-1993 housing units are:

EOCSUR denotes equipment that has been modeled as added and still survives, EOCREP is equipment that has been modeled as added and is in need of replacement in the current year, and

EQCADD is equipment for housing units added in the current year.

Unit energy consumption (UEC) is tracked according to when the equipment was added and by category of housing unit:

EOCUEC is the average UEC for the original pre-1994 equipment in pre-1994

. housing units,

EOCSUEC is the average UEC for surviving equipment in pre-1994 housing units,

EOCAUEC is the average UEC for surviving post-1993 equipment in pre-1994

. housing units,

EQCRUEC is the UEC for all equipment added in the current year to replace 
equipment in pre-1994 housing units, and

EQCNUEC is the UEC for all equipment added or replaced in the current year for post-1993 housing units.

Shell indices are modeled for.three categories of housing units:

EHSHELL is the shell index applicable to pre-1994 housing units,

AHSHELL is the shell index applicable to housing units added in all but the current year, and

NHSHELL is the shell index for housing units added in the current year.

For example, in accounting for the heating energy consumption of surviving equipment installed in pre-1994 housing units, the equipment stock, EOCESE, would be multiplied by the unit energy consumption, EOCUEC, and by the shell index EHSHELL. This explanation was designed to account for heating equipment, but the accounting principle is used throughout the residential module. For the existing housing example above, the appropriate space cooling variables would be multiplied by ECSHELL. The shell indices apply only to heating and cooling, thus, for example ; for refrigeration the accounting requires only EQCESE. and EQCUEC.

\section{EQCOST (Equipment Cost Function)}

EQCOST is a function in the FORTRAN sense. It is a subprogram that can be called with arguments and returns a single value as its result. EOCOST is a time-dependant function for computing the installed capital cost of equipment in new construction and the retail replacement cost of equipment in existing housing. It is called if the cost trend switch COSTTRSW $=1$ in COMMON RTEK (which is the default). Its mathematical description is as follows: 


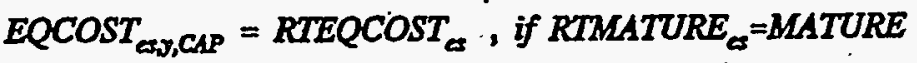

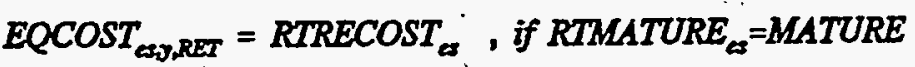

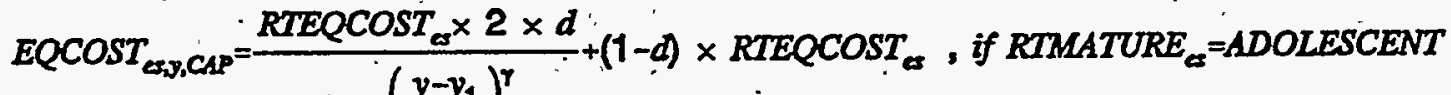

$$
\begin{aligned}
& 1+\left(\frac{y-y_{1}}{y_{0}-y_{1}}\right)^{r}
\end{aligned}
$$

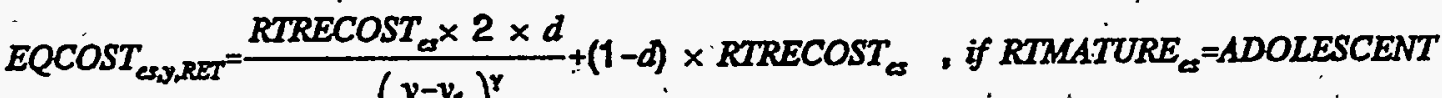

$$
\begin{aligned}
& 1+\left(\frac{y-y_{1}}{y_{0}-y_{1}}\right)^{\gamma} \\
& E Q C O S T_{c s, C A P}=\frac{R T E Q \operatorname{Cos} T_{e s} \times d}{1.0+\left(\frac{y-y_{1}}{y_{0}-y_{1}}\right)^{\gamma}}+(1.0-d) \times R T E Q C O S T_{e s} \text {, if RTMATURE }=I N F A N T \\
& \text { EQCOST } T_{\angle x, R E T}=\frac{R T R E C O S T_{e s} \times d}{1.0+\left(\frac{y-y_{1}}{y_{0}-y_{1}}\right)^{\gamma}}+(1.0-d) \times R T R E C O S T_{\alpha} \text {, if RTMATURE } E_{\alpha}=I N F A N T
\end{aligned}
$$

where,

$E Q \operatorname{COST}_{\text {es,y,ctype }}$ is time-dependant installed capital cost of equipment in new construction or the retail replacement cost of equipment in existing houșing,

ctype tells function type of equipment cost to return,

CAP = Return installed capital cost in new construction, RET = Return retail replacement cost in existing housing,

RTMATURE $_{\text {es }}$ Technology maturity description,

MATURE = No further equipment cost reductions expected, ADOLESCENT = Major cost reductionis occurred before base year,

INFANT = All cost reductions expected after first year available,

RTEQCOST es Installed wholesale capital cost in \$1991 per unit for new homes, remains constant for MATURE technologies only lused when if ctype $=C A P I$, 
RTRECOST es Retail capital cost in $\$ 1990$ per unit for replacements, remains constant for MATURE technologies only (used when if ctype $=$ RET,

Yo is the year of inflection of cost trend,

RTINITYR $R_{e s}$ if ADOLESCENT,

RTCOSTP $1_{\text {es }}$ if INFANT,

$y_{1} \quad$ is the year cost decline began,

RTCOSTP $1_{\text {es }}$ if ADOLESCENT,

$R T I N I T Y R_{e s}$ if INFANT,

d is the total possible proportional decline in equipment cost, RTCOSTP3 $_{\text {es }}$

from $y_{0}$ onward if ADOLESCENT,

from $y_{1}$ onward if INFANT;

is the logistic curve shape parameter, RTCOSTP2 ${ }_{e s}$.

\section{RHTRTEC (Space Heating Technology Choice Component)}

Begin by calculating a factor that adjusts for biased temperatures in either the base year or in the year under consideration, in each region,

$$
{ }_{H D D F A C T}=\frac{H D D A D J_{y,}}{H D D A D J_{1283, r}}
$$

where,

HDDFACT, is a set of regional factors to be used in this year to adjust for unusual temperatures either in this year or in the base year, and

$H D D A D J_{y, r}$ are regional population-adjusted heating degree-days by Census division and historical year, with forecast years filled in with the latest historical year, from the RMISC file.

Compute current year operating costs,

Energy Information Adminstration

NEMS Residential Demand Module Documentation Report

B-19 


$$
O P C O S T_{y, e s, b r, v}=P R I C E S_{f r, y} \times E Q C U E C_{r_{r e g, b}, b} \times H D D F A C T_{r, y} \times R T E F F A C_{e g, i v}
$$

where,

$O P C O S T_{y, e s, b, r, v}$ is the operating cost for the specific equipment type by year, housing type, Census Division, and vintage,

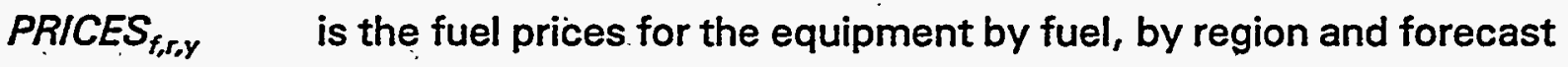
year,

EOCUEC $_{r, e g, b}$ is the unit energy consumption by Census Division, equipment class and housing type, from the RSUEC10 file,

$H_{D D F A C T_{r, y}}$ is a factor, the ratio between heating degree days in the current year and in the base year, for adjusting for abnormally warm weather in either the base year or in the current year, and

$R T E F F A C_{e g, v}$ is the efficiency adjustment for the general equipment class and vintage.

Compute current year life cycle costs, for each equipment type,

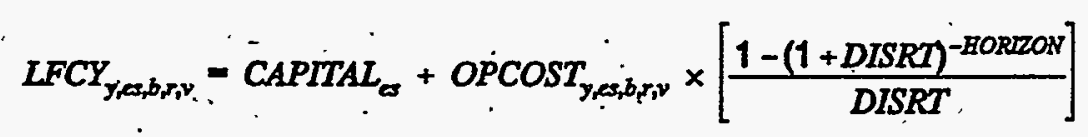

where,

$L F C Y_{y, e s, b, r, v}$ is the current year life cycle cost of specific equipment types by housing type, Census Division, and vintage,

$C A P I T A L_{e s}$ is the installed capital cost of the equipment by equipment type, based on calling function EQCOST with RTEQCOST $T_{\text {es, }}$

$O P C O S T_{y, e s, b, r}$ is the operating cost of the equipment type by housing type, Census Division, and vintage in the forecast year,

HORIZON ' is the number of years into the future that is used to compute the present value of future operating cost expenditures presently set to seven years, and

DISRT is the discount rate applied to compute the present value of future operating costs presently at 20 percent. 
For each equipment class, a weight is calculated to estimate the market share for each of the 11 heating systems for new construction based on a log-linear fit to the cost factors computed above. The functional form is expressed as,

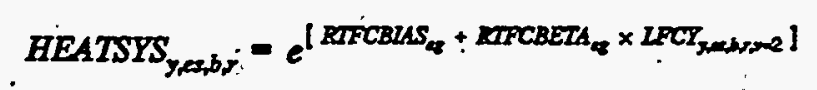

where,

HEATSYS ${ }_{y, e s, b, r}$ is the equipment weight for heating equipment types for new housing by year, housing type, and Census Division,

$R T F C B I A S_{e s}$ is a consumer preference parameter for the equipment class that fits the current market share to historical shipment data,

$L F C Y_{y, e s, b, r, 2}$ is the life cycle cost for the equipment type by year, housing type, and Census Division for new construction, and

RTFCBETA $_{\text {es }}$ is a parameter value of the log-linear function for the equipment class.

Summing over the equipment classes computes the total weight for all of the heating equipment classes:

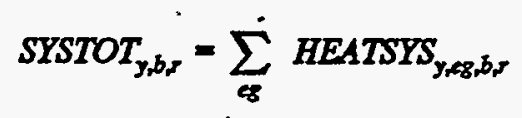

where,

SYSTOT $_{y, b, r}$ is the sum of the equipment weights for all equipment classes.

The fuel shares for all heating equipment classes are computed by

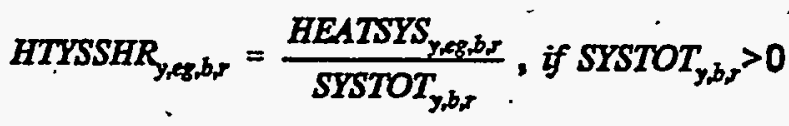

$$
\begin{aligned}
& H T Y S S H R_{y_{, e g}, b_{r}}=0 \quad \text { otherwise }
\end{aligned}
$$

where,

$H T Y S S H R_{\text {y,eg,b,r }}$ is the heating equipment fuel shares by year, building type, and Census Division. 
For each equipment type within each class, a weight is calculated based on the cost factors computed above. The functional form is expressed as,

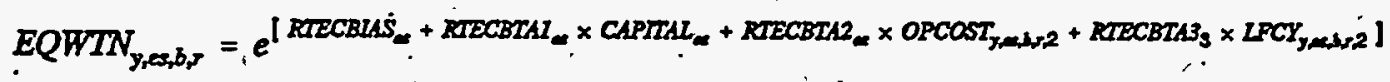

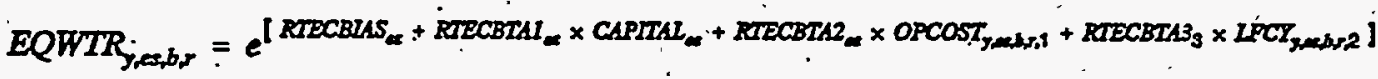

where,

EQWTN $N_{\text {y,es,b,r }}$ is the equipment weight for new equipment types 'by year, housing type, and Census Division,

- EQWTR $R_{y, e s, b, r}$ is the equipment weight for replacement equipment types by year, housing type, and Census Division,

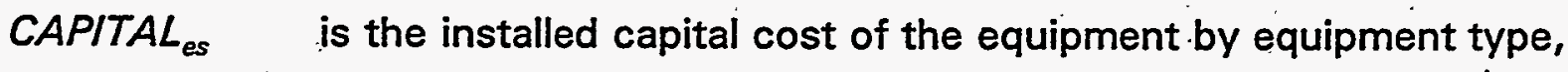
based on calling function EQCOST with RTEOCOST $T_{\text {es }}$

$O P C O S T_{y, e s, b, r, v}$ is the operating cost for the equipment type by year, housing type, Census Division, and vintage

$\angle F C Y_{y, e s, b, r, v}$ is the life cycle cost for the equipment type by year, housing type, Census Division, and vintage;

$R T E C B H A S_{e s}$ is a consumer preference parameter that fits the current market share to shipment data, and

RTECBTA $1_{\text {es' }}$ are parameter values of the same fit.

RTECBTA2,

RTECBTA3

Sums over the equipment types within each class give total weights for the equipment classes:

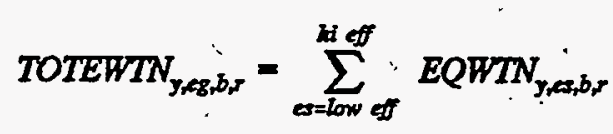

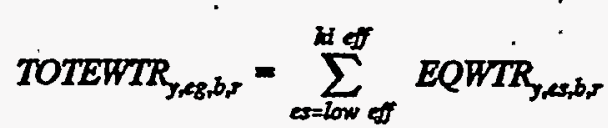

where, 
TOTEWTN $N_{y, e g, b, r}$ is the sum of weights for the new equipment types within equipment classes,

TOTEWTR $R_{y, g g, b, r}$ is the sum of weights for the replacement equipment types within equipment classes.

The following calculation calibrates the Xenergy model to Census data:

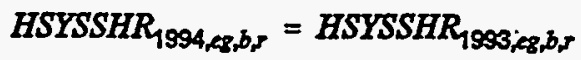

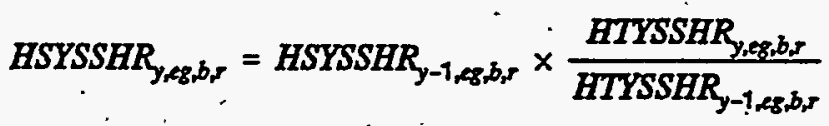

where,

$H S Y S S H R_{y, e g, b, r}$ are space heating equipment shares by year, heating equipment class, housing type and Census Division, with 1993 values from. file RHTRSHR, and

- HTSSHR $_{\text {,eg,b,r }}$ is the heating equipment fuel shares by year, building type, and Census Division.

Which is then normalized:

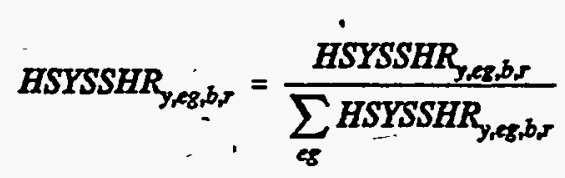

where,

$H S Y S S H R_{y, e g, b, r}$ are now normalized.

Fuel shares for the equipment types within each equipment class are computed from the equipment weights for new and replacement equipment, by the following formulas applied to the current equipment model year, as specified by the equipment type date range $R T I N I T Y R_{e s}$ through $R T L A S T Y R_{e s}$ : 


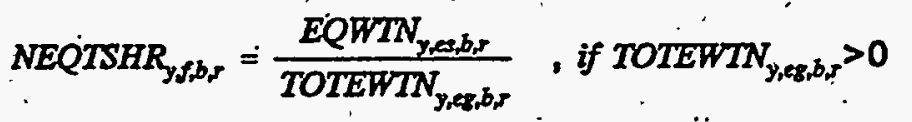

$$
\begin{aligned}
& N E Q T S H R_{\text {ysb, }}=0 \quad \text {, otherwise }
\end{aligned}
$$

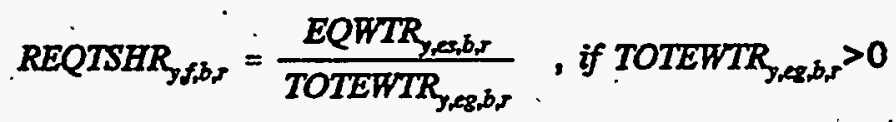

$$
\begin{aligned}
& \text { REQTSHR }_{y f b, y}=0 \text {, otherwise }
\end{aligned}
$$

where,

NEOTSHR $R_{y, t, b, r}$ are the fuel shares of new equipment types by year, housing type and Census Division;

$R E Q T S H R_{y, f, b, r}$ are the fuel shares of replacement equipment types by year, housing type and Census Division,

TOTEWTN $N_{y, e g, b, r}$ are the sums of equipment weights in each equipment class for new equipment,

TOTEWTR $R_{y, e g, b, r}$ are the sums of equipment weights in each equipment class for replacement equipment,

$E Q W T N_{y, e s, b, r}$ are the equipment weights for new equipment, and

$E Q W T R_{y, e s, b, r} \quad$ are the equipment weights for replacement equipment.

The weighted average equipment inverse efficiencies for the equipment types within each equipment class are then computed as, 


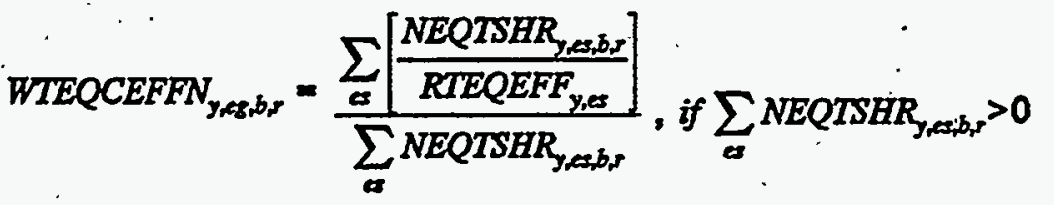

$$
\begin{aligned}
& \text { WTEQCEFFN }_{\mathrm{y}, \mathrm{s}, b_{\mathrm{b}}}=\frac{1}{\text { RTBASEFF }_{\mathrm{eg}}} \quad \text { otherwise }
\end{aligned}
$$

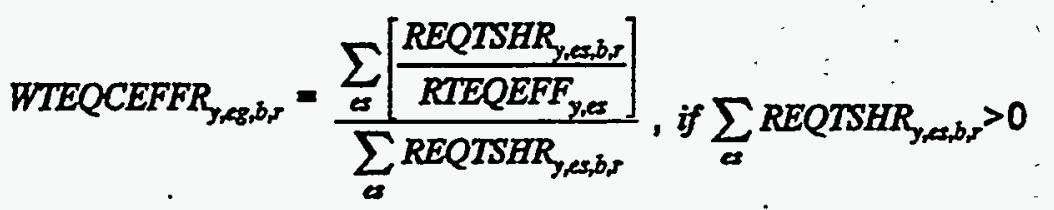

$$
\begin{aligned}
& \text { WTEQCEFFR }_{\text {y,es, }, 5,}=\frac{1}{\text { RTBASEFF }_{\text {eg }}} \text {, otherwise }
\end{aligned}
$$

where,

WTEQCEFFN $N_{y, e g, b, r}$ is the weighted average inverse efficiency of new equipment types within each equipment class by yeár, housing type, and Census Division.

$W T E Q C E F F R_{y, e g, b, r}$ is the weighted average inverse efficiency of replacement equipment types within each equipment class by year, housing type, and Census Division.

\section{HTRADD (Addition and Rejplacement of Space Heating Equipment Component)}

Compute the market shares for heating equipment classes for both new and replacement equipment. For new equipment, it has already been computed; for replacements, it must be added from the shares of equipment types.

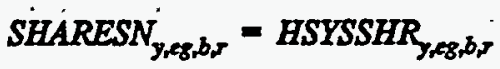

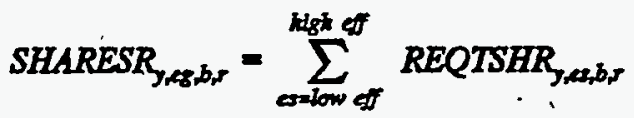

where,

SHARESN $_{y, e g, b, r}$ is the current year, aggregate market share for new equipment by equipment class, housing type and Census Division,

$S H A R E S R_{y, e g, b, r}$ is the current year, aggregate market share for replacement 
equipment by equipment class, housing type and Census Division,

$H S Y S S H R_{y, e g, b, r}$ are space heating equipment shares by year, heating equipment class, housing-type and Census Division, with 1993 values from file RHTRSHR, and

$R E Q T S H R_{y, f, b, r}$ are the fuel shares of replacement equipment types by year, housing type and Census Division.

Given these market shares, and the number of houses of each type built in this year, calculate the number of units of new equipment of each class installed in new houses,

$$
E Q C A D D_{y, e g, b, r}=H S E A D D_{y, b, r} \times S_{S H A R E S N_{y, e g, b, r}}
$$

where,

$E Q C A D D_{y, e g, b, r}$ is the number of post-1993 vintage heating units added in new housing units in the current year by equipment class, housing type and Census Division,

$H S E A D D_{y_{0}, b}$ is the number of new housing units constructed in the current year by housing type and Census Division, and

SHARESN $_{y, e g, b, r}$ are the market shares for heating equipment classes by housing type and Census Division.

For pre-1994 vintage houses, there are two categories of equipment: that which was installed before 1994 and still survives; and that which was replaced since 1993 and still survives. The second of these is calculated as follows:

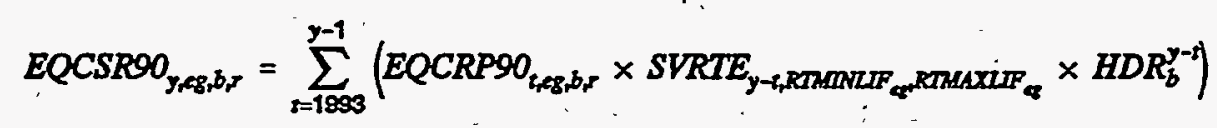

where,

EOCSR9O ${ }_{y, e g, b, r}$ is the surviving post-1993 vintage equipment in pre-1994 housing units, which accounts for housing demolition and equipment by housing type and Census Division,

EQCRP9O ${ }_{t, e g, b, r}$ is the number of replacement (post-1993 vintage) equipment units 
demanded in pre-1994 housing units by housing type and 'Census Division each year,

SVRTE is the equipment survival function,

$H D R_{b}$

is the housing demolition rate by housing type, and

$y-t$ represents the age of the equipment,

RTMINLIF $_{\text {eg * }}$ is the equipment class minimum lifetime from the RTEKCL file, and

RTMAXLIF $_{\text {eg }} \quad$ is the equipment class maximum lifetime from the RTEKCL file.

Surviving post-1993 equipment, originally purchased before the current year as . additions or replacements in post-1993 houses, is calculated as,

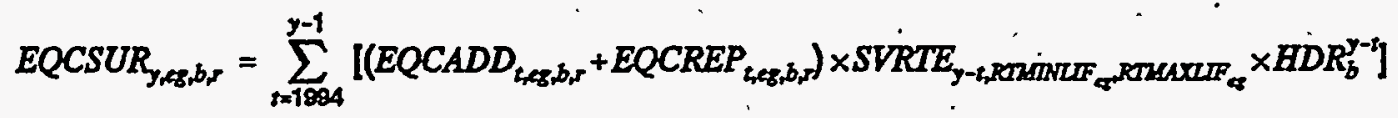

where,

EQCSUR $_{\text {y,eg,b,r }}$ is the surviving post-1993 equipment purchased as additions or replacements in post-1993 houses by housing type and Census Division,

$E Q C A D D_{t, e g, b, r}$ is the quantity of post-1993 vintage equipment added to new construction by forecast year, housing type and Census Division,

EQCREP $_{t, e g, b, r}$ is the number of equipment replacements of post-1993 equipment in post-1993 houses,

SVRTE. is the equipment survival function,

$H D R_{b} \quad$ is the housing demolition rate by housing type,

$y-t$ represents the age of the equipment,

RTMINLIF $_{\text {eg }}$ is the equipment class minimum lifetime from the RTEKCL file, and

RTMAXLIF $F_{\text {eg }} \quad$ is the equipment class maximum lifetime from the RTEKCL file.

For multi-family and mobile post-1993 homes only, the amount of replacement 
equipment (with no technology switching) required this year is

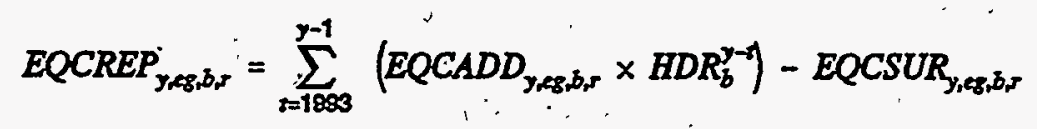

where,

$\dot{E} Q C R E P_{y, e g, b, r}$ is the number of units of equipment required to be replaced this year in post-19.93 multi-family and mobile homes by housing type and Census Division,

$E Q C A D D_{y, e g, b, 5}$ is the number of units of equipment added so far in post-1.993 houses by housing type and Census Division, and

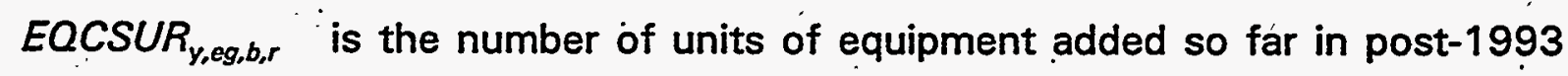
houses that still survive, by housing type and Cenșus Division.

A new model feature, a technology choice component, allows switching when replacing space heaters in post-1993 (and pre-1994) single family homes only. Users may specify the fraction of homes which may switch away from a certain technology by setting the values RTSWFACT eg in the RTEKCL data file. Retiring values are first calculated as in (39) and stored as OEQCREP ${ }_{y, e g, 1, r}$. The code then calls SUBROUTINE REPLACE(EU,RSYR,R,B,RECCL, 1) for replacements with. switching in post-1993 single-family housing where,
EU
is the end use number ( 1 for space heating),
RSYR is the calendar year,
$R$ is the census division,
$B$ is the building type (currently always 1 for single-family),
RECCL is the record number from the RTEKCL file,
FLAG is set $=1$ for post-1993 housing.

REPLACE is described in the next section.

The total amount of pre-1994 equipment remaining in pre-1994 houses is computed 
as:

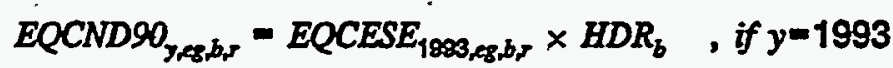

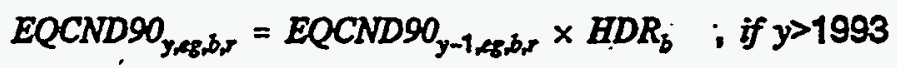

where,

EQCND90 $0_{y, g g, b, r}$ is the total amount of pre-1994 equipment remaining in pre1994 houses by year, equipment class, housing type and Census Division,

EQCESE $_{1993, e g, b, r}$ is the stock of equipment in 1993 by equipment class, housing type and Census Division,

$H D R_{b}$ is the housing demolition rate by housing type.

Replacement units (post-1993) equipment required for pre-1994 houses in the current year for multi-family and mobile homes are calculated as,

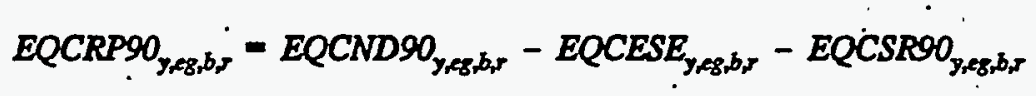

where,

EQCRP9O ${ }_{y, e g, b, r}$ is the number of replacement units required in the current year for pre-1994 multi-family and mobile homes by forecast year, housing type and Census Division,

EQCND9O ${ }_{y, e g, b, r}$ is the total equipment required for pre-1994 houses by forecast year, housing type and Census Division (i.e. the sum of EQCRP9O, EOCSR9O and EQCESE,

EQCESE $E_{y, g, b, r}$ is the surviving pre-1994 vintage stock of equipment in pre-1994 vintage houses by forecast year, housing type and Census Division, and

EQCSR9O ${ }_{y, e g, b, r}$ is the forecast of surviving post-1993 vintage equipment in pre1994 houses.

A second call to SUBROUTINE REPLACE(EU,RSYR,R, B, RECCL,2) allows switching to 
any technology when replacing space heaters in pre-1994 single family homes only. Retiring values are first calculated as and stored as OEQCRP9O ${ }_{y, e g, 1, r}$. Users may specify the fraction of homes which may switch away from a certain technology by setting the values RTSWFACT $T_{\text {eg }}$ in the RTEKCL data file. In the second call, FLAG = 2 for pre-1994 housing. the description of REPLACE follows.

\section{REPLACE (Technology Switching Component)}

The technology switching component allows switching when replacing space heaters, heat pump air conditioners, water heaters, stoves, and clothes dryers $(E U=1,2,3$, 4,5 , respectively) in single-family housing $(B=1)$. When called with $F L A G=1$, the subroutine calculates replacements in post-1993 housing and the local variable RETIRED is set as follows:

$$
R E T T R E D_{\text {yeg, }, 1, r}=O E Q C R E P_{y, e s, 1, r}
$$

where,

OEQCREP

When called with $\mathrm{FLAG}=2$, the subroutine calculates replacements in pre-1994 single-family housing and the local variable RETIRED is set as follows:

$$
\text { RETIRED }{ }_{\text {y,eg, }, 1,5}=\text { OEQCRP } 90_{\text {y,eg, } 1, r}
$$

where,

OEOCRP9O ${ }_{y, 6 g, 1, r}$ is calculated as in (41).

The number of homes that may switch in each equipment class is calculated as,

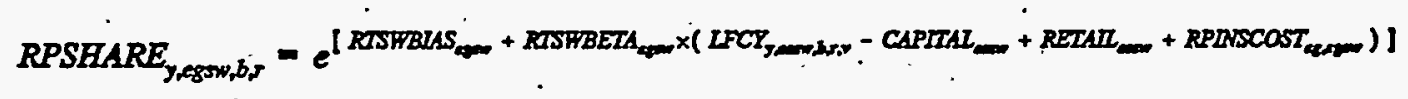

Sum to find the total number of switches. 


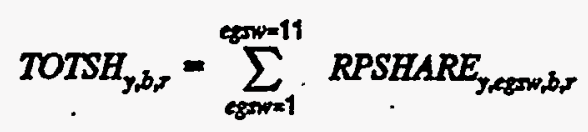

Finally, divide the number of switches in each equipment class by the total number of switches (if $>$ 0) to calculate the share of replacement equipment which may switch.

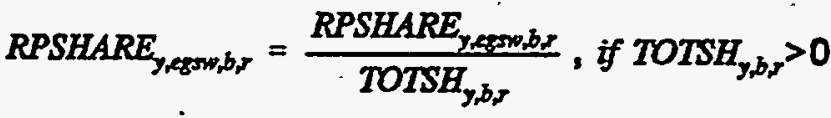

$$
\begin{aligned}
& R P S H A R E_{\text {yegno,bs, }}=0 \quad \text {, otherwise }
\end{aligned}
$$

where,

RPSHARE ${ }_{y, e g s w, b, r}$, is the number that will switch to equipment class egsw on replacement by year, housing type, and Census Division,

RPSHARE $E_{y, e g s w, b, r}$ is the share that will switch to equipment class egsw on replacement by year, housing type, and Census Division,

$R T S W B I A S_{\text {egsw }} \quad$ is the consumer preference parameter for switching to this equipment class,

RTSWBETA $A_{\text {egsw }}$ is the parameter value for the same fit,

$L F C Y_{\dot{y}, e s s w, b, r, v}$ is the life-cycle cost of the equipment type switching to (essw) by year, building type, region, and vintage,

CAPITAL $_{\text {essw }}$ is the installed capital cost of the equipment which is subtracted from the lifecycle cost for replacements, based on calling function EQCOST with RTEOCOST $T_{\text {esswr }}$

RETAIL ${ }_{\text {esswr }}^{\prime} \quad$ is the retail equipment type cost which is added to the lifecycle cost for replacements, based on calling function EQCOST with RTRECOST $T_{\text {essw' }}$

RPINSCOST $T_{\text {og,egsw }}$ is the cost of switching from equipment class eg to egsw on switching, and

TOTSH ${ }_{\text {i,b,r }}$ is the total number of homes that will switch space heater 
technologies.

Replacement units (post-1993) equipment required for pre-1994 homes in the current year for single-family homes where switching is allowed are calculated as,

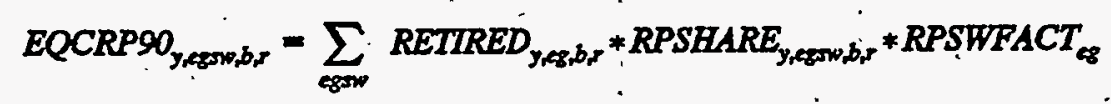

where,

EQCRP9O ${ }_{y, e g s w, b, r}$ is the number of replacement units required for single-family pre-1994 houses by forecast year, housing type and Census Division,

RETIRED ${ }_{y, e g, b, r}$ is calculated as in (43), by forecast year, housing type and Census Division,

RPSHARE $E_{y, e g s w, b, r}$ is the share that will switch equipment class (egsw) on replacement by year, housing type, and Census Division, and $R T S W F A C T_{\text {eg }} \quad$ is the fraction who may switch from equipment class eg.

Replacement units (post-1993) equipment required for pre-1994 homes in the current year for single-family homes where switching is not allowed are calculated as,

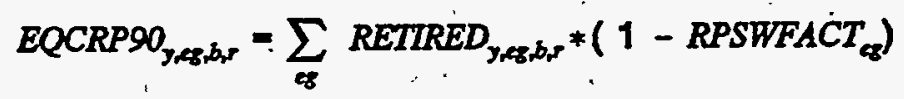

where,

EOCRP9. $0_{y, \theta g, b, r}$ is the number of replacement units required for single-family pre-1994 houses by forecast year, housing type and Census Division,

RETIRED $D_{\text {,eg,b,r }}$ is calculated as in (43), by forecast year, housing type and Census Division,

$1-R T S W F A C T_{e g}$. is the fraction who may not switch from equipment class eg. 
For replacement units. (post 1993) equipment required for post-1993 single family homes in the current year technology switching is allowed. The share of replacement equipment which may switch is calculated as in (44) through (46).

Replacement units (post-1993) equipment required for post-1993 homes in the current year for single-family homes where switching is allowed are calculated as,

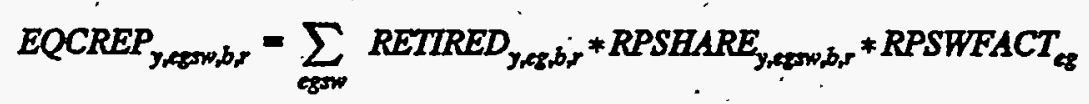

where,

EQCREP $_{\text {y,egsw,b,r }}$ is the number of replacement units required for single-family post-1993 houses by forecast year, housing type and Census Division,

RETIRED $_{\text {y,eg, }, b, r} \quad$ is calculated as in (43), by forecast year, housing type and Census Division,

RPSHARE $_{y, e g s w, b, r}$ is the share that will switch equipment class (egsw) on replacement by year, housing type, and, Census Division, and RTSWFACT $_{\text {eg }}$ is the fraction who may switch from equipment class eg.

Replacement units (post-1993) equipment required for post-1993 homes in the current year for single-family homes where switching is not allowed are calculated as,

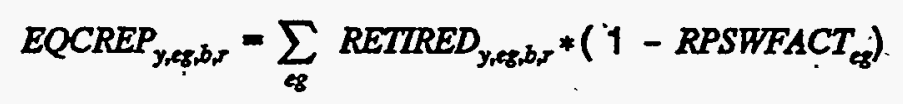

where,

$E Q C R E P_{y, e g, b, r}$ is the number of replacement units required for single-family post-1993 houses by forecast year, housing type and Census Division,

RETIRED $_{\mathrm{y}, e g, b, r}$ is calculated as in (42), by forecast year, housing type and Census Division,

1-RTSWFACT is the fraction who may not switch from equipment class eg. 


\section{RHTRCON (Heating Energy Consumption Component)}

The shell integrity component uses three indices to capture the increases in the energy efficiency of building shells over time. One index corresponds to the pre-1994 housing stock, and two indices correspond to the post-1993 stock, one for housing constructed in the current year and the other for the average post-1993 stock. The shell indices are adjusted each year to account for fuel price increases (decreases have no effect on shell integrity, i.e., shell efficiency increases as price increases) and technology improvements.

An important part of shell integrity is the quality of windows. In the Energy Policy Act, there are regulations that require that all new windows be labeled with an index that describes their insulation properties. These regulations will be phased in over a period of years, beginning in 1995. The residential module evaluates the impacts of these regulations by means of an annual input variable, EPWINPCT, that gives the proportion of existing houses expected to be subject to window labeling. This quantity, when multiplied by the fraction of heat savings expected to be afforded by labeled windows, currently set at .08 , gives the expected savings rate due to window

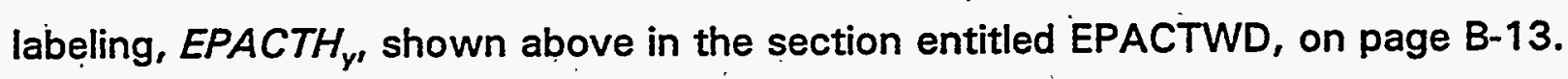

Space heating equipment choice begins with the calculation of a factor that adjusts for biased temperatures in either the base year or in the year under consideration, in each region,

$$
{ }_{H D D F A C T_{r}}=\frac{H D D A D J_{y, r}}{H D D A D J_{198, r}}
$$

where,

HDDFACT, is a set of regional factors to be used in this year to adjust for abnormal temperatures either in this year or in the base year, and HDDADJ $J_{y, r}$ are regional population-adjusted heating degree-days by Census division and historical year, with forecast years filled in with the 
latest historical year, from the RMISC file.

It then calculates the average efficiency of all 1993 heating equipment,

$$
R T B A S E F F_{y, e z}=\left(R T B A S E F F_{y-1, e q}-\left(1 .-\frac{E Q S E S E_{y, e z}}{E Q S E S E_{y-1, e 8}}\right) \times E Q C E F F_{y-1, e 8}\right) \times \frac{E Q S E S E_{y-1,68}}{E Q S E S E_{y, e z}}
$$

where,

$R T B A S E F F_{\text {eg,y }}$ is the stock average efficiency for the remaining 1993 equipment, EOSESE $_{y, e g}$ is the remaining unretired stock of 1993 heating equipment, by year and equipment class, and

EOCEFF $_{\text {y,eg }}$ is the average efficiency of equipment retired in each year, from the RSEFFO 1 file.

The.next step in the component calculates the percentage price change for all heating fuels as,

$$
\text { PRIDELTA }_{f, r}=\frac{\text { PRICES }_{f, r y}-\text { PRICES }_{f, 11983}}{\text { PRICES }} \times \frac{1}{\text { PSTEP }}
$$

where,

PRIDELTA $f_{f, r}$ is the percentage change in price from the base year by fuel and Census Division converted to 5 percentage point increments,

PSTEP is a constant that is set to 0.05 to convert the percentage change in fuel price to the number of 5 percentage point increments of price change,

PRICES $_{\text {t,ry }}$ "is the fuel price by fuel, Census Division and year, and

PRICES $_{f, r, 1993}$ is the 1993 (base year) fuel price by fuel and Census Division."

The existing housing heating shell index is calculated as, 


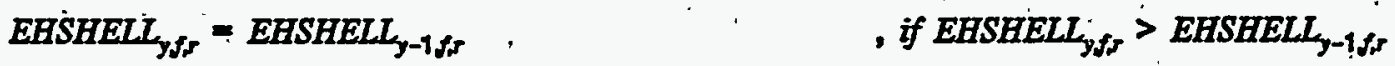

$$
\begin{aligned}
& \text { EHSHELL }_{\text {yfr }}=L I M T T \quad \text {, if EHSHELL } L_{\text {yfr }} \geq L D M T T \\
& \text { EHSHELL }_{y, f r}=\left(1 .- \text { PRDELTA }_{f, r} \times S S T E P\right) \times T E C H G_{1} \\
& \times\left(1 .-E_{1}{ }_{1 C T H}\right) \quad \text { otherwise }
\end{aligned}
$$

where,

EHSHELL $L_{\text {y,fr }}$ is the heating shell integrity index for existing housing by year, fuel and Census Division (the lower the value of the index, the greater the shell efficiency),

LIMIT limits the maximum shell index efficiency to 0.6 (i.e., maximum shell efficiency is limited to being 40 percent more efficient than the base year value),

SSTEP $\because \quad$ is set to 0.01 and is a component of the shell elasticity with respect to heating fuel price,

$T E C H G_{1} \quad$ is a parameter representing the annual. increase in existing shell integrity due to technology improvements, and

EPACTH $_{y}$ is the projected national fractional savings on heating energy consumption from the EPACT window labeling program in year $y$, from the RMISC file.

PSTEP converts the percentage change in price to the number of 5 percentage point increments of price change in Equation (53). In equation (54), PRIDELTA is multiplied by SSTEP and converted to the shell efficiency index. Every 5 percentage point increase in fuel price relative to the base year results in a shell efficiency index decrease of 1 percentage point of the base year shell efficiency up to the limit of 0.6.

For convenience, the heating consumption subroutine also computes the cooling shell integrity index, which is not a function of fuel, as almost all cooling is electric: 


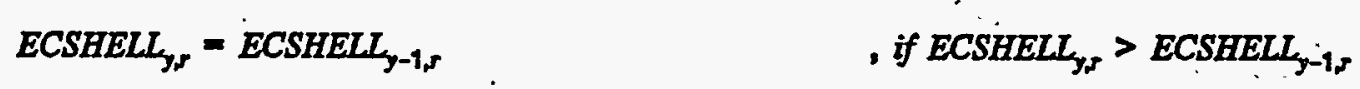

$$
\begin{aligned}
& \text { ECSHELL } L_{y,}=L I M T T \quad \text {, if ECSHELL } \\
& \text { ECSHELL } L_{y,}=\left(1 .- \text { PRIDELTA }_{\text {elie, },} \times S S T E P\right) \times T E C H G_{e} \\
& x\left(1 .-E P A C T C_{y-1}\right) \quad \text { otherwise }
\end{aligned}
$$

where,

ECSHELL $L_{y, r} \quad$ is the cooling shell integrity index for existing housing by year and Census Division the lower the value of the index, the greater the shell efficiency), and

EPACTC $_{y}$ is the projected national fractional savings on cooling energy consumption from the EPACT window labeling program in year $y$, from the RMISC file.

The lower limit, LIMIT, the elasticity, SSTEP, and the technology change TECHG, are the same for cooling as for heating.

The new housing heating and cooling shell indices are calculated as,

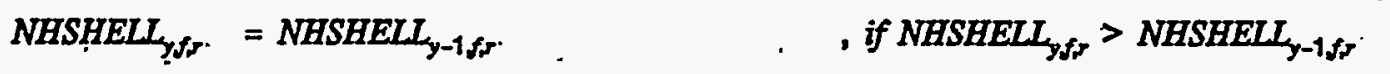

$$
\begin{aligned}
& \text { NHSHELL } L_{y, r}=L I M T \quad \text {, if NHSHELL } L_{y f,}<L I M T \\
& \text { NHSHELL } L_{y f, r}=\text { NHSHELL }_{1983, j ;}-(y-1) \times T E C H G_{2} \\
& +P R I D E L T A_{f, r} \times \text { SSTEP } \quad \text { otherwise } \\
& \text { NCSHELL } L_{y, r}=\text { NCSHELL } L_{y-1, r} \\
& \text { NCSHELL }_{y, r}=\text { LDMT } \\
& \text {, if NCSHELL } y_{, \gamma}>\text { NCSHELL }_{y-1,0} \\
& N_{C S H E L L} L_{y, r}=\text { NCSHELL }_{1993, r}-(y-1) \times T E C H G_{2} \\
& \text {, if NCSHELL } x_{\text {or }}<\text { LMMT } \\
& + \text { PRIDELTA }
\end{aligned}
$$

where,

NHSHELL $L_{y, f, r}$ is the new housing. units shell integrity index for heating by year, fuel and Census Division,

NCSHELL $L_{y, r}$ is the new housing units shell integrity index for cooling by year and Census Division,

Energy Information Adminstration NEMS Residential Demand Module Documentation Report 
$\mathrm{TECHG}_{2}$. is a parameter representing the annual increase in new shell integrity due to technology improvements,

PRIDELTA $t_{t, r} \quad$ is the percent change in price of the fuel by Census Division in 5 percentage point increments, and

SSTEP is set to 0.01 and is a component of the shell elasticity with respect to heating fuel price.

Note here that the EPACT window labeling standards are assumed to apply only to existing homes, not to new ones.

The average post-1993 housing shell indices are calculated as a weighted average across all building types and vintages,

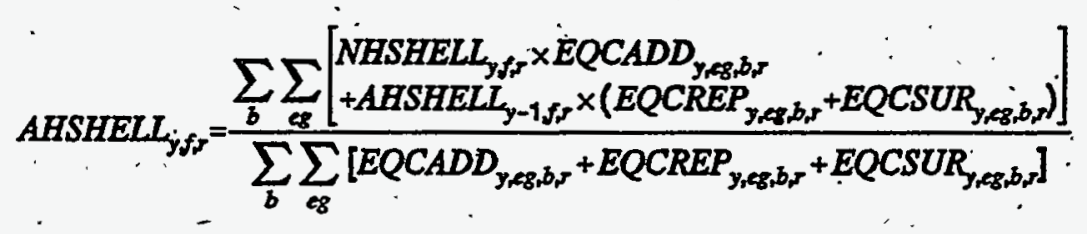

where,

AHSHELL $L_{\text {y,t, }}$ is the average post-1993 heating shell index by year, fuel and Census Division, equal to 1 in 1993 ,

NHSHELL $L_{\text {y,f,r }}$ is the new housing units shell integrity index by year, fuel and Census Division,

$E Q C A D D_{y, e g, b, r}$ is the number of equipment units installed in new construction by forecast year, housing type and Census Division,

EQCREP $_{y, e g, b, r}$ is the number of equipment replacements of post-1993 equipment in post-1993 houses, and

EQCSUR ${ }_{y, e g, b, r}$ is the surviving post-1993 equipment purchased as additions or replacement in post- 1993 houses by forecast year, housing type and Census Division.

In addition to the calculation shown above, the module places the same restrictions 
upon $A H S H E L L_{y, f, r}$ as upon NHSHELL $L_{y, f, r}$ it may never increase, and it must not fall

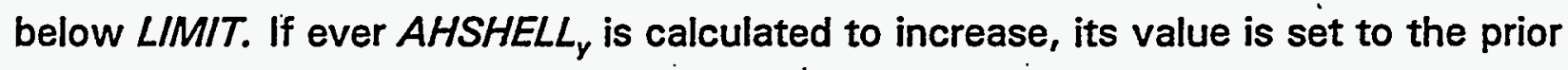
year's value; if it falls below LIMIT, it is set equal to LIMIT.

And for cooling:

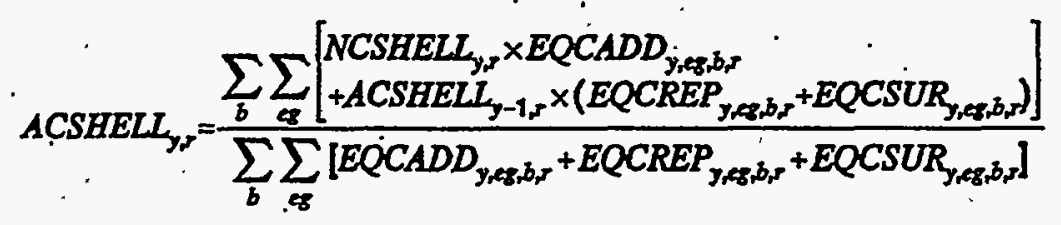

where;

$A C S H E L L_{y, r}$ is the average post-1993 cooling shell index by year and.Census Division, equal to 1 in 1993, and

NCSHELL $L_{y, r}$ is the new housing units cooling shell integrity index by year and Census Division.

As above, the restrictions upon ACSHELL $L_{y, f, r}$ apply to LIMIT and rate of increase.

Unit energy consumption is next calculated for each of the vintages of homes. For surviving equipment in pre-1994 vintage homes,

$$
E Q C S U E C_{y, g, b, r}=E Q C U E C_{r, e g, b} \times H_{i} D D A C T_{r} \times \frac{R T B A S E F F_{1993, e g}}{R T B A S E F F_{y, e g}}
$$

where,

EQCSUEC ${ }_{y, e g, b, r .}$ is the unit energy efficiency of surviving equipment in pre-1994 vintage homes, by year, equipment class, housing type and Census Division,

$E Q C U E C_{r, e g, b}$ is the unit energy efficiency of equipment in homes that existed in 1993 , by Census Division, equipment class, and housing type, $H D D F A C T_{\text {r }}$, are the regional heading degree-day adjustment factors, and RTBASEFF $_{y, e g}$, are the annual average efficiencies for the equipment classes. 
For new equipment:

$$
\begin{aligned}
& E Q C N U E \bar{E} \dot{C}_{y, g, b, r}=E Q C U E C_{r, e g, b} \times H D D F A C T_{r} \times S Q F T A D J_{y, b, r} \\
& \times \text { WTEQCEFFN }_{\mathrm{y}, \mathrm{eg}, b, r} \times \text { RTBASEFF }_{1893, \mathrm{seg}} \text {, if WTEQCEFFN } \mathrm{y}_{\mathrm{y}, \mathrm{eg}, b,>}>0 \\
& \text { EQCNUEC }_{y_{1, e g, b, r}}=E Q C U E C_{r, e g, b} \times H D D F A C T_{r} \times S Q F T A D J_{y, b, r} \text {, otherwise }
\end{aligned}
$$

where,

$E Q C N U E C_{y, e g ; b, r} \quad$ is the unit energy consumption by year for new equipment for new houses by housing type and Census Division,

WTEQCEFFN $N_{y, e g, b, r}$ is the equipment weighted average inverse efficiency by year, equipment class, housing type and Census Division,

RTBASEFF: is the average efficiency of the equipment class,

$E Q C U E C_{r, \theta g, b} \quad$ is unit energy consumption for equipment in 1993 housing by Census Division, equipment class and housing type,

$H_{D D F A C T_{r}}^{\prime} \quad \cdot \quad$ is the heating degree day adjustment factor by Census Division to correct for the unusually warm weather during the RECS survey year, and

SOFTADJ $J_{y, b, r} \quad$ adjusts for the increasing average floor area of new homes, as compared with the RECS base year.

Replacement equipment UEC values are calculated as:

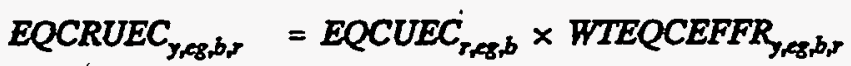

$$
\begin{aligned}
& \times \text { RTBASEFF }_{1983, e g} \times H D D F A C T_{r} \text {, if WTEQCEFFR } R_{\text {y,eg, }, b r}>0 \\
& E Q C R U E C_{\text {y,eg,b,r }}=E Q C U E C_{\text {rag, }, b} \times H D D F A C T_{r} \quad \text {, otherwise }
\end{aligned}
$$

where,

$E Q C R U E C_{y, e g, b, r}$ is the unit energy consumption for replacement equipment by housing type and Census Division,

RTBASEFF $_{1993, \mathrm{eg}}$ is the efficiency of the weighted average of retiring units from the 1993 existing stock, and 


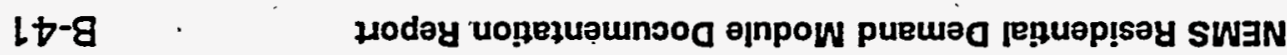

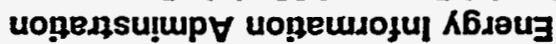

'se uo!?dunsuos quanbasqns pue

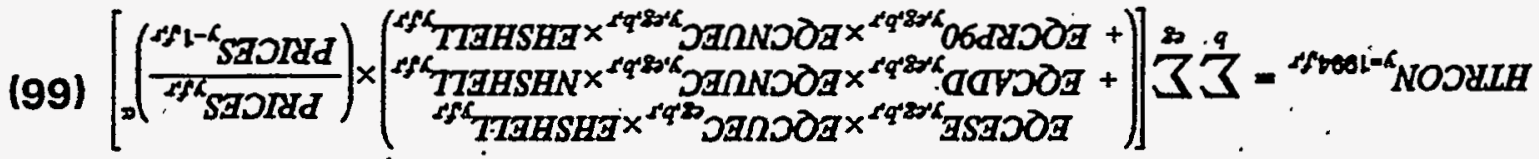

'se

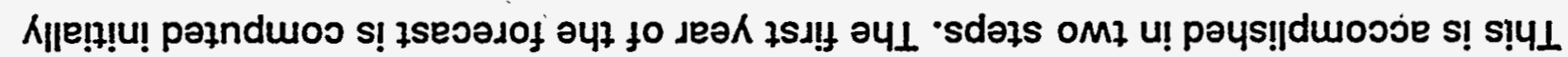
- N1Obəłeo ә0!̣

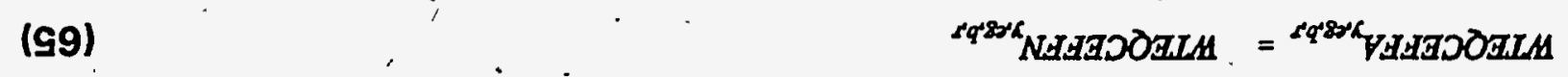

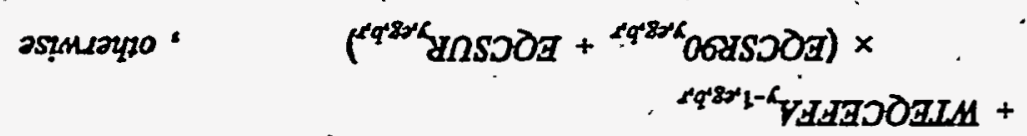

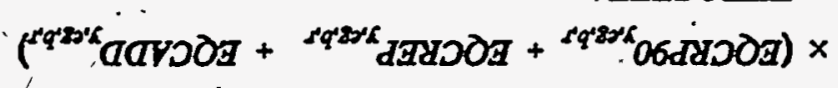

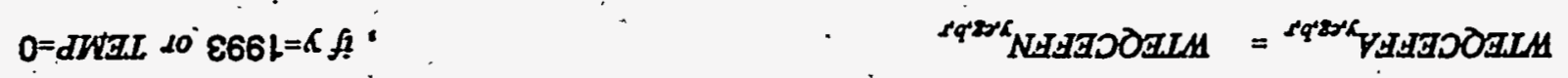

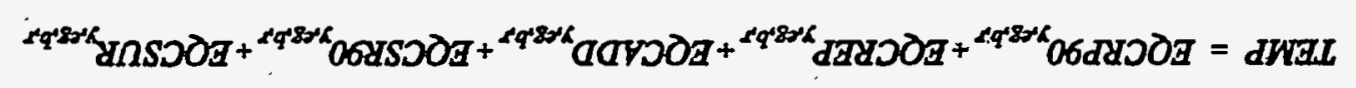

: נeaג 7se|

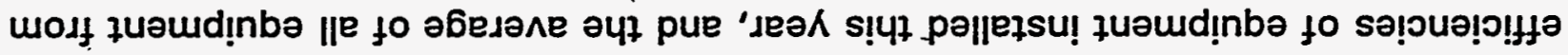

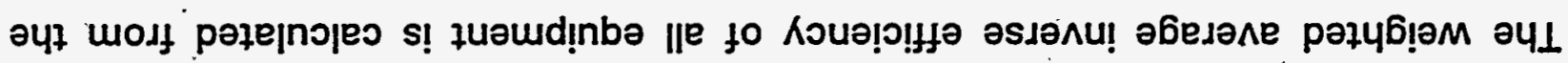

(ع9)

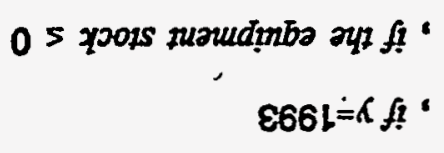

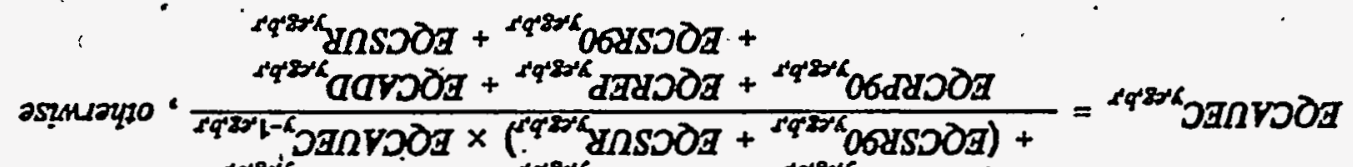

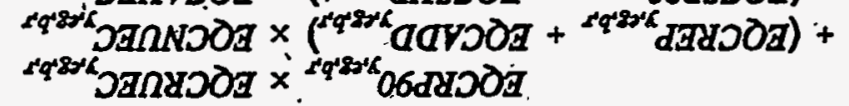

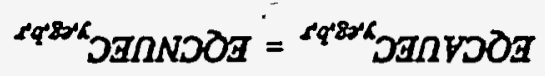

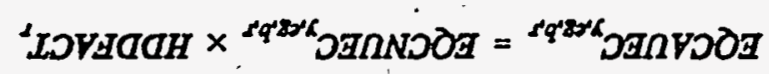

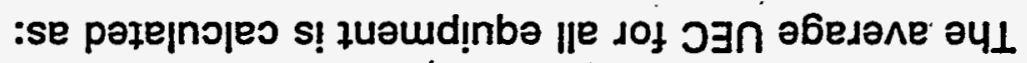

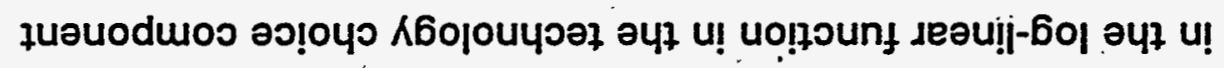

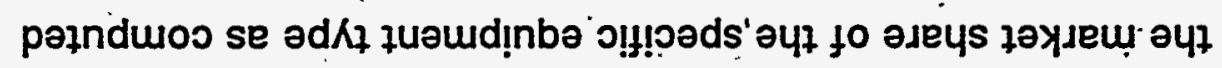

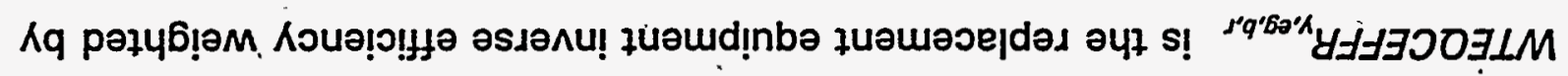


‘uọ̣อd पореә

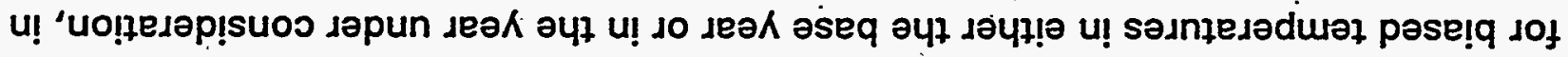

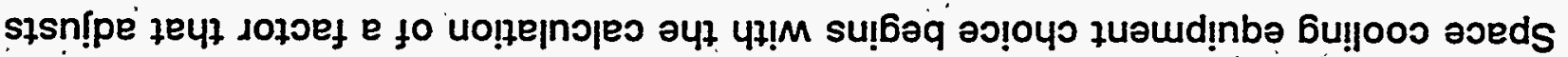

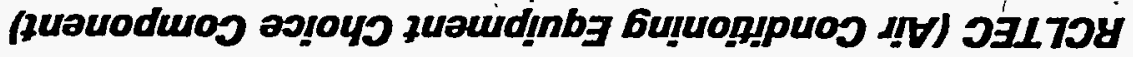

\section{6ulpoos əoeds}

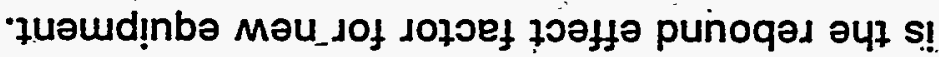

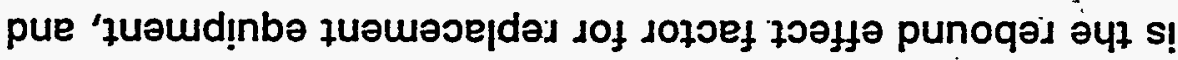

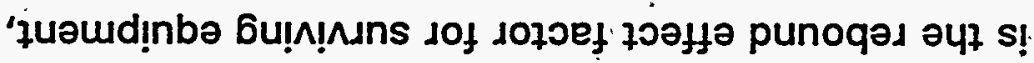

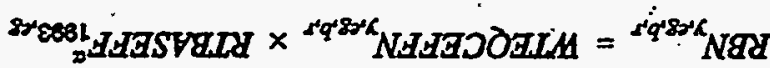

$$
\begin{aligned}
& \text { 'scess }
\end{aligned}
$$

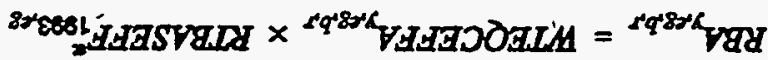

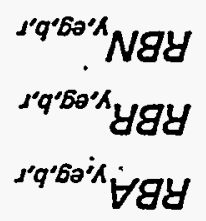

'วงอบМ.

$(0 \angle)$

(69)

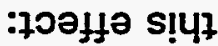

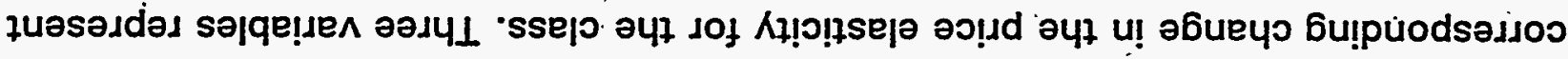

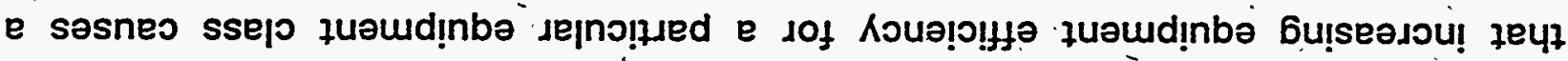

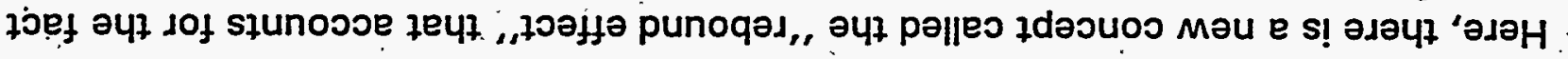

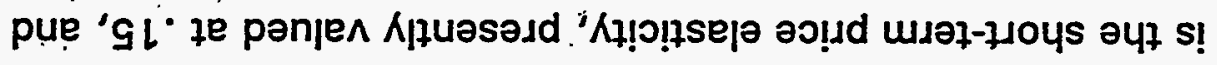

\section{(८9)}

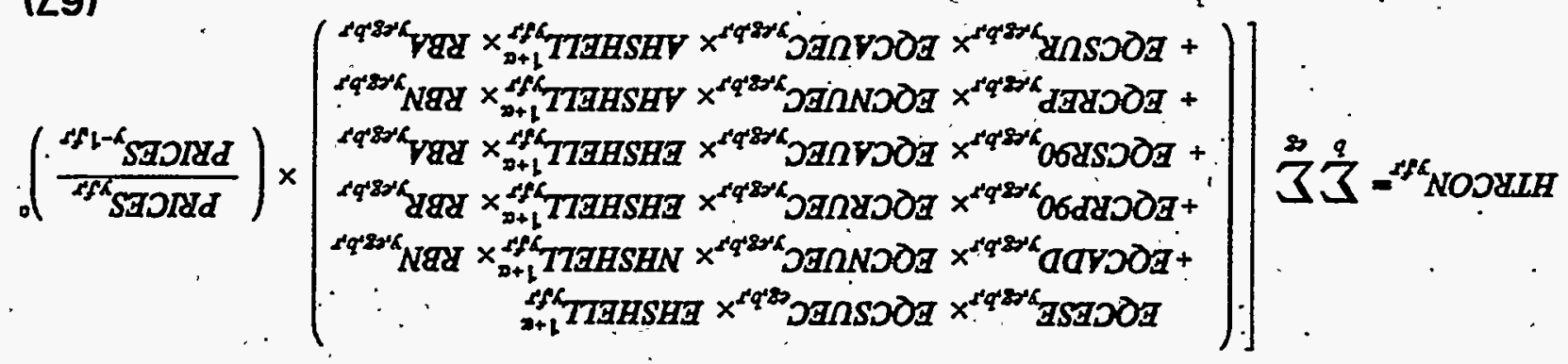




$$
C D D F A C T_{r}=\frac{C D D A D J_{y r}}{C D D A D J_{1823, r}}
$$

where,

CDDFACT, is a set of regional factors to be used in this year to adjust for abnormal temperatures either in this year or in the base year, and $C D D A D J_{y, r} \quad$ are regional population-adjusted cooling degree-days by Census division and historical year, with forecast years filled in with the latest historical year, from the RMISC file.

Operating costs for cooling equipment are calculated like those for heating equipment, with the exception of the degree-days factor:

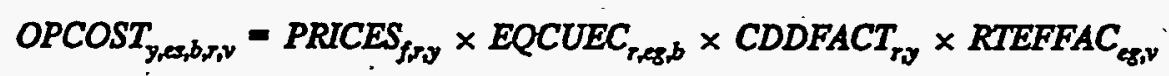

where,

$O P C O S T_{y, e s, b, r, v}$ is the operating cost for the air conditioner equipment type by housing type, Census Division, and vintage in the forecast year,

PRICES f,r,y $\quad$ are the fuel prices by region and forecast year; from elsewhere in the NEMS system,

$E_{\text {ECUEC }}$. is the electricity unit energy consumption of 1993 room air conditioning equipment by Census Division and housing type, and

$R T F F A C_{e g, v}$ - is the efficiency adjustment for the generic equipment type.

The following variables are computed as in the equations indicated:

$L F C Y_{y, e s, b, r, v}$ is the room air conditioner type's life cycle cost by year, housing type and Census Division. It is computed as in (20) above.

EQWTN $N_{y, e s, b, r}$ is the equipment weight for new equipment types by housing type, Census Division and year. It is computed as in (24) above.

$E Q W T R_{y, e s, b, r}$ is the equipment weight for replacement equipment types by . housing type, Census. Division and year. It is computed as in (25) above.

Energy Information Adminstration 
TOTEWTN $N_{y, e g, b, r}$ is the sum of equipment types' weights for the new equipment class. It is computed as in (26) above.

TOTEWTR $_{y, e g, b, r}$ is the sum of equipment types' weights for the new equipment class. It is computed as in (27) above.

Market shares for equipment types within the cooling equipment classes distinguish also between heat pumps, whose numbers have been determined in the heating choice component, and other cooling equipment. For heat pumps,

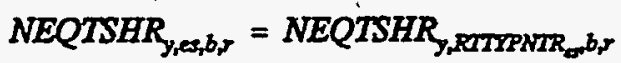

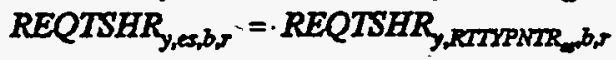

and for other cooling equipment,

$$
\begin{aligned}
& N E Q T S H R_{\text {yess,br }}=\frac{E Q W T N_{\text {yes } b, r}}{T O T E W T N_{\text {y,eg, }, r, r}}
\end{aligned}
$$

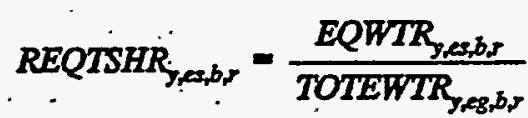

where,

NEQTSHR $R_{y, e s, b, r}$ is the new market share for the new air conditioner equipment type by year, housing type and Census Division,

REQTSHR $R_{y, e s, b, r}$ is the new market share for the replacement air conditioner equipment type by year, housing type and Census Division,

TOTEWTN $N_{y, e g, b, r}$ is the sum of equipment type weights for the new equipment class,

TOTEWTR $R_{y, e g, b, r .}$ is the sum of equipment type weights for the replacement equipment class,

$E Q W T N_{y, e s, b, r}$ is the equipment weight for new equipment, and $E Q W T R_{y, e s, b, r}$ is the equipment' weight for replacement equipment.

Weighted average inverse efficiencies of the types of cooling equipment into their classes are calculated exactly as in the heating component: 
WTEQCEFFN $N_{y, e g, b, r}$ is the weighted average inverse efficiency of new equipment types within each equipment class by year, housing type, and Census Division, computed as in (32).

WTEOCEFFR $_{y, e g, b, r}$ is the weighted average inverse efficiency of replacement equipment types within each equipment class by year, housing type, and Census Division, computed as in (33).

\section{RCLADD (Additions and Replacements of Cooling Equipment Component)}

Given the complex dependencies between choices of heating and cooling equipment, the cooling additions logic begins very differently from that for heating. Central air conditioner additions are calculated from housing additions and a set of saturation levels:

$$
E Q C A D D_{y, C A C, b, r}=H S E A D D_{y, b, r} \times C A C S A T_{b, r}
$$

where,

$E Q C A D D_{y, C A C, b, r}$ is the number of central air conditioners added to new (post-1993) housing units by year, housing type and Census Division,

$H S E A D D_{y, b, r}$ is the amount of housing additions by year, housing type and Census Division, and

$\operatorname{CACSAT}_{b_{r},}$ is the market penetration level or saturation of the market for central air conditioning equipment by housing type and Census Division, from the RMISC file.

For room air conditioners, there are similar saturation levels:

$$
\dot{E} Q C A D D_{y, R A C, b, r}=H S E A D D_{y, b, r} \times R A C S A T_{b, r}
$$

where,

$E Q C A D D_{y, R A C, b, r}$ is the number of room air conditioners added to new (post-1993) housing units by year, housing type and Census Division,

$H S E A D D_{y, b, r}$ is the amount of housing additions by year, housing type and 
Census Division, and

$R A C S A T_{b, r}$, is the market penetration level or saturation of the market for room air conditioning equipment by housing type and Census Division.

For heat pumps, however, additions are determined by the number of associated furnaces installed in the heating additions component:

$$
E Q C A D D_{y, e z, b, r}=E Q C A D D_{y, R T C L P N I R_{i}, b, r}
$$

where,

$E Q C A D D_{y, H P, b, r}$ is the number of heat pumps used for space cooling added to new (post-1993) housing units by year, housing type and Census Division,

$E Q C A D D_{y, H P, b, r}$ is the number of heat pumps used for space heating added to new housing units by year, housing type and Census Division, and

$R_{\text {RCLPNT }}$ is the pointer to the heating equipment class associated with the cooling equipment class.

The number of central air conditioners calculated from the saturation level in equation (76) included electric heat pumps. To convert that to non-heat pump central air conditioners, the component subtracts off electric heat pumps, but leaving ten percent, if heat pumps exceed total central air conditioners:

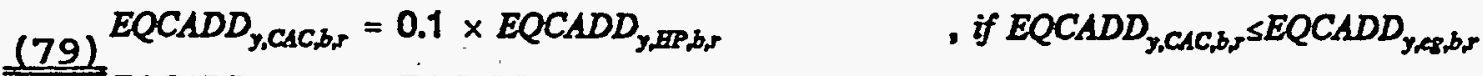

$$
\begin{aligned}
& E Q C A D D_{y, C A C, b, r}=E Q C A D D_{y, C A C, b, r}-E Q C A D D_{y, B P, b, r} \text {, otherwise }
\end{aligned}
$$

where,

$E Q C A D D_{y, e g, b, r}$ is the number of central air conditioners in each equipment class added to new (post-1993) housing units by year, housing type and Census Division,

eg , is the space cooling equipment class where the RTEKCL file defines that $1=\mathrm{RAC} ; 2=\mathrm{CAC}, 3=$ Electric heat pump, 
$4=$ Geothermal heat pump, and $5=$ Natural gas heat pump.

Surviving equipment follows the same dichotomy as the other calculations, between heat pumps and other equipment. For non heat pumps:

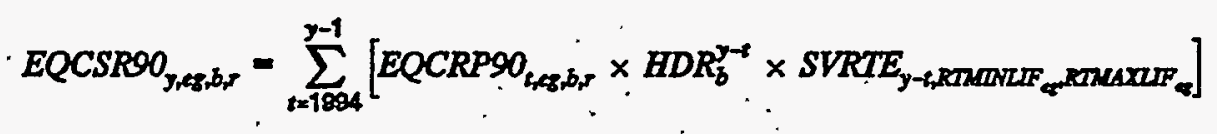

For heat pumps:

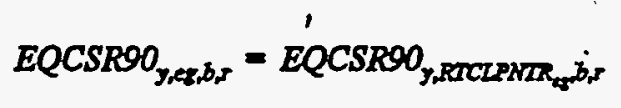

where,

EOCSR9O $_{y, e g, b, r}$ is the surviving post-1993 cooling equipment in pre-1994 housing units by year, housing type and Census Division,

$E{ }^{2}$ is the number of replacement (post-1993 vintage) equipment required for pre-1994 housing units by year, housing type and Census Division,

$H D R_{b} \quad$ is the housing demolition rate by housing type, and

SVRTE is the equipment survival rate,

RTMINLIF $_{\text {eg }}$ is the equipment class minimum lifetime from the RTEKCL file, and

RTMAXLIF $_{e g} \quad$ is the equipment class maximum lifetime from the RTEKCL file.

The cooling equipment needed in pre-1994 housing is

$$
E Q C N D 90_{y, e s, b_{r}, r}=E Q C N D 90_{y-1, \ldots g, b, r} \times H D R_{b} \text {, if } y>1993
$$

where,

EQCND90 ${ }_{y, g g, b, r}$ is the number of air conditioning units needed in pre-1994 housing each year by housing type and Census Division,

EOCESE $_{1993, \text { eg,ber }}$ is the pre-1994 air conditioning equipment in pre-1994 housing units in the base year by housing type and Census Division, and

Energy Information Adminstration 
For centrally air-conditioned single-family houses, there is a penetration rate that describes new units added in pre-1994 houses:

$$
E Q C N D 90_{\text {y,eg,b,r }}=E Q C N D 90_{\text {y,es,b,r }} \times C A C P R \text {. }
$$

where,

$C_{C A C P R_{r}}$ are regional penetration rates for central air conditioners from the RMISC file.

Current year replacement equipment in old housing also involves consideration of heat pumps' association with heaters. For non heat pumps,

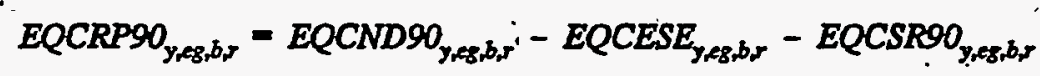

and for heat pumps,

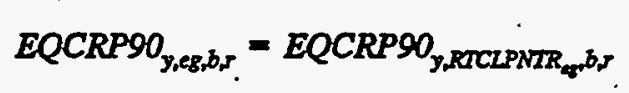

where,

EQCSR90 ${ }_{y, e g, b, r}$ is the surviving post-1993 central and room air conditioning equipment in pre-1994 housing units by year, housing type and Census Division,

EQCRP9O $_{y, e g, b, r}$ is the number of replacement (post-1993 vintage) equipment demanded in pre-1994 housing units by year, housing type and Census Division,

EQCESE $E_{y, e s, b, r}$ is the amount of surviving pre-1994 vintage space cooling equipment in pre-1994 vintage housed by housing type and Census Division,

EQCND90 ${ }_{y, e g, b, r}$ is the total amount of surviving pre-1994 room and central air conditioning equipment in pre-1994 housing each year by housing type and Census Division,

EQCRP9O ${ }_{y, g g, b, r}$ is the number of heat pump replacements for space heating in pre- 
1994 housing units by year, housing type and Census Division, . and

RTCLPNTR $_{\text {eg }}$ is the pointer to the heating equipment class associated with the cooling equipment class.

Surviving equipment in new houses requires the distinction for heat pumps. For non heat pumps,

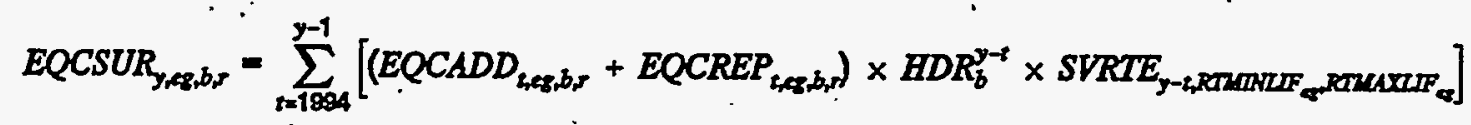

and for heat pumps,

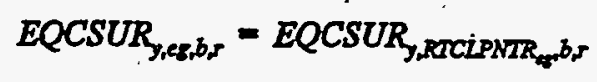

where,

EQCSUR $_{\text {y,eg,b,r }}$ is the number of surviving room and central air conditioners in post-1993 housing units by year, housing type and Census Division,

$E Q C A D D_{t, e g, b, r}$ is the number of units of space cooling equipment in each class added to new (post-1993) housing units by year, housing type and Census Division,

EQCREP $_{t, e g, b, r}$ is the number of equipment replacements demanded in post-1993 housing units by year, housing type and Census Division,

$H D R_{b} \quad$ is the housing demolition rate by housing type, and

SVRTE is the equipment survival rate,

RTMINLIF $_{\text {eg }}$ is the equipment class minimum lifetime from the RTEKCL file, RTMAXLIF $_{\text {eg }}$ is the equipment class maximum lifetime from the RTEKCL file, and

RTCLPNTR $_{\text {eg }}$ is the pointer to the heating equipment class associated with the cooling equipment class.

Finally, demand for replacement cooling equipment in new homes for non heat pumps 


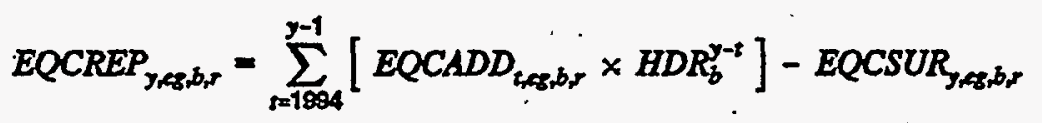

for heat pumps:

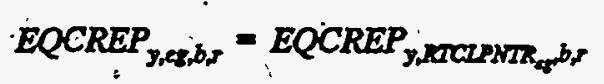

where,

$E Q C R E P_{y, g g, b, r}$ is the number of equipment replacements demanded in post-19.93 housing units by year, housing type and Census Division,

EQCSUR $R_{y, e g, b, r}$ is the number of surviving room and central air conditioners in post-1993 housing units by year, housing type and Census Division,

$E Q C A D D_{y, e g, b, r}$ is the number new central air conditioners originally purchased for new housing additions by year, housing type and Census Division, $H D R_{b}$. is the housing demolition rate by housing type, and

RTCLPNTR $_{\text {eg }}$ is the pointer to the heating equipment class associated with the cooling equipment class.

Since replacements for heat pump air conditioners equal replacements for heat pump furnaces, and switching was allowed on replacement of heat pump furnaces, switching on replacement of heat pump air conditioners occurred in RHTRADD. No switching on replacement of central or room air conditioners is allowed since these numbers are based on historical data. Therefore, Subroutine RCLADD does not call Subroutine REPLACE.

\section{RCLCON (Cooling Energy Consumption Component)}

Energy consumption for space cooling is calculated much like the comparable quantities for space heating. Space cooling equipment consumption begins with the calculation of a factor that adjusts for biased temperatures in either the base year or in the year under consideration, in each region, 


$$
C D D F A C T_{r}=\frac{C D D A D J_{y, r}}{C D D A D J_{1823, r}}
$$

where,

CDDFACT, is a set of regional factors to be used in this year to adjust for abnormal temperatures either in this year or in the base year, and $C D D A D J_{y, r} \quad$ are regional population-adjusted cooling degree-days by Census division and historical year, with forecast years filled in with the latest historical year, from the RMISC file.

It then calculates the average efficiency of all 1993 cooling equipment,

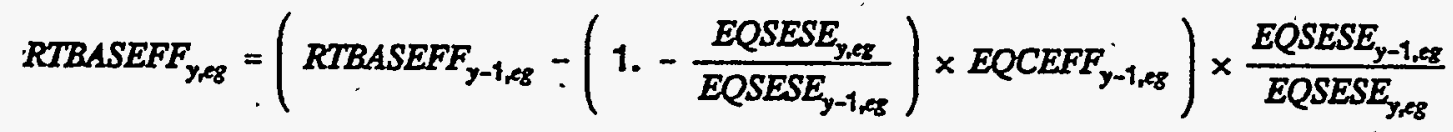

where,

RTBASEFF ${ }_{\text {eg,y }}$. is the stock average efficiency for the remaining 1993 equipment, EQSESE $_{y, e g}$ is the remaining unretired stock of 1.993 cooling equipment, by year and equipment class, and

EQCEFF $_{\text {y,eg }}$ is the average efficiency of equipment retired in each year, from the RSEFF01 file.

Unit energy consumption. is next calculated for each of the vintages of homes. For surviving equipment in pre-1994 vintage homes,

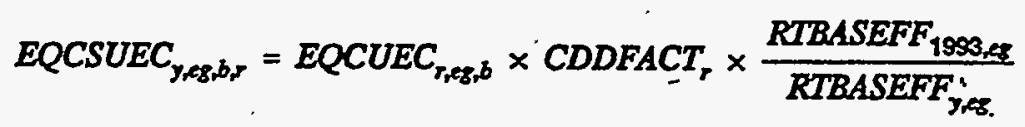

where,

EQCSUEC ${ }_{y, e g, b, r}$ is the unit energy efficiency of surviving equipment in pre-1994 vintage homes; by year, equipment class, housing type and Census Division,

$E Q C U E C_{r, e g, b}$ is the unit energy efficiency of equipment in homes that existed in 1993, by Census Division, equipment class, and housing type, 
CDDFACT,

RTBASEFF $F_{\text {, gg }}$ are the regional heading degree-day adjustment factors, and are the annual average efficiencies for the equipment classes.

For new equipment:

$$
\begin{aligned}
& E Q C N U E C_{y_{\text {,eg, }}, b_{r}}=E Q C U E C_{r, e, b} \times C D D F A C T_{r} \times S Q F T A D J_{y, b r}
\end{aligned}
$$

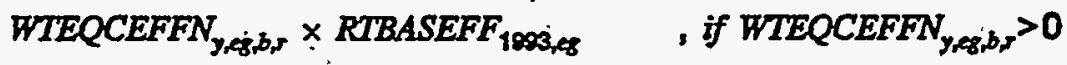

$$
\begin{aligned}
& E Q C N U E C_{y, e g, b, r}=E Q C U E C_{r, g, b} \times C D D F A C T_{r} \times S Q F T A D J_{y, b, r} \text {, otherwise }
\end{aligned}
$$

where,

$$
\begin{aligned}
& E Q C N U E C_{y, e g, b, r} \text { is the unit energy consumption by year for new equipment by } \\
& \text { housing type and Census Division, } \\
& \text { WTEOCEFFN } N_{y, e g, b, r} \text { is the equipment inverse efficiency by year, equipment class, } \\
& \text { housing type and Census Division, } \\
& \text { RTBASEFF }_{y, e g} \text { is the average efficiency of the equipment class, } \\
& \text { EQCUEC } C_{r, e g, b} \\
& \text { is unit energy consumption for equipment in } 1993 \text { housing by } \\
& \text { Census Division, equipment class and housing type, } \\
& \text { CDDFAĆ } \\
& \text { is the heating degree day adjustment factor by Census Division } \\
& \text { to correct for the unusually warm weather during the RECS } \\
& \text { survey year, and }
\end{aligned}
$$

Replacement equipment UEC values are calculated in the same way as new equipment, but without the floor area adjustment:

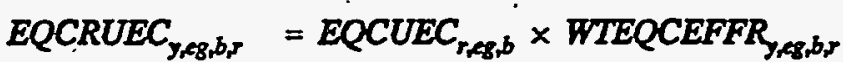

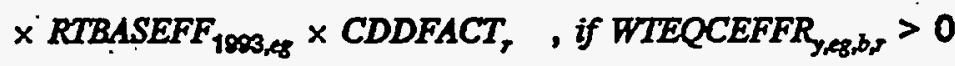

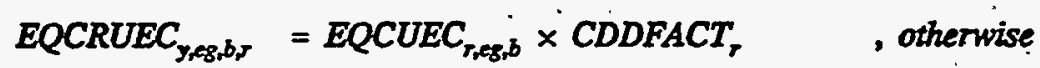

where, 
$E Q C R U E C_{y, g g, b, r}$ is the unit energy consumption for replacement equipment by housing type and Census Division,

RTBASEFF $_{1993, e g}$ is the efficiency of the weighted average of retiring units from the 1993. existing stock, and

WTEOCEFFR $_{y, e g, b, r}$ is the replacement equipment inverse efficiency weighted by the market share of the equipment type as computed in the log-linear function in the technology choice component by housing type and Census Division.

The average UEC for all equipment is calculated as:

$$
\begin{aligned}
& E Q C A U E C_{y, c 8, b s}=E Q C N U E C_{y, e z, b r} \quad \text {, . if } y=1993 \\
& E Q C A U E C_{y, f, b, b r}=E Q C N U E C_{y, g_{b}, b r} \quad \text {, if the equipment stock } \leq 0 \\
& +\left(E Q C R E P_{y, e z, b, r}+E Q C A D P D_{y, c z, b, r}\right) \times E Q C N U E C_{y, e g, b, 5}
\end{aligned}
$$

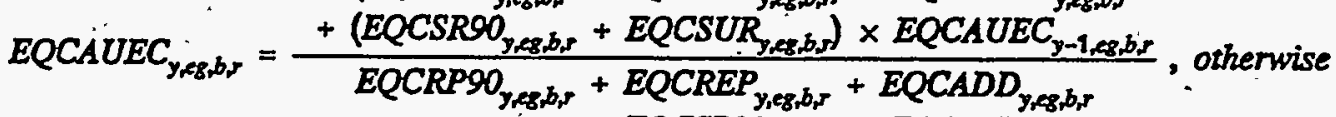

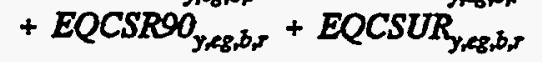

The weighted average inverse efficiency of all equipment is calculated from the efficiencies of equipment installed this year, and the average of all equipment from last year:

$$
\begin{aligned}
& \dot{T E M P}=E Q C R P 90_{y, e s, b, r}+E Q C R E P_{y, e s, b, r}+E Q C A D D_{y, e 8, b, r}+E Q C S R 90_{y, e g, b, r}+E Q C S U R_{y, e s, b, r}
\end{aligned}
$$

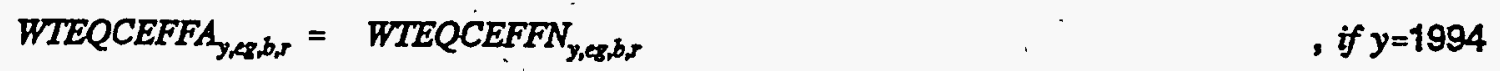

$$
\begin{aligned}
& \text { or TEMP }=0 \\
& \text { WTEQCEFFN } N_{\text {y,eg, },, 5} \times
\end{aligned}
$$

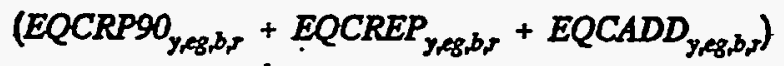

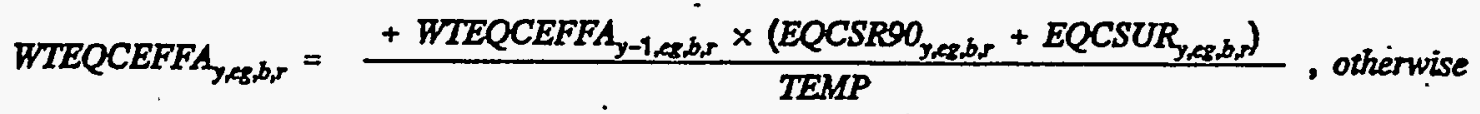

The final step of this component is to calculate consumption for the service category. This is accomplished in two steps. The first year of the forecast is computed as, 


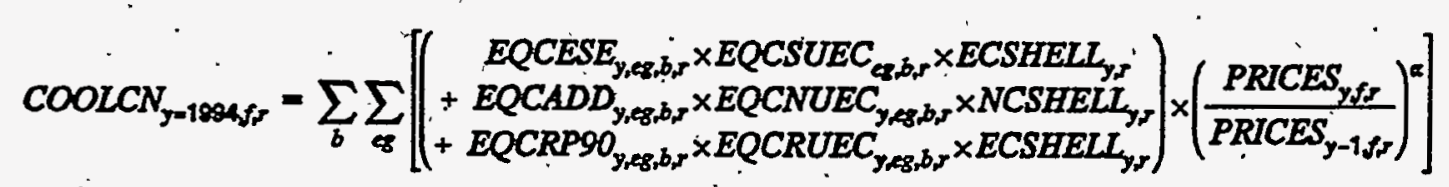

and subsequent consumption as,

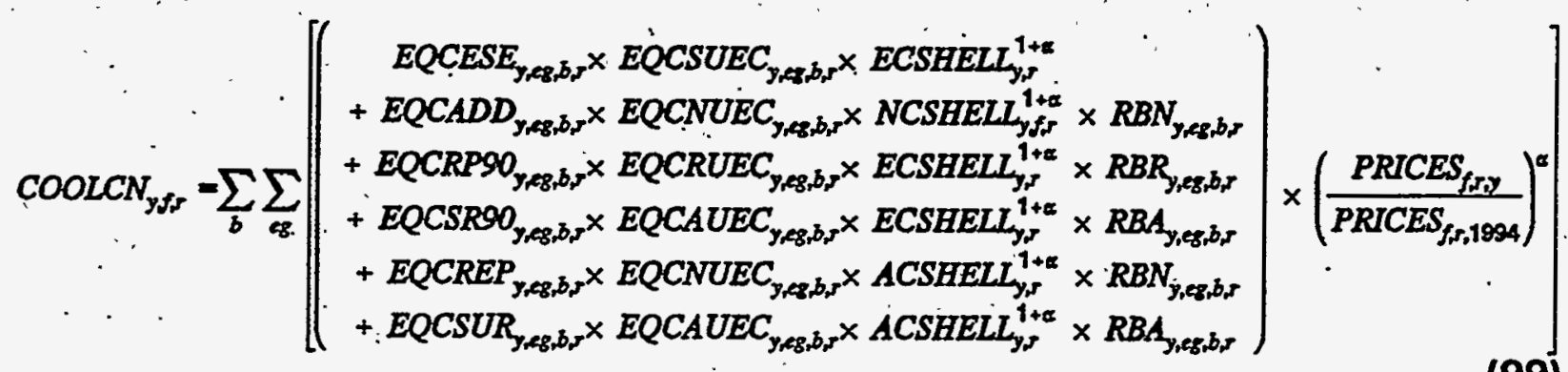

where,

a is the short-term price elasticity, presently valued at .15 .

Here, there is a new concept called the "rebound effect" that accounts for the fact that increasing equipment efficiency. for a particular equipment class causes a corresponding change in the price elasticity for the class. Three variables, calculated as the ratio between the base efficiency and the current efficiency, represent this effect:

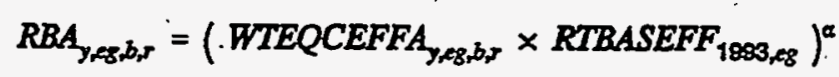

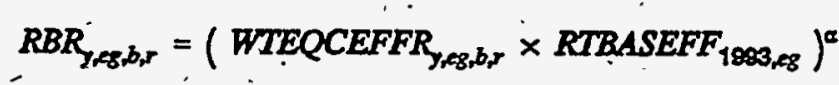

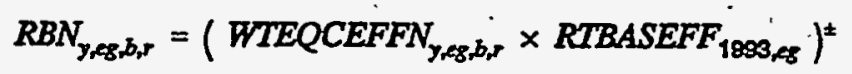

where,

$R B A_{y, e g, b, r}$ is the rebound effect factor for surviving equipment,

$R B R_{y, e g, b, r}$ is the rebound effect factor for replacement equipment, and $R B N_{y, e g, b, r}$ is the rebound effect factor for new equipment.

\section{Water Heating}


Regional solar water heating equipment stock is calculated for 1.993 as

$$
S L E S E_{1093, r}=\sum_{b} E H_{1923, b, r} \times \dot{S L S H R_{b, r}}
$$

where,

SLESE $_{1993, \text { ir }}$ is the existing 1993 solar water heaters by Census Division,

$S L S H R_{b, r} \quad$ is the 1993 market share of solar water heaters in pre-1994 housing units by housing type and Census Division, from the RMISC file, and

$E H_{1993, b, r} \quad$ is the 1993 stock of housing by housing type and Census Division.

For years after 1993, the model projects șolar heaters separately from other water heating equipment. For solar heaters,

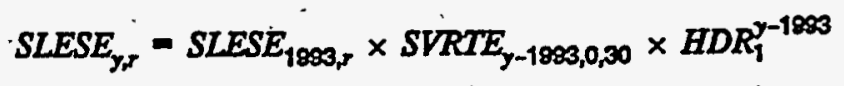

where,

SLESE ${ }_{y, r} \quad$ is the number of surviving pre-1994 vintage solar water heaters in pre-1994 single-family houses:by year and Census Division,

SVRTE $_{y-1993,0,30}$ is the equipment survival rate, using minimum and maximum lifetimes not established in the input database, and

$H D R_{1}$ is the housing demolition rate for single-family homes.

\section{RWHTEC (Water Heater Equipment Choice Component)}

Existing water heaters are assumed to be distributed in proportion to associated space heating equipment, where the association between water heating equipment and space heating equipment is specified by the user in the RTCLPNTR ${ }_{\text {eg }}$ pointer for each water heating equipment class in the RTEKCL file. (Replacement water heaters are not so constrained in single-family housing.) The component first adds up the market shares of all space heating equipment, 


$$
\operatorname{TOTN}_{b, r}=\sum_{c 8} H S Y S S H R_{\text {y,eg,br, }}
$$

where,

$$
\begin{aligned}
& \text { TOTN }_{b, r} \text { is the sum of the base year market shares for space heating } \\
& \text { equipment classes by housing type and Census Division, and } \\
& \text { HSYSSHR } R_{y, g, b, r} \text { is the current year market share for space heating equipment } \\
& \text { classes by housing type and Census Division. }
\end{aligned}
$$

New water heater market șares are therefore calculated by the sum of the market shares of the associated heating equipment,

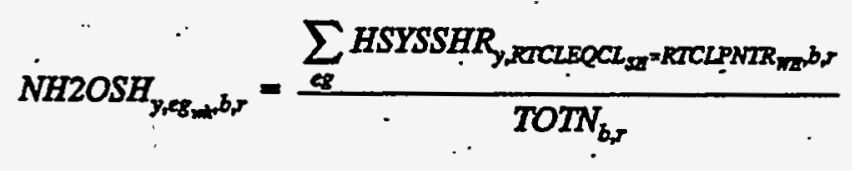

where,

$\mathrm{NH}^{2} \mathrm{OSH}_{\mathrm{y}, e g, b, r}$ is the market share of each new water heater class by housing type and Census Division. There are four equipment classes for water heaters: natural gas, electric, distillate, and LPG.

TOTN $_{b, r} \quad$ is the sum of the base year market shares for space heating equipment classes by housing type and Census Division,

HSYSSHR $_{\mathrm{y}, e g, b, r}$ is the current year market share of the space heating equipment class by housing type and Census Division,

$R T C L E Q C L_{S H}$ is the equipment class number for the space heater class, and - RTCLPNTR $_{\text {wh }}$ is the pointer to a space heater class from a water heater class.

The following variables are computed as in the equations indicated:

$O P C O S T_{y, e s, b, r, y}$ is the operating cost for the water heater equipment type by housing type, Census Division, vintage, and year: It is computed as in (19) above. 
$\angle F C Y_{y, e s, b, r, v}$. is the water heater type's life cycle cost by year, housing type Census Division, and vintage. It is computed as in (20) above.

EOWTN $N_{\text {yes,b,r }}$ is the equipment weight for new equipment types by housing type, Census Division, and year. It is computed as in (24) above.

$E Q W T R_{y, o s, b, r}$ is the equipment weight for replacement equipment types by housing type, Census Division, and year. It is computed as in (25) above.

TOTEWTN $N_{y, e g, b, r}$ is the sum of the equipment types' weights. for the new equipment class. It is computed as in (26) above.

TOTEWTR $_{y, e g, b, r}$ is the sum of the equipment types' weights for the new equipment class. It is computed as in (27) above.

EQFSHRN $N_{y, f, b, r}$ is the fuel share of new equipment type by year, housing type and Census Division. It is computed as in (30) above.

EQFSHRR $_{\text {y,f,b,r }}$ is the fuel share of replacement equipment type by year, housing type and Census Division. It is computed as in (31) above.

The fuel shares are stored into their final places:

$$
\begin{aligned}
& N E Q T \dot{S} H R_{, f, b, r}=E Q F S H R N_{y, e s, b, r}
\end{aligned}
$$

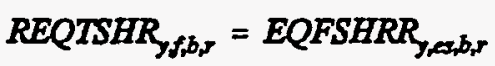

where,

$N E Q T S H R_{y, f, b, r}$ is the fuel shares of new water heaters by fuel, housing type and Census Division, and

REQTSHR $_{\mathrm{j}, t, b, r}$ is the fuel shares of replacement water heaters by fuel, housing type and Census Division.

Weighted average class efficiencies by fuel can then be calculated from the individual equipment types for new and replacement equipment, using exactly the same formulas as for space heating equipment, as shown in equations (32) and (33): 
WTEOCEFFN $_{y, e g, b, r}$ is the weighted average inverse efficiency for new water heating equipment classes by year, housing type and Census Division, and

WTEQCEFFR ${ }_{y, e g, b, r}$ is the weighted average inverse efficiency for replacement water heating equipment classes by year, housing type and Census Division.

\section{REUADD (Water Heating and Cooking Additions and Replacements Component)}

There is only one component in the RDM for addition and replacement of water, heating equipment and cooking equipment. This is an enhancement implemented in the module in 1996 that anticipates the day when integrated logic can handle all calculations for all equipment.types.

The first operation is to calculate the total equipment in pre-1994 housing,

$$
\begin{aligned}
& E Q C N D 90_{y_{1, q}, b_{r} r}=E Q C E S E_{1293, g_{3}, b_{r} r} \times H D R_{b} \text {, if } y=1990
\end{aligned}
$$

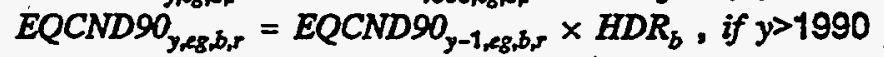

where,

EQCND9O $0_{y, e g, b, r}$ is the total equipment in pre-1994 housing each year by housing type and Census Division,

EOCESE $_{1993, e g, b, r}$ is the pre-1994 equipment stock in pre-1994 housing units in the base year by housing type and Census Division, and

$H D R_{b} \quad$. is the housing demolition rate by housing type.

Next, calculate purchases for new housing,

$$
E Q C A D D_{y, e q, b, r}=H S E A D D_{y, b, r} \times S H A R E
$$

where,

$E Q C A D D_{y, e g, b, r}$ is the number new units originally purchased for new housing additions by year, housing type and Census Division,

$H S E A D D_{y, b, r} \quad$ is the number of housing additions by year, housing type and 
Census Division, and

SHARE is the share of the particular equipment for which the component

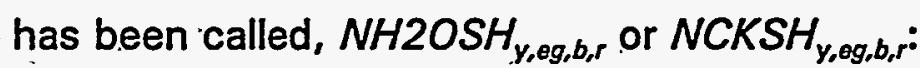

$\mathrm{NH}^{2} \mathrm{SSH}_{\mathrm{y}, e g, b, r}$ is the market penetration level or saturation of the market for water heaters by housing type and Census Division,

$\mathrm{NCKSH}_{y, e g, b, r}$ is the market penetration level or saturation of the market for cookstoves by housing type and Census Division.

The following variables are computed as in the equations indicated:

EQCSR90 $0_{y, e g, b, r}$ is the surviving post-1993 vintage equipment in pre-1994 housing units by year, housing type and Census Division. It is calculated as in (37) above.

EQCSUR $_{\text {y,eg,b,r }}$ is the surviving post-1993 vintage equipment in post-1993 housing by year, housing type and Census Division. It is computed as in (38) above.

EQCREP $_{y, e g, b, r}$ is the number of equipment replacements of post- 1993 equipmient in multi-family or mobile post-1993 housing units by year, housing type and Census Division. It is computed as in (39) above. (No switching allowed.)

The new technology choice component allows switching when replacing water heaters or stoves in post-1993 (and pre-1994) single family homes only. Users may specify the fraction of homes which may switch away from a certain technology by setting the values RTSWFACT eg in the RTEKCL data file. Retiring values are first calculated as in (39) and stored as OEQCREP ${ }_{y, 6 g, 1, r}$. The code then calls SUBROUTINE REPLACE(EU,RSYR,R,B,RECCL,1) for replacements with switching in post-1993 single-family housing where,

EU is the end use number ( 3 for water heating; 4 for stoves), 
RSYR is the calendar year,

$R$. is the census division,

$B \quad$ is the building type (currently always 1 for single-family),

RECCL is the record number from the RTEKCL file,

FLAG is set $=1$ for post -1993 housing.

Replacement equipment in multi-family or mobile pre-1.994 vintage homes:

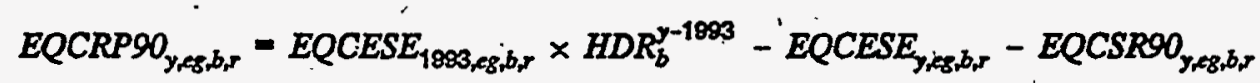

where,

EQCRP90 ${ }_{y, e g, b, r}$ is the number of replacement units demanded in multi-family or mobile pre-1994 housing units by year, housing type and Census Division,

EOCESE $_{y, e g, b, r}$ is surviving pre-1994 vintage equipment in pre-1994 housing units by year, housing type and Census Division,

EQCSR9O $0_{y, e g, b, r}$ is the surviving post- 1993 vintage equipment in pre-1994 housing units by year, housing type and Census Division,

$H D R_{b} \quad$ is the housing demolition rate.

Furthermore, a second call to SUBROUTINE REPLACE(EU,RSYR, R, $B, R E C C L, 2)$ allows switching to any technology when replacing water heaters or stoves in pre-1994 single family homes only. Retiring values are first calculated as in (112) above and stored as OEQCRP90 $0_{y, e g, 1, r}$. Users may specify the fraction of homes which may switch away from a certain technology by setting the values RTSWFACT $T_{e g}$ in the RTEKCL data file. In the second call, FLAG $=2$ for pre-1994 housing.

If the component has been called for water heating rather than for cooking, the solar water heating variables for single-family homes must be calculated, as follows:

$$
\begin{array}{ll}
S L N D 90_{1993,5}=S L E S E_{4993, r} \times H D R_{1} & , \text { if } y=1993 \\
S L N D 90_{3, r}=S L N D 90_{y-1, r} \times H D R_{1} & \text {, otherwise }
\end{array}
$$




$$
\begin{aligned}
& \text { SOLADD } D_{y, F}=H S E A D D_{y, 1, r} \times N E W S L S H R_{r} \\
& S L S R 90_{y, r}=\sum_{t=1284}^{y-1}\left[S L R P 0_{t, r} \times S V R T E_{y-t 5,30} \times H D R_{1}^{y-1}\right]
\end{aligned}
$$

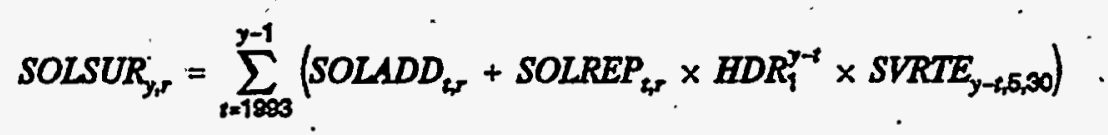

$$
\begin{aligned}
& \text { SOLREP } P_{y, r}=\left(\sum_{r=1893}^{y-1} S O L A D D_{t r} \times H D R_{r}^{j-r}\right)-S O L S U R_{y, r} . \\
& S L R P 90_{y, r}=S L E S E_{1983,} \times H D R_{b}^{y-1993}-S L E S E_{j,}^{\prime}-S L S R 90_{y, r}
\end{aligned}
$$

where,

$S L N D 9 O_{y, r} \quad$ is the total amount of solar water heating equipment surviving in pre-1994 housing each year,

$S O L A D D_{y, r}$ is the number of post-1994 solar water heaters by equipment class added to new housing units in this year,

NEWSLSHR r is a "new solar water heating share" from the RMISC file,

$S L S R 90_{y, r} \quad$ is the surviving post-1993 vintage solar. water heating equipment in pre-1994 housing units by year and Census Division,

SOLSUR $_{y, r}$ is the number of surviving post-1993 solar water heaters by equipment class in post-1993 housing units by year, housing type. and Census Division.

SOLREP $_{y, r}$ is the number of surviving post-1993 solar water heaters to be replaced in post-1993 housing units in this year by equipment class, housing type and Census Division, and

$S^{S L R P O}{ }_{t, r} \quad$ is the replacement (post-1993 vintage) solar water heating equipment demanded in pre-1994 single family housing units by year and Census Division.

RWHCON. (Water Heater Energy Consumption Component)

Energy Information Adminstration.

NEMS Residential Demand Module Documentation Report

B-61 
Energy consumption for space cooling is calculated much like the comparable quantities for space heating. Space cooling equipment consumption begins with the calculation of the national total stock of water heaters for the base year,

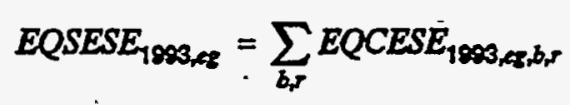

where,

EOSESE $_{1993, \mathrm{eg}}$ is the national total number of water heaters in the original base year stock in each equipment class, and

EQCESE $_{1993, e g, b, r}$ is the number of water heaters in the original base year stock in each equipment class by house type and Census Division.

There is no need to calculate the projection to the current year, as it was already calculated in the RDWHEOC subroutine.

It then calculates the average efficiency of all 1993 water heaters,

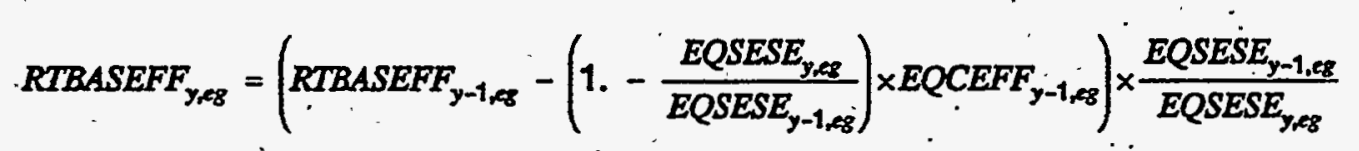

where,

RTBASEFF ${ }_{\text {eg,y }}$ is the stock average efficiency for the remaining 1993 equipment, EQSESE $_{y, e g}$ is the remaining unretired stock of 1993 water heating equipment, by year and equipment class, and

'EQCEFF ${ }_{y, e g}$ is the average efficiency of equipment retired in each year, from the RSEFFO1 file.

The most important determinant of the amount of hot water consumption in households is their number of inhabitants. The component therefore calculates an average household size that will be used, with an elasticity to account for this determinant, 


$$
{ }_{H H S I Z E_{y, r}}=\frac{M C_{-} P O P 16_{y, r}}{\sum_{b}\left(E H_{y, b, r}+N H_{y, b r r}\right)}
$$

where,

$H H S I Z E_{y, r} \quad$ is the average number of persons over age 16 per household by year and region,.

MC_POP16, is the number of persons over age 16 by year and region, from the NEMS Macroeconomic Module,

$E H_{y, b, r} \quad$ is the number of pre-1994 vintage homes existing in year $y$, from the RMISC file; and

$\mathrm{NH}_{y, b, r} \quad$ is the number of post-1993 vintage homes remaining in year $y$, from the NEMS Macroeconomic Module, as shown in equations (3) through (6).

Unit energy consumption is calculated for the usual vintages. First, the surviving baseyear homes,

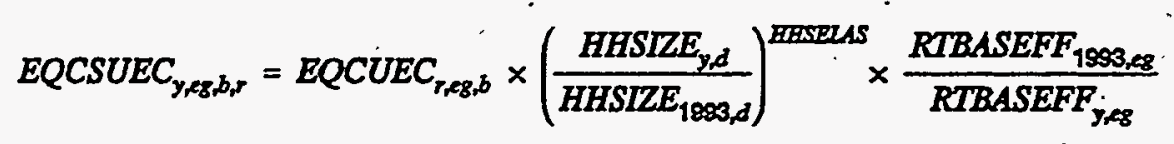

where,

EOCSUEC $C_{y, e g, b, r}$ is the unit energy efficiency of surviving water heating equipment in pre-1994 vintage homes, by year, equipment class, housing type and Census Division,

$E Q C U E C_{r, e g, b}$ is the unit energy efficiency of equipment in homes that existed in 1993, by Census Division, equipment class, and housing type, $H H S I Z E_{y, r}$ is the average household size by year and Census Division, HHSELAS is an elasticity. parameter for the increase in hot water intensity due to increases in household size, estimated at .315; and

RTBASEFF $_{y, g g}$ are the annual average efficiencies for the equipment classes. 
For new purchases in this year, if year < 1995,

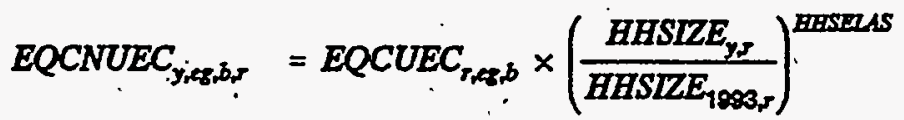

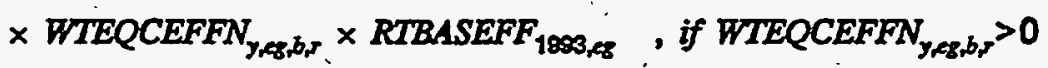

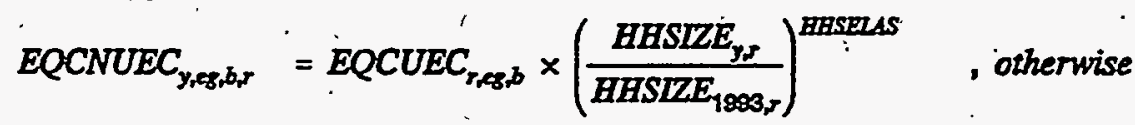

If the year $\geq 1995$,

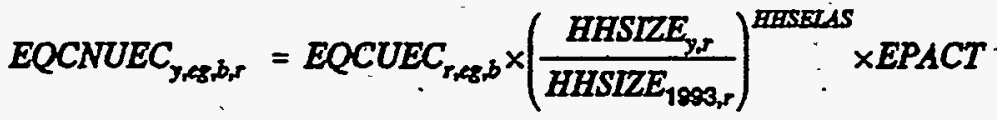

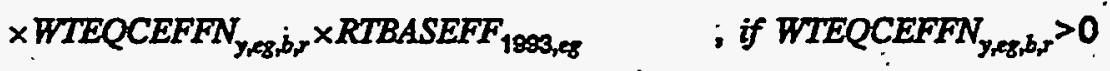

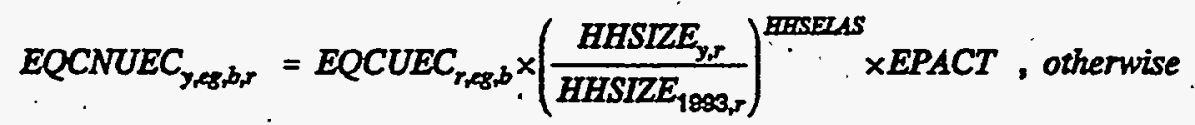

where,

$$
\begin{aligned}
& \text { EQCNUEC }{ }_{y, e g, b, r} \text { is the unit energy consumption for new equipment by year, } \\
& \text { housing type and Censưs Division, } \\
& E_{\text {EOCUEC }}, \text { isg,b the unit energy consumption for the equipment class by } \\
& \text { housing type and Census Division, } \\
& \text { WTEOCEFFN } N_{y, e g, b, r} \text { is the weighted average inverse efficiency for new water } \\
& \text { heating equipment types by year, class, housing type and } \\
& \text { Census Division, }
\end{aligned}
$$


For replacements in this year,

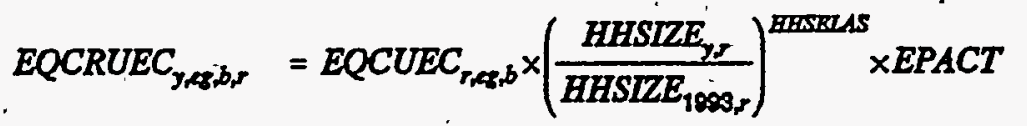

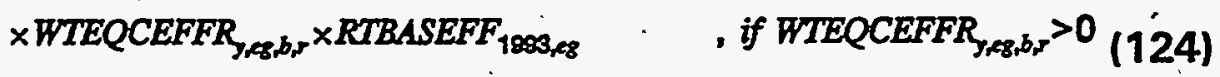

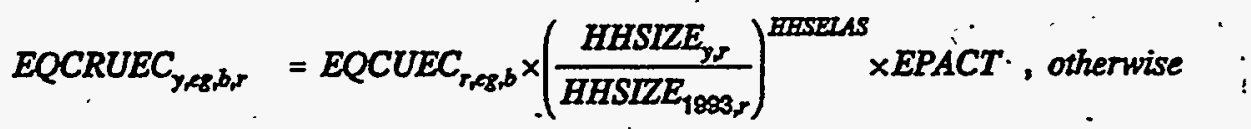

where,

$$
\begin{aligned}
& E Q C R U E C_{y, e g, b, r} \text { is the unit energy consumption for replacement equipment by } \\
& \text { year, housing type and Census Division, } \\
& \text { WTEOCEFFR }_{y, e g, b, r} \text { is the weighted average inverse efficiency for replacement } \\
& \text { water heating equipment classes by year, housing type and } \\
& \text { Census Division, and } \\
& \text { EQCUEC }_{r, e g, b} \cdot{ }^{\prime} \text { is the unit energy consumption for the equipment class by } \\
& \text { housing type and Census Division, and } \\
& \text { RTBASEFF }_{\text {,eg }} \quad \text { is the efficiency of retiring equipment from the } 1993 \text { stock by } \\
& \text { year. }
\end{aligned}
$$

And the average UEC is

$$
\begin{aligned}
& T E M P=E Q C R P 90_{y, e q, b, r}+E Q C R E P_{y, e g, b, r}+E Q C A D D_{y, e g, b, r}+E Q C S R 90_{y, e q, b, r}+E Q C S U R_{y, e q, b, r}
\end{aligned}
$$

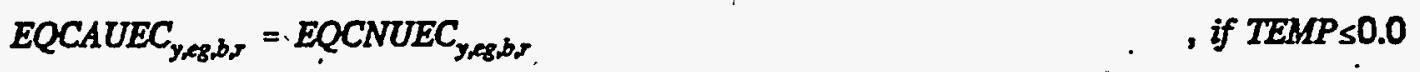

$$
\begin{aligned}
& \text { or } y=1993 \\
& E Q C R P 90_{\text {yes, } b, 5} \times E Q C R U E C_{\text {yeg,b, }}
\end{aligned}
$$

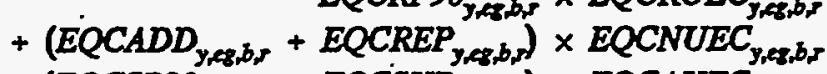

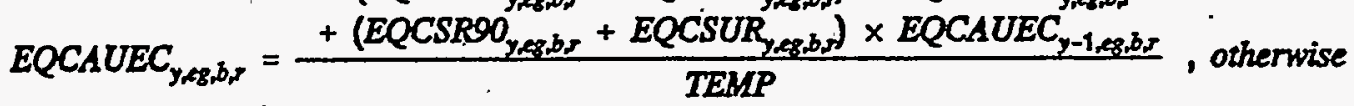

where;

$E Q C A U E C_{y, e g, b, r}$ is the average unit energy consumption for water heaters by year, equipment class, housing type and Census Division.

Water heater efficiency is calculated next. If $y=1994$ or denominator $\leq 0$, 


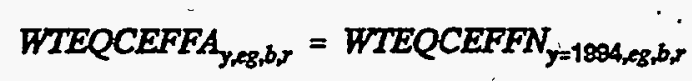

If $y>1994$ and denominator $>0$,

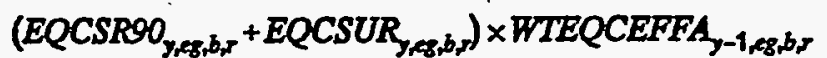

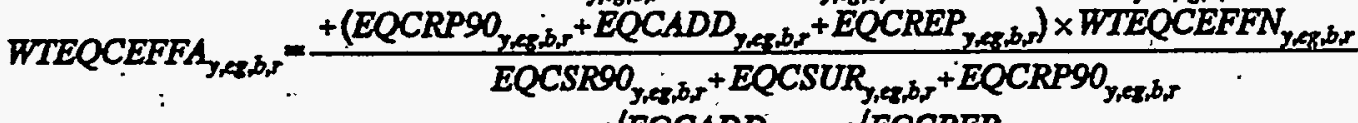

where,

WTंWEFFA ${ }_{y, e g, b, r}$ is the weighted average water heater efficiency by equipment class, housing type, Census Division, and year.

Finally, energy consumption by fuel can be sumimed over the different housing types. If $y=1994$,

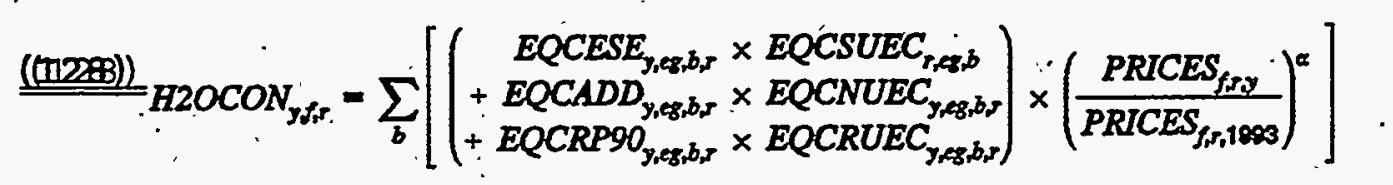

If $y>1994$

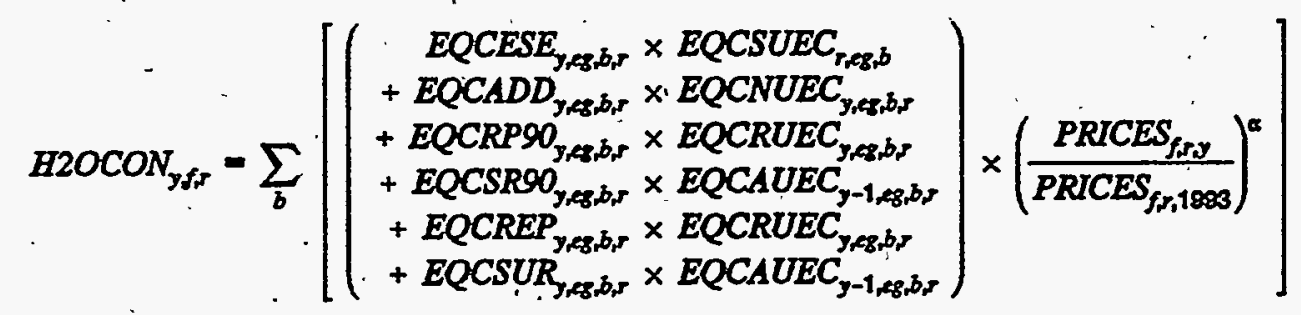

where,

$H 2 O C O N_{y, f, r}$ is consumption for water heating by fuel, and

. $a$. is the short-term price elasticity, presently valued at 0.0 .

And for solar water heaters, 


$$
S L C O N_{y, r}=\left(\begin{array}{c}
S L E S E_{y, r}+S O L A D D_{y, r} \\
+S R L P 90_{y, r}+S L S R P 0_{y-1, r} \\
+\operatorname{SOLREP}_{y, r}+S O L S U R_{, p}
\end{array}\right) \times S L U E C_{r}
$$

where,

$S L C O N_{y, r}$ is consumption for solar water heating.

\section{Cooking Equipment}

\section{RSTVTEC (Choose Cooking Equipment Component)}

The existing cooking equipment distribution is associated with the choice of a water heaters. Homes that heat water with natural gas are allowed to have either gas or electric stoves; homes that heat with LPG cook with LPG; homes that heat water with distillate oil cook with electricity: (Replacément stoves in single-family homes are not so constrained.) These constraints are embodied in the technology choice by using the water heater equipment market shares for calculating the cooking equipment market shares:

$$
\begin{aligned}
& N C K S H_{y, c z, b, r}=N H 2 O S H_{y_{, e q, b,}} \times N G N G F A C T \\
& \text {, if eg }=\text { gas stove }
\end{aligned}
$$

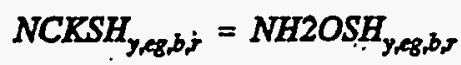

$$
\begin{aligned}
& \text {, if eg = lpg stove }
\end{aligned}
$$

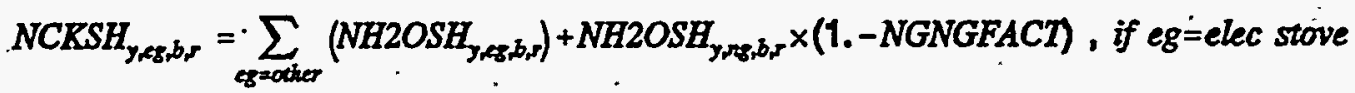

where,

$N C K S H_{y, e g, b, r}$ is the new market share for cooking equipment in the current year by housing type and Census Division,

$\mathrm{NH}^{2} \mathrm{OSH}_{\mathrm{y}, \mathrm{eg}_{0}, \mathrm{r}, \mathrm{r}}$ is the new market share for water heaters in the current year by equipment class, housing type and Census Division, and

NGNGFACT is a factor, currently set to .65 , that defines the fraction of houses having gas water heaters that have gas cookstoves.

In the formula, the summation over eg $=$ other refers to the market shares of all 
water heater classes other than natural gas and LPG: homes that heat water with any other equipment class than these, depending on which are defined in the RTEKCL file, are assumed to cook with electricity.

The following variables are computed as in the equations indicated:

$O P C O S T_{y, e s, b, r, v .}$ is the operating cost for the water heater equipment type by housing type, Census Division, vintage, and year. It is computed as in (19) above.

LFCY $_{y, e s, b, r, v}$ is the water heater type's life cycle cost by year, housing type Census Division, and vintage. It is computed as in (20) above.

$E Q W T N_{y, e s, b, r}$ is the equipment weight for new equipment types by housing type, Census Division, and year. It is computed as in (24) above.

$E Q W T R_{y, e s, b, r}$ is. the equipment weight for replacement equipment types by housing type, Census Division, and year. It is computed as in (25) above.

TOTEWTN $N_{y, e g, b, r}$ is the sum of the equipment types' weights for the new equipment class. It is computed as in (26) above.

TOTEWTR $R_{y, e g, b, r}$ is the sum of the equipment types' weights for the new equipment class. It is computed as in (27) above.

EQFSHRN $_{y, f, b, r}$ is the fuel știare of new equipment type by year, housing type and Census Division. It is computed as in (30) above.

EQFSHRR $_{y, f, b, r}$ is the fuel share of replacement equipment type by year, housing type and Census Division. It is computed as in (31) above.

The final shares for the equipment types are the products of the market shares and the equipment type shares,

$$
\begin{aligned}
& N E Q T S H R D_{\text {yes,b,rs }}=N C K S H_{\text {y,eg, } b_{r}} \times E Q F S H R N_{\text {yes }, b_{r} r} \\
& R E Q T S H R D_{y, a s, b, r}=N C E S H_{y, e z, b, r} \times E Q F S H R R_{y, e s, b r^{\circ}}
\end{aligned}
$$

where, 
NEQTSHRD ${ }_{y, e s, b, r}$ is the new equipment type share for stoves by equipment type, housing type and Census Division,

REQTSHRD $D_{y, e s, b, r}$ is the replacement equipment type share for stoves by equipment type, housing type and Census Division,

$N C K S H_{y, e g, b, r}$ is the new market share for cooking equipment in the current year by housing type and Census Division,

EQFSHRN $\dot{y}_{\text {,es,b,r }}$ is the new market share for stoves by equipment type, housing type and Census Division, and

$E_{\text {EFSHRR }}$,es,b,r is the replacement market share for stoves by equipment type, housing type and Census Division.

For cooking, the weighted average inverse efficiency of each equipment class is calculated differently from the foregoing end uses, because the RTEKTY file datum for RTBASEFF $F_{e s}$ is the usage, measured in $\mathrm{kWh}$ or MMBtu, of the equipment in the class:

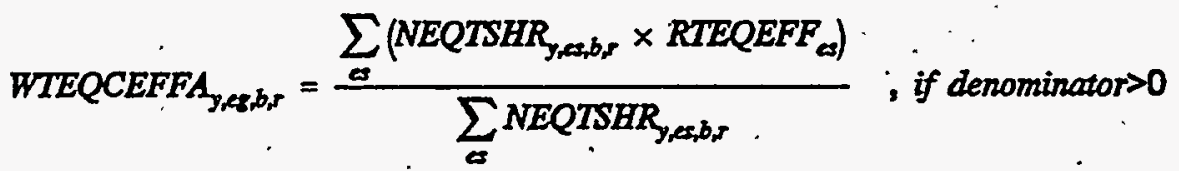

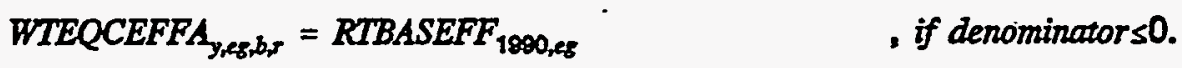

where,

WTEQCEFFA $A_{y, g g, b, r}$ is the weighted average cooking equipment usage in the current year by housing type and Census Division, and .

RTBASEFF $_{1993, e g}$ is the 19.93 base equipment efficiency.

\section{REUADD (Water Heating and Cooking Additions and Replacements Component)}

As mentioned earlier, the capabilities for adding and replacing cooking equipment have been merged into a single component called REUADD. This component was documented above on pages B-58 through B-61.

\section{RSTYCON (Cooking Energy Consumption Component)}


The cooking energy consumption component begins with the usual things. First, the base year stock of equipment

$$
E Q S E S E_{1983, s z}=\sum_{b, r} E Q C E S E_{1908, \& \&, b, r}
$$

where,

EOSESE $_{1993, \mathrm{eg}}$ is the national total number of cookstoves in the original base year stock in each equipment class, and

EQCESE $E_{1993, e g, b, r}$ is the number of cookstoves in the original base year stock in each equipment class by house type and Census Division.

There is no need to calculate the projection to the current year, as it was already calculated in the RDSTVEOC subroutine.

It then calculates the average efficiency of all 1993 cookstoves,

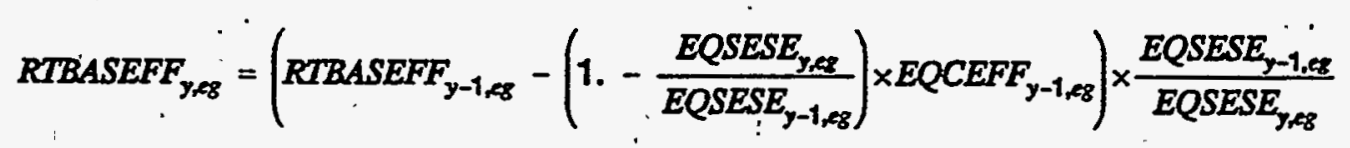

where,

RTBASEFF $_{\text {eg,y }}$ is the stock average efficiency for the remaining 1993 equipment, EQSESE $_{\text {,eg }}$. is the remaining unretired stock of 1993 cooking equipment, by year and equipment class, and

EOCEFF $_{\mathrm{y}, \mathrm{eg}}$ is the average efficiency of equipment retired in each year, from the RSEFFO1 file.

The unit energy consumption calculation for cooking is very simple. First the UEC for the surviving equipment,

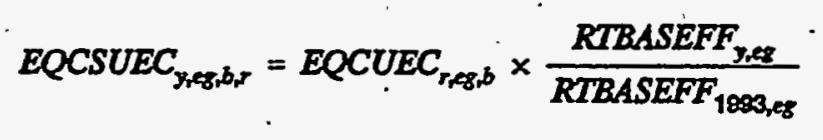

where,

EQCNUEC $C_{y, e g, b, r}$ is the unit energy consumption for surviving cooking equipment 
$E Q C U E C_{r, g, b}$ is the unit energy consumption for cooking equipment in the current year by housing type and Census Division, and

$R T B A S E F F_{y, g g}$ are the annual average efficiencies for the equipment classes.

For new equipment,

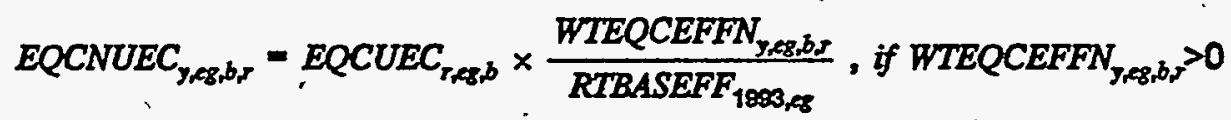

$$
\begin{aligned}
& E Q C N U E C_{y_{1, e g}, b_{r}}=E Q C U E C_{\text {refs,b }} \quad \text {, otherwise }
\end{aligned}
$$

where,

$E Q C N U E C_{y, e g, b, r}$ is the unit energy consumption for new cooking equipment in the current year by housing type and Census Division,

$E_{\text {ECUEC }}$ reg,b is the unit energy consumption for cooking equipment by class, housing type and Census Division;

WTEOCEFFN $_{y, e g, b, r}$ is the weighted average cooking usage for new equipment in the current year by housing type and Census Division, and.

RTBASEFF $_{1993, e g}$ is the 1993 efficiency of the cooking equipment class.

For replacement equipment,

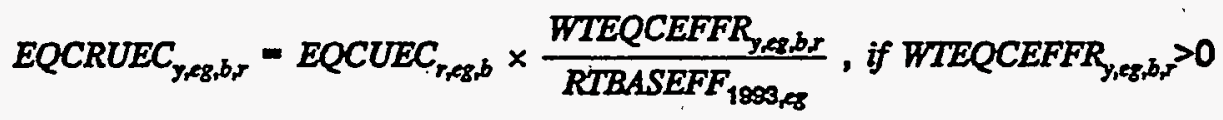

$$
\begin{aligned}
& E Q C R U E C_{\mathrm{y}, \mathrm{g}, b_{b, 5}}=E Q C U E C_{\mathrm{r}, \mathrm{g}, \mathrm{b}} \quad \text {,otherwise }
\end{aligned}
$$

where,

EQCRUEC ${ }_{y, e g, b, r}$ is the unit energy consumption for replacement cooking equipment in the current year by housing type and Census Division,

$E Q C U E C_{r, e g, b}$ is the unit energy consumption for cooking equipment by class, housing type and Census Division,

WTEQCEFFR ${ }_{y, e g, b, r}$ is the weighted average cooking usage for replacement 
equipment in the current year by housing type and Census Division, and

RTBASEFF $_{1993, \mathrm{eg}}$ is the 1993 efficiency of the cooking equipment class.

For the average efficiency, the initial year level is set to the new equipment efficiency: If $\mathrm{y}=1994$,

$$
E Q C A U E C_{\text {yes, }, 5,5}=E Q C N U E C_{y, E s, b, x}
$$

If $\mathrm{y}>1994$,

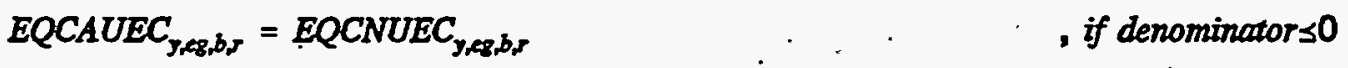

$$
\begin{aligned}
& E Q C R P 90_{y, e g, b, r} \times E Q C R U E C_{y, e g, b r} \\
& +E Q C R E P_{\text {yeg, }, 5,5} \times E Q C N U E C_{\text {y,eg, }, b_{5}}
\end{aligned}
$$

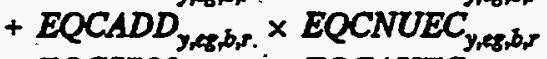

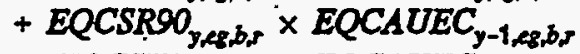

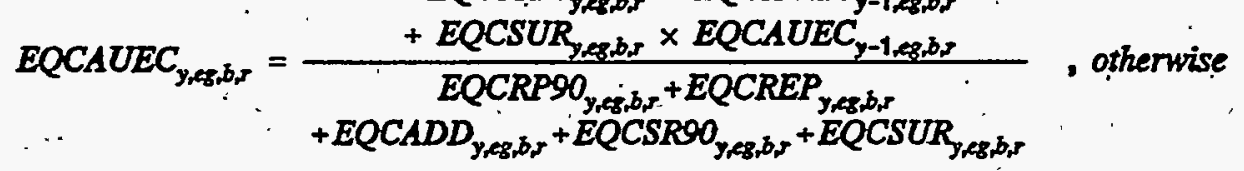

And energy consumption is also defined separately for the base year:

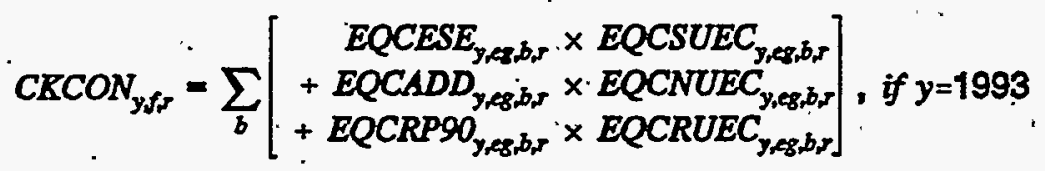

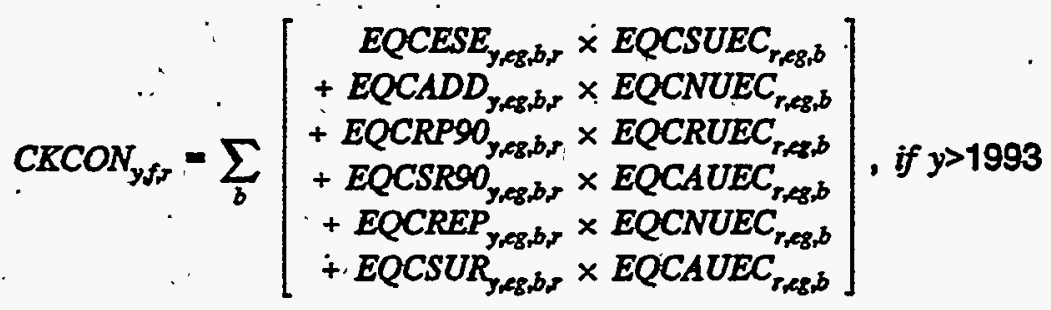

\section{Clothes Drying}

\section{RDŔYTEC (Clothes Dryer Technolog̀y Choice Component)}

B-72

Energy Information Adminstration. NEMS Residential Demand Module Documentation Report 
Compute current year operating costs,

$$
O P C O S T_{y, e s, b, r}=P R I C E S_{f x, y} \times E Q C U E C_{r, e g, b} \times H D D F A C T_{r, y} \times \frac{R T B A S E F F_{1983, q z}}{R T E Q E F F_{c s}}
$$

where,
OPCOST $_{y, e s, b, r, v}$
is the operating cost for the equipment type by year, housing type, Census Division, and vintage,
PRICES f,r,y is the fuel prices for the equipment from NEMS, by fuel, by region and forecast year,
$E Q C U E C_{r, e g, b}$ is the unit energy consumption by Census Division, equipment class and housing type,
RTEQEFF is the equipment efficiency,
RTBASEFF $_{1993, e g}$ is the 1993 stock-average efficiency.

The following variables are computed as in the equations indicated:

$L F C Y_{y, e s, b, r, v}$ is the water heater type's life cycle cost by year, housing type Census Division, and vintage. It is computed as in (20) above. $E Q W T N_{y, e s, b, r}$ is the equipment weight for new equipment type by housing type, Census Division, and year. It is computed as in (24) above.

$E Q W T R_{y, e s, b, r}$ is the equipment weight for replacement equipment by housing type, Census Division, and year. It is computed as in (25) above. TOTEWTN $N_{y, e g, b, r}$ is the sum of equipment weights for the new equipment class. It is computed as in (26) above.

TOTEWTR $R_{y, e g, b, r}$ is the sum of equipment weights for the new equipment class. It is computed as in (27) above. .

Market shares for new and replacement dryers are next: 


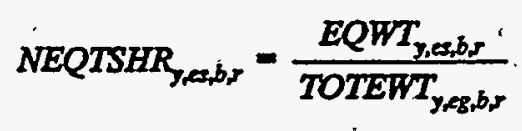

where,

NEQTSHR $R_{y, e s, b, r}$ is the new market share of clothes dryer equipment types by housing type and Census Division in the current year,

TOTEWT $\dot{T}_{\text {eg }}$ is the sum of equipment weights for the new equipment class, $E Q W T_{\text {es }}$. is the equipment weight for new equipment, and

The class averages of equipment type efficiencies for clothes drying equipment are calculated as for other end uses:

$$
\begin{aligned}
& \text { TEMP }=\sum_{\sigma} E Q W T_{y, a, b r} \\
& \text { WTEQCEFFA }_{y, e z, b, r}=\frac{\sum_{e}\left(\frac{E Q W T_{y, e s, b, r}}{\text { RTEQEFF }_{e s}}\right)}{\text { TEMP }} \text {, if TEMP>0. } \\
& \text { WTEQCEFFA }_{y, e g, b, r}=\frac{1}{\text { RTBASEFF }_{a g}} \quad \because \text { otherwise }
\end{aligned}
$$

where,

$W T E O C E F F A_{y, e s, b, r}$ is the weighted average usage of clothes dryer equipment classes in the current year by housing type and Census Division, and

$E Q W T_{\text {es }}$ is the equipment weight for each type of new equipment.

\section{DRYADD (Dryer Additions Cómponent)}

New clothes drying equipment is calculated using a saturation level for newly-bought equipment

$$
E Q C A D D_{y, e s, b, r}=\sum_{e}\left(H S E A D D_{y, b, r} \times N E Q T S H R_{, e, b, r, r} \times \frac{N E W D R Y S A T_{b, r}}{100}\right)
$$

where;

$E Q C A D D_{y, e g, b, r}$ is the amount of new (post-1993 vintage) equipment added in 
new housing units in the current year by housing type and Census Division,

$H S E A D D_{y, b, r}$ is the number of new housing additions in the year by housing type and Census Division,

$N^{\prime}$ OCSHR $R_{y, e s, b, r}$ is the market share of new clothes dryer equipment types by housing type and Census Division in the current year, and NEWDRYSAT $T_{b, r}$ is the level of market penetration of new clothes dryer equipment by housing type and Census Division, expressed as a percent, from the RMISC file.

The next step is to calculate the numbers of dryers of each vintage category. The following variables were computed as in the equations indicated:

EOCSR9O $_{y, e g, b, r}$ is the surviving post-1993 vintage equipment in pre-1994 housing units in the current year by housing type and Census Division. It is computed as in (37) above.

EQCSUR $_{y, e g, b, r}$ is the surviving new (post-1993 vintage) equipment in the current year by housing type and Census Division. It is computed as in (38) above.

EQCREP $_{y, e g, b, r}$ is the number of replacement units (post-1993 vintage) equipment demanded in multi-family or mobile post-1993 vintage housing units by housing type and Census Division, computed as in (39).

The new technology choice component allows switching when replacing clothes dryers in post-1.993 (and pre-1994) single family homes only. Users may specify the fraction of homes which may switch away from a certain technology by setting the values RTSWFACT $T_{\text {eg }}$ in the RTEKCL data file. Retiring values are first calculated as in (39) and stored as OEQCREP ${ }_{y, \theta g, 1, r}$ The code then calls SUBROUTINE REPLACE(EU,RSYR,R,B,RECCL, 1) for replacements with switching in post-1993 
single-family housing where,

EU 'is the end use number (5 for clothes dryers),

$R S Y R$ is the calendar year,

$R$ is the census division,

$B \quad$ is the building type (currently always 1 for single-family),

RECCL is the record number from the RTEKCL file,

FLAG is set $=1$ for post 1993 housing.

Replacement units demanded in multi-family or mobile pre-1994 housing units is,

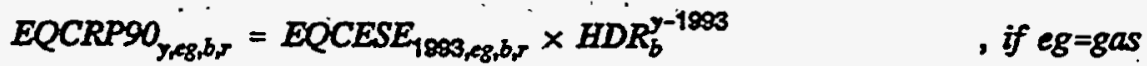

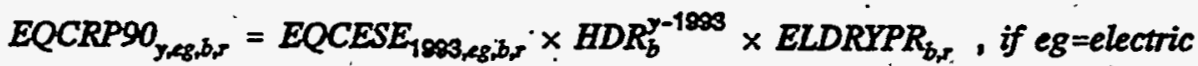

where,

EQCRP9O ${ }_{y, e g, b, r}:$ is the number of replacement unites demanded in multi-family or mobile pre-1994 housing units each year by housing type and Census Division,

EQCSR9O $_{y, e g, b, r}$ is the surviving post-1993 vintage equipment in pre-1994 housing units in the current year by housing type and Census Division,

EOCESE $_{1993, e g, b, r}$ is the base year old equipment in pre-1994 housing units by housing type and Census Division,

$E L D R Y P R_{b, r} \quad$ is a set of dryer penetration rates by housing type and Census Division, from the RMISC file, and

$H D R_{b}$ is the housing demolition rate by housing type.

Furthermore, a second call to SUBROUTINE REPLACE(EU,RSYR, R,B,RECCL, 2) allows switching to any technology when replacing clothes dryers in pre-1994 single family homes only. Retiring values are first calculated as in (147) above and stored as 
$O E Q C R P 90_{y, e g, 1, .}$ Users may specify the fraction of homes which may switch away from a certain technology by setting the values RTSWFACT eg in the RTEKCL data file. In the second call, FLAG $=2$ for pre-1994 housing.

\section{RDRYCON (Clothes Dryer Energy Consumption Component)}

Dryer Energy Consumption begins, as do the other consumption components, with the calculation of the base year dryer stock, which could just as easily have been done in the projection subroutine, and the recalculation of the base efficiency used in earlier subroutines, as shown in equation (91).

Next come the unit energy consumption calculations. For dryers, there are only three. First, for surviving equipment,

$$
{ }^{\prime} Q C S U U E C_{y, e g, b, r}=E Q C U E C_{r, e g, b} \times \frac{R T B A S E F F_{1993, e g}}{R T B A S E F F_{y, e g}}
$$

where,

EOCSUEC $_{y, e g, b, r}$ is the UEC for surviving 1993 equipment in each equipment class, by hoüsing type and Census Division, and

RTBASEFF $_{y, e g}$ is the base efficiency of the same equipment in each year.

For new equipment,

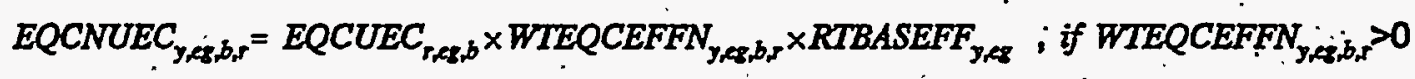

$$
\begin{aligned}
& E Q C N U E C_{\text {yeg, }, b_{r}}=E Q C U E C_{\text {reg, }, b}
\end{aligned}
$$
where,

$E Q C N U E C_{y, e g, b, r}$ is the unit energy consumption by yèar for new equipment by housing type and Census Division,

WTEQCEFFN $N_{y, e g, b, r}$ is the new equipment efficiency by year, equipment class, housing type and Census Division,

RTBASEFF is the base year efficiency of the equipment class, and EQCUEC $C_{r, g g, b}$ is unit energy consumption for equipment in 1993 housing by 
Census Division, equipment class and housing type.

For replacement equipment,

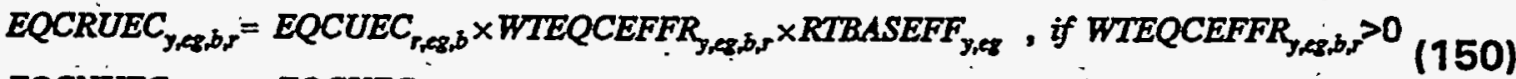

$$
\begin{aligned}
& E Q C N U E C_{y, e s, b, r}=E Q C U E C_{r e s, b} \quad \text {,otherwise }
\end{aligned}
$$

where,

EQCRUEC $C_{y, e g, b, r}$ is the unit energy consumption by year for replacement equipment by housing type and Census Division,

WTEOCEFF $R_{y, e g, b, r}$ is the replacement efficiency by year, equipment class, housing type and Census Division,

RTBASEFF $F_{y, e g .}$ is the base year efficiency of the equipment class, and $E Q C U E C_{r, e g ; b}$ is unit energy consumption for equipment in 1.993 housing by Census Division, equipment class and housing type.

The average of the two unit energy consumption variables is,

$$
\begin{aligned}
& E Q C A U E C_{y, e g, b, r}=E Q C N U E C_{\text {yeg }, b, r} \quad \text {, if } y=1993
\end{aligned}
$$

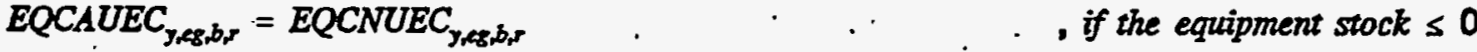

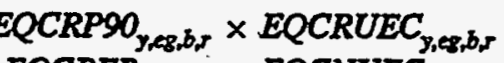

$$
\begin{aligned}
& +E Q C R E P_{y, g, b, b} \times E Q C N U E C_{y, e g, b, r}
\end{aligned}
$$

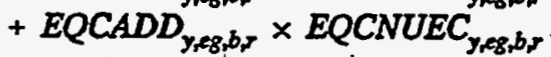

$$
\begin{aligned}
& +E Q C S R 90_{y, c 8, b, r} \times E Q C A U E C_{y-1, r z, b, r}
\end{aligned}
$$

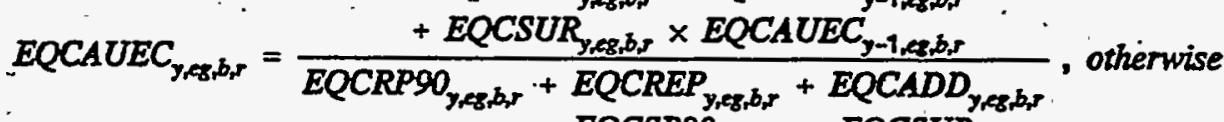

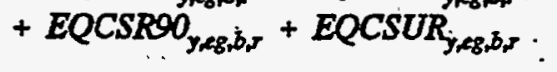

Finally, the energy consumption calculation is simpler than most of the other end uses:

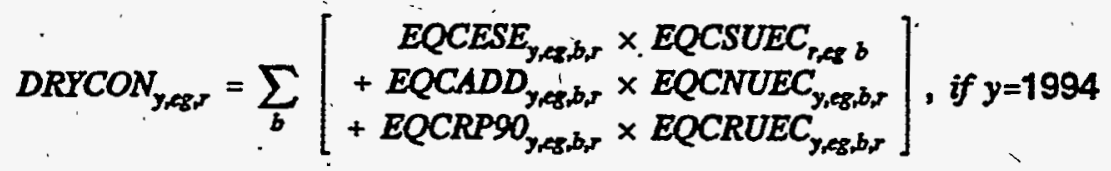

B-78 


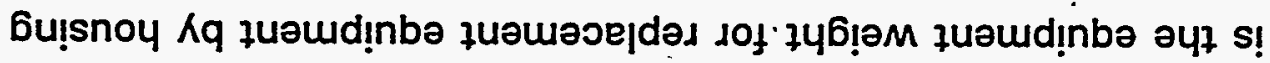

'q'so YLMOت.

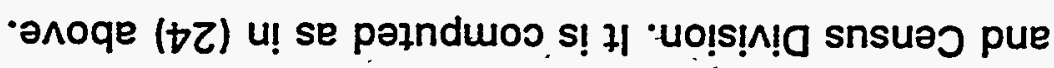

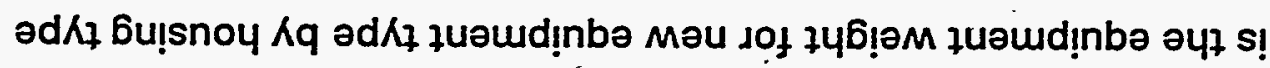

${ }^{\lrcorner}{ }^{\prime} \mathrm{N} N \perp M O \exists$ -anoqe (OZ) U! se paznduos s! 7 •əbequ! pue

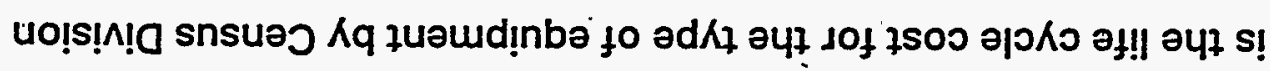

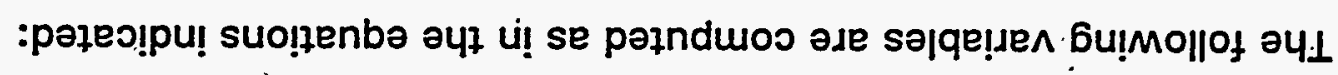

-sanozs dol se Kouə!o!̣ta

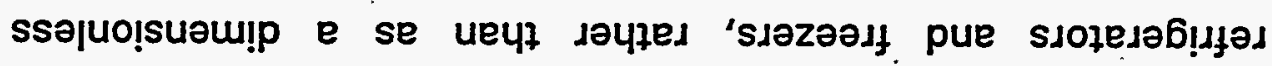

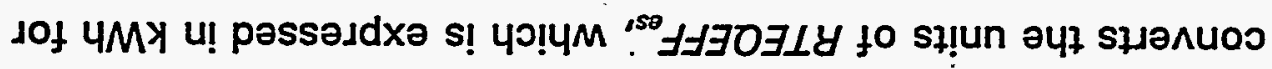

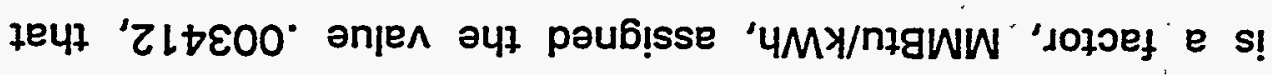

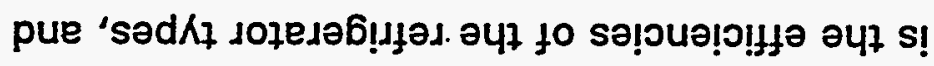
yOLOVJ

‘ə|npow o!wouosaodoew SWJN

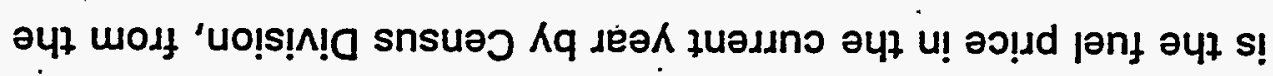

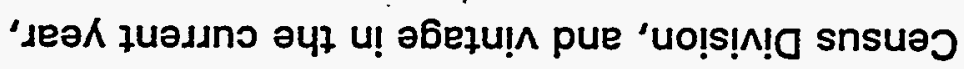

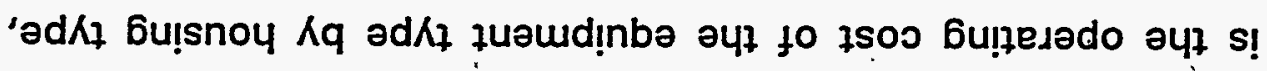
so $\exists \exists \exists 0 \exists \perp y$. "s's SJJlyd. A'J'so' LSOJdO 'әرәบM (tcil)

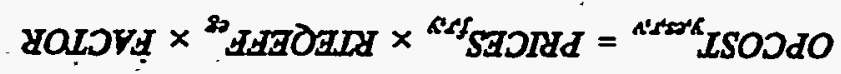

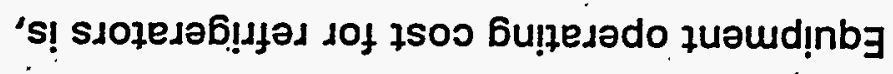


type and Census Division. It is computed as in (25) above.

TOTEWTN $_{b, r}$ is the sum of the individual weights for each type of new equipment by housing type and Census Division. It is computed as in (26) above.

TOTEWTR ${ }_{b, r}$ is the sum of the individual weights for each type of replacement equipment by housing type and Census Division. It is computed as in (27) above.

The two available classes of refrigerators, through-the-door and others, have market shares, distinguished by TTDSHR. For through-the-door refrigerators,

$$
\begin{gathered}
N E Q T S H R_{y, e s, b, r}=T T D S H R \\
\vdots \\
R E Q T S H R_{y, e s, b, 5}=T T D S H R
\end{gathered}
$$

And for all others,

$$
\begin{aligned}
& N E Q T S H R_{y_{p e s, b, r}}=\frac{E Q W T N_{C s, b_{r},}}{T O T E W T N_{b, r}} \times(1-T T S S H R)
\end{aligned}
$$

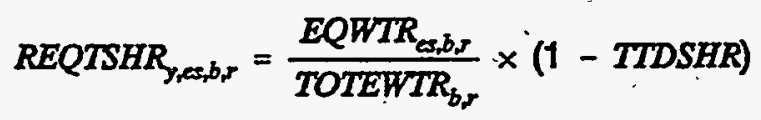

where,

NEQTSHR y,es,b,r $_{\text {is }}$ is the market share for new refrigerators of the equipment type in the current year by housing type and Census Division,

REQTSHR $R_{y, e s, b, r}$ is the market share for the replacements of equipment type in the current year by housing type and Census Division, and

TTDSHR is the share of side-by-side refrigerators with through-the-door access features, presently.set at .267 . 


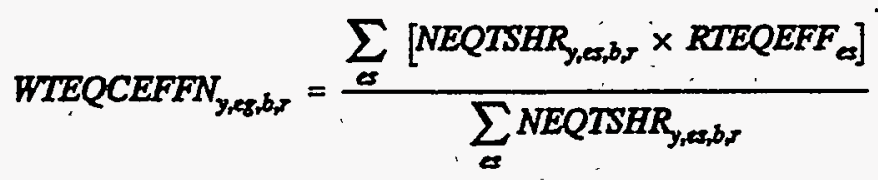

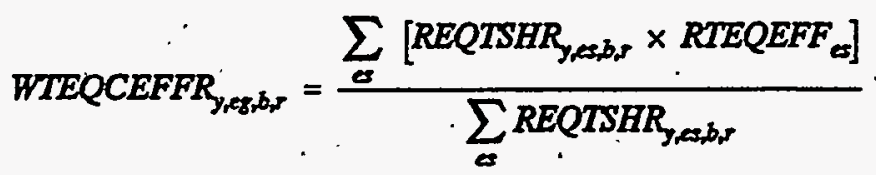

where,

WTEOCEFFN $N_{y, e g, b, r}$ is the weighted average usage of new refrigerator classes by housing type and Census Division,

WTEOCEFFR $_{y, e g, b, r}$ is the weighted average usage of replacement refrigerator classes by housing type and Census Divișion,

RTEQEFF $_{\text {es }} \quad$ is the efficiency by refrigerator type, from the RTEKTY file,

NEQTSHR y,es,b,r $_{\text {is }}$ is the new market share for the equipment types in the current year by housing type and Census Division,

REQTSHR $_{y, e s, b, r}$ is the market share for the replacements of equipment types in the current year by housing type and Census Division.

\section{RREFADD (Additions to the Refrigerator Stock Component)}

Refrigerator additions are very simple. Constant multipliers ensure that 10 percent of new single family homes receive second refrigerators, and that there is one refrigerator in each other home.

$$
\begin{array}{ll}
E Q C A D D_{y, e q, b, r}=H S E A D D_{y, b, r} \times 1.1 & , \text { if } b=\text { single family home } \\
E Q C A D D_{y, e \xi, b, r}=H S E A D D_{y, b, r} & \text {, otherwise }
\end{array}
$$

where,

$E Q C A D D_{y, e g, b, r}$ is the amount of new (post-1993 vintage) refrigerators added in new housing units in the current year by housing type and Census Divișion, and

$H S E A D D_{y, b, r}$ is the number of new housing units constructed in the current year by housing type and Census Division. 
only three other vintage combinations are calculated for refrigerators. The following variables are computed as in the equations indicated:

EQCSR90 $_{y, o g, b, r}$ is the surviving new (post-1993 vintage) equipment in old (pre1994 vintage) housing units by housing type and Census Division. It is computed as in (37) above.

EOCRP90 ${ }_{y, e g, b, r}$ is the number of replacement (post-1993 vintage) equipment in pre-1994 housing units in the current year by housing type and Census Division. It is computed as in (41) above. (Subroutine REPLACE is not called when replacing refrigerators.)

EQCSUR $_{y, e g, b, r}$ is the surviving new (post-1993 vintage) equipment in the current year by housing type and Census Division. It is computed as in (38) above.

EOCREP $_{\text {y,eg,b,r. }}$ is the number of replacement units (post-1993 vintage) equipment demanded in new (post-1993 vintage) housing units by housing type and Census Division. It is computed as in (39). above. (Subroutine REPLACE is not calléd when replacing refrigerators.)

\section{RREFCON (Refrigerator Energy Consumption Component)}

. The national totals of base year stocks of refrigerators, EQSESE $_{1993, \mathrm{eg}}$ are calculated as in the other modules. See equation (14). Also, the normal recalculation of the base efficiency, RTBASEFF $F_{\text {egr }}$ as in equation (91).

Then follow the unit energy consumption calculations for surviving, new, and replacement equipment, and their averages. Firșt, for surviving equipment,

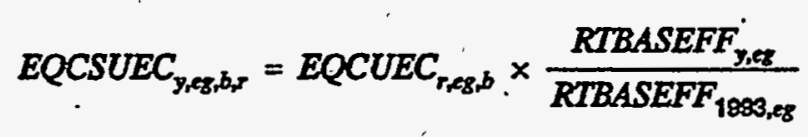

where,

EQCSUEC $_{\text {y,eg,bor }}$ is the UEC for surviving 1993 equipment in each equipment class, 
by housing type and Census Division, and

EQCUEC $_{r, e g, b}$

is the UEC for the original 1993 equipment in each equipment class, by housing type and Census Division, and

RTBASEFF $_{y, e g}$ is the base efficiency of the same equipment in each year. In the equation, the ratio between the efficiencies is inverted because of the convention that RTBASEFF $F_{e g}$ is usage for refrigerators.

For new refrigerators,

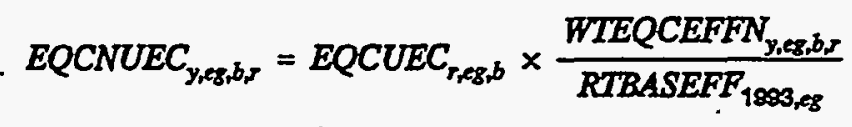

where,

$E Q C N U E C_{y, e g, b, r}$ is the efficiency-weighted unit energy consumption for new refrigerators in the current year by housing type and Census' Division,

$E_{\text {ECUEC }}$ reg,b is the unit energy consumption for 1993 refrigerators by housing type and Census Division,

WTEQCEFFN $_{y, e g, b, r}$ is the market share-weighted usage of new refrigerators in the current year by housing type and Census Division, and

RTBASEFF $_{1993, \mathrm{eg}}$ is the 1993 stock-average efficiency of refrigerators.

For replacement refrigerators,

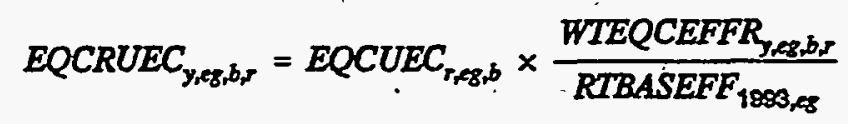

where,

EQCRUEC $_{y, e g, b, r}$ is the efficiency weighted unit energy consumption for replacement refrigerators in the current year by housing type and Census Division,

WTEQCEFFR $_{y, b, r}$ is the market share weighted usage of replacement refrigerators in the current year by housing type and Census 
นodəy uongeนuวunoo

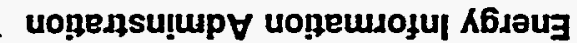

(991)

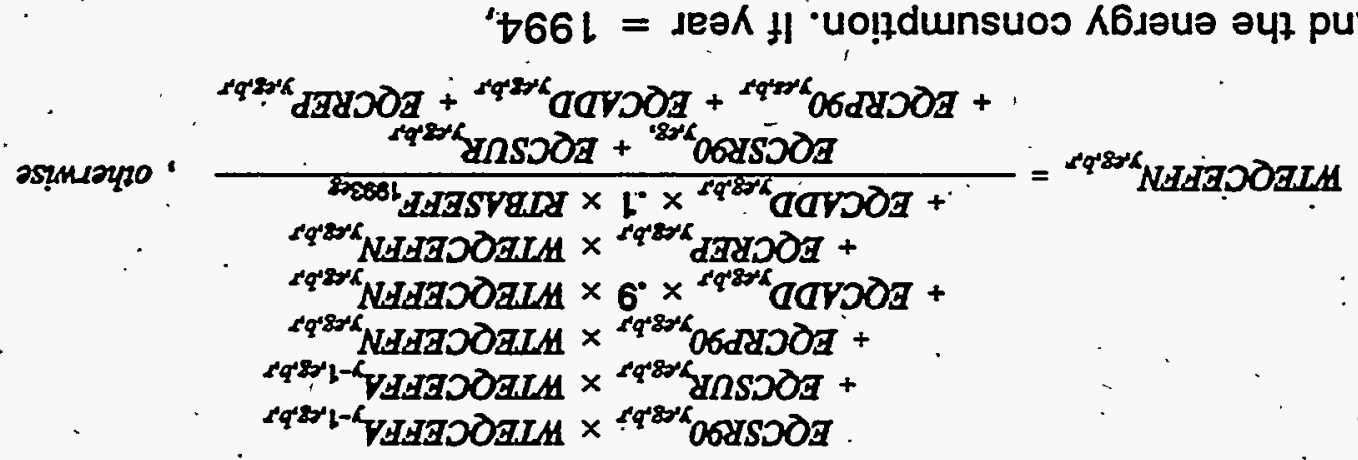

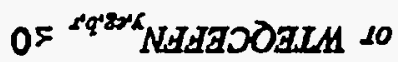

$\neg 66 !=K$ fi?

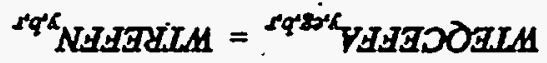

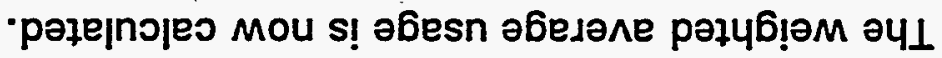

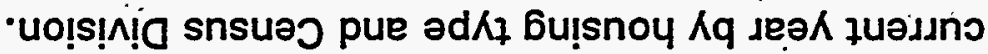

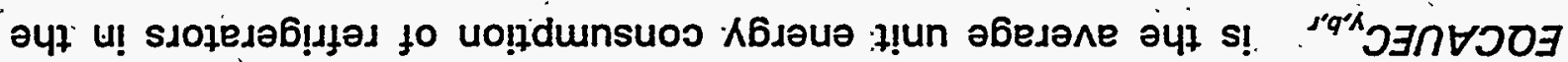

'әлачм

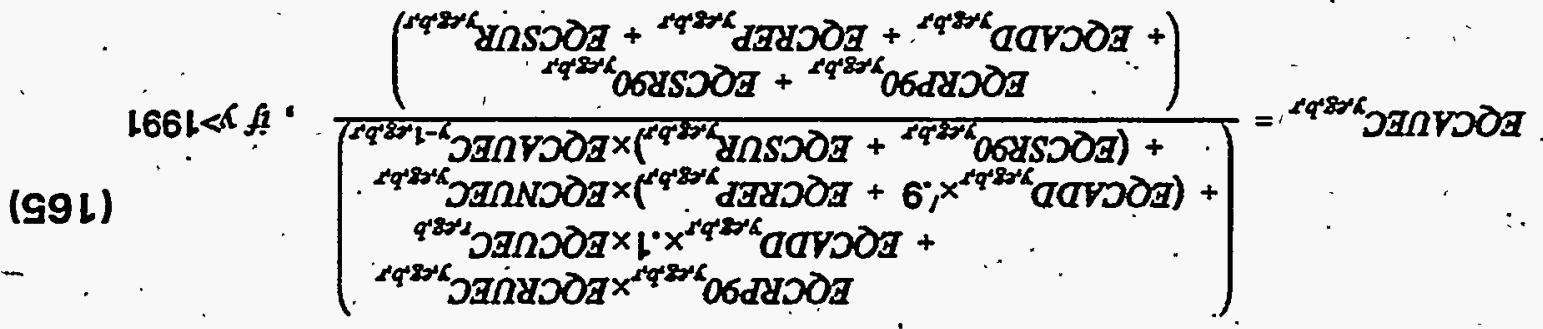

$+66 L=\kappa$ f?:

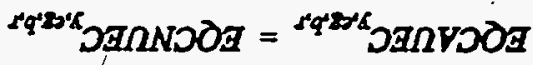

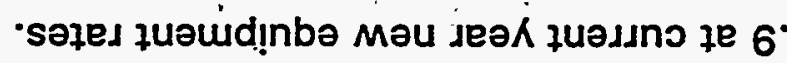

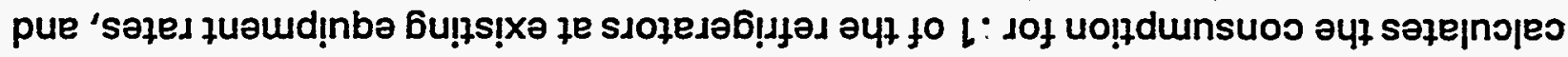

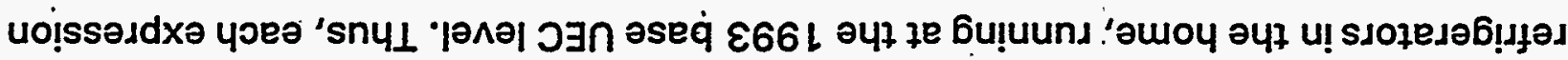

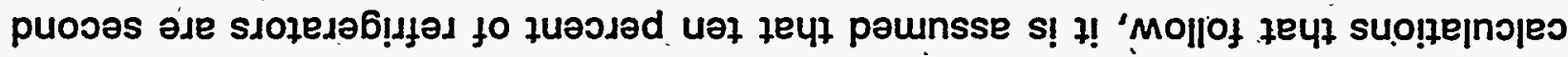

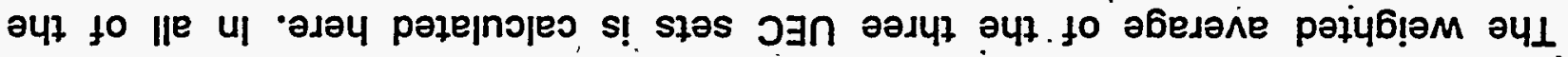




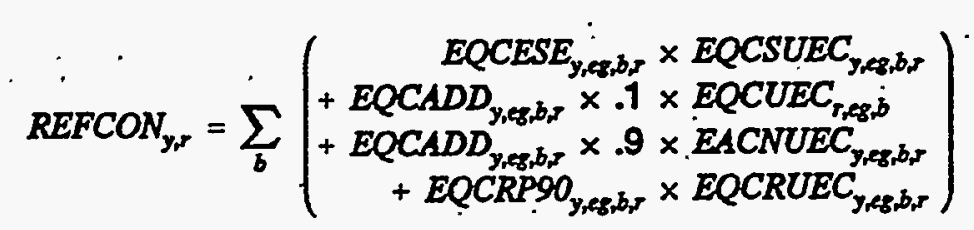

If year $>1994$,

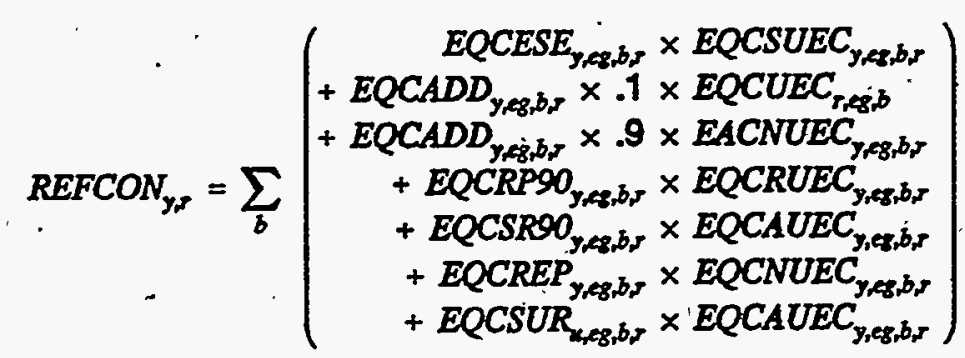

where,

$E Q C C O N_{y, r}$ is energy consumption for refrigeration,

EQCESE $_{y, b ; r}$ is the surviving old (pre-1994 vintage) equipment in old (pre-1994 vintage) housing units in the current year by housing type and Census Division,

$E Q C A D D_{y, b, r}$, is the amount of new (post-1993 vintage) refrigerators added in new housing units in the current year by housing type and Census Division,

EQCRP9O ${ }_{t, b, r}$ is the number of replacement (post-1993 vintage) equipment in pre-1994 housing units in the current year by housing type and Census Division,

$E Q C R U E C_{y, b, r}$ is the efficiency: weighted unit energy consumption for replacement refrigerators in the current year by housing type and Census.Division, and

$E Q C N U E C_{y, b, r}$ is the efficiency weighted unit energy consumption for new refrigerators in the current year by housing type and Census Division.

$E_{\text {ECUEC }}$ is the unit energy consumption for refrigerators by housing type and Census Division.

Energy Information Adminstration NEMS Residential Demand Module Documentation Report 


\section{Freezers}

\section{RFRZTEC (Freezer Technology Choice Component)}

Again, the processing of the market share weights is like the other end uses. The following variables are computed as in the equations indicated:

$O P C O S T_{y, e s, r, v}$ is the operating cost of freezers by housing type and Census Division in the current year. It is computed as for refrigerators. See (154) above.

$L F C Y_{\text {es, }} \quad$ is the life cycle cost for the type of equipment by Census Division. It is computed as in (20) above.

$E O W T N_{e s, b, r}$. is the equipment weight for new equipment types by housing type and Census Division. It is computed as in (24) above.

$E_{\text {EWWTR }}$ es,b,r is the equipment weight for replacement equipment by housing type and Census Division. It is computed as in (25) above.

TOTEWTN $_{b, r}$ is the sum of the individual weights for each type of new equipment by housing type and Census Division. It is computed as in (26) above.

TOTEWTR $R_{b, r}$ is the sum of the individual weights for each type of replacement equipment by housing type and Census Division. It is computed as in (27) above.

Shares for equipment types, in normalized form, are calculated somewhat as usual: 


$$
\begin{aligned}
& \text { NEQTSHR } R_{\text {yes,bs }}=U P S H R \text {. , if es=upright freezer }
\end{aligned}
$$

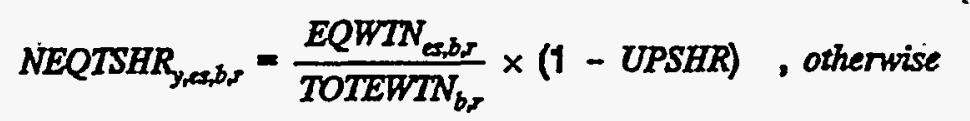

$$
\begin{aligned}
& R E Q T S H R_{\text {yess,brr }}=U P S H R \quad \text {. } \quad \text {, if es=upright freezer }
\end{aligned}
$$

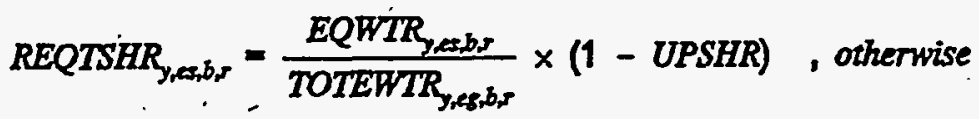

where,

NEQTSHR $R_{y, e s, b, r}$ is the new market share for the equipment type in the current year by housing type and Census Division,

REQTSHR ${ }_{y, e s, b, r}$ is the market share for replacement of equipmient types in the current year by housing type and Census Division, and

UPSHR is the market share for upright freezers, set in the component to a constant value of .414 .

The average efficiencies for new and replacement equipment are standard:

$$
\begin{aligned}
& W T E Q C E F F N_{y, e g, b, r}=\frac{\sum_{e} R T E Q E F F_{e s} \times \overline{N E Q T S H R}_{y, e s, b, r}}{\sum_{e s} N E Q T S H R_{y, s, b, r}} \\
& W T E Q C E F F R_{y, e g, b, r}=\frac{\sum_{e} R T E Q E F F_{e s} \times R E Q T S H R_{y, e s, b, r}}{. \sum_{e} R E Q T S H R_{y, a, b, r}}
\end{aligned}
$$

where,

WTEQCEFFN ${ }_{y, e g, b, r}$ is the market share-weighted usage of new refrigerators in the current year by housing type and Census Division,

WTEQCEFFR $R_{y, e g, b, r}$ is the market share-weighted usage of replacement refrigerators in the current year by housing type and Census Division,

$N E \dot{Q} T S H R_{y, e s, b, r} \quad$ is the new market share for the equipment type in the current year by housing type and Census Division, and

REQTSHR $R_{y, e s, b, r} \quad$ is the market share for the replacements of equipment type in 
the current year by housing type and Census Division.

\section{RFRZADD (Additions to the Freezer Stock Component)}

Calculations of changes in the freezing equipment stock include all seven categories of vintages. Additions post-1994:

$$
E Q C A D D_{y, e, b, r}=H S E A D D_{y, b, r} \times \frac{F R Z S A T_{b, r}}{100}
$$

where,

$E Q C A D D_{y, e g, b, 5}$ is the amount of new (post-1993 vintage) equipment added in new housing units in the year by housing type and Census Division,

$H S E A D D_{y, b, r}$ is the number of new housing units constructed in the current year by housing type and Census Division, and

$F R Z S A T_{b, r} \quad$ is the market penetration level of freezers by housing type and Census Division, from the RMISC file, expressed as percents.

The following variables are computed as in the equations indicated:

EQCSR9O $_{y, b, r}$ is the surviving new (post-1993 vintage) equipment in old (pre1994 vintage) housing units by housing type and Census Division: It is computed as in (37) above.

EQCSUR $R_{y, b, r}$. is the amount of surviving new (post-1993 vintage) equipment in new (post-1993 vintage) housing units in the current year by housing type and Census Division. It is computed as in (38) above.

EQCREP $_{y, b, r}$ is the number of replacements for the current year in new (post1993 vintage) housing units by housing type and Census Division. It is computed as in (39) above. (Subroutine REPLACE is not called when replacing freezers.) 
And the number of freezers for replacement in old houses is

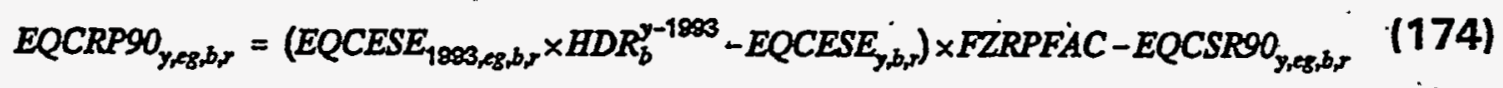

where,

EQCRP9O $_{y, b, r} \quad$ is the number of replacement (post-1993 vintage) equipment in pre-1994 housing units in the current year by housing type and Census Division, and

FZRPFAC is the percent of retired freezers that are replaced, presently set to .7 in the component. (Subroutine REPLACE is not called when replacing freezers.)

\section{FRZCON (Freezer Energy Consumption Component)}

The detailed unit energy consumption variables are computed exactly as for refrigerators:

EOCSUEC $C_{y, e g, b, r}$ is the UEC for surviving 1993 equipment in each equipment class, by housing.type and Census Division, calculated as in equation (162),

EQCNUEC $C_{y, e g, b, r}$ is the efficiency-weighted unit energy consumption for new refrigerators in the current year by housing type and Census Division, calculated as in equation (163),

$E Q C R U E C_{y, e g, b, r}$ is the efficiency, weighted unit energy consumption for replacement refrigerators in the current year by housing type and Census Division, calculated as in equation (164).

Average UEC's are different, however. They follow the pattern of cooling equipment, given in equation (95).

Weighted average usages are then calculated, 


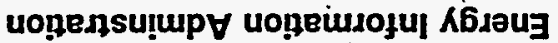

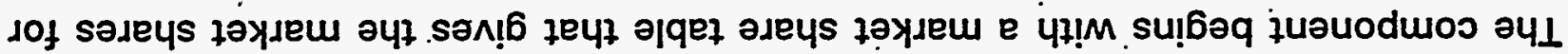

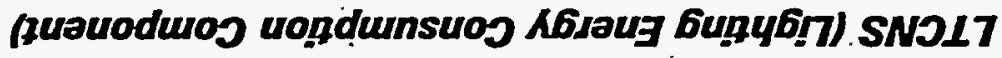

-uo!toas bu!mollof әył u! umoys se 'quauoduos

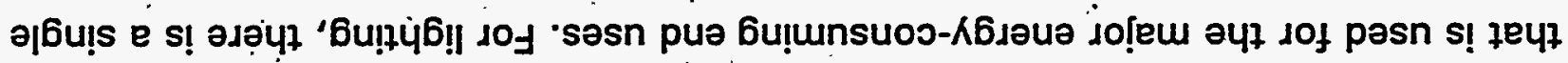
'sə|!

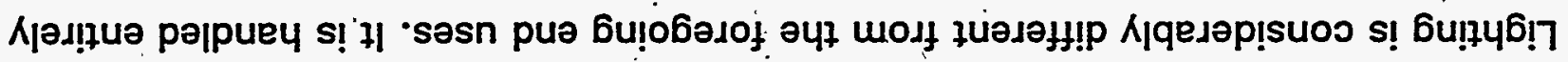

6u!zบ6!ฺ

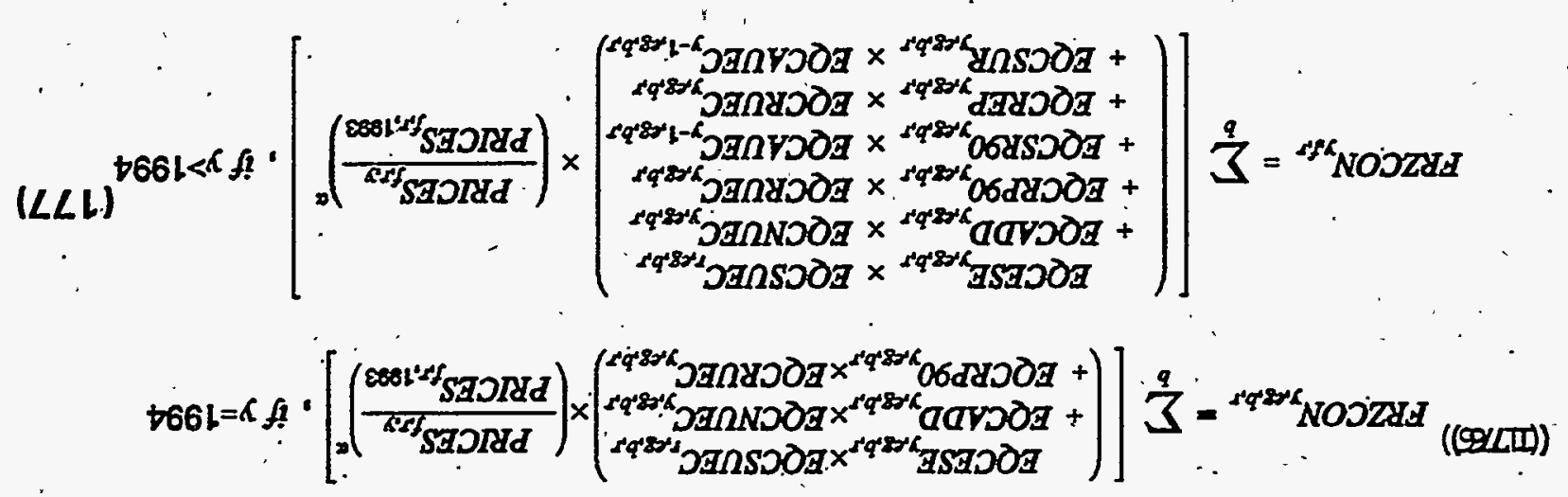

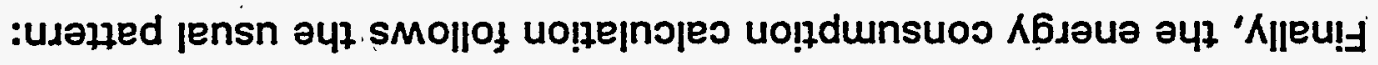

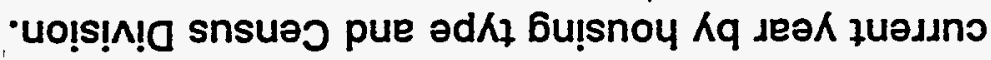

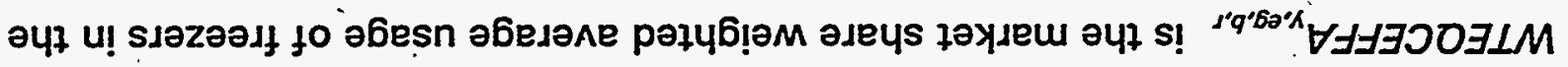

'כ1วบM

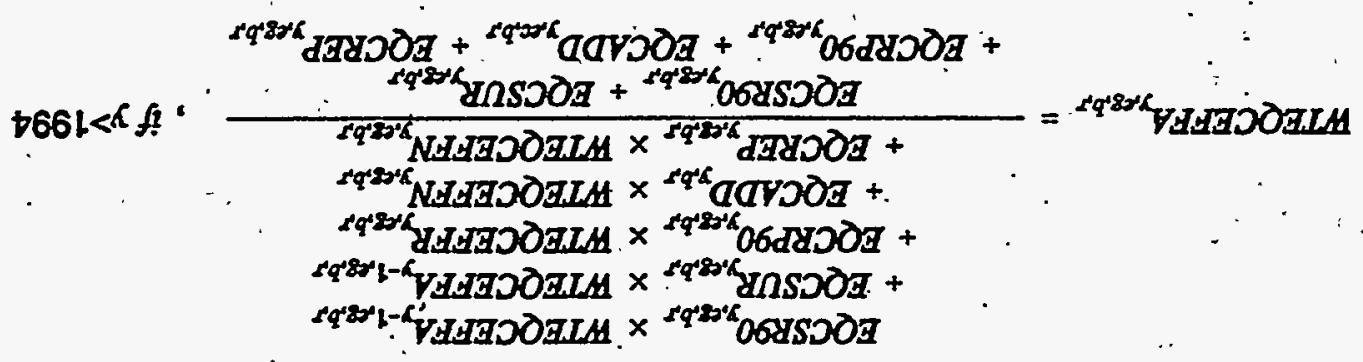

0 \& VAGGDOGLM 10

$766 \mathrm{~L}=\mathrm{K}$ f?

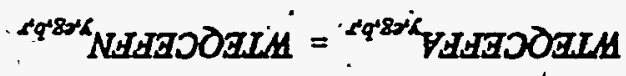


three different efficiency levels of light bulbs, $E F F_{e s}$

\begin{tabular}{ccccc}
\hline $\begin{array}{c}\text { Efficiency } \\
\text { Level }\end{array}$ & \multicolumn{3}{c}{ Market Shares } \\
\cline { 3 - 5 } \cline { 4 - 5 } & $\frac{1993}{18}$ & $\frac{2004}{.97}$ & $\frac{2015}{.90}$ & $\frac{2010}{.80}$ \\
67 & & .03 & .10 & .20 \\
88 & .00 & .00 & .00 \\
\hline
\end{tabular}

Using a linear interpolation over each of the.11-year time spans in the above table, the component calculates a matrix, MKTSHR $R_{y, \text { es }}$ of lighting market shares as a function of time. From that, it calculates a matrix of average usages that are assigned equally to all housing types and regions:

$$
\text { WTLEFF } F_{y, b, r}=\sum_{e s}\left(\frac{1}{E F F_{e s}} \times M K T S H R_{y, e s}\right), \text { for } e s=1,2,3
$$

where,

WTLEFF $F_{y, b, d}$ are weighted-average usages for lighting, by year, housing type and Census Division,

$\dot{E F}_{e s} \quad$ are efficiencies of the three classes of light bulbs, from the table above, and

MKTSHR ${ }_{y, e s}$ are annual market shares for the lighting classes, from the table above.

Next, the component calculates unit energy consumption

$$
\text { LTNUEC }_{y, b, b}=\text { LTUEC }_{r, b} \times \text { WTLEFF } F_{y, b d} \times \text { BASEFF }
$$

where,

LTNUEC $_{y, r, b}$ is the unit energy consumption for lighting by year, Census Division and housing type,

LTUEC $_{r, b}$ is base year unit energy consumption for lighting by Census Division and housing type, from the RSUEC10 file,

WTLEFF $_{y, b, d}$ is the weighted-average usage for lighting calculated above, and 
BASEFF is the base efficiency for lighting equipment, set at present to .18 in the component.

Lighting energy consumption is calculated from the UEC as follows:

$$
\operatorname{LTCON}_{y, r}=\sum_{b}\left[\left(E H_{y, b, r}+N H_{y, b, r} \times \operatorname{SQFTLTS}_{y, b, r}\right) \times L T N U E C_{y, r, b}\right]
$$

where,

$\operatorname{LTCON}_{y, r}$ is the energy consumption for lighting by year and Census Division,

$E H_{1993, b, r}$ is the number of old (pre-1994). housing units in the current year by housing type and Census Division,

$\mathrm{NH}_{1993, b, \mathrm{r}}$ is the number of new (post-1993) housing units in the current year by housing type and Census Division,

$\angle T N U E C_{y, r, b}$ is the unit energy consumption for lighting by year, Census : Division and housing type, and

SOFTLTS $S_{y, b, r}$ is the average floor area of homes, relative to 1993 floor areas, calculated from the floor areas given in the RSSORFT file, used to adjust for increased lighted areas in future new homes.

\section{Other Electric Appliances}

Other electrical appliances is a catch-all category that includes miscellaneous electrical uses like toasters and hair dryers that are used in homes, but do not fall into any of the other categories of equipment that have their own module components. The component is even simpler than the lighting component, as it uses two parameters to evaluate consumption.

\section{APCNS (Electric Appliance Energy Consumption Component)}

The two simple parameters are a simple adjustment to new homes, and a penetration 
rate:

$$
A P C O N_{y, r}=\sum_{b}\left[\left(N H_{y, b, r}+E H_{y, b, r}\right) \times E A U E C_{r, b} \times P E N R A T E^{y-1993}\right]
$$

where,

$A P C O N_{y, r}$ is electric appliance energy consumption,

$E H_{1993, b, r}$ is the number of old (pre-1994) housing units in the current year by. housing type and Census Division,

$\mathrm{NH}_{1993, b, r}$ is the number of new (post-1993) housing units in the current year by housing type and Census Division,

$E A U E C_{r, b}$ is base year unit energy consumption for small electrical appliances by Census Division and housing type, from the RTSUEC10 file, and

PENRATE is the penetration rate from RECS 87,90 and 93 annual growth rates, set in the component to a value of 1.08 declining to 1.02 .

\section{Secondary Space Heating}

Secondary space heating refers to small supplemental heaters, normally portable, fired by electricity, kerosene or other fuels, that are used for spot heating or other occasional stopgaps.

\section{SHTCNS (Secondary Heating Energy Consumption Component)}

Energy consumption by secondary heaters is calculated directly from shares by fuel read into the model from a user file:

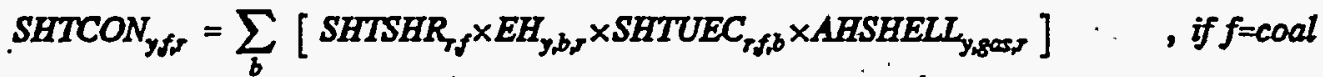

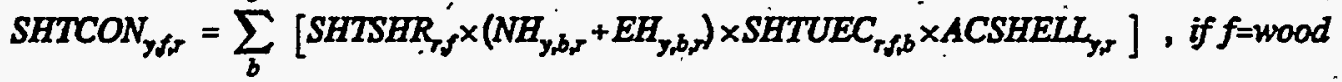

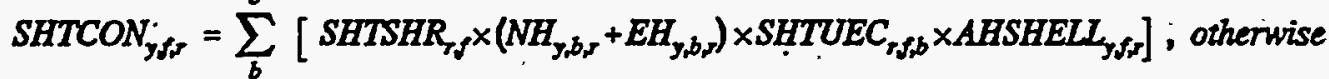

where,

SHTCON $N_{y, f, r}$ is the consumption of energy by seçondary space heating equipment 
by year, fuel and Census Division,

SHTSHR $R_{r, f}$ are shares of seven fuels for secondary space heating by Census Division,

$E H_{1993, b, 5}$ - is the number of old (pre-1994) housing units in the current.year by housing type and Census Division,

$\mathrm{NH}_{1993, b, r}$ is the number of new (post-1993) housing units in the current year by housing type and Census Division,

$S_{\text {SHTEC }}$ r,f,b is base year unit energy consumption for small electrical appliances by Census Division and housing type, from the RTSUEC10 file,

$A H S H E L L_{y, f, r}$ is the average post-1993 heating shell index by year, fuel and Census Division, equal to 1 in 1993, and

ACSHELL $L_{y, r}$ is the average post-1993 cooling shell index by year and Census Division, equal to 1 in 1993.

The logic is designed as shown to constrain the component to disallow coal supplemental heat in post-1993 homes, and to use the cooling shell index for wood supplemental heat, rather than the heating one, because wood is.not one of the fuels for heating shell indices.

\section{Other Appliances}

Other appliances refers to small appliances not covered in the other categories that do not use electricity as their primary fuel, such as backyard grills. Consumption alone is calculated.

\section{APPCNS (Appliance Energy Consumption Component)}

The formula is a simple calculation from housing stock and unit energy consumption:

$$
A P L C O N_{y, r, r}=\sum_{b}\left[\left(N A_{y, b, r}+E H_{j, b, r}\right) \times A P P U E C_{r, f, b}\right]
$$

where, 
$A P L C O N_{y, f, r}$ is the energy consumption by other appliances by year, fuel and Census Division,

$E H_{1993, b, r}$ is the number of old (pre-1994) housing units in the current year by housing type and Census Division,

$\mathrm{NH}_{1993, b, r}$ is the number of new (post-1993) housing units in the current year by housing type and Census Division, and

$A P P U E C_{r, f, b}$ are unit energy consumption estimates from the RSUEC10 file, by year, housing type, and Census Division.

\section{Fuel Consumpṭion Totals}

\section{FUELCN (Fuel Consumption Totals Component)}

The total residential energy consumption for the nation is computed by summing end use service consumption by fuel for each Census Division. The division by a million converts units from million Btu per year to trillion Btu per year. The factor LEAPYR in each equation takes on the value of 1 in all years but leap years, when it has the value $366 / 365$.

Natural Gas

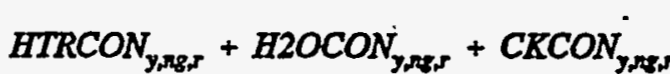

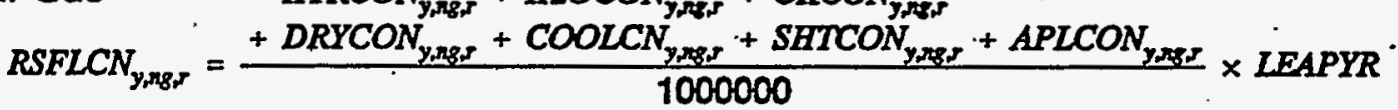

Distillate

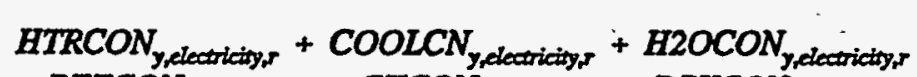

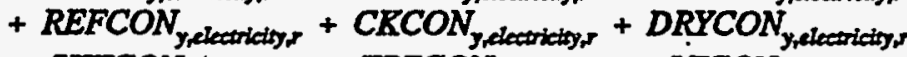

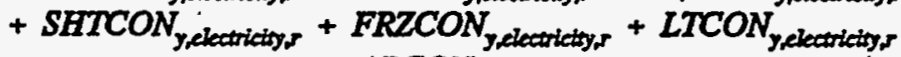

$$
\begin{aligned}
& \operatorname{RSFLCN}_{\text {yelectricity, }}=\frac{+\triangle P C O N_{\text {yelectrictiox }}}{1000000} \times L E A P Y R
\end{aligned}
$$

Electricity

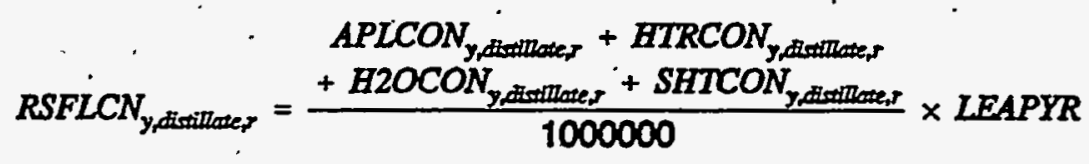

LPG

$$
\begin{aligned}
& \text { SHTCON }{ }_{y, L P G, T}+A P L C O N_{y, L P G,}
\end{aligned}
$$

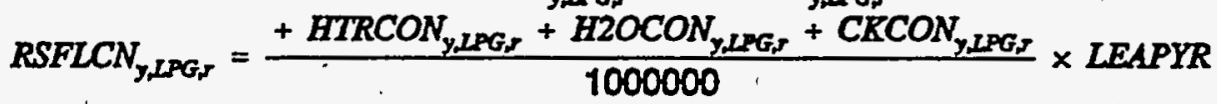


Kerosene.

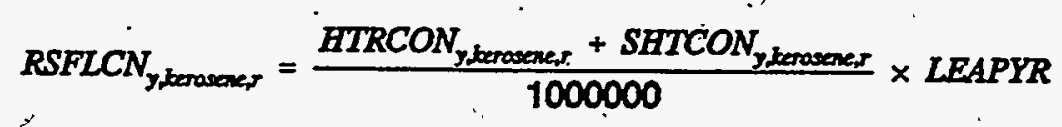

Coal

$$
\text { RSFLCN }_{\mathrm{y}, \text { cocl, } r}=\frac{S H T C O N_{\mathrm{y}, \mathrm{coal}, \mathrm{r}}}{1000000} \times \text { LEAPYR. }
$$

Wood

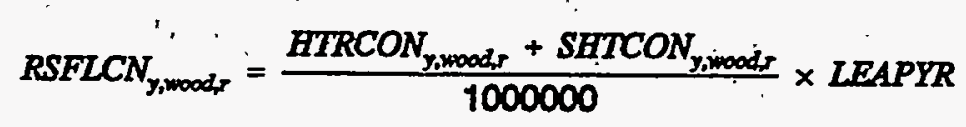

Geothermal

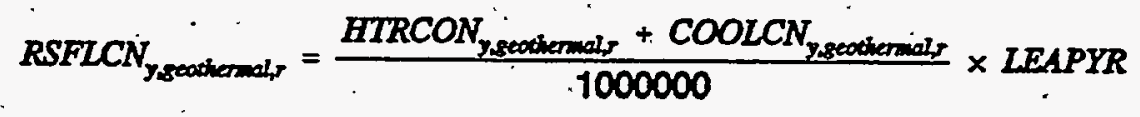

National Total

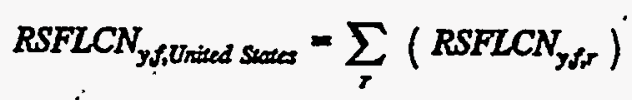




\section{Appendix C: Bibliography.}

Air Conditioning and Refrigeration Institute, "Directory of Certified Cooling Equipment," Arlington, VA, 1994.

1

American Council for an Energy-Efficient Economy, "Energy Savings Estimates from the Energy Efficiency Provisions in the Senate and House Energy Bills," Washington, D.C., August, 1993.

American Gas Association, "Residential Natural Gas Market Survey: 1992," Arlington, VA, June, 1993.

Arthur D. Little, "ElA Technology Forecast Updates," 1995.

Association of Home Appliance Manufacturers, "Freezers: Energy Efficiency and Consumption Trends," Chicago, IL, July, 1995.

Association of Home Appliance Manufacturers, "Refrigerators: Energy Efficiency and Consumption Trends," Chicago, IL, July, 1995.

Electric Power Research Institute, "Draft Model Documentation for Residential Enduse Energy Planning System (REEPS), Version 2.0," Palo Alto, CA, 1990.

Electric Power Research Institute, "Residential End-Use Energy Consumption: A Survey of Conditional Demand Estimates," Palo Alto, Ca, 1989.

Electric Power Research Institute, "Residential End-Use Energy Planning System (REEPS), Version 1.0, Palo Alto, CA, 1982.

Energy Information Administration, "A Recommended Design for the National Energy Modeling System," 1991.

Energy Information Administration, "Residential Sector Component Design Report," January 19, 1993.

Energy Systems and Policy, "The LBL Residential Energy Model: An. Improved Policy Analysis Tool," 1987.

Federal Register, "Part III: Department of Energy," May 14, 1991.

Gas Appliance Manufacturers Association, "Consumers' Directory for Certified Efficiency Ratings," Arlington, VA, 1994. 
Gas Research Institute, "1991 Edition of the GRI Baseline Projection Methodology and Assumptions Topical Report," Lexington, MA, 1990.

Gas Research Institute, "Baseline Projection Data Book," 1990.

Koomey, J.G., et. al., "The Potential for Electricity Efficiency Improvements in the U.S. Residential Sector," Lawrence Berkeley Laboratory, Berkeley, CA, July, 1991.

Lawrence Berkeley Laboratory, "Baseline Data for the Residential Sector and Development of a Residential Forecasting Database," Berkeley, CA, May, 1994.

Turiel, I., et. al., "U.S. Residential Sector Appliance Energy Efficiency: Present Status and Future Directions," Lawrence Berkeley Laboratory, Berkeley, CA, December, 1992.

U.S. Bureau of the Census, "Annual Housing Survey: 1983," 1983.

U.S. Bureau of the Census, "Components of Inventory Change," 1980.

U.S. Bureau of the Census, "Current Construction Reports-Series C25 Characteristics of New Housing: 1993," 1994.

U.S. Department of Energy, Energy Information Administration, Residential Energy Consumption Survey: ; Housing Characteristics 1993, DOE/EIA-0314(93), Washington, DC, June 1995.

U.S. Department of Energy, Energy Information Administration, Residential Energy Consumption Survey: Household Energy Consumption and Expenditures 1993, DOE/EIA-0321(93)., Washington, DC, October 1995.

U.S. Department of Energy; Technical Support Document: Energy Conservation Standards for Consumer Products: Dishwashers, Clothes Washers, and Clothes Dryers, DOE/CE-0267, Washington, D.C., July 1989.

U.S. Department of Energy, Technical Support Document: Energy Conservation Standards for Consumer Products: Refrigerators and Furnaces, DOE/CE0277, Washington, D.C., November, 1989. 


\section{Appendix D: Model Abstract}

\section{Model Name:}

NEMS Residential Sector Demand Module

\section{Model Acronym:}

None

\section{Description:}

- The NEMS Residential Sector Demand Module is an integrated dynamic modeling system that projects residential energy demand by service, fuel, and Census Division. The modeling methodology is based on accounting principles and considers important issues related to consumer behavior. Housing and equipment stocks are tracked over the forecast period for seven major services. The major services considered are space heating, space cooling, water heating, cooking, clothes drying, refrigeration, and freezers. A logit function is used to estimate market shares of each equipment technology within each major service based on either the installed capital and operating costs or the life-cycle cost. Lighting choices are modeled by assuming market shares for three specific lighting technologies in specific forecast years. Miscellaneous appliance consumption is calculated as a function of Unit Energy-Consumption (UEC), a measure of energy intensity developed from the Residential Energy Consumption Survey (RECS) data base.

\section{Purpose of the Model:}

As a component of the National Energy Modeling System, the Residential Sector Demand Module generates mid-term forecasts of residential sector energy demand 
for the period 1993 through 2015. The model facilitates policy analysis of energy. markets, technological development, and regulatory development.

\section{Most Recent Model Update:}

October 1996.

\section{Component of Another Modeling System:}

The Residential Sector Demand Module is designed, executed, and.maintained as part of the National Energy Modeling System (NEMS).

\section{Model Interfaces:}

The NEMS Residential Sector Demand Module receives population and housing construction input data from the NEMS Macroeconomic Activity Module (MAM). Outputs in the form of quantities of fuel demanded in the residential sector are provided to the NEMS Integrating Module and the NEMS Supply Modules: Electricity Market Module, Petroleum Market Module, and Natural Gas Supply Module.

\section{Office Model Representative:}

John H. Cymbalsky

Office of Integrated Analysis and Forecasting

Energy Demand Analysis Branch

(202) $586-4815$

\section{Documentation:}

Model Documentation Report: Residential Sector Demand Model of the National. Energy Modeling System, February 1997. 


\section{Archive Media and Installation Manual:}

The NEMS Residential Sector Demand Module has been archived as part of the NEMS production runs that generate the Annual Energy Outlook 1997 (AEO97) on the EIA IBM RS-6000 workstation. The archive tape is a Verbatim 8mm-DL 112M data cartridge, serial number $1046 \mathrm{G} 112$, under the name file1.

\section{Energy System Described:}

U.S. residential sector energy consumption:

\section{Scope of Coverage:}

- Geographic: Nine Census Divisions: New England, Middle Atlantic, East North Central, West North Central, South Atlantic, East South Central, West South Central, Mountain, and Pacific

- Time Unit/Frequency: Annual, 1993 through 2015 is the current mid-term horizon

- Products: Fuel consumption including: electricity, natural gas, distillate, liquefied petroleum gas, kerosene, geothermal, wood, solar thermal, and coal. Energy consumption per household.. Equipment stock and efficiency.

- Economic Sectors: Domestic residential sector

Services: Space heating, space cooling, water heating, cooking, clothes drying, refrigeration, freezers, lighting, other electric appliances, other appliances, and secondary space heating.

- Housing Types: Single-Family, Multifamily, and Mobile Homes

\section{Model Features:}

- Model Structure: Sequential algorithm composed of housing and equipment stock flow algorithms, technology choice algorithm, housing shell integrity 
algorithm, end-use consumption, and emissions calculations.

- Modeling Technique: Housing and equipment stock turnover are modeled using linear decay functions. Market shares for each type of equipment choice are based ón a logit function employing installed capital costs and operating costs. Unit energy consumption estimates, fuel prices, and equipment market shares are user inputs that drive the calculation of final end-use consumption.

- Special Features: Technology choice logit function has the ability to use installed capital, and operating costs or life-cycle costs to determine new market shares.

\section{Non-DOE Input Sources:}

American Home Appliance Manufacturers Association.

- $\quad$ Shipment-weighted efficiency ratings for refrigerators, freezers, and room air conditioners.

U.S. Bureau of the Census, "Current Construction Reports-Series C25 Characteristics of New Housing: 1993," 1994.

- New housing and base year market shares for some services and equipment types.

Gas Appliance Manufacturers Association, "Consumers' Directory fọ Certified Efficiency Ratings," 1994.

Lawrence Berkeley Laboratory, "The Potential for Electricity Efficiency Improvements in the U.S. Residential Sector," 1991

Residential equipment technical characterization data.

Expected minimum and maximum appliance lifetimes. 
- Expected lifetimes of housing types.

The major data input sources are discussed in this Appendix. Appendix $C$ provides additional bibliographic citations of data sources used in the Residential Sector Demand Module.

\section{DOE Input Sources:}

U.S. Department of Energy, Energy Information Administration, Residential Energy Consumption Survey 1993.

- Base year market shares for services and equipment types.

- Base year housing stock.

- Unit energy consumption values (UECs)

The major data input sources are discussed in this Appendix. Appendix $C$ provides additional bibliographic citations of data sources used in the Residential Sector Demand Module.

\section{Computing Environment:}

- Hardware Used: IBM RS-6000 370 Series

- Operating System: AiX 3.2.5

- Language/Software Used: IBM XL. FORTRAN Compiler/6000, Version 3.1.1

- Memory Requirement: 3,000K

- Storage Requirement: Since the Residential Sector. Demand Module has not yet been archived at the time of this writing, the number of tracks of an IBM 3380 disk pack that are required are currently unknown. This information will be provided upon completion of the archival process.

- Estimated Run Time: 0.8 seconds CPU time per iteration

- Special Features: None 


\section{Independent Expert Reviews Conducted:}

Independent expert reviews of the Residential Sector Component Design Report, May 28,1992 were conducted by Inderjit Kundra, Office of Statistical Standards; Fred Joutz, Office of Statistical Standards; Ronald D. Sands, Batelle Pacific - Northwest Laboratory, James E.. McMahon, Lawrence Berkeley Laboratory; and Francịs X. Johnson, Lawrence Berkeley Laboratory.

\section{Status of Evaluation Efforts by Sponsor:}

None. 


\section{Appendix E: Data Quality}

This Appendix discusses the quality of the survey data source from which the majority of the historical housing stock, appliance stock, and technology information that drives the NEMS Residential Sector Demand Module is drawn. This survey is the 1993 Residential Energy Consumption Survey (RECS). Data quality information. pertinent to additional sources used in the module development is not available for this report. The parameter estimates included in the Residential Sector Demand Module are user-specified. A sensitivity analysis of the major parameters is included in Appendix F, Model Sensitivities.

\section{Quality of Input Data}

\section{RECS Implementation}

The RECS procedure is composed of two instruments: the household survey and the energy supplier survey. Data is collected from a representative sample of households through personal interviews. Billing data is next collected through mail questionnaires from the energy supplier to the participating household, provided that authorization is obtained from the household. The results of the household and energy supplier surveys are presented in the Department of Energy documentation of the RECS 1993 survey $^{3,2}$.

Stage I of RECS consists of a personal interview. The sample for the interviews is

i U.S. Department of Energy, Energy Information Administration, Residential Energy Consumption Survey: Housing Characteristics 1993, DOE/EIA-0314(93), Washington, D.C., June 1995.

2 U.S. Department of Energy, Energy Information Administration, Residential Energy Consumption Survey: Household Energy Consumption and Expenditures, DOE/EIA0321(93), Washington, D.C., October 1995. 
developed based on all units occupied as a primary residence in the $\mathbf{5 0}$ states and the District of Columbia. The sample design process is composed of five steps that disaggregate the geographic scope into housing clusters of approximately 5 housing units to be surveyed.

The interview responses provide information on housing structure including insulation, doors, windows, space conditioning systems, use of wood fuel, energy conservation improvements, household appliances, household vehicles, receipt of government assistance for the cost of space heating, and demographics. Householders were also asked to sign authorization forms to allow access to their billing records with energy suppliers.

Stage II of the survey design consists of a mail questionnaire for energy suppliers of the households interviewed in Stage I. Suppliers of residential electricity, natural gas, fuel oil, kerosene, and liquified propane gas (LPG) are contacted in Stage II. For the 1993 RECS, each supplier was asked to supply billed quantities and expenditures for the households interviewed in Stage I.

Data verification begins with a manual verification of the interview data from Stage I. The questionnaires are checked for completeness and consistency. Interview responses are compared to energy supplier data, and respondents are contacted in the event that an inconsistency persists. These data collection and verification procedures ensure the quality of the survey data.

Energy Information Administration 


\section{Appendix F: Model Sensitivities}

\section{Solution Methodology}

As the description in Section 4; Model Structure, and Appendix B, Detailed Mathematical Description, shows, the solution methodology of the NEMS Residential Module is a direct, onepass, computation of linear and non-linear systems of equations to develop the residential module outputs such as quantity demanded by fuel type. Consequently, convergence within the NEMS Residential Module is never an issue nor is it relevant since the algorithm within the residential module is not iterative.

The model requires no estimate of the current-year solution to compute the solution to the NEMS Residential Module since the current year solution depends on only the values of the solution in the previous year plus the current economic conditions and other inputs from the rest of NEMS. Listed in descending order of model sensitivity (as will be shown below), variation in weather patterns, equipment efficiencies, housing starts and fuel prices do influence the residential module equipment purchase decisions and total quantity of fuel consumed. This appendix contains a series of sensitivity analyses for the purpose of illustrating the behavior of the residential module. These sensitivities illustrate how the model responds to changes in key model inputs.

Although rigorous tests have not been performed to determine the maximal meaningful values for the key model inputs, an indication of values for which the model has proven to be valid is given by those used in the sensitivity analyses. It must be stressed that care must be exercised in selecting input values so that the model produces meaningful results. 


\section{Theoretical Considerations}

Because of the direct (rather then iterative) solution algorithm and because all of the functions in the NEMS Residential Module are continuous and differentiable in the domain of applicability of the model (that is, when "reasonable and consistent inputs" are provided into the model) the model always produces a unique solution. Existence and convergence are not an issue. As previously mentioned, some of the inputs to the model may be correlated (as in certain demographic and macro-economic inputs) and if inconsistent pairs of such inputs or negative prices are chosen, then the model will produce meaningless results. This behavior, however, is consistent with the well know reality in computer models of "garbage in - garbage out". When' the model is run in a stand-alone fashion, the user must be certain that the inputs are consistent and credible.

Examples of input assumptions that will cause the model to produce meaningless results include:

- severely altering base year data, e.g., doubling the existing 1990 housing stock, characterizing unrealistically "super-efficient" technologies with low acquisition costs, and

- modifying prices considerably in excess of variations historically experienced, such as quadrupling prices in one year. 


\section{Sensitivity Analyses}

To demonstrate the NEMS Residential Module's behavior under a variety of situations, several model runs were made to test its sensitivity to altered values for key input variables. These runs were then compared with the Reference Case forecast used for the AEO 95. The sections below describe the six major inputs and outputs chosen for this exercise, as well as the results of the analysis in tabular and graphical form.

\section{Input Variables}

The six input variables chosen for the sensitivity analyses were selected based upon their perceived importance in producing the AEO 95 forecast. The six variables and the magnitude of variation are given below.

Electricity, natural gas, and distillate prices. Prices for the three major residential fuels were each increased by 25 percent over their values in the AEO 95 Reference Case in every year of the forecast (1995 through 2010). Fuel prices affect the projected consumption levels in two ways. First, there is an immediate "short-run" response best thought of as immediate behavioral changes. For example, higher heating fuel prices will result in lower thermostat settings. These near term behavioral responses are captured through the model's short-term price elasticities. Over a longer interval, the efficiency level of both the building shell and the energy-using equipment inside the house will also vary in response to prices. For example, when the replacement of space heating equipment is necessary, higher fuel prices lead to greater efficiency for purchased equipment and lower energy consumption. The longer-term equipment-related responses will alter fuel consumption over an extended number of years in contrast to the immediate short-run effects. Based on these two price-related responses.(which operate in the same direction but over different intervals), it is expected that continued higher fuel prices will lower fuel consumption and energy intensity and that the effects will tend to increase over time. 
Housing starss. Housing starts by Census Division and housing type (single-family, multifamily, and mobile homes) are the macroeconomic variables which drive the NEMS Residential Model. For each Census Division and housing type, starts were increased by 10 percent every year, relative to the AEO 95 Reference Case beginning in 1995. Logically, these variables represent household formation and are consistent with a scenario with implicitly higher population growth. New residential construction embodies new techniques and technologies and tends to be more efficient than the average existing stock. Thus, it is expected that increasing housing starts will increase overall energy consumption, but at a rate which is less than proportional. Thus, energy consumption per household (energy intensity) will decline for this model run:

Equipment efficiencies. The efficiency of new equipment entering the stock plays a central role in determining the average level of energy intensity for the residential sector. For this sensitivity analysis, every equipment efficiency represented in the model was increased 10 percent relative to the AEO 95 Reference Case beginning in 1995. It is expected that higher equipment efficiencies will cause both energy consumption and energy intensity to decline. It is further expected that the decline in consumption and intensity will deviate further from the Reference Case over time as equipment purchases make up larger and larger shares of total equipment.

Weather. Weather also has a significant effect on residential energy consumption, since the majority of the energy use in the sector is for space heating and cooling. The Unit Energy Consumption (UEC) estimates are defined as energy consumption per household for specific equipment and end-use categories (examples includè gas forced air space heating, electric air conditioning, electric resistance space heating and gas water heating). The UECs are estimated from the Energy Information Administration's Residential Energy Consumption Survey: 1990. These UEC estimates reflect the weather conditions of the 1990 survey year which happened to be abnormally warm. To account for weather-related effects on energy consumption, the forecast UEC values are adjusted from their base year values based on actual weather in 1991 through 1994 and for "normal" weather reflective of long-term climatic conditions for all other forecast years. Depending on the fuel, the heating UEC values are adjusted upward by varying amounts 
to account for the extremely warm winter during the survey year. For this sensitivity analysis, no weather adjustments were made. It is expected that energy consumption and intensity will fall relative to the AEO 95 Reference.Case, since this scenario embodies a forecast of warmerthan-normal winters.

\section{Output Variables}

For each input selected, six outputs were chosen to test their sensitivities to these inputs. The six outputs chosen are:

- the quantity demanded of electricity,

- the quantity demanded of natural gas,

- the quantity demanded of distillate oil,

- the quantity demand for all fuels in total,

- the number of occupied households (relevant only to increased housing starts case), and

- the space heating intensity in million Btu per household per year.

Tables F-1 through F-3 show the relationship between the inputs and outputs for the years 2000 and 2010. Table F-1 summarizes the absolute change of each output relative to the AEO 95 Reference Case with separate panels for 2000 and 2010. Similarly, Table F-2 shows the percent change of each output relative to the AEO 95 Reference Case. Table F-3 provides the elasticities (the percent change of the output divided by the percent change of the input) of the selected output variables with respect to the selected input variables. Following the tables, a series of six figures display the elasticities of selected output variables as a time series for each of the six input variable scenarios, respectively. Finally, the summary and conclusions section discusses the results presented in the tables and figures. 


\begin{tabular}{|c|c|c|c|c|c|c|c|c|}
\hline 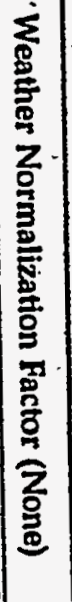 & 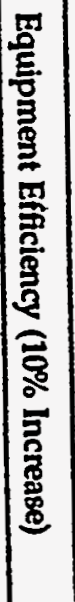 & 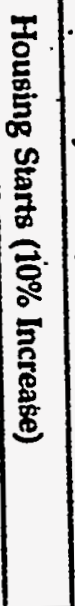 & 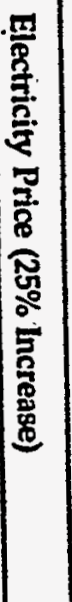 & 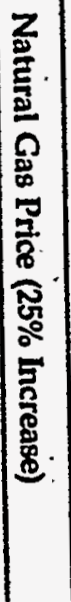 & 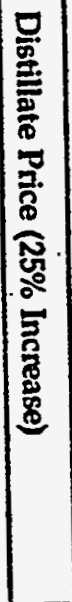 & & $\begin{array}{l}\text { 豞 } \\
\text { ऊ } \\
\cdots\end{array}$ & 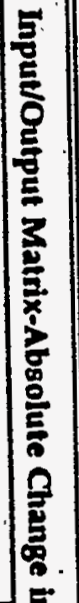 \\
\hline )े & ${ }_{0}^{0}$ & 옹 & ஜ & ¿̊ & $\stackrel{b}{0}$ & $\begin{array}{l}\text { 믐 } \\
\text { 言 } \\
\frac{\tilde{\sigma}}{\tilde{\sigma}}\end{array}$ & & 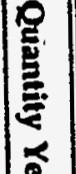 \\
\hline$\dot{\vec{\xi}}$ & $\underset{\omega}{\dot{\omega}}$ & \% & ํํํ & 忠 & 号 & 足 & & 롱. \\
\hline bे & 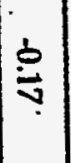 & 8 & 잉 & 응 & 0 & ·四 & & \\
\hline 容 & 해 & : & $\dot{\mathrm{b}}$ & $\stackrel{d}{\dot{c}}$ & : & 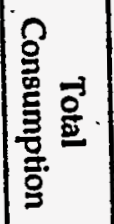 & 올 & \\
\hline$\frac{z}{p}$ & $\frac{z}{z}$ & 岕 & $\frac{z}{p}$ & $\frac{z}{z}$ & $\frac{2}{2}$ & 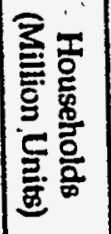 & & \\
\hline $\begin{array}{l}d \\
\hat{N}\end{array}$ & 离 & 해 & 它 & $\stackrel{N}{2}$ & ১্ & 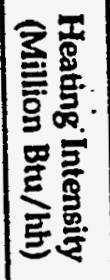 & & \\
\hline
\end{tabular}

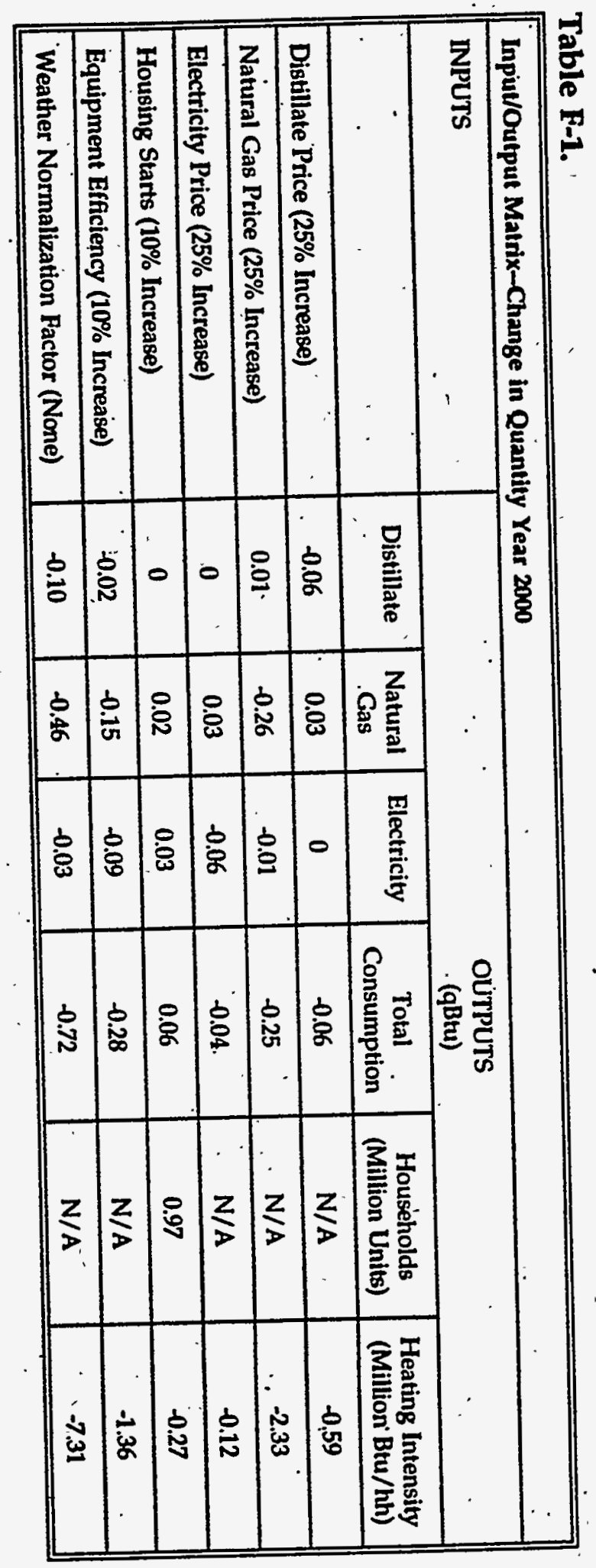

Energy Information Administration NEMS Residential Demand Module Documentation Report 
Table F-2.

\begin{tabular}{|c|c|c|c|c|c|c|}
\hline \multicolumn{7}{|c|}{ Input/Output Matrix-Percent Change Year 2000} \\
\hline \multirow[t]{2}{*}{ INPUTS } & \multicolumn{6}{|c|}{ OUTPUTS } \\
\hline & Distillate & $\begin{array}{l}\text { Natural } \\
\text { Gas }\end{array}$ & Electricity & $\begin{array}{c}\text { Total } \\
\text { Consumption }\end{array}$ & Households & $\begin{array}{l}\text { Heating } \\
\text { Intensity }\end{array}$ \\
\hline Distillate Price (25\% Increase) & $-7.98 \%$ & $0.62 \%$ & $\mathbf{0}$ & $-0.59 \%$ & N/A & $-1.03 \%$ \\
\hline Natural Gas Price (25\% Increase) & $1.55 \%$ & $-5.03 \%$ & $-0.27 \%$ & $-2.32 \%$ & $\mathrm{~N} / \mathrm{A}$ & $-4.11 \%$ \\
\hline Electricity Price (25\% Increase) & 0.03 & $0.55 \%$ & $-1.77 \%$ & $-0.35 \%$ & N/A & $-0.20 \%$ \\
\hline Housing Starts (10\% Increase) & 0.52 & $0.44 \%$ & $0.87 \%$ & $0.60 \%$ & $0.95 \%$ & $-0.47 \%$ \\
\hline Equipment Efficiency (10\% Increase) & $-2.70 \%$ & $-2.89 \%$ & $-2.62 \%$ & $-2.60 \%$ & N/A & $-2.40 \%$ \\
\hline Weather Normalization Factor (None) & $-12.13 \%$ & $-8.92 \%$ & $-0.84 \%$ & $-6.69 \%$ & . N/A & $-12.89 \%$ \\
\hline
\end{tabular}

\begin{tabular}{|l|c|c|c|c|c|c||}
\hline \multicolumn{7}{||l|}{ Input/Output Matrix-Percent Change Year 2010 } \\
\hline INPUTS & \multicolumn{7}{|c|}{ OUTPUTS } \\
\hline & Distillate & $\begin{array}{c}\text { Natural } \\
\text { Gas }\end{array}$ & Electricity & $\begin{array}{c}\text { Total } \\
\text { Consumption }\end{array}$ & Households & $\begin{array}{c}\text { Heating } \\
\text { Intensity }\end{array}$ \\
\hline Distillate Price (25\% Increase) & $-12.59 \%$ & $1.15 \%$ & 0 & $-0.59 \%$ & N/A & $-1.38 \%$ \\
\hline Natural Gas Price (25\% Increase) & $4.57 \%$ & $-6.85 \%$ & $-0.13 \%$ & $-2.73 \%$ & N/A & $-5.16 \%$ \\
\hline Electricity Price (25\% Increase) & $0.07 \%$ & $0.97 \%$ & $-1.86 \%$ & $-0.24 \%$ & N/A & $-0.06 \%$ \\
\hline Housing Starts (10\% Increase) & $2.43 \%$ & $1.40 \%$ & $2.26 \%$ & $1.80 \%$ & $2.24 \%$ & $-0.52 \%$ \\
\hline Equipment Efficiency (10\% Increase) & $-5.55 \%$ & $-6.41 \%$ & $-4.30 \%$ & $-5.18 \%$ & N/A & $-5.24 \%$ \\
\hline Weather Normalization Factor (None) & $-10.97 \%$ & $-8.75 \%$ & $-0.67 \%$ & $-6.20 \%$ & N/A & $-12.69 \%$ \\
\hline
\end{tabular}


Table F-3.

\begin{tabular}{|c|c|c|c|c|c|c|}
\hline \multicolumn{7}{|c|}{ Input/Output Matrix-Elasticities Year 2000} \\
\hline \multirow[t]{2}{*}{ INPUTS } & \multicolumn{6}{|c|}{ OUTIPUTS } \\
\hline & Distillate & $\begin{array}{c}\text { Natural } \\
\text { Gas }\end{array}$ & Electricity & $\begin{array}{c}\text { Total } \\
\text { Consumption }\end{array}$ & Households & $\begin{array}{l}\text { Heating } \\
\text { Intensity }\end{array}$ \\
\hline Distillate Price (25\% Increase) & -0.32 & 0.02 & $\mathbf{0}$ & -0.02 & N/A & -0.04 \\
\hline Natural Gas Price (25\% Increase) & 0.06 & -0.20 & -0.01 & -0.09 & N/A & -0.16 \\
\hline Electricity Price (25\% Incrèase) & $\mathbf{0}$ & 0.02 & -0.07 & -0.01 & N/A & -0.01 \\
\hline Housing Starts (10\% Increase) & 0.05 & 0.04 & 0.09 & 0.06 & 0.09 & -0.05 \\
\hline Equipment Efficiency (10\% Increase) & -0.27 & -0.29 & -0.26 & -0.26 & N/A & -0.24 \\
\hline Weather Normalization Factor (None) & -0.87 & -0.64 & -0.06 & -0.48 & N/A & -0.92 \\
\hline
\end{tabular}

\begin{tabular}{|l|c|c|c|c|c|c|}
\hline \multicolumn{7}{|l|}{ InputVutput Matrix-Elasticities Year 2010} \\
\hline INPUTS & \multicolumn{5}{|c|}{ OUTPUTS } \\
\hline & Distillate & $\begin{array}{c}\text { Natural } \\
\text { Gas }\end{array}$ & Electricity & $\begin{array}{c}\text { Total } \\
\text { Consumption }\end{array}$ & Households & $\begin{array}{c}\text { Heating } \\
\text { Intensity }\end{array}$ \\
\hline Distillate Price (25\% Increase) & -0.50 & 0.05 & 0 & -0.03 & N/A & -0.06 \\
\hline Natural Gas Price (25\% Inrease) & 0.18 & -0.27 & -0.01 & -0.11 & N/A & -0.21 \\
\hline Electricity Price (25\% Increase) & 0 & 0.04 & -0.07 & -0.01 & N/A & 0 \\
\hline Housing Starts (10\% Increase) & 0.24 & 0.14 & 0.23 & 0.18 & 0.22 & -0.05 \\
\hline Equipment Efficiency (10\% Increase) & -0.55 & -0.64 & -0.43 & -0.52 & N/A & -0.52 \\
\hline Weather Normalization Factor (None) & -0.78 & -0.63 & -0.05 & -0.44 & N/A & -0.91 \\
\hline
\end{tabular}




\section{Residential Model Sensitivity}

\section{Percent Higher Distillate Prices Relative to AEO 95}

Percent Change in Output / Percent Change in Input

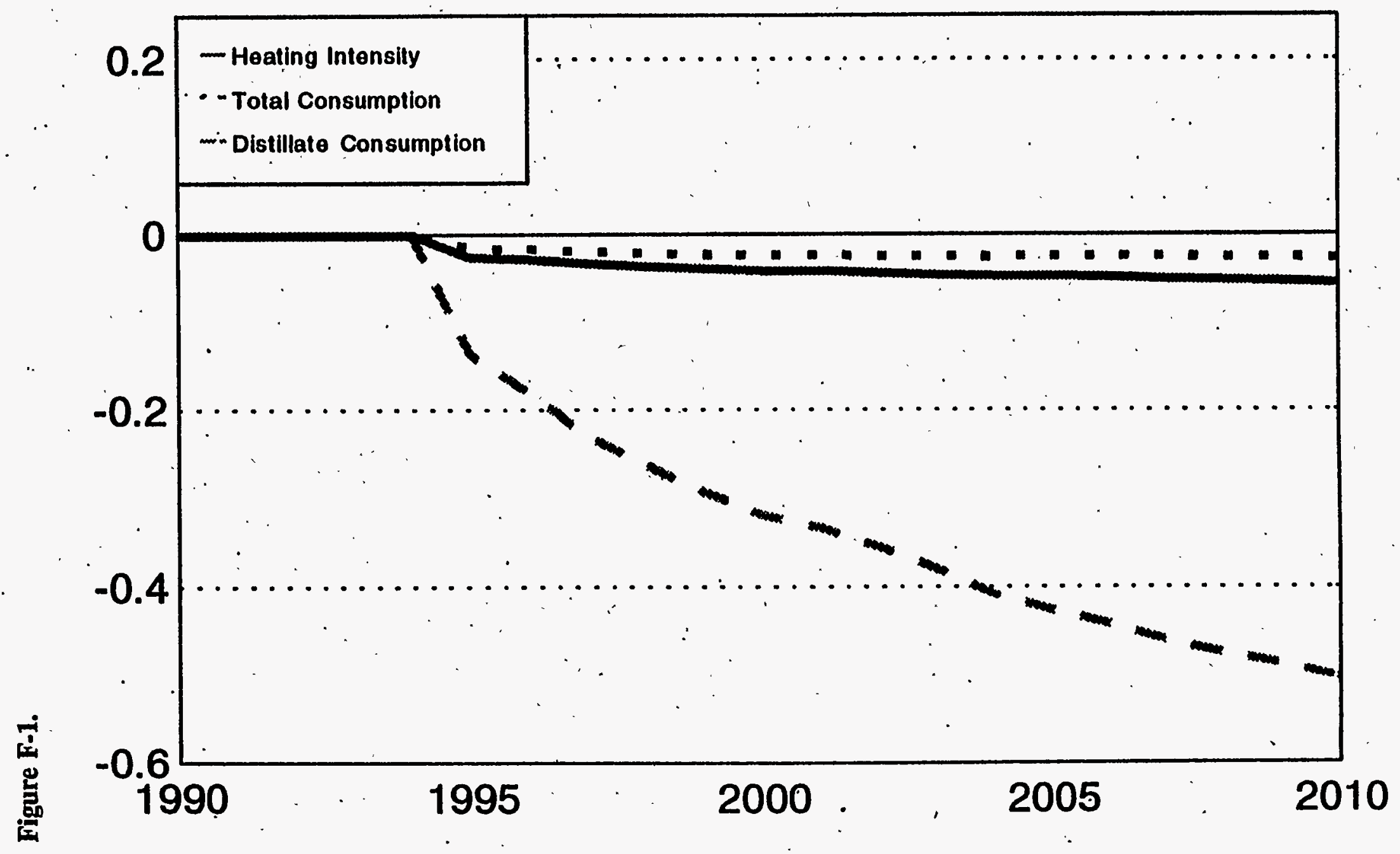




\section{Residential Model Sensitivity \\ 25 Percent Higher Natural Gas Prices Relative to AEO 95}

Percent Change in Output / Percent Change in Input

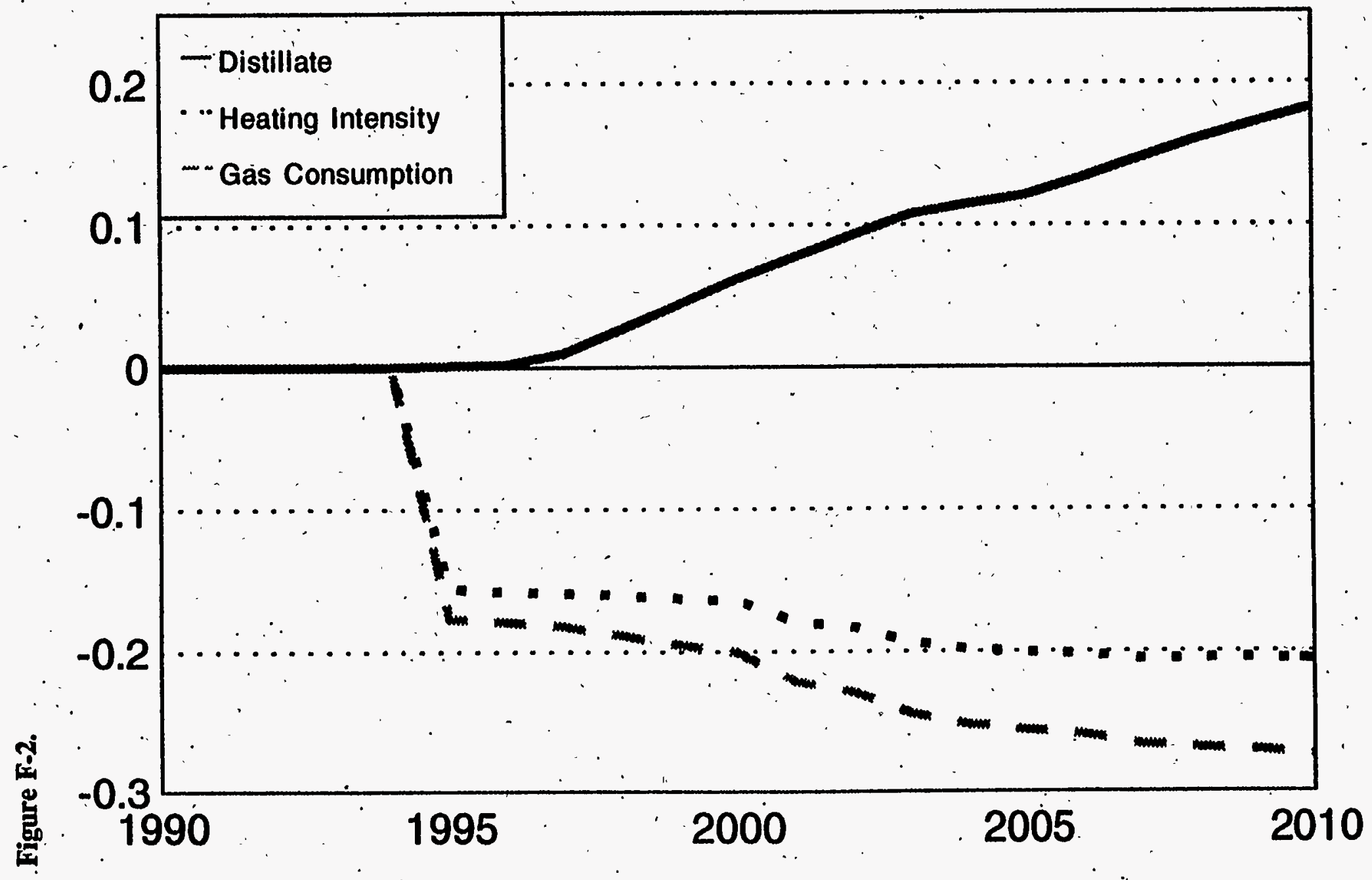




\section{Residential Model Sensitivity}

\section{Percent Higher Electricity Prices Relative to AEO 94}

Percent Change in Output / Percent Change in Input

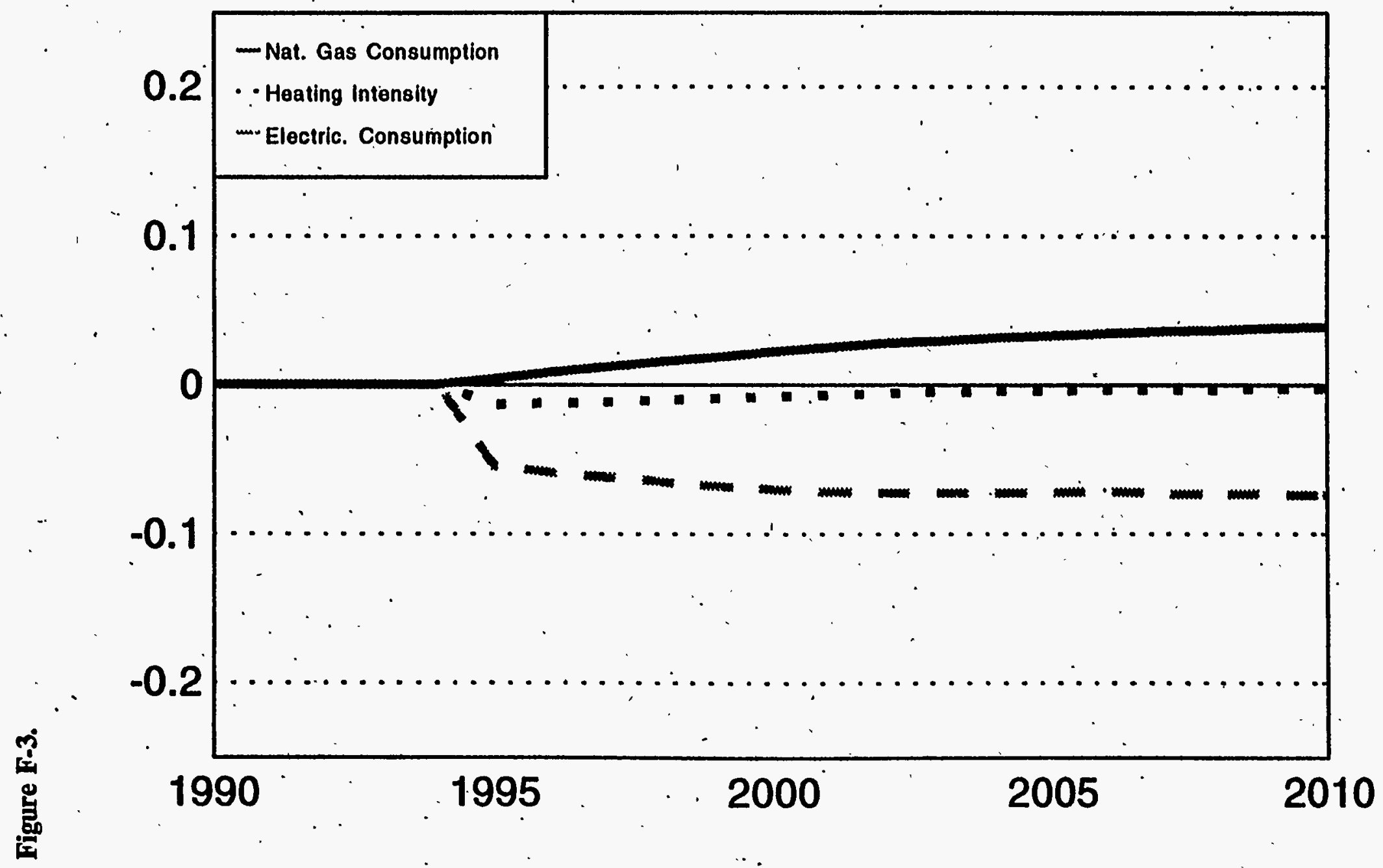




\section{Residential Model Sensitivity}

10 Percent Increse in Housing Starts Relative to AEO 95

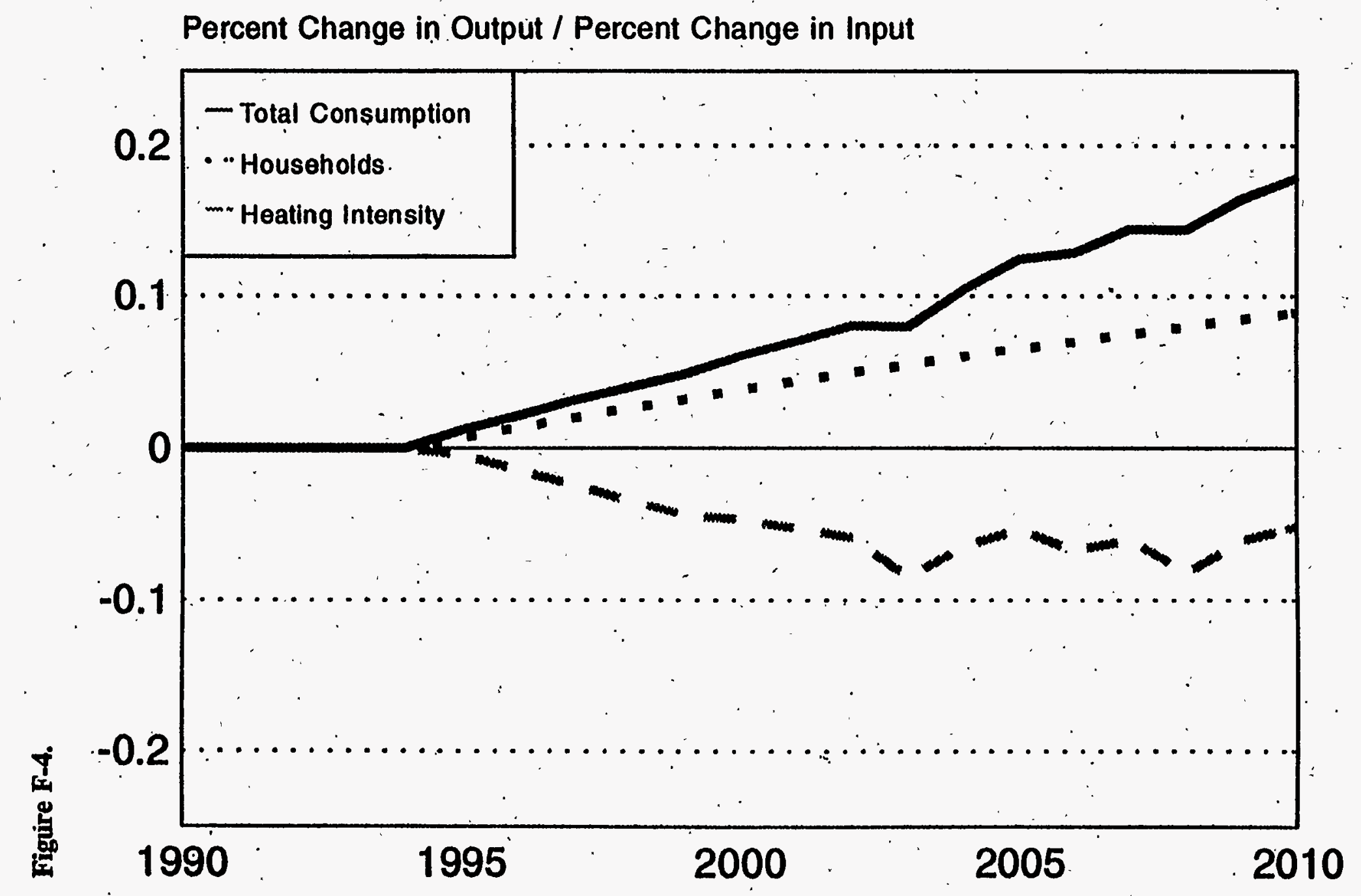




\section{Residential Model Sensitivity}

Percent Change in Output / Percent Change in Input

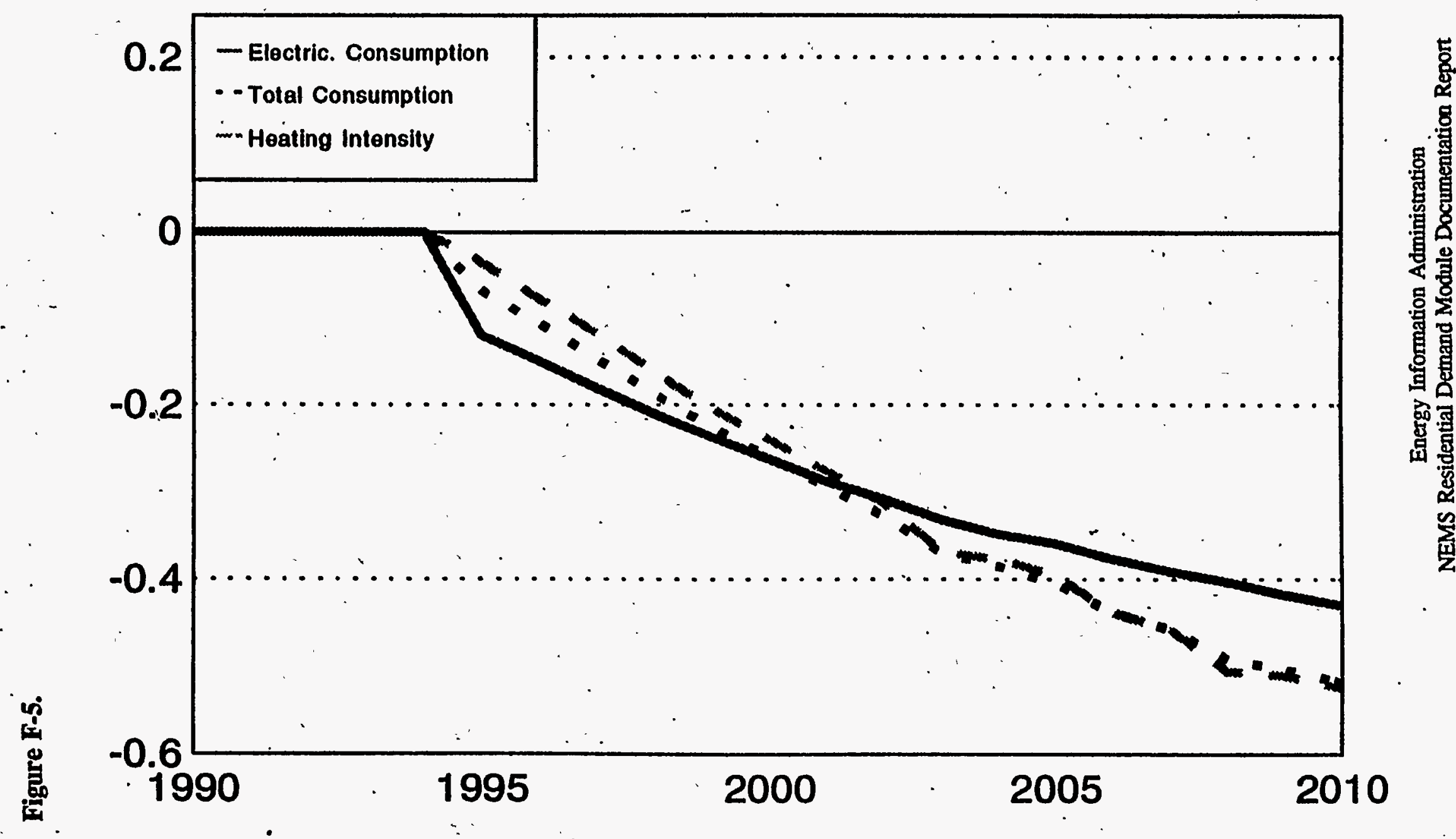




\section{Residential Model Sensitivity}

No Weather Normalization Factors

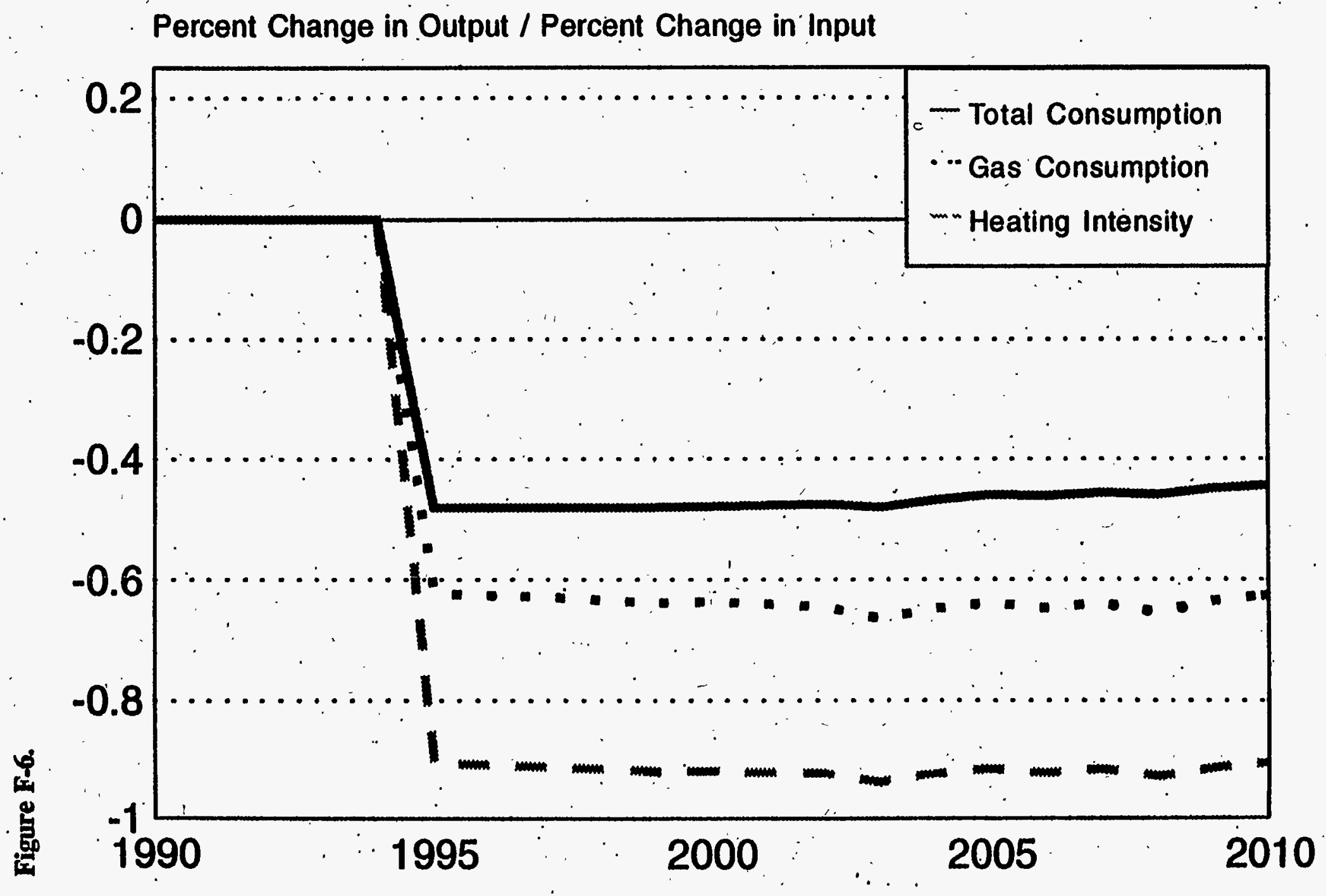




\section{Summary and Conclusions}

\section{Price Responsiveness.}

As shown on Table F-3, the NEMS Residential Module exhibits major fuel own-price elasticities for 2010 in the range of -0.07 (electricity) to -0.50 (distillate). Figures F-1 through F-3 further demonstrate that major fuel price elasticities generally increase over time, reflecting increasing shares of relatively more efficient end-use equipment. Intuitively speaking, electricity demand is expected to exhibit a smaller price elasticity than the other major fuels. This is because the use of electricity is spread across many end uses which are less directly controllable than is space heating, which is readily adjusted via the thermostat setting. Since distillate and natural gas use are dominated by space heating, their price elasticities are expected to be somewhat greater than those for electricity.

\section{Responsiveness to Altered Housing Starts}

As shown in Figure F-4, increased housing starts result in the expected decline in heating intensity. This is because new homes on average use less energy per unit for space heating than older homes because of increased shell efficiency. Thus, as the forecast for housing starts is adjusted upward (downward), sectoral energy intensity will decline (increase). In this scenario, a 10 percent increase in housing starts between 1995 and 2010 results in a 0.5 percent decline in space heating intensity relative to the AEO 95 Reference Case -- total energy consumption in 2010 is 1.8 percent higher while total households are 2.2 percent higher.

\section{Responsiveness to Altered Equipment Efficiency}

In terms of total energy consumption, the model is most sensitive to equipment efficiency. This is because over the 20-year forecast horizon, a substantial amount of residential equipment will be replaced. For example, roughly two-thirds of all furnace equipment and all of the existing heat pumps and air conditioning equipment will be replaced, along with all existing water heaters and refrigerators. Nearly all replacements occur at higher efficiency levels so that over time the assumed 10 percent increase in new equipment efficiencies will have greater and greater effects 
on - energy consumption levels. This continuously increasing reduction in total energy consumption is clearly demonstrated in Figure F-5. By the year 2010, total energy consumption is 5.2 percent lower that the AEO 95 Reference Case as shown in Table F-2.

\section{Weather Sensitivity}

Because of the dominance of space heating for natural gas and distillate, these fuels are more responsive to weather conditions than is electricity. Space heating intensity is most sensitive to weather changes and least sensitive to electricity prices, since electricity represents only a small percentage of total space heating consumption. For the year 2010, the effects of warmer weather would result in a 6.2 percent reduction in total energy consumption and an 12.7 percent reduction in space heating intensity. 